\title{
The morphological, physiological, and genetic underpinnings of intraspecific salinity tolerance in Sorghum bicolor
}

Ashley N. Henderson

West Virginia University, ahende11@mix.wvu.edu

Follow this and additional works at: https://researchrepository.wvu.edu/etd

Part of the Agronomy and Crop Sciences Commons, Genomics Commons, Plant Biology Commons, and the Plant Breeding and Genetics Commons

\section{Recommended Citation}

Henderson, Ashley N., "The morphological, physiological, and genetic underpinnings of intraspecific salinity tolerance in Sorghum bicolor" (2020). Graduate Theses, Dissertations, and Problem Reports.

7524.

https://researchrepository.wvu.edu/etd/7524

This Dissertation is protected by copyright and/or related rights. It has been brought to you by the The Research Repository @ WVU with permission from the rights-holder(s). You are free to use this Dissertation in any way that is permitted by the copyright and related rights legislation that applies to your use. For other uses you must obtain permission from the rights-holder(s) directly, unless additional rights are indicated by a Creative Commons license in the record and/ or on the work itself. This Dissertation has been accepted for inclusion in WVU Graduate Theses, Dissertations, and Problem Reports collection by an authorized administrator of The Research Repository @ WVU.

For more information, please contact researchrepository@mail.wvu.edu. 


\title{
THE MORPHOLOGICAL, PHYSIOLOGICAL, AND GENETIC UNDERPINNINGS OF INTRASPECIFIC SALINITY TOLERANCE IN SORGHUM BICOLOR
}

\author{
Ashley N. Henderson \\ A dissertation submitted \\ to the Eberly College of Arts and Sciences \\ at West Virginia University \\ in partial fulfillment of the requirements for the degree of \\ DOCTOR OF PHILOSOPHY
}

\author{
Jennifer S. Hawkins, Ph.D., Chair \\ Stephen DiFazio, Ph.D. \\ Jonathan Cumming, Ph.D. \\ Timothy Driscoll, Ph.D. \\ Vagner Benedito, Ph.D. \\ Department of Biology \\ Morgantown, West Virginia \\ 2020
}

Keywords: abiotic stress, comparative analysis, domestication, environmental adaptation, genetic architecture, $\mathrm{Na}^{+}$extrusion, recombinant inbred line population, salt detoxification, salinity stress, sorghum landraces, Sorghum bicolor, quantitative trait loci, vacuolar $\mathrm{Na}^{+}$ sequestration

Copyright (C) Ashley N. Henderson, 2020. All rights reserved. 


\section{ABSTRACT \\ The morphological, physiological, and genetic underpinnings of intraspecific salinity tolerance in Sorghum bicolor}

\section{Ashley N. Henderson}

Decreases in land quality and quantity threaten the efficient production of agriculturally and economically pivotal crops. Such reductions in arable lands are a consequence of population growth and urbanization, and often result in the introduction of various abiotic stresses. The most common abiotic stressors include water limitation (drought), water logging (over watering), poor water quality (salinity), and extreme temperatures (cold, frost, heat). Each of these stressors negatively impact plant growth, development, and yield. Soil salinity, specifically, is a considerable constraint affecting lands used in agriculture. Salts in the soil rise both naturally and through anthropogenic factors making the abundance a threat. Salt toxicity affects plants in two phases, the first of which is osmotic stress. Similar to drought stress, salinity imposed osmotic stress is when soil water potential is lower than the osmotic potential of the plant, therefore limiting water and nutrient extraction. Following osmotic stress, plants accumulate salt ions (e.g. $\left.\mathrm{Na}^{+}, \mathrm{Cl}^{-}, \mathrm{SO}_{4}{ }^{2-}, \mathrm{NO}^{3-}\right)$ that can increase to toxic concentrations and disrupt normal metabolic processes. Such toxicity results in reduction of important traits such as root biomass, live aboveground biomass, height, and grain yield. The goals of my dissertation work involved dissecting the various morphological, physiological, and genetic underpinnings of salinity tolerance in Sorghum bicolor. Since research to date demonstrates a significant amount of underlying genetic variation, I designed various projects to investigate the genetic controls associated with phenotypic responses to salinity stress among a diverse group of Sorghum genotypes. In my first research chapter, I screened 21 sorghum accessions and interpreted tolerance as the ability to maintain biomass, similar to plants in control conditions, in response to a long-term treatment of $75 \mathrm{mM} \mathrm{NaCl}$. Findings from this research chapter, when combined with published phylogenetic relationships, suggest that the greater salinity tolerance observed in some accessions of Sorghum bicolor, specifically in the landrace durra, are a byproduct of drought tolerance acquired during domestication. To further expand on these findings, I selected two accessions that showed significant variation in tolerance and used qPCR to investigate expression variation of genes associated with salt detoxification. During the secondary phase of salinity stress (referred to as ion toxicity) $\mathrm{Na}^{+}$and $\mathrm{Cl}^{-}$ions enter the plant and disrupt normal metabolic processes. If the ions are not effectively managed, the primary evident effect is increased leaf senescence. Tolerant genotypes, however, are able to overcome ion toxicity if they can 1) continue production of new growth and 2) efficiently and effectively exclude, extrude, sequester, and transport ions. Results from this chapter indicate that the tolerant accession experienced an earlier onset of osmotic adjustment, promoting the efficient uptake and transport of water. Additionally, the sensitive accession experienced an earlier onset of ionic stress, suggesting poor exclusion at the root level. These findings suggest that the tolerant genotype has better control over osmotic adjustment and ion transport systems, therefore requiring fewer resources to be diverted for the stress response, providing more available energy that can be utilized for new growth and development. Finally, to further investigate the variation in genetic 
response to salt exposure, I evaluated the salinity tolerance that existed within a recombinant inbred line (RIL) population produced from a cross between Sorghum bicolor and Sorghum propinquum, two species that differ in response to salt exposure. In this study, I used a highdensity genetic map to identify genetic markers correlated with salinity tolerance. I identified 146 candidate genes within the18 QTL intervals. QTL containing candidate genes that aid in the alleviation of osmotic stress (i.e. water acquisition, osmotic adjustment) were significantly associated with live aboveground biomass, and QTL containing candidate genes that aid in ionic detoxification (i.e. sensing, signaling, transporting) were significantly associated with an increase in dead aboveground biomass. Given the QTL and their associated phenotypes observed in the study, I suspect that the increased tolerance observed in S. bicolor is a result of early osmotic adjustment followed by effective sensing and signaling during the ionic phase of salinity response. In summary my dissertation work suggests that salinity stress in sorghum triggers a complex network of tightly regulated response elements, where the accumulation of ions, if properly transported and sequestered, aid in osmotic adjustment and ionic alleviation. Further, given Sorghum bicolor's domestication history, it appears that increased salinity tolerance arose as a byproduct of the drought tolerance acquired during domestication, therefore aiding in an early osmotic adjustment and subsequent water acquisition. 
For my fiancé, Justin,

who has been supportive and patient while 1 figured out how to

'finish this thing' called a Ph.D.

Thank you for taking my late-night-post-data-analysis (grumpy) comments, with a grain of salt.

Your love and encouragement have never gone unnoticed,

1 love you. 


\section{TABLE OF CONTENTS}

DEDICATION

TABLE OF CONTENTS V V

LIST OF FIGURES IX ix

LIST OF TABLES - xi

CHAPTER 1: OVERVIEW AND OBJECTIVES 1

Dissertation Organization 1

Literature Cited 3

CHAPTER 2: AN INTRODUCTION TO SALINITY STRESS 4

Environmental Stress, Marginal Soils, and the Impacts on Agriculture $\quad 4$

Osmotic and Ionic Effects of Salinity Stress $\quad 4$

Morphological Consequences of Salinity Stress $\quad 6$

Physiological Response to Salinity Stress $\quad 6$

Molecular Responses to Salinity Stress $\quad 7$

Sorghum as a Model for Salinity Stress $\quad 8$

$\begin{array}{ll}\text { Literature Cited } & 10\end{array}$

$\begin{array}{ll}\text { Figures } & 18\end{array}$

CHAPTER 3: PHENOTYPIC AND PHYSIOLOGICAL RESPONSES TO SALT EXPOSURE IN SORGHUM REVEAL DIVERSITY AMONG DOMESTICATED LANDRACES $\quad 19$

$\begin{array}{ll}\text { Abstract } & 19\end{array}$

$\begin{array}{ll}\text { Introduction } & 20\end{array}$

$\begin{array}{ll}\text { Materials and Methods } & 21\end{array}$

$\begin{array}{ll}\text { Plant Material } & 21\end{array}$

$\mathrm{NaCl}$ Exposure $\quad 21$

Biomass Measurements $\quad 22$

$\begin{array}{ll}\text { Phenotype Measurements } & 22\end{array}$

$\begin{array}{ll}\text { Physiology Measurements } & 22\end{array}$

Tolerance Indices $\quad 23$

$\begin{array}{ll}\text { Statistical Analyses } & 24\end{array}$

$\begin{array}{ll}\text { Results } & 25\end{array}$

$\begin{array}{ll}\text { Treatment Effects } & 25\end{array}$ 
Landrace and Accession Effects

Relative Decrease in Plant Biomass (RDPB) 25

Stress Tolerance Index (STI) 25

Sodium and Potassium Accumulation 26

Proline Accumulation 26

Discussion 26

Phenotypic Responses to Salinity Stress 26

Physiological responses to salinity stress 28

Evolution, domestication, and adaptation of salt tolerant sorghum accessions 28

Conclusions 29

$\begin{array}{lr}\text { Acknowledgements } & 29\end{array}$

$\begin{array}{ll}\text { Literature Cited } & 31\end{array}$

Tables $\quad 35$

$\begin{array}{ll}\text { Figures } & 37\end{array}$

Supplementary Information $\quad 42$

CHAPTER 4: VARIATION IN THE EXPRESSION OF DETOXIFICATION GENES SUGGESTS THAT EARLY WATER ACQUISITION COMBINED WITH SODIUM EXCLUSION LEADS TO INCREASED SALT TOLERANCE IN SORGHUM BICOLOR

$\begin{array}{ll}\text { Abstract } & 53\end{array}$

Introduction $\quad 54$

Materials and Methods $\quad 55$

Plant Material 55

Experimental Design $\quad 55$

Gene Selection $\quad 56$

Gene Verification $\quad 56$

RNA Isolation and cDNA Synthesis $\quad 57$

qRT-PCR $\quad 57$

Fold Change $\quad 57$

Statistical Analysis $\quad 57$

Results $\quad 58$

Plant response to the addition of non-saline water 58

Plant response to the addition of $\mathrm{NaCl} \quad 58$ 
Discussion $\quad 59$

$\begin{array}{ll}\text { Conclusions } & 61\end{array}$

$\begin{array}{ll}\text { Acknowledgements } & 61\end{array}$

$\begin{array}{ll}\text { Literature Cited } & 62\end{array}$

$\begin{array}{ll}\text { Figures } & 67\end{array}$

Supplementary Tables $\quad 72$

$\begin{array}{ll}\text { Supplementary Figures } & 78\end{array}$

CHAPTER 5: DOMESTICATION \& DETOXIFICATION: EARLY SENSING, SIGNALING, AND OSMOTIC ADJUSTMENT AID IN THE INCREASED SALINITY TOLERANCE OF SORGHUM BICOLOR 92

Abstract $\quad 92$

$\begin{array}{ll}\text { Introduction } & 93\end{array}$

$\begin{array}{ll}\text { Materials and Methods } & 94\end{array}$

$\begin{array}{ll}\text { Plant Material } & 94\end{array}$

$\begin{array}{ll}\text { Experimental Conditions } & 94\end{array}$

$\begin{array}{ll}\text { Phenotypic Measurements } & 94\end{array}$

Statistical analysis of phenotypic values 95

Genetic map construction and QTL analysis 96

Results 96

High quality genetic map $\quad 96$

Treatment Effect $\quad 97$

QTL Results and Phenotypic Responses $\quad 97$

$\begin{array}{ll}\text { Total biomass (TB) } & 97\end{array}$

$\begin{array}{ll}\text { Total aboveground biomass (TAGB) } & 97\end{array}$

$\begin{array}{ll}\text { Dead aboveground biomass (DAGB) } & 98\end{array}$

Live aboveground biomass (LAGB) 98

Root biomass (RB) 98

Rank Score (RS) $\quad 99$

Height (HT) 99

$\begin{array}{ll}\text { Discussion } & 100\end{array}$

$\begin{array}{ll}\text { Conclusions } & 102\end{array}$

$\begin{array}{ll}\text { Acknowledgements } & 103\end{array}$

$\begin{array}{ll}\text { Literature Cited } & 104\end{array}$ 
$\begin{array}{ll}\text { Tables } & 109\end{array}$

$\begin{array}{ll}\text { Figures } & 111\end{array}$

$\begin{array}{ll}\text { Supplementary Tables } & 114\end{array}$

$\begin{array}{ll}\text { Supplementary Figures } & 130\end{array}$

CHAPTER 6: GENERAL CONCLUSIONS 138

$\begin{array}{lr}\text { Literature Cited } & 140\end{array}$

ACKNOWLEDGEMENTS 142 


\section{LIST OF FIGURES}

2.1 Figure 1. Effects on Biomass During Osmotic and Ionic Phases of Salinity Stress.

3.1 Figure 1. Non-metric multidimensional scaling using Bray-Curtis dissimilarity coefficient to two-dimensionally visualize plant response to treatment.

3.2 Figure 2. Relative percent of plant biomass retained in response to $75 \mathrm{mM} \mathrm{NaCl}$ for each accession.

3.3 Figure 3. Rank ordered stress tolerance index (STI) scores for live aboveground biomass, dead aboveground biomass, and root biomass, for each accession in response to $\mathrm{NaCl}$.

3.4 Figure 4. Proline accumulation in a subset of accessions.

3.5 Figure 5. A neighbor-joining tree constructed using SNP data by Mace et al. (2013)

3.6 Appendix $\mathrm{S} 1 . \mathrm{NaCl}$ effects (Pilot Study)

3.7 Appendix S3. Non-metric multidimensional scaling using Bray-Curtis dissimilarity coefficient to two-dimensionally visualize plant response to $0 \mathrm{mM}$ and $75 \mathrm{mM} \mathrm{NaCl}$.

3.8 Appendix S7. Pearson correlation matrix in $75 \mathrm{mM} \mathrm{NaCl}$

3.9 Appendix S8. Correlation between (A) $\mathrm{Na}^{+}$accumulation and RDPB (B) $\mathrm{Na}^{+}$accumulation and live aboveground biomass STI

3.10 Appendix S9. A neighbor-joining tree constructed by Mace et al. (2013) using SNP data 52

4.1 Figure 1. Overview of SOS1, NHX2, and SbHKT3 genes and their role in sodium detoxification.

4.2 Figure 2. Gene expression changes for SbSOS1, SbNHX2, and SbHKT3 after the addition of non-saline water.

4.3 Figure 3. Gene expression changes for salt detoxification genes at 30 minutes, 2 hours, 3 hours, and 6 hours after salt exposure.

4.4 Figure 4. Gene expression changes for salt detoxification genes at 12 hours, 24 hours, and 72 hours after salt exposure.

4.5 Supplementary Figure S1. SbPP2A gene sequence and primer location.

4.6 Supplementary Figure S2. SbSOS1 gene sequence and primer location.

4.7 Supplementary Figure S3. SbNHX2 gene sequence and primer location.

4.8 Supplementary Figure S4. SbHKT3 gene sequence and primer location.

4.9 Supplementary Figure S5. DNA and cDNA PCR for gene verification.

5.1 Figure 1. Phenotypic averages in control $(0 \mathrm{mM} \mathrm{NaCl})$ and treatment $(75 \mathrm{mM} \mathrm{NaCl})$ conditions.

5.2 Figure 2. A non-metric multidimensional scaling (NMDS) analysis was paired with an analysis of similarity (ANOSIM).

5.3 Figure 3. Sorghum genetic map with QTL locations for 14 traits from 177 $7_{\mathrm{F} 3: \mathrm{F} 5}$ RILs. 
5.4 Supplementary Figure S1. Pearson correlations on raw phenotypes and transformed phenotypes for control and salt populations at 15 days and 45 days after treatment.

5.5 Supplementary Figure S2. Sorghum genetic map (after bin calling).

5.6 Supplementary Figure S3. Sorghum genetic map (after removal of distorted markers).

5.7 Supplementary Figure S4. Final Sorghum genetic map. 


\section{LIST OF TABLES}

3.1 Table 1. Summary of sorghum accessions. 35

3.2 Table 2. Summary of Sorghum ion profiles. 36

3.3 Appendix S2. (A) Accession STI (B) Growth variation in response to $\mathrm{NaCl}$. 43

3.4 Appendix S4. Relative decrease in plant biomass (RDPB) for each landrace. 46

3.5 Appendix S5. (A) Landrace STI scores and (B) growth variation in response to NaCl. 47

3.6 Appendix S6. Mean proline content for control and $\mathrm{NaCl}$ conditions. 49

4.1 Supplementary Table S1. Target gene and primer sequences. 72

4.2 Supplementary Table S2. Sequence data for SbPP2A, SbNHX2, and SbHKT3

PCR products.

4.3 Supplementary Table S3. Analysis of variance results.

4.4 Supplementary Table S4. Effect of salt exposure on gene expression of SbSOS1 and SbNHX2 of Sorghum bicolor accessions in root tips.

4.5 Supplementary Table S5. Effect of salt exposure on gene expression of SbSOS1,

SbNHX2, and SbHKT3 of Sorghum bicolor accessions in the second leaf.

4.6 Supplementary Table S6. Effect of salt exposure on gene expression of SbSOS1, SbNHX2, and SbHKT3 of Sorghum bicolor accessions in the second leaf.

5.1 Table 1. Rank scoring parameters of plant vigor.

5.2 Table 2. QTLs identified in the RIL population using transformed least square means in control conditions, salt conditions, and with stress tolerance index values.

5.3 Supplementary Table S1. Transformations of phenotypes

5.4 Supplementary Table S2. Summary of markers retained following bin calling, removal of distorted regions, and removal of duplicate markers.

5.5 Supplementary Table S3. Genetic map summary.

5.6 Supplementary Table S4. Summary statistics of phenotypic values for control and salt treated populations.

5.7 Supplementary Table S5. Analysis of variance summary.

5.8 Supplementary Table S6. Genes within a 1.0 logarithm of the odds (LOD) confidence interval for each QTL when markers that deviated significantly from the expected Mendelian ratio (1:1) were removed. omitted from the document

5.9 Supplementary Table S7. Genes within a 1.0 logarithm of the odds (LOD) confidence interval for each QTL when markers that deviated significantly from the expected Mendelian ratio (1:1) were included. omitted from the document

5.10 Supplementary Table S8. Candidate genes identified in QTL windows when markers that deviated significantly from the expected Mendelian ratio (1:1) were removed. 
5.11 Supplementary Table S9. QTLs identified in the RIL population using transformed least square means in control conditions, salt conditions, and with stress tolerance index values when markers that deviated from the expected Mendelian ratio (1:1) were included. 


\section{CHAPTER 1}

\section{OVERVIEW AND OBJECTIVES}

Due to myriad factors that include rapid population growth and global climate change, agriculture is being forced onto marginal lands. Currently, it is estimated that the Earth's population is 7.7 billion, but this number is continuing to rise, and by 2100 it is expected to reach 11.18 billion (Frejka; Population Reference Bureau). It is critically and immediately necessary to efficiently use both arable and marginal lands to increase the food, fuel, water, and shelter available in order to meet the demands of the increasing population (Food and Agriculture Organization (FAO), 2008, 2009; Food and Agriculture Organization of the United Nations, 2017). Marginal lands are areas where crop production is currently limited in the absence of human inputs due to naturally occurring abiotic and biotic stressors (Elbersen et al., 2018; Von Cossel et al., 2019). Common abiotic stressors associated with marginal lands include low $\mathrm{pH}$, high concentrations of salts, and high concentrations of heavy metals (Shahid \& Al-Shankiti, 2013). Therefore, a deep understanding of the overall plant responses to abiotic stress will be crucial in order to meet global production needs.

To fully characterize abiotic stress tolerance from a whole plant perspective, we need to understand not only the gross plant response, but also the cellular events that contribute to variation in sensing and signaling among different genotypes and species. The overall objectives of my dissertation work include the identification of salt tolerant and salt sensitive Sorghum genotypes and their associated physiological, morphological, and genetic responses. I chose Sorghum bicolor as my primary study system to answer several questions in the field of salinity stress in crops:

1. What is the extent of intraspecific variation in salinity tolerance within $S$. bicolor?

2. Are there key morphological and physiological indicators associated with tolerance within S. bicolor?

3. What are the spatial and temporal sensing and signaling responses at the onset of salt exposure?

4. Do sensitive and tolerant genotypes differ in the spatial and temporal genetic response at the onset of salt exposure?

5. What regions of the genome correlate with higher degrees of salt tolerance?

6. What are the candidate genes for increased tolerance observed in domesticated sorghum?

\section{Dissertation Organization}

The body of my dissertation is organized into six chapters, with this chapter (Chapter 1: Overview and Objectives) being the first. Chapter 2, entitled "An Introduction to Salinity Stress", provides a brief overview of the current literature addressing the intensifying constraints on agriculture. In this chapter, I discuss soil salinity and its overall impact on agriculture. I then elaborate on the osmotic and ionic effects of salinity stress on plants, including the genetic regulators, physiological responses, and morphological consequences. Finally, I introduce 
Sorghum as a model system for my dissertation work. Subsequently, I present three original research chapters. Chapter 3, entitled "Phenotypic and physiological responses to salt exposure in Sorghum reveal diversity among domesticated landraces" and accepted in the American Journal of Botany, describes a study in which I screened a diverse group of Sorghum species and S. bicolor landraces and rank-ordered the accessions for salinity tolerance based on biomass traits. I then analyzed foliar proline and ion accumulation of individuals spanning a wide range of responses and compared the observed variation to known phylogenetic relationships (Mace et al., 2013; Henderson et al., 2019). Chapter 4, entitled "Variation in the expression of detoxification genes suggests that early water acquisition combined with $\mathrm{Na}^{+}$exclusion leads to increased salt tolerance in Sorghum bicolor" describes a study in which I addressed early spatial and temporal variation of salt detoxification genes in both a tolerant and a sensitive accession of Sorghum bicolor. Chapter 5, entitled "Domestication \& Detoxification: Early sensing, signaling, and osmotic adjustment aid in the increased salinity tolerance of Sorghum bicolor" extends the findings of Chapter 3 and Chapter 4. In this chapter, I use a recombinant inbred line population that was derived from a cross between a wild sorghum species, S. propinquum, and a domesticated genotype, S. bicolor. I characterized QTL related to several stress-associated phenotypes and discovered candidate genes that may play a role in increased tolerance in Sorghum bicolor. A final conclusion chapter (Chapter 6, entitled "General Conclusions") summarizes the key findings, results, and importance of this dissertation work. 


\section{Literature Cited}

Elbersen B, Verzandvoort M, Boogaard S, Mucher S, Cicarelli T, Elbersen W, Mantel S, Bai Z, MCallum I, Iqbal Y, et al. 2018. Definition and classification of marginal lands suitable for industrial crops in Europe. The Netherlands.

Food and Agriculture Organization (FAO). 2008. Land and plant nutrition management service.

Food and Agriculture Organization (FAO). 2009. Land and plant nutrition management service.

Food and Agriculture Organization of the United Nations (Ed.). 2017. The future of food and agriculture: trends and challenges. Rome: Food and Agriculture Organization of the United Nations.

Frejka T. Future Population Growth. Our World in Data.

Henderson AN, Crim PM, Cumming JR, Hawkins JS. 2019. Phenotypic and physiological responses to salt exposure in Sorghum reveal diversity among domesticated landraces. bioRxiv: 848028.

Mace ES, Tai S, Gilding EK, Li Y, Prentis PJ, Bian L, Campbell BC, Hu W, Innes DJ, Han $\mathrm{X}$, et al. 2013. Whole-genome sequencing reveals untapped genetic potential in Africa's indigenous cereal crop sorghum. Nature Communications 4: 2320.

Population Reference Bureau. 2019 World Population Data.

Shahid SA, Al-Shankiti A. 2013. Sustainable food production in marginal lands - Case of GDLA member countries. International Soil and Water Conservation Research 1: 24-38.

Von Cossel M, Lewandowski I, Elbersen B, Staritsky I, Van Eupen M, Iqbal Y, Mantel S, Scordia D, Testa G, Cosentino SL, et al. 2019. Marginal Agricultural Land Low-Input Systems for Biomass Production. Energies 12: 3123. 


\section{CHAPTER 2}

\section{AN INTRODUCTION TO SALINITY STRESS}

\section{Environmental Stress, Marginal Soils, and the Impacts on Agriculture}

Rapid increases in population size will have a significant impact on our ability to ensure the provision of basic human needs such as food, water, and shelter (Food and Agriculture Organization (FAO), 2008, 2009). As such, population growth is forcing housing and industrial developments onto lands that have been traditionally used for crop production. Such shifts limit the use of these lands for agriculture, and forces production on to marginal lands. It is estimated that the population will reach 9.3 billion by 2050 , which is $34 \%$ higher than today's population (Food and Agriculture Organization (FAO), 2009), and with this, a 70-110\% increase in food production will be required (Tilman et al., 2011; Munns et al., 2012). To achieve these challenging levels of production, increased yield will be required on both developed arable land as well as marginal soils where crops will need to be effectively cultivated.

Marginal soils are lands that have limitations in their use, especially without inputs (Elbersen et al., 2018). Common characteristics of marginal soils include high $\mathrm{pH}$, high concentrations of salts, and high concentrations of heavy metals that cause stress on plants, impacting growth and yield (Shahid \& Al-Shankiti, 2013; Von Cossel et al., 2019). Saline soils are a result of an overabundance in the following ions: sodium, chloride, calcium, sulphate, and magnesium, with sodium chloride $(\mathrm{NaCl})$ being the most prominent and destructive to plants (Tari et al., 2013; Munns et al., 2020). Salt-affected soils have long been a concern in agriculture, but the magnitude and intensity is becoming progressively imperative, given that $6 \%$ of total land (Food and Agriculture Organization (FAO), 2008) and 33\% of irrigated land is affected by salinity, and these numbers are increasing at a rate of $10 \%$ per year (Shrivastava \& Kumar, 2015).

Some salts within the soil are expected, but large increases in abundance are often interrelated, via both human interference and natural processes. For example, global climate change has triggered more frequent and prolonged periods of drought, which has ultimately affected the rate of soil water evaporation (increasing soil salt content) and this has led to an increased need for irrigation (Asif et al., 2018). Irrigation leads to increases in soil salinity in both new areas where irrigation was not previously needed and in areas where soil salinity was already a problem (Abrol et al., 1988; Flowers \& Yeo, 1995; Munns et al., 2020). Additional examples include land clearing, ingression of sea water, changes in the rate of soil water evaporation, the use of animal manures as fertilizers, and soil run off (Abrol et al., 1988; Munns, 2005, 2010; Mahajan \& Tuteja, 2005; Jenks et al., 2007; Shabala, 2012; Asif et al., 2018; Vaishnav et al., 2019). For these reasons, soil salt concentrations will continue to rise. Therefore, understanding the effects of soil salinity on crop growth and production is critical to meet demands.

\section{Osmotic and Ionic Effects of Salinity Stress}

Salinity stress, induced by an over-abundance of ions in the soil, leads to both osmotic and ionic stress (Rengasamy, 2006; Munns \& Tester, 2008; Morton et al., 2019). Osmotic stress results from the inhibition of water absorption, rather than overall toxicity (Bernstein \& Hayward, 1958; 
Munns \& Tester, 2008). Highly saline environments are soils where ions are present in the area surrounding the rhizosphere and therefore generate a low water potential in the soil (Mahajan \& Tuteja, 2005; Iqbal et al., 2014). Even when soil conditions are wet, because soil water potential is lower than the plants osmotic potential, water and nutrients will not be extracted from the soil by the roots, therefore simulating drought-like conditions. The overall major effect of osmotic stress observed in both tolerant and sensitive species and genotypes is decreased above- and belowground growth due to lack of water (Figure 1) (Munns, 2005; Iqbal et al., 2014). The initial shock of salinity stress causes cells to lose water, resulting in decreased volume and turgor; however, this decrease is not permanent. The initial loss of cell size is regained within hours, but the cell elongation rate is reduced, resulting in decreased leaf size (Yeo et al., 1991; Passioura \& Munns, 2000; Munns \& Tester, 2008). Generally, leaf surface area is affected to a greater extent than depth, therefore resulting in smaller but thicker leaves. In order to mitigate the primary osmotic effect, plants must maintain cell turgor, which can be accomplished by osmotic adjustment (Flowers \& Colmer, 2008; Turner, 2018). Plants produce and accumulate compatible solutes, which lowers the plants osmotic potential to assist in maintenance of turgor and enable the movement of water through the plant, therefore aiding in osmotic adjustment (Bernstein, 1961, 1963; Hsiao et al., 1976; Turner, 2018). Examples of compatible solutes, or osmolytes, include various amino acids, carbohydrates, methylamines, sugars, and polyols (Negrão et al., 2017; Turner, 2018).

The secondary phase of salinity stress results from the accumulation of ions as they infiltrate the plant during water uptake. Once the plant has overcome the primary phase of salinity stress by altering osmotic potential, ions enter the root symplast by passive influx through non-selective cation channels (NSCC) from the soil (Tyerman \& Skerrett, 1998; Davenport \& Tester, 2000; Demidchik \& Tester, 2002; Munns et al., 2020). Once $\mathrm{Na}^{+}$enters the root symplast, it is actively transported to the xylem where ions enter the shoot symplast from the xylem apoplast and move into mesophyll cells via NSCCs (Munns et al., 2020). This overabundance of ions in the cytoplasm of cells becomes toxic and ultimately leads to ionic disequilibrium that results in premature leaf senescence, inactivation of enzymes, oxidative stress, and overall toxicity (Iqbal et al., 2014). Because salts can be compartmentalized into older leaves or sequestered into vacuoles, plants can survive the ionic component of salt stress if the rate of new leaf emergence exceeds the rate of leaf death (Koyama et al., 2001). This enables the plant to continue photosynthesizing and therefore producing enough carbon for growth and development (Munns, 2005, 2010).

Because cells have a negative electrical potential, $\mathrm{Cl}^{-}$is less of a concern because uptake is less energy-demanding, and $\mathrm{Cl}^{-}$cannot passively enter a cell unless cytosolic concentrations are extremely low (Feng et al., 2015). The accumulation of $\mathrm{Na}^{+}$, on the other hand, disrupts the uptake and distribution of $\mathrm{K}^{+}$, an essential ion for basic biological functions (Tari et al., 2013). The ability to maintain a high $\mathrm{K}^{+} / \mathrm{Na}^{+}$ratio is a strong indication of a tolerant genotype (Figure 1). Much of the research aimed at dissecting the underpinnings of salinity tolerance indicates that survival on saline soils depends on the ability to exclude toxic sodium ions. However, recent studies have suggested that targeting additional mechanisms of tolerance is critical to fully understand osmotic and ionic tolerance. 


\section{Morphological Consequences of Salinity Stress}

A myriad of morphological changes are associated with increased salinity (Munns \& Tester, 2008; Tari et al., 2013). For example, it has been observed that decreases in total germination and increases in the time taken to germinate result from salt exposure (Gill et al., 2003; Almodares et al., 2007; Tari et al., 2013). Following germination, biomass accumulation is negatively affected, predominantly as a result of the initial osmotic stress (Figure 1) (Munns \& Tester, 2008; Negrão et al., 2017). Osmotic stress reduces cell elongation and division, and directly affects leaf area, plant height, and stem diameter (Yeo et al., 1991; Passioura \& Munns, 2000; Cramer, 2002; Fricke \& Peters, 2002; Munns \& Tester, 2008; Silva et al., 2019). Further, with long-term osmotic stress, lateral shoot development becomes inhibited and overall aboveground biomass is reduced (Silva et al., 2019). While reductions in root growth have been observed (Rahnama et al., 2011; Jung \& McCouch, 2013), root growth is not as severely affected as leaf growth. This is likely an adaptive response because with decreased leaf biomass, less water is extracted from the soil, ultimately affecting soil salt concentrations and ion uptake (Munns \& Tester, 2008; Munns \& Gilliham, 2015; Hanin et al., 2016). Additionally, the ability to maintain lateral root growth is important for the exploration of non-saline water (GalvanAmpudia et al., 2013; Munns \& Gilliham, 2015). In cereal crops, tillering is correlated with increased biomass, but with increased salinity, there is a decrease in tillering, resulting in reduced growth and early maturation (Munns, 2002; Jenks et al., 2007; Shabala, 2012). Given what we know about osmotic and ionic stress and the morphological consequences associated with salinity, it is important to note that tolerant genotypes can be identified by their ability to maintain live aboveground biomass and limit dead aboveground biomass.

\section{Physiological Response to Salinity Stress}

Physiological responses associated with salinity stress include changes in potassium $\left(\mathrm{K}^{+}\right)$uptake, photosynthetic efficiency (Nazar et al., 2011), chlorophyll content, antioxidant metabolism, hormone signaling (Wang \& Huang, 2019), and the accumulation of compatible solutes (Misra \& Gupta, 2005; Khan et al., 2012; Tari et al., 2013). Potassium uptake $\left(\mathrm{K}^{+}\right)$is critical for normal metabolic function (Wu et al., 2018). Specifically, $\mathrm{K}^{+}$is an essential nutrient for protein synthesis (Jones et al., 1979; Blaha et al., 2000; Wu et al., 2018), phloem transport (Gajdanowicz et al., 2011; De Schepper et al., 2013), photosynthesis (Fischer, 1968; Wu et al., 2018), enzyme activity (Bhandal \& Malik, 1988), and signaling (De Schepper et al., 2013; Shabala, 2017). Because of the similarity in size and weight of $\mathrm{Na}^{+}$and $\mathrm{K}^{+}, \mathrm{Na}^{+}$competes with $\mathrm{K}^{+}$, and therefore disrupts normal ion ratios (Pardo \& Quintero, 2002; Munns \& Tester, 2008; Wu et al., 2018). Photosynthesis is affected most in expanded leaves, not due to the accumulation of toxic salt ions, but due to stomatal closure, a plant response to avoid excess loss of water (Munns \& Tester, 2008; Munns, 2010). When stomata close, the light-independent reactions of photosynthesis are inhibited and photosynthesis halts (Liu et al., 2017; Nounjan et al., 2018). Impaired photosynthesis leads to leaf chlorosis and results in leaf senescence (Munns, 1993, 2002; Tari et al., 2013). 


\section{Molecular Responses to Salinity Stress}

Osmotic stress is the result of limited water absorption, regardless of the abiotic stress causing it; however, research indicates that the underlying genetic responses differ depending on the specific type of stress to which the plant is exposed. For example, in Arabidopsis, gene expression profiles during exposure to a suite of abiotic stresses (drought, salt, temperature, and UV-B light) provided evidence that there is a common set of genes that are initially induced. Over time, however, gene expression patterns diverge in a stress-dependent manner (Kilian et al., 2007), indicating that it is critical to delineate the expression patterns for the initial response (generalized) from the specialized response (specific).

The specific genetic responses to salinity stress can be grouped into three broad functional categories: 1) genes that control uptake and transport of toxic ions, 2) genes that aid in osmotic adjustment, and 3 ) genes that aid in increased growth and tissue tolerance, regardless of salinity (Munns, 2005; Munns \& Tester, 2008). Most genes are not exclusive to one functional category, but rather play a role in all three components of salinity tolerance. For example, Munns and Tester (2008) organized six groups of genes that are involved in different tolerance processes and described the role of each in aiding in salinity tolerance. Processes described included: (1) sensing and signaling in roots (2) shoot growth (3) photosynthesis (4) accumulation of $\mathrm{Na}^{+}$in shoots (5) accumulation of $\mathrm{Na}^{+}$in vacuoles and (6) accumulation of organic solutes. The genes in each of these processes play a role in both osmotic and ionic stress tolerance $\left(\mathrm{Na}^{+}\right.$exclusion and tissue tolerance).

Genes known to play a role in sensing and signaling in roots include salt-overly sensitive3 (SOS3) and sucrose nonfermenting-1-related kinases (SnRK) (Munns \& Tester, 2008). During osmotic stress and adjustment (category 2), these genes aid in the modification of long-distance signaling, and during ionic stress they aid in net ion transport to the shoot (category 1) and vacuoles (category 3 ). Genes that are involved in the photosynthetic response include ERA1 (enhanced response to ABA1), PP2C (protein phosphatase 2C), AAPK (abscisic acid-activated protein kinase), and PKS3 (phytochrome kinase substrate-like protein). These genes are involved in stomatal closure during the osmotic phase of salinity stress (category 2) and aid in decreased toxicity in chloroplasts (category 1 and 3 ) during the ionic phase. Genes involved in the accumulation of $\mathrm{Na}^{+}$in shoots include high-affinity K transporter (HKT) and SOS1. These genes aid in tolerance via increased osmotic adjustment (category 2 ) by altering $\mathrm{Na}^{+}$transport and extrusion during ionic stress (category 1 and 3). HKT, specifically, unloads $\mathrm{Na}^{+}$ions from the xylem sap to prevent overaccumulation in the aboveground portion of the plant (Sunarpi et al., 2005; Ren et al., 2005; Huang et al., 2006). With decreased sodium in the leaf sheaths, plants are able to maintain photosynthetic efficiency and capacity. The SOS1 antiporter removes $\mathrm{Na}^{+}$from the cytoplasm in a process known as extrusion (Batelli et al., 2007; Yue et al., 2012; Lekshmy Sathee et al., 2015; Miranda et al., 2017; Mahi et al., 2019; Baghour et al., 2019). Genes involved in the accumulation of $\mathrm{Na}^{+}$in vacuoles include NHX (sodium-hydrogen exchanger), a plasma membrane-localized transporter that is important in sequestration of $\mathrm{Na}^{+}$into vacuoles, and AVP (inorganic H pyrophatase) (Shi \& Zhu, 2002; Leidi et al., 2010; Bassil et al., 2011; Li et al., 2011; Barragán et al., 2012; Baghour et al., 2019, p. 2011). During the osmotic phase, these genes aid in increased osmotic adjustment (category 2), and during the ionic phase they control the sequestration of $\mathrm{Na}^{+}$into root and leaf vacuoles (category 1 and 3). Lastly, candidate genes that have been shown to play a role in osmotic regulation as a compatible solute include 
P5CS (putative delta-1-pyrroline-5-carboxylate synthase), OTS (overly tolerant to salt), MT1 (metallothionein-like protein 1), M6PR (mannose-6- phosphate receptor), S6PDH (nadpdependent d-sorbitol-6-phosphate dehydrogenase), and IMT1 (initiator methionine tRNA). During the osmotic phase, these genes aid in increased osmotic adjustment (category 2), and during the ionic phase they control the transport of $\mathrm{Na}^{+}$(category 1 and 3) (Munns \& Tester, 2008).

\section{Sorghum as a Model for Salinity Stress}

Crops that are most affected by global climate change, and therefore increased salinity, include the major grain crops maize, sorghum, wheat, rye, barley, oat, millets, and rice. Among these is Sorghum bicolor (L.) Moench, which is a C4 crop used for a variety of purposes (Wiersema \& Dahlberg, 2007; Paterson, 2008; Ali \& Idris, 2015; McCormick et al., 2018). Sorghum is important in grain (ranks fifth), biofuel (ranks second), animal feed, fiber, fermentation, and fertilizer production (Paterson, 2008; Tari et al., 2013). Sorghum is especially well adapted to hot, dry, saline, and waterlogged environments (Steduto et al., 1997; Almodares et al., 2008b,a; Promkhambu et al., 2010; Morris et al., 2013; Mace et al., 2013; Zhang et al., 2016; Kadam et al., 2017). It is, therefore, tolerant to most abiotic stresses, even with limited input (Doggett, 1970; Steduto et al., 1997; Almodares et al., 2008b,a; Paterson, 2008). With millet being an exception, sorghum is ranked the highest within agricultural crops for drought tolerance, which is consistent with a historical domestication background in Africa (Steduto et al., 1997; Almodares et al., 2008a). Sorghum was first domesticated >8,000 years ago in Ethiopia and Sudan (Wendorf et al., 1992). Following domestication, S. bicolor diffused to various regions in Africa, and adaptation to various environments resulted in four landraces (Morris et al., 2013; Mace et al., 2013; Smith et al., 2019). Kafir, which tends to predominate in South Africa, shows the largest genetic variation compared to other landraces, likely due to migration into a contrasting agroclimate (Morris et al., 2013). Guinea tends to be widely distributed in western Africa in tropical savannas. A subgroup of guinea, referred to as guinea-margaritiferum, is present in the same geographical area as guinea but appears to have undergone a separate, more recent, domestication event (Morris et al., 2013; Mace et al., 2013; Mullet et al., 2014). Caudatum, primarily found in central-west Africa in tropical savanna climates, displays the least amount of population structure due to exposure of adjacent and varying climates. Lastly, durra is distributed in the warm semiarid deserts of northern Africa and India (Morris et al., 2013; Mace et al., 2013; Mullet et al., 2014; Smith et al., 2019). Given that each landrace adapted in various geographical regions, and each landrace possesses a diverse gene pool, Sorghum is a valuable resource for dissecting genetic adaption to various environments.

Further, Sorghum shares a common ancestor with Zea mays ( 12 mya); however Sorghum has a simple genome compared to maize (Gaut et al., 1997; Swigoňová et al., 2004). Since their divergence, maize has undergone a whole-genome duplication event followed by rediploidization resulting in massive genomic reorganization and a $\sim 2.5 \mathrm{~Gb}$ genome $(2 \mathrm{n}=20)$ with $85 \%$ repetitive DNA content. In contrast, sorghum has a much smaller $(\sim 730 \mathrm{Mb})$ diploid genome with less repetitive DNA ( $\sim 61 \%)$ making it an ideal model system for genomic studies (Paterson et al., 2009). The genome of S. bicolor has been well annotated and the transcriptome has been fully interrogated across the juvenile, vegetative, and reproductive stages of development (McCormick et al., 2018). Further, more than 49 additional diverse genotypes have 
been sequenced (Mace et al., 2013; McCormick et al., 2018; Boyles et al., 2019). This makes thorough investigations in more specific studies of the genome and transcriptome manageable because we can utilize the information already available in conjunction with our salt-specific data. These key features of sorghum make it easier to dissect the genetic underpinnings associated with morphological and physiological responses, and, due to the close evolutionary relationship, it is an excellent model for crop improvement in maize and other related cereal grasses. 


\section{Literature Cited}

Abrol IP, Yadav JSP, Massoud FI. 1988. Salt-affected soils and their management. United

Nations, Rome: Food \& Agriculture Org.

Ali SAM, Idris AY. 2015. Response of Sorghum (Sorghum bicolor L.) Cultivars to Salinity Levels at Early Growth Stages. Journal of Agricultural Science and Engineering 1: 11-16.

Almodares A, Hadi MR, Ahmadpour H. 2008a. Sorghum stem yield and soluble carbohydrates under different salinity levels. African Journal of Biotechnology 7: 4051-4055.

Almodares A, Hadi MR, Dosti B. 2007. Effects of salt stress on germination percentage and seedling growth in sweet sorghum cultivars. Journal of Biological Sciences 7: 1492-1495.

Almodares A, Hadi MR, Dosti B. 2008b. The effects of salt stress on growth parameters and Carbohydrates Contents in Sweet Sorghum. Research Journal of Environmental Sciences 2: 298-304.

Asif MA, Schilling RK, Tilbrook J, Brien C, Dowling K, Rabie H, Short L, Trittermann C, Garcia A, Barrett-Lennard EG, et al.2018. Mapping of novel salt tolerance QTL in an Excalibur $\times$ Kukri doubled haploid wheat population. Theoretical and Applied Genetics 131: 2179-2196.

Baghour M, Gálvez FJ, Sánchez ME, Aranda MN, Venema K, Rodríguez-Rosales MP. 2019. Overexpression of LeNHX 2 and SISOS 2 increases salt tolerance and fruit production in double transgenic tomato plants. Plant Physiology and Biochemistry 135: 77-86.

Barragán V, Leidi EO, Andrés Z, Rubio L, Luca AD, Fernández JA, Cubero B, Pardo JM. 2012. Ion exchangers $\mathrm{NHX} 1$ and $\mathrm{NHX} 2$ mediate active potassium uptake into vacuoles to regulate cell turgor and stomatal function in Arabidopsis. The Plant Cell.

Bassil E, Ohto M, Esumi T, Tajima H, Zhu Z, Cagnac O, Belmonte M, Peleg Z, Yamaguchi T, Blumwald E. 2011. The Arabidopsis intracellular $\mathrm{Na}^{+} / \mathrm{H}^{+}$antiporters $\mathrm{NHX} 5$ and $\mathrm{NHX} 6$ are endosome associated and necessary for plant growth and development. The Plant Cell: tpc.110.079426.

Batelli G, Verslues PE, Agius F, Qiu Q, Fujii H, Pan S, Schumaker KS, Grillo S, Zhu J-K. 2007. SOS2 promotes salt tolerance in part by interacting with the vacuolar $\mathrm{H}^{+}$-ATPase and upregulating its transport activity. Molecular and Cellular Biology 27: 7781-7790.

Bernstein L. 1961. Osmotic adjustment of plants to saline media. I. Steady State. American Journal of Botany 48: 909-918.

Bernstein L. 1963. Osmotic adjustment of plants to saline media. II. Dynamic Phase. American Journal of Botany 50: 360-370.

Bernstein L, Hayward HE. 1958. Physiology of salt tolerance. Annual Review of Plant Physiology 9: 25-46. 
Bhandal IS, Malik CP. 1988. Potassium estimation, uptake, and its role in the physiology and metabolism of flowering plants. In: Bourne GH, Jeon KW, Friedlander M, eds. International Review of Cytology. Academic Press, 205-254.

Blaha G, Stelzl U, Spahn CMT, Agrawal RK, Frank J, Nierhaus KH. 2000. [19] Preparation of functional ribosomal complexes and effect of buffer conditions on tRNA positions observed by cryoelectron microscopy. In: Methods in Enzymology. Elsevier, 292-309.

Boyles RE, Brenton ZW, Kresovich S. 2019. Genetic and genomic resources of sorghum to connect genotype with phenotype in contrasting environments. The Plant Journal 97: 19-39.

Cramer GR. 2002. Response of abscisic acid mutants of Arabidopsis to salinity. Functional Plant Biology 29: 561-567.

Davenport RJ, Tester M. 2000. A weakly voltage-dependent, nonselective cation channel mediates toxic sodium influx in wheat. Plant Physiology 122: 823-834.

De Schepper V, De Swaef T, Bauweraerts I, Steppe K. 2013. Phloem transport: a review of mechanisms and controls. Journal of Experimental Botany 64: 4839-4850.

Demidchik V, Tester M. 2002. Sodium fluxes through nonselective cation channels in the plasma membrane of protoplasts from Arabidopsis roots. Plant Physiology 128: 379-387.

Doggett H. 1970. Sorghum. Sorghum.

Elbersen B, Verzandvoort M, Boogaard S, Mucher S, Cicarelli T, Elbersen W, Mantel S, Bai Z, MCallum I, Iqbal Y, et al.2018. Definition and classification of marginal lands suitable for industrial crops in Europe. The Netherlands.

Feng Z-J, He G-H, Zheng W-J, Lu P-P, Chen M, Gong Y-M, Ma Y-Z, Xu Z-S. 2015. Foxtail millet NF-Y families: Genome-wide survey and evolution analyses identified two functional genes important in abiotic stresses. Frontiers in Plant Science 6.

Fischer RA. 1968. Stomatal opening: Role of potassium uptake by guard cells. Science 160: 784-785.

Flowers TJ, Colmer TD. 2008. Salinity tolerance in halophytes. New Phytologist 179: 945-963.

Flowers TJ, Yeo AR. 1995. Breeding for salinity resistance in crop plants: where next?

Functional Plant Biology 22: 875-884.

Food and Agriculture Organization (FAO). 2008. Land and plant nutrition management service.

Food and Agriculture Organization (FAO). 2009. Land and plant nutrition management service.

Fricke W, Peters WS. 2002. The biophysics of leaf growth in salt-stressed barley. A study at the 
cell level. Plant Physiology 129: 374-388.

Gajdanowicz P, Michard E, Sandmann M, Rocha M, Correa LGG, Ramirez-Aguilar SJ, Gomez-Porras JL, Gonzalez W, Thibaud J-B, van Dongen JT, et al.2011. Potassium $\left(\mathrm{K}^{+}\right)$ gradients serve as a mobile energy source in plant vascular tissues. Proceedings of the National Academy of Sciences 108: 864-869.

Galvan-Ampudia CS, Julkowska MM, Darwish E, Gandullo J, Korver RA, Brunoud G, Haring MA, Munnik T, Vernoux T, Testerink C. 2013. Halotropism is a response of plant roots to avoid a saline environment. Current Biology 23: 2044-2050.

Gaut BS, Clark LG, Wendel JF, Muse SV. 1997. Comparisons of the molecular evolutionary process at rbcL and ndhF in the grass family (Poaceae). Molecular Biology and Evolution 14: 769-777.

Gill PK, Sharma AD, Singh P, Bhullar SS. 2003. Changes in germination, growth and soluble sugar contents of Sorghum bicolor (L.) Moench seeds under various abiotic stresses. Plant Growth Regulation 40: 157-162.

Hanin M, Ebel C, Ngom M, Laplaze L, Masmoudi K. 2016. New insights on plant salt tolerance mechanisms and their potential use for breeding. Frontiers in Plant Science 7.

Hsiao TC, Acevedo E, Fereres E, Henderson DW, Monteith JL, Weatherley PE. 1976. Water stress, growth and osmotic adjustment. Philosophical Transactions of the Royal Society of London. B, Biological Sciences 273: 479-500.

Huang S, Spielmeyer W, Lagudah ES, James RA, Platten JD, Dennis ES, Munns R. 2006. A sodium transporter (HKT7) is a candidate for Nax1, a gene for salt tolerance in durum wheat. Plant Physiology 142: 1718-1727.

Iqbal N, Umar S, Khan NA, Khan MIR. 2014. A new perspective of phytohormones in salinity tolerance: Regulation of proline metabolism. Environmental and Experimental Botany 100: $34-42$.

Jenks MA, Hasegawa PM, Jain SM (Eds.). 2007. Advances in Molecular Breeding Toward Drought and Salt Tolerant Crops. Dordrecht: Springer Netherlands.

Jones WRG, Brady CJ, Speirs J. 1979. Ionic and osmotic relations in plant cells. In: Recent advances in cereal biochemistry. London: Academic Press, 63-103.

Jung JKHM, McCouch SRM. 2013. Getting to the roots of it: Genetic and hormonal control of root architecture. Frontiers in Plant Science 4.

Kadam S, Abril A, Dhanapal AP, Koester RP, Vermerris W, Jose S, Fritschi FB. 2017. Characterization and regulation of aquaporin genes of sorghum [Sorghum bicolor (L.) Moench] in response to waterlogging stress. Frontiers in Plant Science $\mathbf{8}$.

Khan MIR, Iqbal N, Masood A, Khan NA. 2012. Variation in salt tolerance of wheat cultivars: 
Role of glycinebetaine and ethylene. Pedosphere 22: 746-754.

Kilian J, Whitehead D, Horak J, Wanke D, Weinl S, Batistic O, D'Angelo C, BornbergBauer E, Kudla J, Harter K. 2007. The AtGenExpress global stress expression data set: protocols, evaluation and model data analysis of UV-B light, drought and cold stress responses. The Plant Journal 50: 347-363.

Koyama ML, Levesley A, Koebner RMD, Flowers TJ, Yeo AR. 2001. Quantitative trait loci for component physiological traits determining salt tolerance in rice. Plant Physiology 125: 406422.

Leidi EO, Barragán V, Rubio L, El-Hamdaoui A, Ruiz MT, Cubero B, Fernández JA, Bressan RA, Hasegawa PM, Quintero FJ, et al.2010. The AtNHX1 exchanger mediates potassium compartmentation in vacuoles of transgenic tomato. The Plant Journal 61: 495-506.

Lekshmy Sathee, Sairam RK, Chinnusamy V, Jha SK. 2015. Differential transcript abundance of salt overly sensitive (SOS) pathway genes is a determinant of salinity stress tolerance of wheat. Acta Physiologiae Plantarum 37: 169.

Li W, Wang D, Jin T, Chang Q, Yin D, Xu S, Liu B, Liu L. 2011. The vacuolar $\mathrm{Na}^{+} / \mathrm{H}^{+}$ antiporter gene SsNHX1 from the halophyte Salsola soda confers salt tolerance in transgenic alfalfa (Medicago sativa L.). Plant Molecular Biology Reporter 29: 278-290.

Liu X, Fan Y, Mak M, Babla M, Holford P, Wang F, Chen G, Scott G, Wang G, Shabala S, et al.2017. QTLs for stomatal and photosynthetic traits related to salinity tolerance in barley. BMC Genomics 18: 9.

Mace ES, Tai S, Gilding EK, Li Y, Prentis PJ, Bian L, Campbell BC, Hu W, Innes DJ, Han $\mathrm{X}$, et al.2013. Whole-genome sequencing reveals untapped genetic potential in Africa's indigenous cereal crop sorghum. Nature Communications 4: 2320.

Mahajan S, Tuteja N. 2005. Cold, salinity and drought stresses: An overview. Archives of Biochemistry and Biophysics 444: 139-158.

Mahi HE, Perez-Hormaeche J, Luca AD, Villalta I, Espartero J, Gamez-Arjona F, Fernandez JL, Bundo M, Mendoza I, Mieulet D, et al.2019. A critical role of sodium flux via the plasma membrane $\mathrm{Na}^{+} / \mathrm{H}^{+}$exchanger SOS1 in the salt tolerance of rice. Plant Physiology: pp.00324.2019.

McCormick RF, Truong SK, Sreedasyam A, Jenkins J, Shu S, Sims D, Kennedy M, Amirebrahimi M, Weers BD, McKinley B, et al.2018. The Sorghum bicolor reference genome: improved assembly, gene annotations, a transcriptome atlas, and signatures of genome organization. The Plant Journal 93: 338-354.

Miranda R de S, Mesquita RO, Costa JH, Alvarez-Pizarro JC, Prisco JT, Gomes-Filho E. 2017. Integrative control between proton pumps and SOS1 antiporters in roots is crucial for maintaining low $\mathrm{Na}^{+}$accumulation and salt tolerance in ammonium-supplied Sorghum bicolor. Plant and Cell Physiology 58: 522-536. 
Misra N, Gupta AK. 2005. Effect of salt stress on proline metabolism in two high yielding genotypes of green gram. Plant Science 169: 331-339.

Morris GP, Ramu P, Deshpande SP, Hash CT, Shah T, Upadhyaya HD, Riera-Lizarazu O, Brown PJ, Acharya CB, Mitchell SE, et al.2013. Population genomic and genome-wide association studies of agroclimatic traits in sorghum. Proceedings of the National Academy of Sciences 110: 453-458.

Morton MJL, Awlia M, Al-Tamimi N, Saade S, Pailles Y, Negrão S, Tester M. 2019. Salt stress under the scalpel - dissecting the genetics of salt tolerance. The Plant Journal 97: 148163.

Mullet J, Morishige D, McCormick R, Truong S, Hilley J, McKinley B, Anderson R, Olson SN, Rooney W. 2014. Energy Sorghum--a genetic model for the design of C4 grass bioenergy crops. Journal of Experimental Botany 65: 3479-3489.

Munns R. 1993. Physiological processes limiting plant growth in saline soils: some dogmas and hypotheses. Plant, Cell and Environment 16: 15-24.

Munns R. 2002. Comparative physiology of salt and water stress. Plant, Cell and Environment 25: $239-250$.

Munns R. 2005. Genes and salt tolerance: bringing them together. New Phytologist 167: 645663.

Munns R. 2010. Approaches to identifying genes for salinity tolerance and the importance of timescale. In: Sunkar R, ed. Methods in Molecular Biology. Plant Stress Tolerance: Methods and Protocols. Totowa, NJ: Humana Press, 25-38.

Munns R, Day DA, Fricke W, Watt M, Arsova B, Barkla BJ, Bose J, Byrt CS, Chen Z-H, Foster KJ, et al.2020. Energy costs of salt tolerance in crop plants. New Phytologist: 10721090.

Munns R, Gilliham M. 2015. Salinity tolerance of crops - what is the cost? New Phytologist 208: $668-673$.

Munns R, James RA, Xu B, Athman A, Conn SJ, Jordans C, Byrt CS, Hare RA, Tyerman SD, Tester M, et al.2012. Wheat grain yield on saline soils is improved by an ancestral $\mathrm{Na}^{+}$ transporter gene. Nature Biotechnology 30: 360-364.

Munns R, Tester M. 2008. Mechanisms of salinity tolerance. Annual Review of Plant Biology 59: $651-681$.

Nazar R, Iqbal N, Syeed S, Khan NA. 2011. Salicylic acid alleviates decreases in photosynthesis under salt stress by enhancing nitrogen and sulfur assimilation and antioxidant metabolism differentially in two mungbean cultivars. Journal of Plant Physiology 168: 807-815.

Negrão S, Schmöckel SM, Tester M. 2017. Evaluating physiological responses of plants to 
salinity stress. Annals of Botany 119: 1-11.

Nounjan N, Chansongkrow P, Charoensawan V, Siangliw JL, Toojinda T, Chadchawan S, Theerakulpisut P. 2018. High performance of photosynthesis and osmotic adjustment are associated with salt tolerance ability in rice carrying drought tolerance QTL: Physiological and co-expression network analysis. Frontiers in Plant Science 9.

Pardo JM, Quintero FJ. 2002. Plants and sodium ions: keeping company with the enemy. Genome Biology 3: reviews1017.1.

Passioura JB, Munns R. 2000. Rapid environmental changes that affect leaf water status induce transient surges or pauses in leaf expansion rate. Functional Plant Biology 27: 941-948.

Paterson AH. 2008. Genomics of Sorghum. International Journal of Plant Genomics 2008: e362451.

Paterson AH, Bowers JE, Bruggmann R, Dubchak I, Grimwood J, Gundlach H, Haberer G, Hellsten U, Mitros T, Poliakov A, et al.2009. The Sorghum bicolor genome and the diversification of grasses. Nature 457: 551-556.

Promkhambu A, Younger A, Polthanee A, Akkasaeng C. 2010. Morphological and physiological responses of Sorghum (Sorghum bicolor L. Moench) to waterlogging. Asian Journal of Plant Sciences 9: 183-193.

Rahnama A, Munns R, Poustini K, Watt M. 2011. A screening method to identify genetic variation in root growth response to a salinity gradient. Journal of Experimental Botany 62: 6977.

Ren Z-H, Gao J-P, Li L-G, Cai X-L, Huang W, Chao D-Y, Zhu M-Z, Wang Z-Y, Luan S, Lin H-X. 2005. A rice quantitative trait locus for salt tolerance encodes a sodium transporter. Nature Genetics 37: 1141-1146.

Rengasamy P. 2006. World salinization with emphasis on Australia. Journal of Experimental Botany 57: 1017-1023.

Shabala S. 2012. Plant Stress Physiology. Wallingford, UK: CAB International.

Shabala S. 2017. Signalling by potassium: another second messenger to add to the list? Journal of Experimental Botany 68: 4003-4007.

Shahid SA, Al-Shankiti A. 2013. Sustainable food production in marginal lands - Case of GDLA member countries. International Soil and Water Conservation Research 1: 24-38.

Shi H, Zhu J-K. 2002. Regulation of expression of the vacuolar $\mathrm{Na}^{+} / \mathrm{H}^{+}$antiporter gene AtNHX1 by salt stress and abscisic acid. Plant Molecular Biology 50: 543-550.

Shrivastava P, Kumar R. 2015. Soil salinity: A serious environmental issue and plant growth promoting bacteria as one of the tools for its alleviation. Saudi Journal of Biological Sciences 22: 
$123-131$.

Silva ML dos S, Sousa HG de, Silva ML dos S, Lacerda CF de, Gomes-Filho E, Silva ML dos S, Sousa HG de, Silva ML dos S, Lacerda CF de, Gomes-Filho E. 2019. Growth and photosynthetic parameters of saccharine sorghum plants subjected to salinity. Acta Scientiarum. Agronomy 41.

Smith O, Nicholson WV, Kistler L, Mace E, Clapham A, Rose P, Stevens C, Ware R, Samavedam S, Barker G, et al.2019. A domestication history of dynamic adaptation and genomic deterioration in sorghum. Nature Plants 5: 369-379.

Steduto P, Katerji N, Puertos-Molina H, Unulu M, Mastrorilli M, Rana G. 1997. Water-use efficiency of sweet sorghum under water stress conditions gas-exchange investigations at leaf and canopy scales. Field Crops Research 54: 221-234.

Sunarpi, Horie T, Motoda J, Kubo M, Yang H, Yoda K, Horie R, Chan W-Y, Leung H-Y, Hattori K, et al.2005. Enhanced salt tolerance mediated by AtHKT1 transporter-induced $\mathrm{Na}^{+}$ unloading from xylem vessels to xylem parenchyma cells. The Plant Journal 44: 928-938.

Swigoňová Z, Lai J, Ma J, Ramakrishna W, Llaca V, Bennetzen JL, Messing J. 2004. Close split of sorghum and maize genome progenitors. Genome Research 14: 1916-1923.

Tari I, Laskay G, Takacs Z, Poor P. 2013. Response of sorghum to abiotic stresses: A review. Journal of Agronomy and Crop Science 199: 264-274.

Tilman D, Balzer C, Hill J, Befort BL. 2011. Global food demand and the sustainable intensification of agriculture. Proceedings of the National Academy of Sciences 108: 2026020264.

Turner NC. 2018. Turgor maintenance by osmotic adjustment: 40 years of progress. Journal of Experimental Botany 69: 3223-3233.

Tyerman SD, Skerrett IM. 1998. Root ion channels and salinity. Scientia Horticulturae 78: $175-235$.

Vaishnav A, Shukla AK, Sharma A, Kumar R, Choudhary DK. 2019. Endophytic bacteria in plant salt stress tolerance: Current and future prospects. Journal of Plant Growth Regulation 38: 650-668.

Von Cossel M, Lewandowski I, Elbersen B, Staritsky I, Van Eupen M, Iqbal Y, Mantel S, Scordia D, Testa G, Cosentino SL, et al.2019. Marginal agricultural land low-input systems for biomass production. Energies 12: 3123.

Wang J, Huang R. 2019. Modulation of ethylene and ascorbic acid on reactive oxygen species scavenging in plant salt response. Frontiers in Plant Science $\mathbf{1 0 .}$

Wendorf F, Close AE, Schild R, Wasylikowa K, Housley RA, Harlan JR, Królik H. 1992. Saharan exploitation of plants 8,000 years BP. Nature 359: 721-724. 
Wiersema JH, Dahlberg J. 2007. The nomenclature of Sorghum bicolor (L.) Moench (Gramineae). Taxon 56: 941-946.

Wu H, Zhang X, Giraldo JP, Shabala S. 2018. It is not all about sodium: revealing tissue specificity and signalling roles of potassium in plant responses to salt stress. Plant and Soil 431: $1-17$.

Yeo AR, Lee $\lambda$-S, Izard P, Boursier PJ, Flowers TJ. 1991. Short- and long-term effects of salinity on leaf growth in rice (Oryza sativa L.). Journal of Experimental Botany 42: 881-889.

Yue Y, Zhang M, Zhang J, Duan L, Li Z. 2012. SOS1 gene overexpression increased salt tolerance in transgenic tobacco by maintaining a higher $\mathrm{K}^{+} / \mathrm{Na}^{+}$ratio. Journal of Plant Physiology 169: 255-261.

Zhang F, Wang Y, Yu H, Zhu K, Zhang Z, Zou FLJ. 2016. Effect of excessive soil moisture stress on sweet Sorghum: physiological changes and productivity. Pakistan Journal of Botany 48: $1-9$. 


\section{Figures}

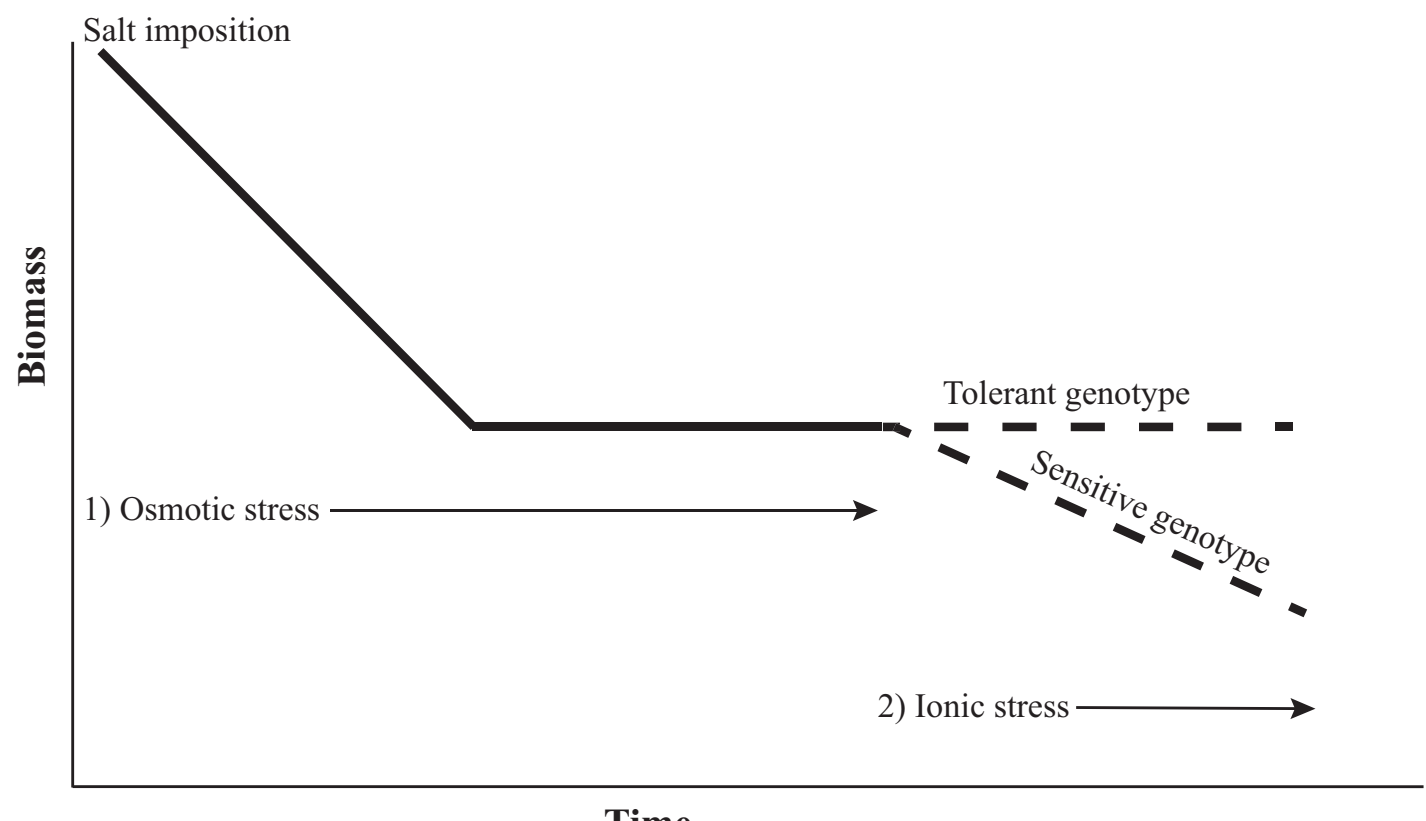

Figure 1. Effects on Biomass During Osmotic and Ionic Phases of Salinity Stress.

Figure 1. Effects on Biomass During Osmotic and Ionic Phases of Salinity Stress. The initial decline in total plant biomass is a result of osmotic stress, but after a prolonged period of time, a salt specific response occurs. Plants that are better able to handle the ionic component via extrusion and compartmentalization display increased tolerance. Modified from "Mechanisms of salinity tolerance" (Munns \& Tester, 2008). 


\title{
CHAPTER 3
}

\section{PHENOTYPIC AND PHYSIOLOGICAL RESPONSES TO SALT EXPOSURE IN SORGHUM REVEAL DIVERSITY AMONG DOMESTICATED LANDRACES}

\author{
An original research article accepted for publication in American Journal of Botany
}

Ashley N. Henderson; Philip M. Crim; Jonathan R. Cumming; Jennifer S. Hawkins

\begin{abstract}
Soil salinity negatively impacts plant function, development, and yield. To overcome this impediment to agricultural productivity, variation in morphological and physiological response to salinity among genotypes should be explored in agriculturally and economically important crops. Sorghum bicolor is a staple crop that has adapted to a variety of environmental conditions and contains a significant amount of standing genetic diversity, making it an exemplary species to study phenotypic and physiological variation in salinity tolerance. In our study, a diverse group of sorghum landraces and accessions were first rank-ordered for salinity tolerance and then individuals spanning a wide range of response were analyzed for foliar proline and ion accumulation. We found that, while proline is often a good indicator of osmotic adjustment and is historically associated with increased salt tolerance in many species, proline accumulation in sorghum reflects a stress response injury rather than acclimation. When combining ion profiles with growth responses and stress tolerance indices, the variation observed in tolerance was not a sole result of $\mathrm{Na}^{+}$accumulation, but rather reflected accession-specific mechanisms that may integrate these and other metabolic responses. We then compared our results with known phylogenetic relationships within sorghum. The most parsimonious explanation for our findings is that salinity tolerance was acquired early during domestication and subsequently lost in areas that vary in soil salinity.
\end{abstract}

Key words: comparative analysis; environmental adaptation; osmotic adjustment; potassium sodium ratio; proline; relative decreases in plant biomass; salinity stress; stress tolerance; stress tolerance index

\section{Abbreviations:}

RDPB: relative decrease in plant biomass

ST: stress tolerance

STI: stress tolerance index 


\section{Introduction}

Soil salinity is a major constraint to agricultural crop productivity, limiting the provision of food, fuel, and fiber to large portions of the world's population (Munns \& Tester, 2008; Qadir et al., 2014; Morton et al., 2019). Soil salinity, defined as concentrations of soluble salts above $40 \mathrm{mM}$ sodium chloride $(\mathrm{NaCl})$ or greater than $4 \mathrm{dSm}^{-1}$ electrical conductivity (Jamil et al., 2011; Shrivastava \& Kumar, 2015), is a global problem affecting more than $20 \%$ of the irrigated land used for agriculture (Qadir et al., 2014). Salts increase in soils naturally through the rise and ingression of sea water (Abrol et al., 1988; Singh, 2015; Liu et al., 2017), weathering of soil parent material (Abrol et al., 1988), and high surface evaporation associated with low precipitation (Chhabra, 1996; Shrivastava \& Kumar, 2015; Singh, 2015). Anthropogenic factors, such as irrigation with saline water, inadequate field drainage, and over application of animal waste, also result in increased soluble salts in agricultural soils (Munns \& Tester, 2008; Thomson et al., 2010; Singh, 2015; Lemanowicz \& Bartkowiak, 2017).

Increased salinity negatively impacts plant function and development through both osmotic and ionic effects (Munns \& Tester, 2008; Negrão et al., 2017). In the osmotic phase, salinity impedes plant water acquisition. Water uptake is disrupted even when soils contain adequate moisture due to lower soil water potentials compared to plant osmotic potentials. This imbalance inhibits water extraction by plant roots, simulating drought-like conditions (Munns \& Tester, 2008; Negrão et $a l ., 2017)$. In response to osmotic stress, leaf emergence and growth rate is reduced, stomata close resulting in decreased/inhibited photosynthesis, and leaf temperature increases (Munns \& Tester, 2008; Alqahtani et al., 2019). In the ion-dependent phase, ions such as $\mathrm{Na}^{+}$and $\mathrm{Cl}^{-}$enter the plant, accumulate to toxic levels in the cytoplasm, and disrupt normal metabolic function (Munns \& Tester, 2008).

Various plant responses result from both ion-independent and dependent phases. Key growth responses to osmotic stress include decreased leaf and root growth due to lack of turgor (Munns, 2005). Leaf growth is affected to a greater extent than root growth, resulting in a decreased shoot to root ratio (Negrão et al., 2017). Toxic ions accumulate in leaves and affect ion homeostasis and photosynthesis, resulting in premature leaf senescence (Munns, 1993, 2002). As ions accumulate, $\mathrm{Na}^{+}$specifically disrupts the uptake and distribution of $\mathrm{K}^{+}$, an essential ion for basic biological functions such as stomatal opening, enzyme activity (Tari et al., 2013), or cellular metabolism (Zhu, 2003).

Sorghum bicolor (L.) Moench is an African grass that is cultivated for food, fuel, and fiber. There are five landraces of sorghum (bicolor, kafir, guinea, caudatum, and durra) that are classified based on morphology (Shehzad et al., 2009) and reflect genetic diversity associated with different geographical regions of adaptation (Price et al., 2005; Morris et al., 2013; Mace et al., 2013; Mullet et al., 2014; Smith et al., 2019). There are also 10 intermediate landraces that are a combination of the five landraces (Oliveira et al., 1996; Price et al., 2005). Worldwide, sorghum ranks fifth as a contributor to grain production and second as a biofuels feedstock (Wiersema \& Dahlberg, 2007). Sorghum thrives in areas that are often not suitable for other crops and requires minimal human input while delivering high yields (Mullet et al., 2014). Given these traits, sorghum provides a model system for studying the complex basis of salt tolerance because it is relatively drought tolerant (Mullet et al., 2014; Fracasso et al., 2016; McCormick et 
$a l ., 2018$ ) and, as with drought stress, salinity stress results in osmotic imbalance (Munns \& Tester, 2008).

Here, we evaluated the variation in whole-plant response to salt exposure in a diverse panel of sorghum accessions that are representative of a diversity of sorghum landraces and species. Specifically, we included a hybrid species, three wild progenitors, and a variety of cultivated landraces in order to evaluate the association between standing genotypic and phenotypic diversity and salinity tolerance. Because Sorghum bicolor was originally domesticated $>8,000$ years ago in eastern Africa and has since adapted to a variety of geographical regions (Wendorf et al., 1992; Mace et al., 2013; Winchell et al., 2017; Smith et al., 2019), we hypothesized that variation in salt tolerance may be a result of post-domestication adaptation to areas varying in soil salinity. Therefore, we expected to observe landraces that adapted in regions with high soil salt content to have increased salinity tolerance compared to landraces that adapted in low soil salt content.

\section{Materials and Methods}

\section{Plant Material}

Seeds for 21 diverse Sorghum accessions representative of the different landraces were obtained from the Germplasm Resources Information Network (GRIN). Landrace information was provided by GRIN and arbitrary codes were assigned and used to reference specific accessions throughout this study (Table 1).

\section{$\mathrm{NaCl}$ Exposure}

A pilot study, in which five randomly selected accessions were exposed to increasing salt concentrations, was used to determine an appropriate experimental treatment level. Replicates were treated with $0 \mathrm{mM}, 25 \mathrm{mM}, 75 \mathrm{mM}, 125 \mathrm{mM}, 150 \mathrm{mM}$, or $200 \mathrm{mM} \mathrm{NaCl}$ beginning at the third leaf stage of development and for a period of four weeks. There was a clear reduction in growth and biomass as $\mathrm{NaCl}$ increased (Appendix S1, see the Supplementary Data with this article). Because soil is considered to be saline at concentrations greater than $40 \mathrm{mM}$ (Shrivastava \& Kumar, 2015) and we observed growth reduction without mortality at $75 \mathrm{mM}$ $\mathrm{NaCl}$, we used $75 \mathrm{mM} \mathrm{NaCl}$ as our treatment.

Twenty seeds of each accession (10 replicates per treatment and a total of two treatments) were germinated in metromix soil in $5 \mathrm{~cm} \times 5 \mathrm{~cm} \times 5 \mathrm{~cm}$ planting plugs in a controlled greenhouse. Target germination conditions were: $29 / 24^{\circ} \mathrm{C}$ (day/night temperatures), $60 \%$ humidity, and with ambient daylight at 14 hours a day. During germination, all seedlings were misted regularly with non-saline tap water and watered with a 20-10-20 N-P-K fertilizer (J.R. Peters, Inc., Allentown, PA, USA) fertilizer diluted to $200 \mathrm{mg} \mathrm{N} \mathrm{L}^{-1}$ once a week. When $90 \%$ of the seedlings were at the third leaf stage of development, seedlings were transplanted into $5 \mathrm{~cm} \times 5 \mathrm{~cm} \times 25 \mathrm{~cm}$ tree pots (Stuewe and Sons, Tangent, OR, USA) filled with a 1:1 mix of \#2 and \#4 silica sand. Seedlings were watered with tap water for one-week post-transplant to provide a period of establishment.

At the seedling stage and well before flowering (the $4^{\text {th }}-6^{\text {th }}$ leaf stage of development), plants were watered to saturation daily with tap water (control) or tap water containing $75 \mathrm{mM} \mathrm{NaCl}$ 
solution (treatment). Twice each week, all plants were additionally watered to saturation with a 20-10-20 N-P-K fertilizer at a rate of $200 \mathrm{mg} \mathrm{N} \mathrm{L}^{-1}$ (J.R. Peters, Inc., Allentown, PA, USA). Treatment was carried out for a total of 12 weeks.

\section{Biomass Measurements}

At 12 weeks post-treatment, five of the ten replicates were collected for biomass measurements. At harvest, plants were separated into roots and shoots. Roots were brushed free of adhering sand and the biomass of each plant was dried in five categories (root biomass, main stem, live leaves [ $>50 \%$ green], dead leaves [ $<50 \%$ green], and tillers [shoots from the base of the stem]). All biomass samples were dried at $65^{\circ} \mathrm{C}$ for a minimum of 72 hours.

Throughout this study, the following terms were used to describe the following tissues: live aboveground biomass was the sum of the live stem, live leaves, and live tillers. Dead aboveground biomass was the sum of the dead stem, dead leaves, and dead tillers. Total aboveground biomass was the sum of live and dead aboveground biomass. Percent of alive aboveground biomass was the ratio of live aboveground biomass by the total aboveground biomass as a fraction of 100 .

\section{Phenotype Measurements}

The remaining five replicates were used for phenotypic measurements. The following measurements were recorded after 12 weeks of treatment: total number of leaves, total number of live leaves, percent live leaves (calculated from live leaves and total leaves), mortality (defined as 1 for alive and 0 for dead), and height $(\mathrm{cm})$. Height was measured from the base of the main stem to the tip of the newest emerged leaf.

\section{Physiology Measurements}

Physiology measurements were taken at 12 weeks post treatment on the third leaf from the top because it was the oldest living leaf across all plants. The same five replicates used for phenotypic measurements were used for quantification of chlorophyll content (SPAD 502 Plus Chlorophyll Meter, Konica Minolta, Osaka, Japan) and quantification of proline concentration. Leaf ion profiles were measured on the same five replicates used for biomass measurements. Proline and ion concentrations were quantified on a subset of accessions that showed variation in phenotypic responses.

Foliar sodium and potassium concentrations were determined on microwave-assisted acid digests (MARSXpress, CEM Corporation, Matthews, NC, USA). Leaf tissue was dried for $72 \mathrm{~h}$ at $70^{\circ} \mathrm{C}$, ground in a CyclotecTM 1093 sample mill (FOSS, Hilleroed, Denmark), and digested in $4 \mathrm{~mL}$ of $70 \% \mathrm{HNO}_{3}$ and $1 \mathrm{~mL}$ of $30 \% \mathrm{H}_{2} \mathrm{O}_{2}$ (Carrilho et al., 2002). Digests were analyzed for elemental concentrations by inductively coupled plasma optical emission spectrometry (ICP-OES) by the Pennsylvania State University Analytical Laboratory (State College, PA, USA). Elemental yields were obtained using ground apple leaves from the National Institute of Standards and Technology and were used to calculate elemental content from the ICP-OES data.

Quantification of proline was determined colorimetrically by comparisons with standards. Following harvest, samples were flash frozen and immediately stored at $-80^{\circ} \mathrm{C}$. Tissue was 
ground to a fine powder and $2 \mathrm{~mL}$ of $70 \%$ ethanol was added to each sample. Samples were incubated at room temperature with continuous agitation for $24 \mathrm{~h}$, after which they were centrifuged, and the supernatant was transferred to a new tube. The ground tissue was then resuspended in fresh $2 \mathrm{~mL}$ of $70 \%$ ethanol for an additional $24 \mathrm{~h}$ at room temperature with agitation. After the second extraction, both $2 \mathrm{~mL}$ extracts were combined. Samples were then incubated at $95^{\circ} \mathrm{C}$ for $20 \mathrm{~min}$ with a $1 \%$ ninhydrin and $60 \%$ acetic acid reaction mix and quantified on a Tecan Infinite ${ }^{\circledR} 200$ PRO plate reader (Tecan, Grödig, Austria) at $520 \mathrm{~nm}$.

\section{Tolerance Indices}

Salinity tolerance in plants is often defined as the ability of a plant to sustain growth in the presence of salts (Munns, 2010). In our study, several traits were evaluated and tolerance was defined by the ability to maintain biomass (live and total) when comparing salt exposure to control conditions (Negrão et al., 2017).

Stress Tolerance (ST) - The stress tolerance value was calculated for SPAD of the oldest living leaf across all plants, percent of live leaves, height $(\mathrm{cm})$, mortality, live aboveground biomass (dry weight in g), dead aboveground biomass (dry weight in g), and root biomass (dry weight in g) as (Negrão et al., 2017):

$$
S T=\frac{Y_{\text {Salt at } T_{2}}}{Y_{\text {Control at } T_{2}}}
$$

Where $\mathrm{Y}$ is a growth-related trait measured at the end of the experiment $\left(\mathrm{T}_{2}\right)$ under control and salt treatments as indicated. The ST value normalizes performance by accession.

Relative Decrease in Plant Biomass (RDPB) - The sum of biomass for all tissues separated during a destructive harvest was used to determine the relative decrease in plant biomass (RDPB, Negrão et al., 2017) for each accession and landrace. The RDPB describes the reduction of growth in stressed conditions compared to control conditions. The RDPB is calculated as:

$$
R D P B=\frac{M_{f \text { control }}-M_{f \text { salt }}}{M_{f \text { control }}}
$$

Where $\mathrm{M}_{\mathrm{f}}$ is plant mass under control and salt treatments as indicated. Lower RDPB values indicate less reduction in biomass under stress conditions and are representative of higher degrees of tolerance. RDPB was converted to percent of plant biomass retained (1-RDPB). Tolerant genotypes were individuals with high amounts of biomass retained, while sensitive individuals retained less biomass in response to treatment.

Stress Tolerance Index (STI) - The stress tolerance index (STI, Negrão et al., 2017) was calculated for biomass traits (live aboveground biomass, dead aboveground biomass, root biomass). The STI was calculated as:

$$
\text { Stress Tolerance Index }=\frac{Y_{\text {control }}}{Y_{\text {control average }}} \times \frac{Y_{\text {salt }}}{Y_{\text {control average }}}
$$


Where $Y_{\text {control }}$ and $Y_{\text {salt }}$ are measured traits for control and salt treatments for each accession, and $\mathrm{Y}_{\text {control average }}$ is the trait response under control conditions for the entire population evaluated. A greater STI for an accession indicates higher degrees of salt tolerance. The STI accounts for genotypic response to salinity stress and compares it to a population response to reveal accessions that are performing superior to others. Raw STI values for live aboveground biomass, dead aboveground biomass, and root biomass (Appendix S2) were converted to a rank order. STI was rank ordered with 0 indicating missing data, 1 indicating the lowest STI, and 21 indicating the highest possible STI.

\section{Statistical Analyses}

Treatment Effects - Non-metric multidimensional scaling (NMDS) (Julkowska et al., 2019), performed in R v. 3.6.0 (R Core Team, 2013), was used to evaluate plant response to salt exposure and to determine groupings among accessions across treatments. The dimcheckMDS function in the geoveg package generated the associated stress value with each reduction in dimension. A lower stress value indicates higher conformity between the true multivariate distance between samples and the distance between samples in reduced dimensions. Two dimensions were deemed appropriate. NMDS was paired with analysis of similarity (ANOSIM), which statistically tests clusters and ordination results from the NMDS. The ANOSIM determines whether the dissimilarity matrix used in the NMDS ordination is significantly different. Using an ANOSIM, we tested treatment effects. Dissimilarities were determined using a Bray-Curtis similarity to test whether accessions were more similar within a treatment compared to among treatments.

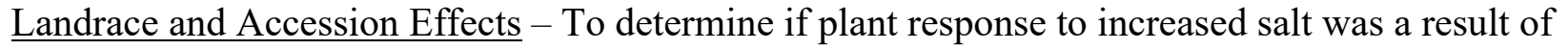
genetic mechanisms (accession response or landrace structure), an NMDS was coupled with ANOSIM. The Bray-Curtis dissimilarity coefficients for ST values were used in the NMDS to visualize patterns in the data. Two dimensions were specified. NMDS was paired with ANOSIM to statistically test clusters and ordination results. We tested whether individuals were more similar with an accession compared to among accessions; we tested whether individuals were more similar within a landrace compared to among landraces.

Treatment Effects on Growth - One-way analysis of variance (ANOVA) was used to deduce whether there was a statistical difference among accessions for live aboveground biomass STI values, dead aboveground biomass STI values, and root biomass STI values in response to salt exposure. An ANOVA was used to evaluate differences between landraces in response to salt exposure. If significant differences were found, Tukey's HSD was used to separate accession/landrace means.

In R v. 3.6.0 (R Core Team, 2013), Shapiro-Wilk tests were used to test population response normality, and Levene's test, in the car package (Fox \& Weisberg, 2019), was used to test homogeneity of variance. Response variables that did not pass a threshold of $\alpha=0.05$ in the Shapiro-Wilk tests were transformed prior to ANOVA. For the accession ANOVA, STI values for live aboveground biomass, dead aboveground biomass, and root biomass were square-root transformed. For the landrace ANOVA, STI values for live aboveground biomass and dead aboveground biomass were log transformed. STI values for root biomass were square-root transformed. 
Treatment Effects on Sodium and Potassium Accumulation - To determine whether there was significant variation among treatments and accessions with respect to $\mathrm{Na}^{+}$content, $\mathrm{K}^{+}$content, and the potassium to sodium ratio $\left(\mathrm{K}^{+} / \mathrm{Na}^{+}\right)$, a two-way ANOVA was performed in $\mathrm{R}$ v. 3.6.0 ( $\mathrm{R}$ Core Team, 2013). If a significant difference was found ( $P<0.05)$, Tukey's HSD was performed to determine which treatments and accessions were significantly different from one another.

Treatment Effects on Proline Accumulation - To determine whether there was significant variation among treatments and accessions for proline accumulation, a two-way ANOVA was performed on proline values that were log transformed using R v. 3.6.0 (R Core Team, 2013). If a significant difference was found $(\mathrm{P}<0.05)$, Tukey's HSD was performed to determine which treatments and accessions significantly differed from one another.

\section{Results}

\section{Treatment Effects}

Salt exposure reduced live aboveground biomass, root biomass, the shoot-to-root ratio, height, the percent of live leaves, and foliar SPAD across all accessions and landraces, while dead aboveground biomass and mortality increased (Appendix S3). We observed a differential response to $\mathrm{NaCl}$ exposure among accessions indicating that variation in salt tolerance exists within our tested population.

\section{Landrace and Accession Effects}

Based on accession and landrace ST values calculated for the measured growth parameters, plants were more similar within an accession rather than across accessions and within a landrace rather than across landraces (Fig. 1) when exposed to salt.

\section{Relative Decrease in Plant Biomass (RDPB)}

The percent of biomass retained in response to $\mathrm{NaCl}$ ranged from $98 \%$ to $3 \%$ across accessions (Fig. 2). Accessions showing sustained growth included V-1 (subs. verticilliflorum), Sb-18 (durra), Sb-7 (caudatum), Sb-9 (guinea-margaritiferum), Sb-10 (durra), and Sb-3 (guineamargaritiferum). These six accessions retained $>90 \%$ of live aboveground biomass when exposed to $\mathrm{NaCl}$. RDPB values within the $\mathrm{NaCl}$ treatment also varied among landraces $\left(F_{8,83}=\right.$ 5.22, $P<0.001$; Appendix S4).

\section{Stress Tolerance Index (STI)}

STI values for live aboveground biomass, dead aboveground biomass, and root biomass differed among accessions $\left(\mathrm{F}_{20,66}=3.82, \mathrm{~F}_{17,56}=61.65, \mathrm{~F}_{20,60}=30.36\right.$, respectively, $\mathrm{P}<0.001$ for each $)$. STI values ranged from 0.01 to 1.51 for live aboveground biomass, 0.10 to 3.35 for dead aboveground biomass, and 0.05 to 1.97 for root biomass. Some accessions ranked high for all three traits while others ranked high for only one or two of the traits. For example, P-1 ranked low for live aboveground biomass $\left(1^{\text {st }}\right.$ out of $\left.21^{\text {st }}\right)$ but ranked $17^{\text {th }}$ out of $21^{\text {st }}$ for root biomass (Fig. 3). The largest overall scores (additive rank score for live aboveground biomass, dead aboveground biomass, and root biomass) were observed for the accessions Sb-10, V-1, Sb-9, Sb3, Sb-2, and Sb-12, indicating overall better performance compared to other accessions (Fig. 3). 
When comparing the STI values among landraces, differences were observed for live aboveground biomass, dead aboveground biomass, and root biomass $\left(\mathrm{F}_{8,83}=38.93, \mathrm{~F}_{7,72}=4.68\right.$, $\mathrm{F}_{8,71}=32.87$, respectively, $\mathrm{P}<0.001$ for each; Appendix S5). STI values ranged from 0.01 to 1.28 for live aboveground biomass. S. propinquum had the lowest STI for live aboveground biomass with a mean of 0.01 and landrace durra had the highest STI for live aboveground biomass with a mean of 1.28. STI values ranged from 0.32 to 2.08 for dead aboveground biomass with the intermediate landraces displaying the least STI values and the landrace guinea-margaritiferum displaying the highest. STI values ranged from 0.11 to 1.69 for root biomass. The landrace guinea-margaritiferum had the highest STI for root biomass (1.69), while most other landraces averaged about 0.2 to 0.5 (Appendix S2).

\section{Sodium and Potassium Accumulation}

A subset of accessions that showed variation in growth under salt treatment were evaluated for ion accumulation. Variation in $\mathrm{Na}^{+}$content was found among treatment and accessions $\left(\mathrm{F}_{11,87}=\right.$ 3.04, $\mathrm{P}<0.01)$. Foliar $\mathrm{Na}^{+}$under control conditions was low but varied 35-fold across accessions (Table 2). When exposed to $\mathrm{NaCl}, \mathrm{Sb}-3$ and $\mathrm{Sb}-4$ accumulated the least amount of $\mathrm{Na}^{+}$while $\mathrm{P}-1$ and V-2 accumulated the most (Table 2).

As with $\mathrm{Na}^{+}$, foliar $\mathrm{K}^{+}$concentrations also varied among accessions and these differed in response to treatments $\left(\mathrm{F}_{11,87}=13.83, \mathrm{P}<0.001\right)$. For example, $\mathrm{P}-1$ exhibited similar $\mathrm{K}^{+}$content to the tested population mean under control conditions and then declined more than other accessions under $\mathrm{NaCl}$ exposure $\left(79 \%\right.$ decline), whereas $\mathrm{K}^{+}$increased significantly in Sb-3 and Sb-9 under $\mathrm{NaCl}$ exposure (Table 2).

In sorghum, we found variation among treatments and accessions for the $\mathrm{K}^{+} / \mathrm{Na}^{+}$ratio $\left(\mathrm{F}_{11,87}=\right.$ 4.44, $\mathrm{P}<0.001)$. Under control conditions, $\mathrm{V}-2$ had the lowest $\mathrm{K}^{+} / \mathrm{Na}^{+}$ratio and $\mathrm{Sb}-16$ the greatest (Table 2). The ratio declined (by 49\% to 99\%) in many accessions under $\mathrm{NaCl}$ exposure, most notably in $\mathrm{P}-1$ (99\%) and Sb-15 (97\%), while the ratio did not change in Sb-3.

\section{Proline Accumulation}

In response to salt exposure, proline accumulation in sorghum foliage increased, with the magnitude of increase depending on the accession $\left(\mathrm{F}_{11,87}=4.44, \mathrm{P}<0.001\right.$; Fig. 4). Proline accumulation ranged from 0.07 to $0.26 \mathrm{gfw}^{-1}$ in the control treatment and 0.07 to $2.63 \mathrm{gfw}^{-1}$ in the salt treatment (Appendix S6).

\section{Discussion}

\section{Phenotypic Responses to Salinity Stress}

Salinity tolerance is a product of maintenance mechanisms that occur during both the osmotic and ionic phases of salinity stress (Munns \& Tester, 2008). During the osmotic phase, continued growth of aboveground biomass indicates the ability to overcome osmotic stress, since sensitivity to water deprivation typically results in decreased growth (Munns \& Tester, 2008). 
During the ionic phase, mechanisms of tolerance include compartmentalization of toxic ions into vacuoles and/or extrusion of $\mathrm{Na}^{+}$from cells and the removal of $\mathrm{Na}^{+}$from the xylem stream, which reduces potential exposure in the leaf. Therefore, the accumulation of dead aboveground biomass can be used as proxy for evaluating compartmentalization and extrusion efficiency (Munns \& Tester, 2008; Deinlein et al., 2014). We found that accessions with high STI values for dead aboveground biomass included both tolerant (Sb-10, Sb-9, and V-1) and sensitive (Sb16 and V-2) accessions. This, combined with the results for live aboveground biomass, suggests that tolerance in sorghum is correlated to a greater extent with the plant's ability to overcome the osmotic phase via continued growth rather than exclusion and/or compartmentalization of ions during the ionic phase. This is most evident for accessions such as Sb-10, Sb-9, and V-1. These tolerant accessions accumulated large amounts of both live and dead aboveground biomass (Fig. 3), reflecting the ability to maintain continued growth under salt exposure. The ability to continue new growth aids in the dilution of $\mathrm{Na}^{+}$in leaves, and if new growth exceeds the rate of leaf senescence, plants can continue photosynthesizing and producing enough carbon to support overall plant growth (Munns \& Tester, 2008; Carillo et al., 2011).

Plants may exhibit limited root growth as a result of low soil water potential, or conversely, increased growth as a search response for non-saline water (Rahnama et al., 2011; Jung \& McCouch, 2013; Munns \& Gilliham, 2015; Hanin et al., 2016). In our study, we found that three of the overall most tolerant accessions (Sb-10, Sb-9, Sb-3) ranked in the top five highest STIs for root biomass (Fig. 3). This suggests that maintenance of root biomass in response to treatment is associated with salinity tolerance (Galvan-Ampudia et al., 2013; Munns \& Gilliham, 2015). S. propinquum, one of the most sensitive accessions, had the largest RDPB and the lowest live aboveground biomass STI, yet had the fifth highest overall STI for root biomass (Fig. 2 and Fig. 3, respectively). The larger STI for root biomass in S. propinquum is most likely a product of its naturally more extensive root system compared to $S$. bicolor, rather than tolerance, per se.

In our study, we assessed tolerance by relative decrease in plant biomass (RDPB) and the stress tolerance index (STI) (Negrão et al., 2017). We observed that some accessions displayed less than $10 \%$ decrease in plant biomass (RDPB) but ranked low in the STI analysis. For example, V1 and $\mathrm{Sb}-10$ displayed $2 \%$ and $10 \%$ decreases in plant biomass respectively (or $98 \%$ and $90 \%$ retained biomass, respectively), in response to treatment and ranked in the top 5 most tolerant accessions in the STI analysis for live aboveground biomass, dead aboveground biomass and root biomass. However, Sb-18, which lost only $4 \%$ of its biomass (retained $96 \%$ of its biomass) in response to treatment, ranked $16^{\text {th }}, 1^{\text {st }}$, and $14^{\text {th }}$ for live aboveground biomass, dead aboveground biomass, and root biomass respectively. The discordance between a high rank in the RDPB analysis versus STI analysis suggests that different modes of tolerance may exist in sorghum. Different modes of tolerance may reflect reductions in $\mathrm{Na}^{+}$accumulation achieved by multiple mechanisms, such as reduction in root uptake, reduction in xylem loading, increased extrusion, and increased retrieval from aboveground tissue (Munns \& Tester, 2008; Deinlein et al., 2014; Wu et al., 2019). Each of these mechanisms results in reduced $\mathrm{Na}^{+}$in the cytoplasm. Regardless of the mechanism, reduced $\mathrm{Na}^{+}$typically results in increased tolerance. Therefore, we propose that the RDPB analysis is the better indicator of tolerance because it depicts the outcome of $\mathrm{NaCl}$ exposure regardless of the mechanism operating in tolerant genotypes. 


\section{Physiological responses to salinity stress}

Historically, proline accumulation under salt and/or osmotic stress has been used as an indicator of tolerance (Iqbal et al., 2014). When comparing proline accumulation across accessions, we found that leaf proline increased between the control and $\mathrm{NaCl}$ treatment, although this increase was accession dependent (Fig. 4). V-1 and Sb-10, two of our most tolerant accessions according to RDPB and STI analysis, displayed low amounts of proline in both control and treatment conditions. In contrast, Sb-7 and Sb-17 exhibited large NaCl-induced increases in proline content but were only moderately salt tolerant. The lack in correlation of proline accumulation with the rank score of tolerant accessions (Appendix S7) suggests that, in sorghum, proline accumulation may reflect stress injury rather than osmotic adjustment/osmoprotection for increased tissue tolerance (Munns \& Tester, 2008; Roy et al., 2014). The QTLs for proline accumulation under salinity stress and for stress tolerance are not linked in barley (Fan et al., 2015) and, in rice, saltsensitive accessions accumulated higher levels of $\mathrm{Na}^{+}$and proline compared to salt-tolerant accessions (Lutts et al., 1999; Vaidyanathan et al., 2003; Theerakulpisut et al., 2005). Therefore, although proline accumulation does occur in sorghum in response to $\mathrm{NaCl}$ (Weimberg et al., 1982; Surender Reddy et al., 2015), our results suggest that it is not an accurate predictor of protective capacity against stress injury.

Significant variation in sodium and potassium concentrations among accessions suggests that differences in the mechanisms responsible for sodium uptake and distribution and/or regulation of potassium concentration exist in sorghum (Table 2). When comparing the variation in $\mathrm{Na}^{+}$ accumulation with tolerance categories, we do not observe patterns suggestive of a unifying mechanism of sorghum response to excess $\mathrm{Na}^{+}$(Appendix S8 and Appendix S7). For example, $\mathrm{Sb}-1$ and $\mathrm{Sb}-10$, a sensitive and a tolerant accession, respectively, did not significantly differ in foliar $\mathrm{Na}^{+}$accumulation. In control conditions, both accessions averaged approximately $0.02 \mathrm{mg}$ $\mathrm{Na}^{+} \mathrm{g}^{-1}$, and in treatment conditions both averaged about $0.59 \mathrm{mg} \mathrm{Na}^{+} \mathrm{g}^{-1}$; however, in terms of relative decreases in plant biomass, $\mathrm{Sb}-10$ displayed less than $10 \%$ loss in live aboveground biomass while Sb-1 had greater than 50\% loss. Although our analysis of foliar $\mathrm{Na}^{+}$by ICP is unable to assess subcellular localization, $\mathrm{Sb}-10$ may have elevated tissue tolerance as a result of better compartmentalization of $\mathrm{Na}^{+}$ions into vacuoles, resulting in less cell death due to ionic imbalance.

Salt sensitivity is often associated with changes in $\mathrm{K}^{+}$uptake resulting from competition between $\mathrm{Na}^{+}$and $\mathrm{K}^{+}$(Deinlein et al., 2014). In sorghum, we observed variation in $\mathrm{K}^{+}$among accessions and $\mathrm{NaCl}$ treatments. Most variation in $\mathrm{K}^{+}$was observed between accessions and not between treatments. The only accession exhibiting a decline in $\mathrm{K}^{+}$between the control and $\mathrm{NaCl}$ treatments was P-1, whereas exposure led to an increase in $\mathrm{K}^{+}$in Sb-3 and Sb-9. Sb-3 and Sb-9 are both from the landrace guinea-margaritiferum and both exhibit low RDPB. In contrast, P-1 had a high RDPB. These patterns suggest that, at least in the sorghum accessions included in this study, the loss of $\mathrm{K}^{+}$homeostasis may not underlie $\mathrm{NaCl}$ toxicity, but rather may represent the basis of salt sensitivity in the wild relative, S. propinquum.

\section{Evolution, domestication, and adaptation of salt tolerant sorghum accessions}

Where population structure and geographic distribution of sorghum has been studied, landraces show genetic diversity and racial structure with strong geographical patterning (Morris et al., 
2013; Mace et al., 2013). We found, however, that salinity tolerance was not solely associated with landrace, suggesting that accessions exposed to high local and regional soil salt contents may have adapted mechanisms to overcome the stresses associated with $\mathrm{NaCl}$ exposure. We initially hypothesized that the driving force of variation in salt tolerance may be a result of postdomestication adaptation to saline environments; however, when we evaluate our findings within the phylogenetic framework presented in Mace et al. (2013), we observe that the most tolerant $S$. bicolor accessions are those that originated shortly after the domestication event, particularly those accessions within the durra clade (Fig. 5). Further, the two S. verticilliflorum accessions included in both this study and the Mace et al. (2013) study displayed significantly different responses to salinity. V-1 (PI226096), which had the lowest RDPB and ranked $5^{\text {th }}$ largest for live aboveground biomass STI, dead aboveground biomass STI, and root biomass STI, is positioned in the first post-domestication clade; however, V-2 (PI300119), which lost approximately 70\% of its biomass in response to treatment and ranked in the $3^{\text {rd }}$ to last position for live aboveground biomass and the last position for root biomass, is placed in the clade prior to the domestication event (Appendix S9). This, combined with the observations for the durra accessions, suggests that salinity tolerance was gained during or shortly after sorghum domestication. In contrast, accessions from the landrace caudatum, which displayed a diversity of stress tolerance rankings, are not monophyletic, and are found in diverse positions throughout the tree (Fig. 5). Interpretation of these results within this phylogenetic context suggests that, during further selection and improvement, salinity tolerance was lost in lineages that were no longer subjected to continued environmental salt exposure. Lastly, given that S. bicolor and especially the landrace durra (Smith et al., 2019) is known to be relatively drought tolerant (Mullet et al., 2014; Fracasso et al., 2016; McCormick et al., 2018; Guo et al., 2018) and, as with drought stress, salt stress has an initial osmotic component, we propose that salinity tolerance in sorghum originated in combination with, or as a by-product of, drought tolerance during domestication.

\section{Conclusions}

With more than 500 million people relying on food, fuel, and fiber production from sorghum (Mace et al., 2013), the standing genetic diversity of this staple crop should be utilized to maximize production needs, especially in adverse soils. Because of its ability to thrive in environments associated with high degrees of abiotic stressors, it is imperative that the genetic, physiological, and morphological responses to salt exposure in sorghum are understood and utilized to enhance production on saline soils. We identified significant variation in response to salinity exposure among a diverse group of sorghum accessions, and we conclude that the variation seen in tolerance is not due to landrace alone, but rather a byproduct of domestication and improvement. Given our results, and in combination with results of Mace et al. (2013), we propose that accessions from the landrace durra would serve as valuable resources for genetic improvement of sorghum salinity tolerance in agriculture.

\section{Acknowledgements}

The author(s) wish to thank Dr. Jeffrey Bennetzen for providing Sorghum propinquum seed, Dr. Stephen DiFazio for guidance in project design, and Janna Kleinsasser, Natalie Nedley, Rachel Bainbridge, and Margo Folwick for their assistance in data collection. We also wish to thank two anonymous reviewers and the associate editor for their insightful comments on this manuscript. We acknowledge the Pennsylvania State University Analytical Laboratory, State College PA, 
U.S. National Plant Germplasm System for supplying seed and the West Virginia University Evansdale Greenhouse for supplying space. This work was partially funded by the Eberly College of Arts and Sciences research award (West Virginia University), the Biology Graduate Student Association graduate student research award (West Virginia University), both awarded to Ashley N. Henderson, and the United States Department of Agriculture National Institute of Food and Agriculture (grant number 2018-67014-27469). 


\section{Literature Cited}

Abrol IP, Yadav JSP, Massoud FI. 1988. Salt-affected Soils and Their Management. Food \& Agriculture Org.

Alqahtani M, Roy SJ, Tester M. 2019. Increasing salinity tolerance of crops. In Meyers RA, ed. Encyclopedia of Sustainability Science and Technology. New York, NY: Springer New York, 1-24.

Carillo P, Annunziata MG, Pontecorvo G, Fuggi A, Woodrow P. 2011. Salinity stress and salt tolerance. In Abiotic Stress in Plants - Mechanisms and Adaptations, A. K. Shanker and B. Veenkateswarlu, Eds., 21-38, InTech, Rijeka, Croatia.

Carrilho ENVM, Gonzalez MH, Nogueira ARA, Cruz GM, Nóbrega JA. 2002. Microwaveassisted acid decomposition of animal- and plant-derived samples for element analysis. Journal of Agricultural and Food Chemistry 50: 4164-4168.

Chhabra R. 1996. Soil salinity and water quality. Brookfield, VT 05036 USA: A.A. Balkema Publishers.

Deinlein U, Stephan AB, Horie T, Luo W, Xu G, Schroeder JI. 2014. Plant salt-tolerance mechanisms. Trends in Plant Science 19: 371-379.

Fan Y, Shabala S, Ma Y, Xu R, Zhou M. 2015. Using QTL mapping to investigate the relationships between abiotic stress tolerance (drought and salinity) and agronomic and physiological traits. BMC Genomics 16: 43.

Fox J, Weisberg S. 2019. An $\{R\}$ Companion to Applied Regression. Thousand Oaks, CA: Sage.

Fracasso A, Trindade L, Amaducci S. 2016. Drought tolerance strategies highlighted by two Sorghum bicolor races in a dry-down experiment. Journal of Plant Physiology 190: 1-14.

Galvan-Ampudia CS, Julkowska MM, Darwish E, Gandullo J, Korver RA, Brunoud G, Haring MA, Munnik T, Vernoux T, Testerink C. 2013. Halotropism is a response of plant roots to avoid a saline environment. Current Biology 23: 2044-2050.

Guo YY, Tian SS, Liu SS, Wang WQ, Sui N. 2018. Energy dissipation and antioxidant enzyme system protect photosystem II of sweet sorghum under drought stress. Photosynthetica 56: 861872.

Hanin M, Ebel C, Ngom M, Laplaze L, Masmoudi K. 2016. New insights on plant salt tolerance mechanisms and their potential use for breeding. Frontiers in Plant Science 7: 1787.

Iqbal N, Umar S, Khan NA, Khan MIR. 2014. A new perspective of phytohormones in salinity tolerance: Regulation of proline metabolism. Environmental and Experimental Botany 100: 34-42.

Jamil A, Riaz S, Ashraf M, Foolad MR. 2011. Gene expression profiling of plants under salt stress. Critical Reviews in Plant Sciences 30: 435-458. 
Julkowska MM, Saade S, Agarwal G, Gao G, Pailles Y, Morton MJL, Awlia M, Tester M. 2019. MVApp - Multivariate analysis application for streamlined data analysis and curation. Plant Physiology 180: 1261-1276.

Jung JKHM, McCouch SRM. 2013. Getting to the roots of it: Genetic and hormonal control of root architecture. Frontiers in Plant Science 4: 186.

Lemanowicz J, Bartkowiak A. 2017. Changes in the activity of phosphatase and the content of phosphorus in salt-affected soils grassland habitat natura 2000. Polish Journal of Soil Science 49: 149-165.

Liu X, Ruecker A, Song B, Xing J, Conner WH, Chow AT. 2017. Effects of salinity and wetdry treatments on $\mathrm{C}$ and $\mathrm{N}$ dynamics in coastal-forested wetland soils: Implications of sea level rise. Soil Biology and Biochemistry 112: 56-67.

Lutts S, Majerus V, Kinet J-M. 1999. $\mathrm{NaCl}$ effects on proline metabolism in rice (Oryza sativa) seedlings. Physiologia Plantarum 105: 450-458.

Mace ES, Tai S, Gilding EK, Li Y, Prentis PJ, Bian L, Campbell BC, Hu W, Innes DJ, Han $\mathrm{X}$, et al. 2013. Whole-genome sequencing reveals untapped genetic potential in Africa's indigenous cereal crop sorghum. Nature Communications 4: 2320.

McCormick RF, Truong SK, Sreedasyam A, Jenkins J, Shu S, Sims D, Kennedy M, Amirebrahimi M, Weers BD, McKinley B, et al. 2018. The Sorghum bicolor reference genome: improved assembly, gene annotations, a transcriptome atlas, and signatures of genome organization. The Plant Journal 93: 338-354.

Morris GP, Ramu P, Deshpande SP, Hash CT, Shah T, Upadhyaya HD, Riera-Lizarazu O, Brown PJ, Acharya CB, Mitchell SE, et al. 2013. Population genomic and genome-wide association studies of agroclimatic traits in sorghum. Proceedings of the National Academy of Sciences 110: 453-458.

Morton MJL, Awlia M, Al-Tamimi N, Saade S, Pailles Y, Negrão S, Tester M. 2019. Salt stress under the scalpel - dissecting the genetics of salt tolerance. The Plant Journal 97: 148163.

Mullet J, Morishige D, McCormick R, Truong S, Hilley J, McKinley B, Anderson R, Olson SN, Rooney W. 2014. Energy Sorghum - a genetic model for the design of C4 grass bioenergy crops. Journal of Experimental Botany 65: 3479-3489.

Munns R. 1993. Physiological processes limiting plant growth in saline soils: some dogmas and hypotheses. Plant, Cell and Environment 16: 15-24.

Munns R. 2002. Comparative physiology of salt and water stress. Plant, Cell and Environment 25: $239-250$.

Munns R. 2005. Genes and salt tolerance: bringing them together. New Phytologist 167: 645663. 
Munns R. 2010. Approaches to identifying genes for salinity tolerance and the importance of timescale. In Sunkar R, ed. Methods in Molecular Biology. Plant Stress Tolerance: Methods and Protocols. Totowa, NJ: Humana Press, 25-38.

Munns R, Gilliham M. 2015. Salinity tolerance of crops - what is the cost? New Phytologist 208: $668-673$.

Munns R, Tester M. 2008. Mechanisms of salinity tolerance. Annual Review of Plant Biology 59: $651-681$.

Negrão S, Schmöckel SM, Tester M. 2017. Evaluating physiological responses of plants to salinity stress. Annals of Botany 119: 1-11.

Oliveira AC de, Richter T, Bennetzen JL. 1996. Regional and racial specificities in sorghum germplasm assessed with DNA markers. Genome 39: 579-587.

Price HJ, Dillon SL, Hodnett G, Rooney WL, Ross L, Johnston JS. 2005. Genome Evolution in the genus Sorghum (Poaceae). Annals of Botany 95: 219-227.

Qadir M, Quillérou E, Nangia V, Murtaza G, Singh M, Thomas RJ, Drechsel P, Noble AD. 2014. Economics of salt-induced land degradation and restoration. Natural Resources Forum 38: $282-295$.

R Core Team. 2013. $R$ : A language and enviornment for satistical computing. Vienna, Austria: $\mathrm{R}$ Foundation for Statistical Computing.

Rahnama A, Munns R, Poustini K, Watt M. 2011. A screening method to identify genetic variation in root growth response to a salinity gradient. Journal of Experimental Botany 62: 6977.

Roy SJ, Negrão S, Tester M. 2014. Salt resistant crop plants. Current Opinion in Biotechnology 26: $115-124$.

Shehzad T, Okuizumi H, Kawase M, Okuno K. 2009. Development of SSR-based sorghum (Sorghum bicolor (L.) Moench) diversity research set of germplasm and its evaluation by morphological traits. Genetic Resource Crop Evolution 56: 809-827.

Shrivastava P, Kumar R. 2015. Soil salinity: A serious environmental issue and plant growth promoting bacteria as one of the tools for its alleviation. Saudi Journal of Biological Sciences 22: $123-131$.

Singh A. 2015. Soil salinization and waterlogging: A threat to environment and agricultural sustainability. Ecological Indicators 57: 128-130.

Smith O, Nicholson WV, Kistler L, Mace E, Clapham A, Rose P, Stevens C, Ware R, Samavedam S, Barker G, et al. 2019. A domestication history of dynamic adaptation and genomic deterioration in sorghum. Nature Plants 5: 369-379. 
Surender Reddy P, Jogeswar G, Rasineni GK, Maheswari M, Reddy AR, Varshney RK, Kavi Kishor PB. 2015. Proline over-accumulation alleviates salt stress and protects photosynthetic and antioxidant enzyme activities in transgenic sorghum [Sorghum bicolor (L.) Moench]. Plant Physiology and Biochemistry 94: 104-113.

Tari I, Laskay G, Takacs Z, Poor P. 2013. Response of Sorghum to abiotic stresses: A review. Journal of Agronomy and Crop Science 199: 264-274.

Theerakulpisut P, Bunnag S, Kong-ngern K. 2005. Genetic diversity, salinity tolerance and physiological responses to $\mathrm{NaCl}$ of six rice (Oryza sativa L.) cultivars. Asian Journal of Plant Sciences 4: 562-573.

Thomson MJ, Ocampo M de, Egdane J, Rahman MA, Sajise AG, Adorada DL, Tumimbang-Raiz E, Blumwald E, Seraj ZI, Singh RK, et al. 2010. Characterizing the saltol quantitative trait locus for salinity tolerance in rice. Rice 3: 148-160.

Vaidyanathan H, Sivakumar P, Chakrabarty R, Thomas G. 2003. Scavenging of reactive oxygen species in NaCl-stressed rice (Oryza sativa L.) - differential response in salt-tolerant and sensitive varieties. Plant Science 165: 1411-1418.

Weimberg R, Lerner HR, Poljakoff-Mayber A. 1982. A relationship between potassium and proline accumulation in salt-stressed Sorghum bicolor. Physiologia Plantarum 55: 5-10.

Wendorf F, Close AE, Schild R, Wasylikowa K, Housley RA, Harlan JR, Królik H. 1992. Saharan exploitation of plants 8,000 years BP. Nature 359: 721-724.

Wiersema JH, Dahlberg J. 2007. The nomenclature of Sorghum bicolor (L.) Moench (Gramineae). Taxon 56: 941-946.

Winchell F, Stevens CJ, Murphy C, Champion L, Fuller DorianQ. 2017. Evidence for Sorghum domestication in fourth millennium BC eastern Sudan: Spikelet morphology from ceramic impressions of the butana group. Current Anthropology 58: 673-683.

Wu H, Shabala L, Zhou M, Su N, Wu Q, Ul-Haq T, Zhu J, Mancuso S, Azzarello E, Shabala S. 2019. Root vacuolar $\mathrm{Na}^{+}$sequestration but not exclusion from uptake correlates with barley salt tolerance. The Plant Journal: 1-13.

Zhu J-K. 2003. Regulation of ion homeostasis under salt stress. Current Opinion in Plant Biology 6: 441-445. 


\section{Tables}

Table 1. Summary of sorghum accessions. Sorghum accessions and associated information (identification code used to reference accessions throughout the study and landrace). Accession information and landrace information was supplied by GRIN.

\begin{tabular}{llll}
\hline Accession & ID & Landrace & Sorghum Association Panel \\
\hline PI33027204SD & D-1 & drummondii & \\
subs. propinquum & P-1 & subs. propinquum & \\
PI57112801SD & Sb-1 & caudatum & SAP-208 \\
PI53412801SD & Sb-2 & durra & \\
PI52569503SD & Sb-3 & guinea-margaritiferum & SAP-65 \\
PI57613001SD & Sb-4 & kafir & SAP-268 \\
PI53391004SD & Sb-5 & caudatum & \\
PI53383401SD & Sb-6 & caudatum & SAP-140 \\
PI53379202SD & Sb-7 & caudatum & \\
PI65606902SD & Sb-8 & intermediate (unknown) & \\
PI58643001SD & Sb-9 & guinea-margaritiferum & \\
PI58574902SD & Sb-10 & durra & SAP-80 \\
PI56512103SD & Sb-11 & caudatum & SAP-233 \\
PI53413301SD & Sb-12 & durra & SAP-127 \\
PI53375201SD & Sb-13 & caudatum & SAP-73 \\
PI65361702SD & Sb-14 & intermediate (unknown) & SAP-74 \\
PI61353602SD & Sb-15 & durra-caudatum & \\
PI56351602SD & Sb-16 & durra-caudatum & \\
PI60933601SD & Sb-17 & intermediate (unknown) & SAP-37 \\
PI65602902SD & Sb-18 & durra & \\
Tx7000 & Tx-1 & durra & \\
PI22609603SD & V-1 & subs. verticilliflorum & \\
PI30011903SD & V-2 & subs. verticilliflorum & \\
\hline
\end{tabular}

Note: $\mathrm{Tx}-1$ and $\mathrm{Sb}-6$ were excluded from the study 
Table 2. Summary of Sorghum ion profiles. Sodium $\left(\mathrm{Na}^{+}\right)$, potassium $\left(\mathrm{K}^{+}\right)$, and potassium sodium $\left(\mathrm{K}^{+} / \mathrm{Na}^{+}\right)$molar ratios for NaCl treatments for a subset of accessions that showed variability in phenotypic responses. Data shown are means \pm (the standard error) of $\mathrm{Na}^{+}$ content, $\mathrm{K}^{+}$content, and $\mathrm{K}^{+} / \mathrm{Na}^{+}$ratio for each accession in the third leaf from the top. Different letters represent significant differences when comparing accessions $(\mathrm{P}<0.05)$.

\begin{tabular}{|c|c|c|c|c|c|c|c|c|c|c|c|c|}
\hline \multirow{3}{*}{$\begin{array}{l}\text { Accession } \\
\mathrm{P}-1\end{array}$} & \multicolumn{4}{|c|}{$\begin{array}{c}\text { Mean } \\
\mathrm{Na}^{+} \mathbf{m g} / \mathrm{g}\end{array}$} & \multicolumn{4}{|c|}{$\begin{array}{c}\text { Mean } \\
\mathrm{K}^{+} \mathrm{mg} / \mathrm{g}\end{array}$} & \multicolumn{4}{|c|}{$\begin{array}{c}\text { Mean } \\
\mathrm{K}^{+} / \mathrm{Na}^{+}\end{array}$} \\
\hline & \multicolumn{2}{|c|}{ Control } & \multicolumn{2}{|c|}{$75 \mathrm{mM} \mathrm{NaCl}$} & \multicolumn{2}{|c|}{ Control } & \multicolumn{2}{|c|}{$75 \mathrm{mM} \mathrm{NaCl}$} & \multirow{2}{*}{ Control } & \multicolumn{3}{|c|}{$75 \mathrm{mM} \mathrm{NaCl}$} \\
\hline & 0.13 & $(0.03)^{\text {bcdefg }}$ & 2.58 & $(0.48)^{\mathrm{gh}}$ & 14.32 & $(1.54)^{\text {bcde }}$ & 3.06 & $(1.08)^{\mathrm{a}}$ & & $(25.47)^{\text {cdefg }}$ & 0.67 & $(0.12)^{\mathrm{a}}$ \\
\hline $\mathrm{Sb}-1$ & 0.02 & $(0.01)^{\mathrm{abc}}$ & 0.59 & $(0.16)^{\mathrm{efgh}}$ & 17.89 & $(1.27)^{\mathrm{ef}}$ & 18.18 & $(3.03)^{\mathrm{ef}}$ & 564.71 & $(122.52)^{\mathrm{gh}}$ & 23.72 & $(6.36)^{\mathrm{bcde}}$ \\
\hline $\mathrm{Sb}-3$ & 0.19 & $(0.14)^{\mathrm{abcde}}$ & 0.15 & $(0.07)^{\text {abcde }}$ & 9.45 & $(0.29)^{\mathrm{b}}$ & 14.52 & $(0.82)^{\mathrm{cde}}$ & 124.51 & $(46.12)^{\text {cdefg }}$ & 142.67 & $(45.08)^{\operatorname{defg}}$ \\
\hline $\mathrm{Sb}-4$ & 0.17 & $(0.10)^{\mathrm{abcdef}}$ & 0.22 & $(0.11)^{\text {bcdefg }}$ & 13.05 & $(0.69)^{\text {bcde }}$ & 17.11 & $(0.96)^{\mathrm{def}}$ & 147.21 & $(85.36)^{\text {cdefg }}$ & 74.87 & $(20.78)^{\operatorname{cdefg}}$ \\
\hline $\mathrm{Sb}-7$ & 0.03 & $(0.01)^{\mathrm{abc}}$ & 0.22 & $(0.08)^{\operatorname{cdefg}}$ & 22.54 & $(1.34)^{\mathrm{f}}$ & 22.84 & $(0.62)^{\mathrm{f}}$ & 806.73 & $(240.01)^{\mathrm{gh}}$ & 108.48 & $(41.20)^{\text {cdefg }}$ \\
\hline $\mathrm{Sb}-8$ & 0.04 & $(0.01)^{\mathrm{abcd}}$ & 0.92 & $(0.27)^{\mathrm{efgh}}$ & 17.06 & $(0.80)^{\mathrm{def}}$ & 18.85 & $(0.90)^{\mathrm{ef}}$ & 246.46 & $(41.32)^{\mathrm{fgh}}$ & 14.55 & $(4.68)^{\mathrm{abcde}}$ \\
\hline $\mathrm{Sb}-9$ & 0.03 & $(0.01)^{\mathrm{abc}}$ & 0.51 & $(0.12)^{\mathrm{efgh}}$ & 10.93 & $(0.85)^{\mathrm{bc}}$ & 16.70 & $(0.81)^{\mathrm{def}}$ & 235.69 & $(30.71)^{\mathrm{fgh}}$ & 24.12 & $(4.75)^{\mathrm{bcde}}$ \\
\hline $\mathrm{Sb}-10$ & 0.02 & $(0.01)^{\mathrm{ab}}$ & 0.60 & $(0.23)^{\operatorname{defgh}}$ & 10.28 & $(0.68)^{\mathrm{bc}}$ & 11.43 & $(0.92)^{\mathrm{bcd}}$ & 703.49 & $(466.73)^{\mathrm{fgh}}$ & 18.92 & $(5.44)^{\mathrm{bcd}}$ \\
\hline $\mathrm{Sb}-15$ & 0.09 & $(0.07)^{\mathrm{abc}}$ & 1.95 & $(0.64)^{\mathrm{gh}}$ & 18.68 & $(0.81)^{\mathrm{ef}}$ & 19.34 & $(2.23)^{\mathrm{ef}}$ & 936.91 & $(475.01)^{\mathrm{fgh}}$ & 25.15 & $(20.61)^{\mathrm{abc}}$ \\
\hline $\mathrm{Sb}-16$ & 0.01 & $(0.01)^{\mathrm{a}}$ & 0.13 & $(0.06)^{\mathrm{abcde}}$ & 17.86 & $(1.22)^{\mathrm{ef}}$ & 23.22 & $(1.07)^{\mathrm{f}}$ & 1569.94 & $(674.41)^{\mathrm{h}}$ & 351.98 & $(179.91)^{\mathrm{efgh}}$ \\
\hline $\mathrm{Sb}-17$ & 0.35 & $(0.24)^{\text {bcdefgh }}$ & 1.79 & $(0.74)^{\mathrm{fgh}}$ & 14.88 & $(0.91)^{\text {bcdef }}$ & 18.28 & $(0.64)^{\mathrm{def}}$ & 94.21 & $(65.45)^{\text {cdefg }}$ & 9.46 & $(4.46)^{\mathrm{abc}}$ \\
\hline $\mathrm{V}-2$ & 0.32 & $(0.20)^{\text {bcdefg }}$ & 3.47 & $(1.19)^{\mathrm{h}}$ & 11.28 & $(1.52)^{\mathrm{bcd}}$ & 12.28 & $(1.72)^{\text {bcde }}$ & 56.12 & $(22.40)^{\mathrm{cdef}}$ & 2.80 & $(0.74)^{\mathrm{ab}}$ \\
\hline SEM & 0.45 & & & & 0.08 & & & & 0.45 & & & \\
\hline $\mathrm{P}_{\text {Accession }}$ & $\mathrm{P}<0.0$ & & & & $\mathrm{P}<0.0$ & & & & $\mathrm{P}<0.001$ & & & \\
\hline $\mathrm{P}_{\text {Treatment }}$ & $\mathrm{P}<0.0$ & & & & $\mathrm{P}<0.05$ & & & & $\mathrm{P}<0.001$ & & & \\
\hline $\mathrm{P}_{\text {Interaction }}$ & $\mathrm{P}<0.0$ & & & & $\mathrm{P}<0.0$ & & & & $\mathrm{P}<0.001$ & & & \\
\hline
\end{tabular}




\section{Figures}

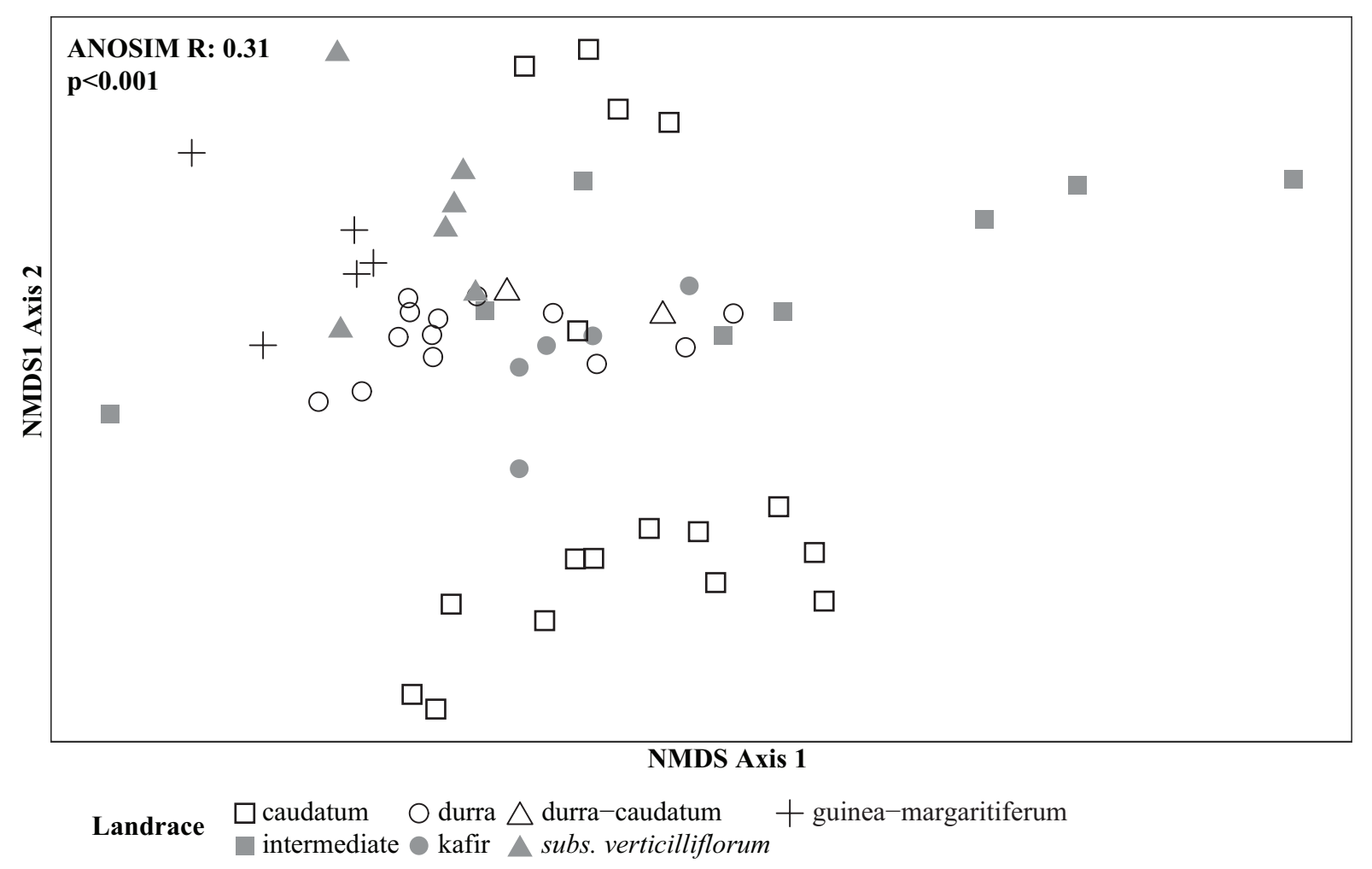

Fig. 1. Non-metric multidimensional scaling using Bray-Curtis dissimilarity coefficient to two-dimensionally visualize plant response to treatment. For the $\mathrm{NaCl}$ treatment, accessions were ordinated in two-dimensional space. The following measurements were analyzed for dissimilarity among individuals: SPAD, percent of live leaves (live leaf count/total leaf count), height $(\mathrm{cm})$, mortality, live aboveground biomass (dry weight in $\mathrm{g}$ ), dead aboveground biomass (dry weight in g), and root biomass (dry weight in $\mathrm{g}$ ). Shapes indicate the landrace grouping for each accession. The analysis of similarity revealed plants were more similar within a landrace than among landraces $(\mathrm{R}=0.31, \mathrm{P}<0.001)$. 


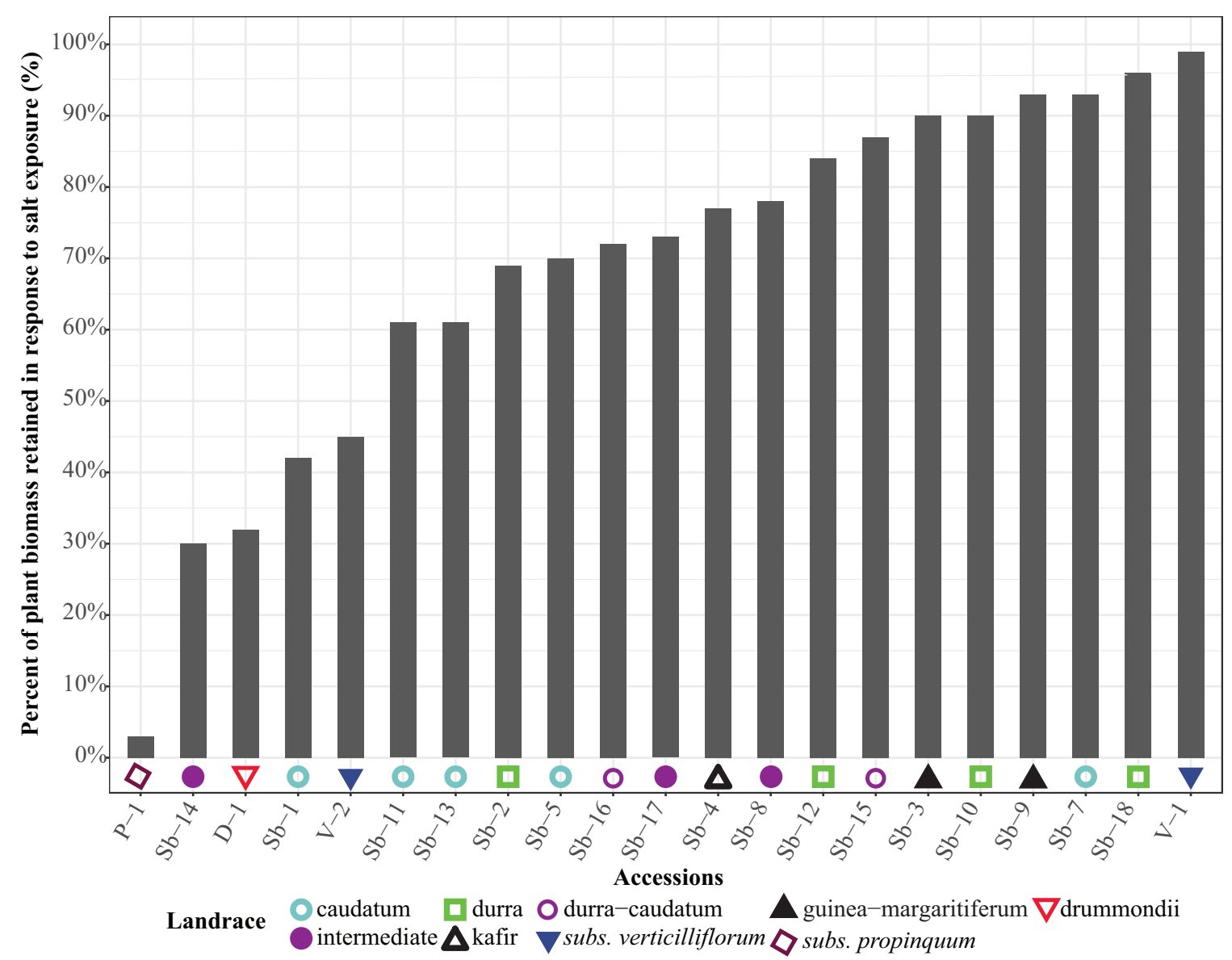

Fig. 2. Relative percent of plant biomass retained in response to $75 \mathrm{mM} \mathrm{NaCl}$ for each accession. Relative percent of plant biomass retained was calculated by 1-RDPB. Shapes indicate the landrace grouping for each accession. Larger percentages indicate higher amounts of biomass retained in response to $\mathrm{NaCl}$. Lower percentages indicate higher amounts of biomass lost in response to $\mathrm{NaCl}$. RDPB was calculated on mean live aboveground biomass in control and treatment conditions. 


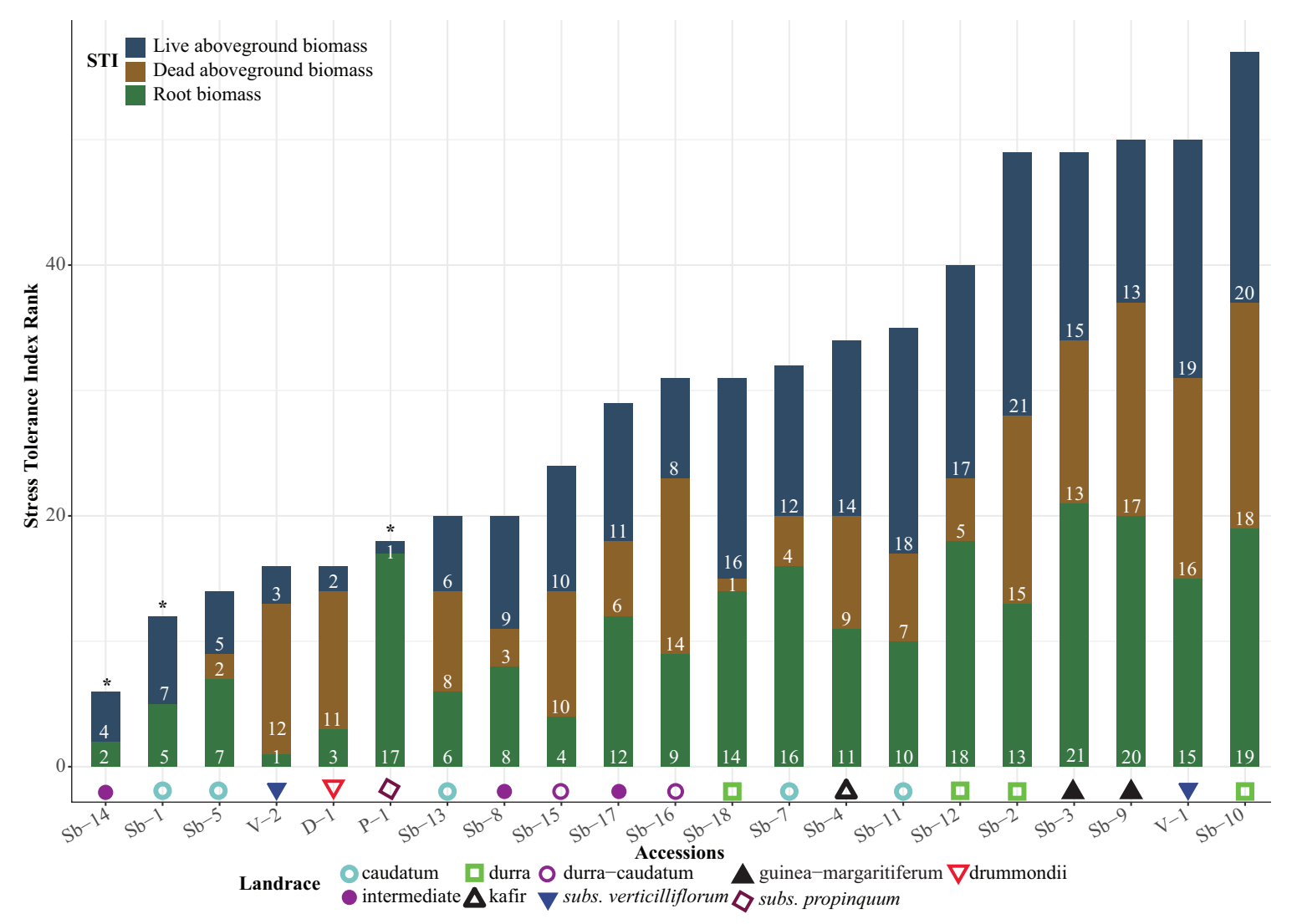

Fig. 3. Rank ordered stress tolerance index (STI) scores for live aboveground biomass, dead aboveground biomass, and root biomass, for each accession in response to $\mathrm{NaCl}$.

Accessions were arranged with the lowest overall STI rank on the left and the largest overall STI rank on the right. Overall rank was calculated by the sum of live aboveground biomass, dead aboveground biomass, and root biomass rank. Colors indicate portion of overall rank contributed by live aboveground biomass, dead aboveground biomass, and root biomass. Higher values indicate better performers compared to other individuals within the population. Lower values indicate poor performers compared to other individuals within the population. Note: Sb-14, Sb-1, and P-1 are missing STI values for dead aboveground biomass. 


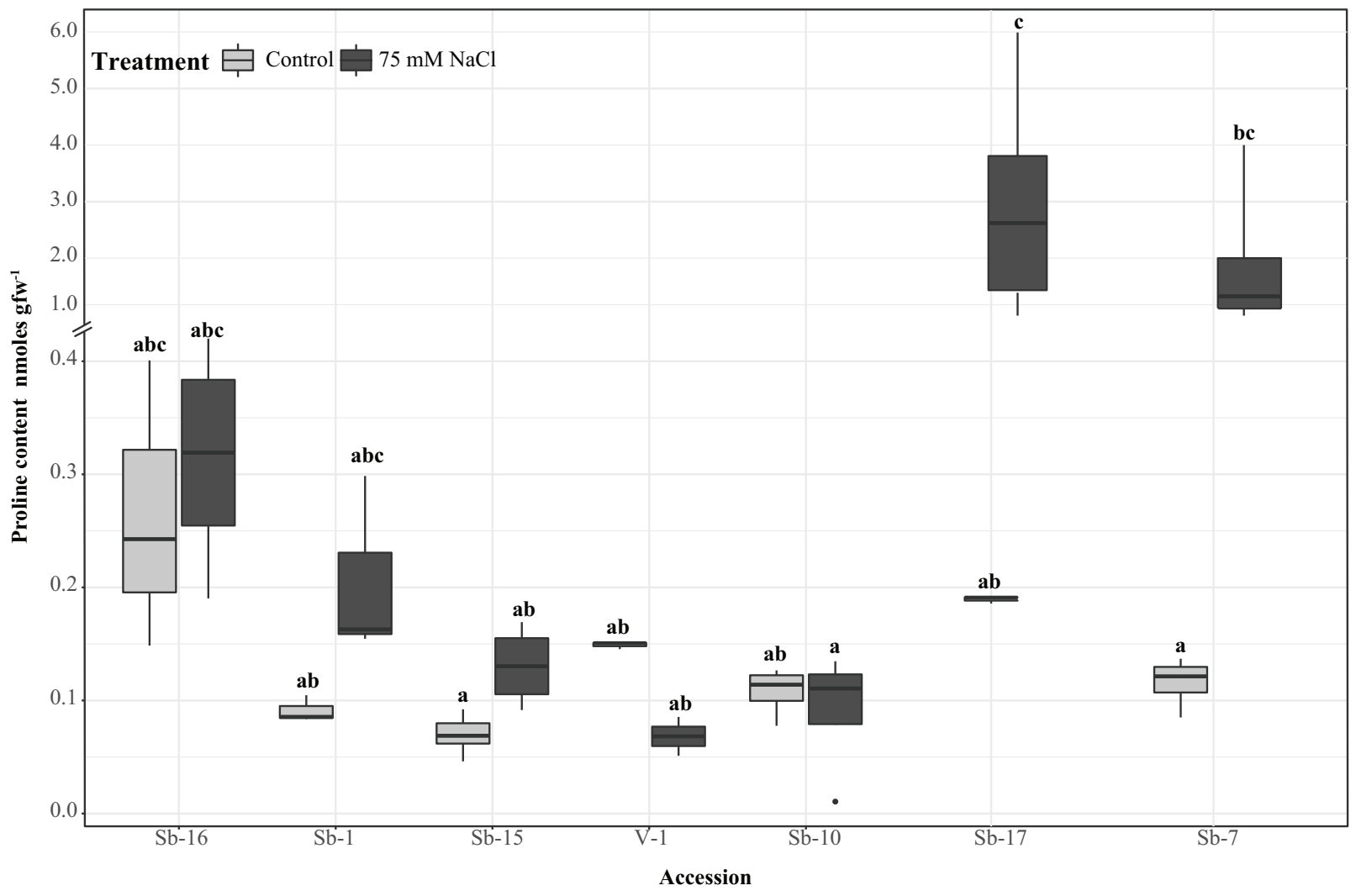

Fig. 4. Proline accumulation in a subset of accessions. Some accessions showed no increase in proline accumulation in response to $75 \mathrm{mM} \mathrm{NaCl}$; however, trends for Sb-17 and Sb-7 show that, with increased salt exposure, proline accumulated. Statistical significance was found among accessions and proline accumulation in response to treatment $\left(\mathrm{P}_{\text {Accession }}<0.001, \mathrm{P}_{\text {Treatment }}<0.001\right.$, $\left.\mathrm{P}_{\text {Treatment*Accession }}<0.01\right)$. Values are the mean of five biological replicates with \pm standard error. Different letters represent significant differences. Note: Break in axis to account for scale differences. 

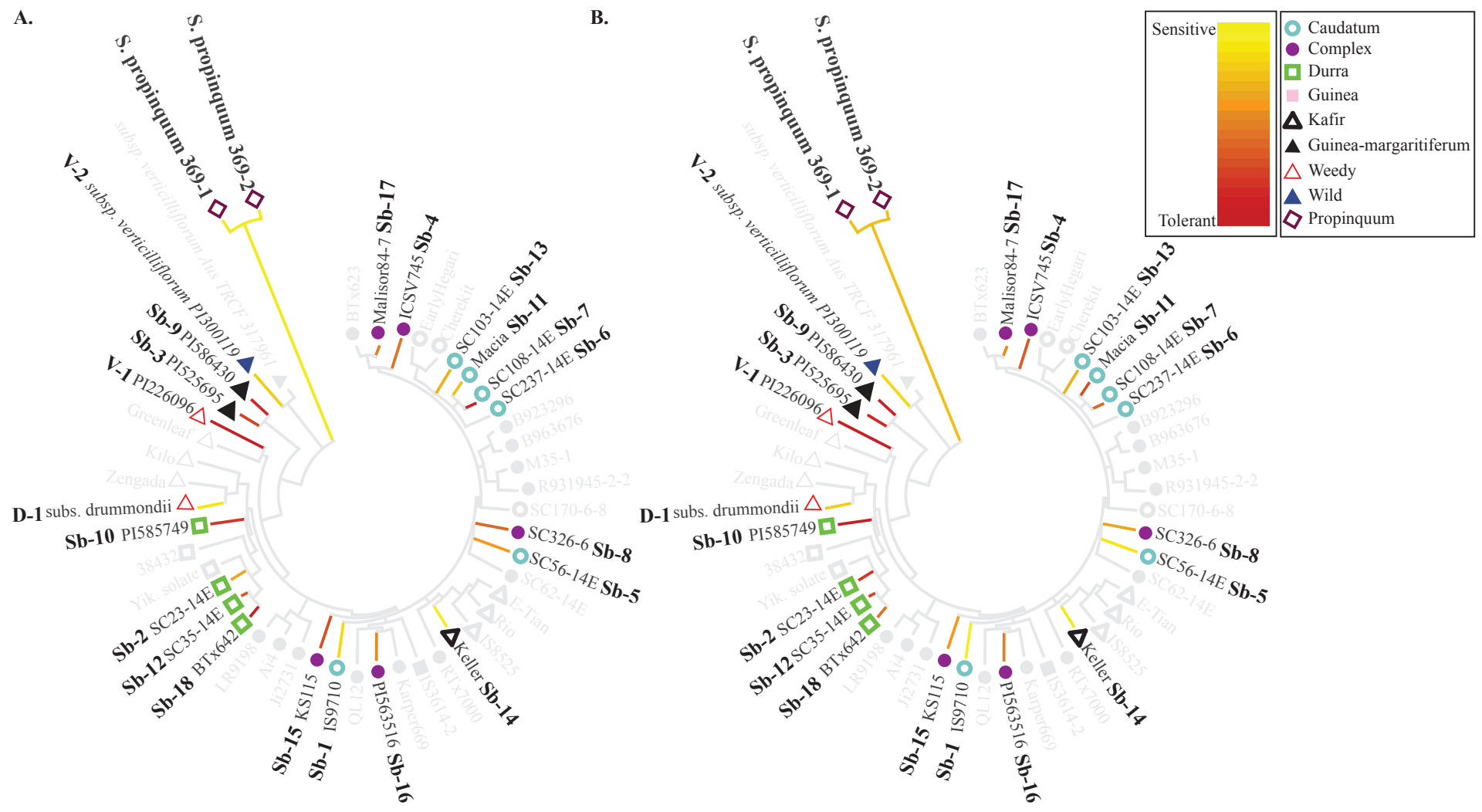

Figure 5. A neighbor-joining tree constructed by Mace et al. (2013) using SNP data. (A) RDPB (live aboveground biomass) overlaid on neighbor-joining tree. Large amounts of biomass lost in response to treatment (yellow) indicates sensitivity whereas, small amounts of biomass lost in response to treatment (red) indicates tolerance. (B) Overall STI rank score for each accession overlaid on neighbor-joining tree. Smaller STI rank scores (yellow) indicates sensitivity, whereas larger STI rank scores (red) indicate tolerances. Figure modified from Mace, E., Tai, S., Gilding, E. et al. Whole-genome sequencing reveals untapped genetic potential in Africa's indigenous cereal crop sorghum. Nat Commun 4, 2320 (2013). https://doi.org/10.1038/ncomms3320 


\section{Supporting Information}

Appendix S1. A pilot study showing the effect of increasing concentrations of $\mathrm{NaCl}$ on biomass accumulation.

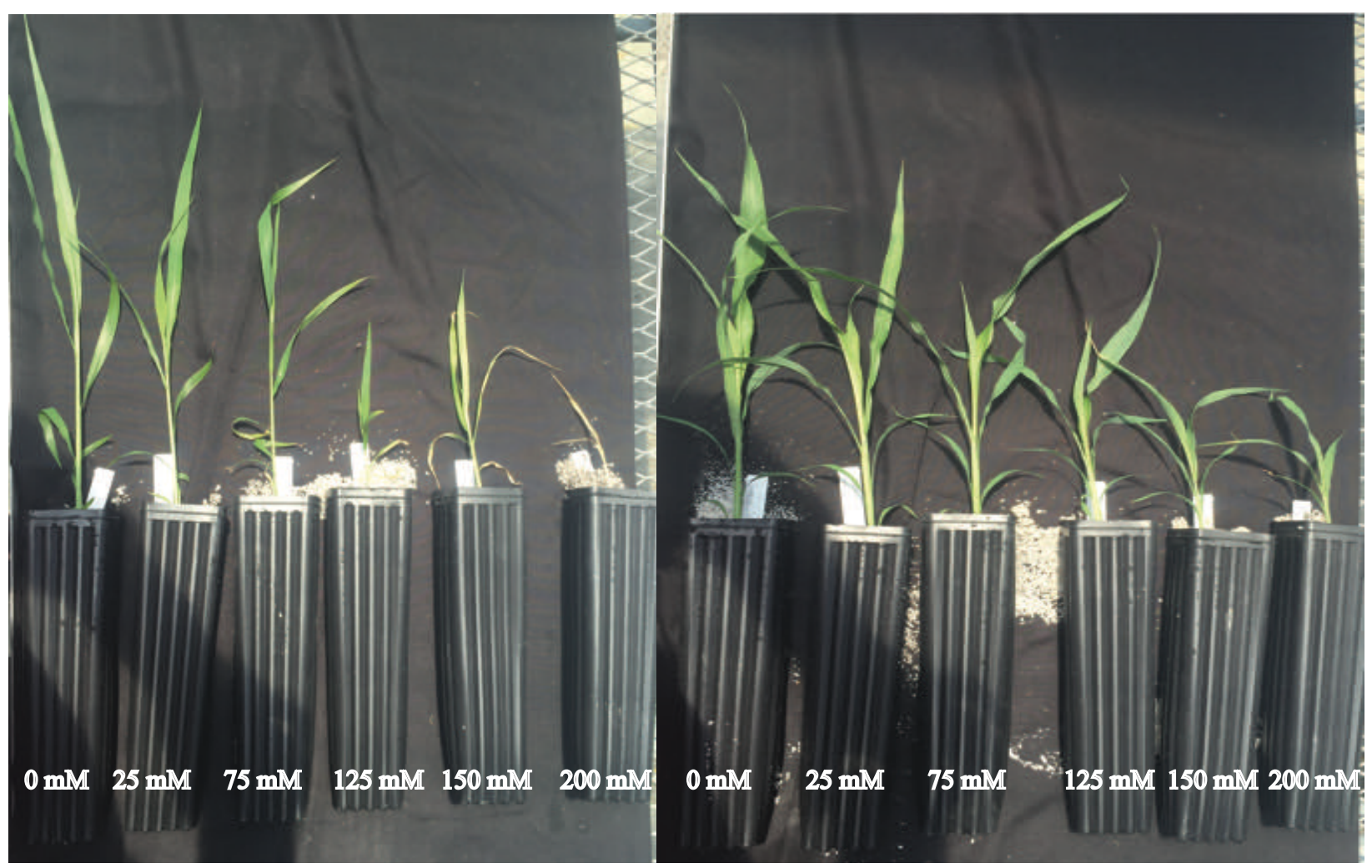


Appendix S2. (A) Accession STI (B) Growth variation in response to NaCl. Data shown are means \pm the standard error. Different letters represent significant differences when comparing accessions $(\mathrm{P}<0.05)$.

\begin{tabular}{|c|c|c|c|c|c|c|c|c|c|c|c|c|}
\hline \multirow{3}{*}{$\begin{array}{l}\text { A. } \\
\text { Landrace } \\
\text { drummondii }\end{array}$} & \multirow{3}{*}{$\begin{array}{l}\text { Accession } \\
\text { D-1 }\end{array}$} & \multicolumn{11}{|c|}{ Stress Tolerance Index } \\
\hline & & \multicolumn{4}{|c|}{ STI $_{\text {LAGB }}$} & \multicolumn{4}{|c|}{ STI $_{\text {DAGB }}$} & \multicolumn{3}{|c|}{ STI $\mathbf{I B}_{\mathrm{RB}}$} \\
\hline & & 0.18 & \pm & 0.01 & $\mathrm{i}$ & 0.99 & \pm & 0.13 & d & 0.11 & 0.03 & gh \\
\hline subs. propinquum & $\mathrm{P}-1$ & 0.01 & \pm & 0.00 & $\mathrm{j}$ & & & & & 0.57 & 0.00 & cde \\
\hline caudatum & $\mathrm{Sb}-1$ & 0.56 & \pm & 0.00 & efgh & & & & & 0.22 & 0.00 & efgh \\
\hline durra & $\mathrm{Sb}-2$ & 1.51 & \pm & 0.16 & a & 1.79 & \pm & 0.16 & $\mathrm{bc}$ & 0.39 & 0.04 & def \\
\hline guinea-margaritiferum & $\mathrm{Sb}-3$ & 0.80 & \pm & 0.08 & cdef & 0.95 & \pm & 0.01 & d & 1.97 & 0.34 & a \\
\hline kafir & $\mathrm{Sb}-4$ & 0.88 & \pm & 0.08 & bcde & 0.75 & \pm & 0.09 & def & 0.31 & $\pm \quad 0.01$ & defg \\
\hline caudatum & $\mathrm{Sb}-5$ & 0.41 & \pm & 0.03 & ghi & 0.22 & \pm & 0.01 & hi & 0.20 & $\pm \quad 0.03$ & efgh \\
\hline caudatum & $\mathrm{Sb}-7$ & 0.87 & \pm & 0.06 & cde & 0.40 & \pm & 0.07 & fgh & 0.58 & 0.08 & cde \\
\hline Intermediate (unknown) & $\mathrm{Sb}-8$ & 0.55 & \pm & 0.12 & efgh & 0.31 & \pm & 0.05 & ghi & 0.21 & $\pm \quad 0.06$ & efgh \\
\hline guinea-margaritiferum & $\mathrm{Sb}-9$ & 0.69 & \pm & 0.04 & defg & 3.23 & \pm & 0.26 & a & 1.32 & 0.09 & $\mathrm{ab}$ \\
\hline durra & $\mathrm{Sb}-10$ & 1.32 & \pm & 0.05 & $\mathrm{ab}$ & 3.35 & \pm & 0.33 & a & 0.85 & $\pm \quad 0.10$ & $\mathrm{bc}$ \\
\hline caudatum & $\mathrm{Sb}-11$ & 1.13 & \pm & 0.13 & $a b c$ & 0.50 & \pm & 0.06 & defgh & 0.27 & $\pm \quad 0.03$ & efg \\
\hline durra & $\mathrm{Sb}-12$ & 1.12 & \pm & 0.07 & abc & 0.43 & \pm & 0.04 & efgh & 0.63 & $\pm \quad 0.04$ & $\mathrm{~cd}$ \\
\hline caudatum & $\mathrm{Sb}-13$ & 0.43 & \pm & 0.07 & ghi & 0.55 & \pm & 0.09 & defgh & 0.20 & $\pm \quad 0.05$ & fgh \\
\hline Unknown & $\mathrm{Sb}-14$ & 0.47 & \pm & 0.05 & fgh & & & & & 0.13 & 0.04 & gh \\
\hline durra-caudatum & $\mathrm{Sb}-15$ & 0.65 & \pm & 0.04 & efg & 0.68 & \pm & 0.08 & defg & 0.18 & 0.01 & fgh \\
\hline durra-caudatum & $\mathrm{Sb}-16$ & 0.64 & \pm & 0.02 & efg & 1.11 & \pm & 0.26 & $\mathrm{~cd}$ & 0.28 & 0.09 & efgh \\
\hline Intermediate (unknown) & Sb-17 & 0.69 & \pm & 0.03 & defg & 0.33 & \pm & 0.08 & ghi & 0.26 & 0.05 & efgh \\
\hline durra & Sb-18 & 1.06 & \pm & 0.06 & abcd & 0.10 & \pm & 0.02 & $\mathrm{i}$ & 0.45 & $\pm \quad 0.03$ & cdef \\
\hline subs. verticilliflorum & $\mathrm{V}-1$ & 1.37 & \pm & 0.11 & $\mathrm{a}$ & 2.17 & \pm & 0.16 & $\mathrm{~b}$ & 0.52 & $\pm \quad 0.07$ & cde \\
\hline \multirow[t]{3}{*}{ subs. verticilliflorum } & $\mathrm{V}-2$ & 0.28 & \pm & 0.03 & hi & 0.88 & \pm & 0.05 & de & 0.05 & $\pm \quad 0.01$ & $\mathrm{~h}$ \\
\hline & SEM & \multicolumn{4}{|c|}{0.01} & \multicolumn{4}{|c|}{0.01} & \multicolumn{3}{|c|}{0.01} \\
\hline & $\mathrm{P}_{\text {Landrace }}$ & \multicolumn{4}{|c|}{$\mathrm{p}<0.001$} & \multicolumn{4}{|c|}{$\mathrm{p}<0.001$} & \multicolumn{3}{|c|}{$\mathrm{p}<0.001$} \\
\hline
\end{tabular}

$\mathrm{LAGB}=$ live aboveground biomass; $\mathrm{DAGB}=$ dead aboveground biomass; $\mathrm{RB}=$ root biomass; $\mathrm{STI}=$ stress tolerance index 


\begin{tabular}{|c|c|c|c|c|c|c|c|c|c|c|c|c|c|c|c|c|c|c|c|}
\hline \multirow{3}{*}{$\begin{array}{l}\text { B. } \\
\text { Landrace } \\
\text { drummondii }\end{array}$} & \multirow{3}{*}{$\begin{array}{l}\text { Accession } \\
\text { D-1 }\end{array}$} & \multicolumn{9}{|c|}{ Control } & \multicolumn{9}{|c|}{$75 \mathrm{mM} \mathrm{NaCl}$} \\
\hline & & \multicolumn{3}{|c|}{ Total LAGB } & \multicolumn{3}{|c|}{ Total DAGB } & \multicolumn{3}{|c|}{ RB } & \multicolumn{3}{|c|}{ Total LAGB } & \multicolumn{3}{|c|}{ Total DAGB } & \multicolumn{3}{|c|}{ RB } \\
\hline & & 2.49 & & & 0.41 & & & 1.18 & & & 0.83 & \pm & 0.03 & 0.25 & & & 0.29 & \pm & 0.09 \\
\hline subs. propinquum & P-1 & 2.01 & \pm & 0.15 & 0.09 & \pm & 0.02 & 1.04 & \pm & 0.11 & 0.07 & \pm & 0.01 & & & & 1.41 & \pm & 0.00 \\
\hline caudatum & $\mathrm{Sb}-1$ & 3.91 & \pm & 0.36 & 0.59 & \pm & 0.07 & 1.29 & \pm & 0.18 & 1.62 & \pm & 0.01 & & & & 0.45 & \pm & 0.01 \\
\hline durra & $\mathrm{Sb}-2$ & 5.11 & \pm & 0.60 & 0.63 & \pm & 0.08 & 1.64 & \pm & 0.33 & 3.64 & \pm & 0.32 & 0.34 & \pm & 0.03 & 0.65 & \pm & 0.07 \\
\hline guinea-margaritiferum & $\mathrm{Sb}-3$ & 3.04 & \pm & 0.47 & 0.51 & \pm & 0.01 & 4.76 & \pm & 0.74 & 3.29 & \pm & 0.30 & 0.21 & \pm & 0.00 & 1.24 & \pm & 0.03 \\
\hline kafir & $\mathrm{Sb}-4$ & 3.68 & \pm & 0.48 & 0.27 & \pm & 0.05 & 1.28 & \pm & 0.21 & 2.48 & \pm & 0.19 & 0.28 & \pm & 0.03 & 0.65 & \pm & 0.09 \\
\hline caudatum & $\mathrm{Sb}-5$ & 2.60 & \pm & 0.13 & 0.11 & \pm & 0.02 & 1.18 & \pm & 0.09 & 1.95 & \pm & 0.23 & 0.20 & \pm & 0.01 & 0.54 & \pm & 0.12 \\
\hline caudatum & $\mathrm{Sb}-7$ & 3.57 & \pm & 0.00 & 0.18 & \pm & 0.02 & 2.06 & \pm & 0.03 & 2.49 & \pm & 0.17 & 0.22 & \pm & 0.04 & 0.67 & \pm & 0.14 \\
\hline Intermediate (unknown) & $\mathrm{Sb}-8$ & 2.85 & \pm & 0.16 & 0.06 & \pm & 0.02 & 1.00 & \pm & 0.10 & 2.70 & \pm & 0.08 & 0.52 & \pm & 0.04 & 0.69 & \pm & 0.09 \\
\hline guinea-margaritiferum & Sb-9 & 2.92 & \pm & 0.15 & 0.92 & \pm & 0.19 & 4.02 & & & 3.07 & & & 0.48 & & & & & \\
\hline durra & Sb-10 & 4.31 & \pm & 0.20 & 0.94 & \pm & 0.11 & 1.92 & \pm & 0.04 & 3.46 & \pm & 0.18 & 0.52 & \pm & 0.14 & 1.11 & \pm & 0.11 \\
\hline caudatum & Sb-11 & 4.52 & \pm & 0.23 & 0.24 & \pm & 0.06 & 1.30 & \pm & 0.10 & 2.96 & \pm & 0.54 & 0.25 & \pm & 0.04 & 0.55 & \pm & 0.10 \\
\hline durra & Sb-12 & 3.83 & \pm & 0.41 & 0.25 & \pm & 0.03 & 3.18 & \pm & 0.74 & 3.36 & \pm & 0.19 & 0.19 & \pm & 0.02 & 0.51 & \pm & 0.03 \\
\hline caudatum & $\mathrm{Sb}-13$ & 2.89 & \pm & 0.24 & 0.21 & \pm & 0.03 & 0.99 & \pm & 0.10 & 1.96 & \pm & 0.19 & 0.32 & \pm & 0.05 & 0.62 & \pm & 0.09 \\
\hline Unknown & $\mathrm{Sb}-14$ & 4.51 & \pm & 0.47 & 0.44 & \pm & 0.03 & 0.96 & \pm & 0.05 & 1.10 & \pm & 0.11 & & & & 0.26 & \pm & 0.06 \\
\hline durra-caudatum & Sb-15 & 2.87 & \pm & 0.11 & 0.26 & \pm & 0.02 & 0.91 & \pm & 0.05 & 2.70 & \pm & 0.18 & 0.30 & \pm & 0.03 & 0.50 & & \\
\hline durra-caudatum & $\mathrm{Sb}-16$ & 3.13 & \pm & 0.27 & 0.21 & \pm & 0.04 & 1.29 & \pm & 0.08 & 2.34 & \pm & 0.06 & 0.59 & \pm & 0.14 & 0.55 & \pm & 0.10 \\
\hline Intermediate (unknown) & Sb-17 & 2.96 & \pm & 0.32 & 0.15 & \pm & 0.04 & 0.88 & \pm & 0.19 & 2.62 & & & 0.33 & & & 1.18 & & \\
\hline durra & $\mathrm{Sb}-18$ & 3.61 & & & 0.05 & & & 1.62 & & & 2.98 & \pm & 0.26 & 0.19 & \pm & 0.03 & 0.71 & \pm & 0.04 \\
\hline subs. verticilliflorum & $\mathrm{V}-1$ & 3.74 & \pm & 0.00 & 0.56 & \pm & 0.03 & 1.46 & \pm & 0.11 & 3.78 & \pm & 0.69 & 0.38 & \pm & 0.07 & 0.81 & \pm & 0.19 \\
\hline \multirow[t]{3}{*}{ subs. verticilliflorum } & $\mathrm{V}-2$ & 3.22 & \pm & 0.49 & 0.40 & \pm & 0.05 & 0.96 & \pm & 0.12 & 1.06 & \pm & 0.18 & 0.25 & \pm & 0.03 & 0.16 & \pm & 0.06 \\
\hline & SEM & & & & & & & & & & & & & & & & & & \\
\hline & $\mathrm{P}_{\text {Landrace }}$ & & & & & & & & & & & & & & & & & & \\
\hline
\end{tabular}

LAGB = live aboveground biomass; DAGB = dead aboveground biomass; RB = root biomass; $\mathrm{STI}=$ stress tolerance index 
Appendix S3. Non-metric multidimensional scaling using Bray-Curtis dissimilarity coefficient to two-dimensionally visualize plant response to $0 \mathrm{mM}$ and $75 \mathrm{mM} \mathrm{NaCl}$. The analysis of similarity revealed that plants were more similar within a treatment than across treatments $(\mathrm{R}=0.11 ; \mathrm{P}<0.001)$. Gray triangles represent individuals within the control treatment and black circles represent individuals within the $75 \mathrm{mM} \mathrm{NaCl}$ treatment.

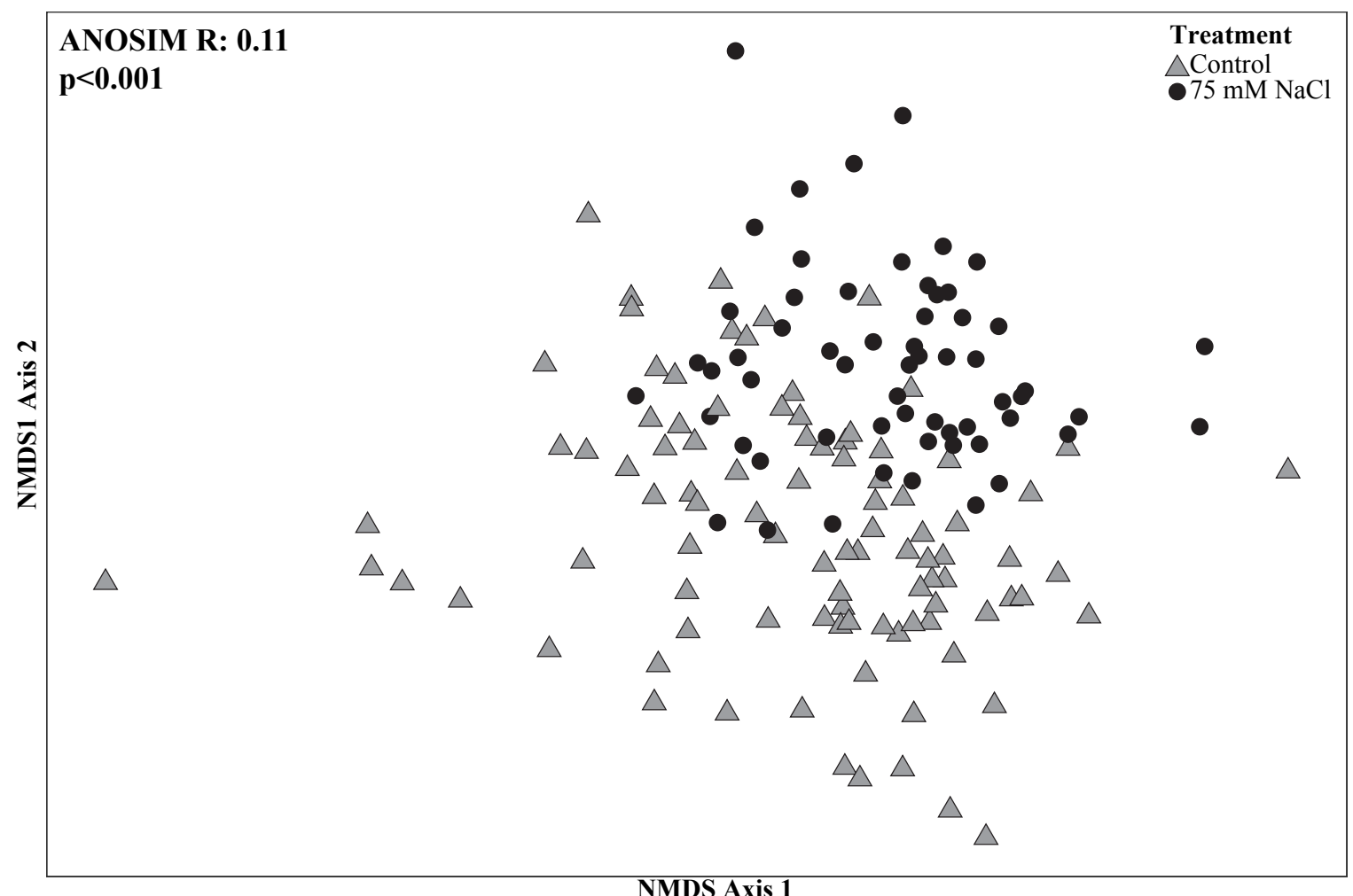


Appendix S4. Relative decrease in plant biomass (RDPB) for each landrace. Data shown are means \pm the standard error of RDPB values for each landrace. Different letters represent significant differences when comparing landraces $(\mathrm{P}<0.05)$.

\begin{tabular}{|c|c|c|c|c|}
\hline Landrace & \multicolumn{4}{|c|}{ RDPB $_{\text {Landrace }}$} \\
\hline caudatum & 0.35 & \pm & 0.04 & $\mathrm{bc}$ \\
\hline drummondii & 0.66 & \pm & 0.01 & $\mathrm{ab}$ \\
\hline durra & 0.15 & \pm & 0.04 & $\mathrm{c}$ \\
\hline durra-caudatum & 0.18 & \pm & 0.04 & $\mathrm{bc}$ \\
\hline guinea-margaritiferum & 0.09 & \pm & 0.05 & $\mathrm{c}$ \\
\hline Intermediate (unknown) & 0.40 & \pm & 0.10 & $\mathrm{abc}$ \\
\hline kafir & 0.29 & \pm & 0.04 & $\mathrm{bc}$ \\
\hline subs. propinquum & 0.97 & \pm & 0.00 & $\mathrm{a}$ \\
\hline subs. verticilliflorum & 0.32 & \pm & 0.14 & $\mathrm{bc}$ \\
\hline SEM & \multicolumn{4}{|c|}{0.06} \\
\hline $\mathrm{P}_{\text {Landrace }}$ & \multicolumn{4}{|c|}{$<0.001$} \\
\hline
\end{tabular}

$\mathrm{RDPB}=$ relative decrease in plant biomass 
Appendix S5. (A) Landrace STI scores and (B) growth variation in response to NaCl. Data shown are means \pm the standard error. Different letters represent significant differences when comparing landraces $(\mathrm{P}<0.05)$.

\begin{tabular}{|c|c|c|c|c|c|c|c|c|c|c|c|}
\hline \multirow{3}{*}{$\begin{array}{l}\text { A. } \\
\text { Landrace } \\
\text { drummondii }\end{array}$} & \multicolumn{11}{|c|}{ Stress Tolerance Index } \\
\hline & \multicolumn{4}{|c|}{ STI LAGB $_{\text {L }}$} & \multicolumn{4}{|c|}{ STI } & \multicolumn{3}{|c|}{$\mathbf{S T I}_{\mathrm{RB}}$} \\
\hline & 0.18 & \pm & 0.01 & $\mathrm{c}$ & 0.99 & \pm & 0.13 & ab & 0.11 & $\pm \quad 0.03$ & c \\
\hline $\begin{array}{l}\text { Intermediate } \\
\text { (unknown) }\end{array}$ & 0.57 & \pm & 0.05 & $\mathrm{~b}$ & 0.32 & \pm & 0.05 & $\mathrm{~b}$ & 0.20 & $\pm \quad 0.03$ & bc \\
\hline durra-caudatum & 0.65 & \pm & 0.03 & $\mathrm{~b}$ & 0.90 & \pm & 0.13 & ab & 0.24 & $\pm \quad 0.04$ & bc \\
\hline caudatum & 0.69 & \pm & 0.06 & $\mathrm{~b}$ & 0.42 & \pm & 0.04 & $\mathrm{~b}$ & 0.24 & $\pm \quad 0.01$ & bc \\
\hline subs. verticilliflorum & 0.81 & \pm & 0.17 & $\mathrm{~b}$ & 1.46 & \pm & 0.23 & a & 0.27 & $\pm \quad 0.08$ & bc \\
\hline kafir & 0.88 & \pm & 0.08 & ab & 0.75 & \pm & 0.09 & ab & 0.31 & $\pm \quad 0.01$ & bc \\
\hline durra & 1.28 & \pm & 0.08 & a & 1.64 & \pm & 0.41 & ab & 0.55 & $\pm \quad 0.05$ & $\mathrm{~b}$ \\
\hline subs. propinquum & 0.01 & \pm & 0.00 & d & & & & & 0.57 & $\pm \quad 0.00$ & $\mathrm{~b}$ \\
\hline guinea-margaritiferum & 0.75 & & 0.05 & $\mathrm{~b}$ & 2.08 & & 0.40 & $\mathrm{a}$ & 1.69 & $\pm \quad 0.20$ & a \\
\hline SEM & \multicolumn{4}{|c|}{0.04} & \multicolumn{4}{|c|}{0.76} & \multicolumn{3}{|c|}{0.03} \\
\hline$P_{\text {Landrace }}$ & \multicolumn{4}{|c|}{$\mathrm{p}<0.001$} & \multicolumn{4}{|c|}{$\mathrm{p}<0.001$} & \multicolumn{3}{|c|}{$\mathrm{p}<0.001$} \\
\hline
\end{tabular}

LAGB $=$ live aboveground biomass; $\mathrm{DAGB}=$ dead aboveground biomass $; \mathrm{RB}=$ root biomass; $\mathrm{STI}=$ stress tolerance index 


\begin{tabular}{|c|c|c|c|c|c|c|c|c|c|c|c|c|c|c|c|c|c|c|}
\hline \multirow{3}{*}{$\begin{array}{l}\text { B. } \\
\text { Landrace } \\
\text { drummondii }\end{array}$} & \multicolumn{9}{|c|}{ Control } & \multicolumn{9}{|c|}{$75 \mathrm{mM} \mathrm{NaCl}$} \\
\hline & \multicolumn{3}{|c|}{ Total LAGB } & \multicolumn{3}{|c|}{ Total DAGB } & \multicolumn{3}{|c|}{$\mathbf{R B}$} & \multicolumn{3}{|c|}{ Total LAGB } & \multicolumn{3}{|c|}{ Total DAGB } & \multicolumn{3}{|c|}{ RB } \\
\hline & 2.49 & & & 0.41 & & & 1.18 & & & 0.83 & \pm & 0.03 & 0.25 & & & 0.29 & \pm & 0.09 \\
\hline $\begin{array}{l}\text { Intermediate } \\
\text { (unknown) }\end{array}$ & 3.24 & \pm & 0.27 & 0.18 & \pm & 0.05 & 0.93 & \pm & 0.10 & 1.89 & \pm & 0.36 & 0.46 & \pm & 0.07 & 0.56 & \pm & 0.16 \\
\hline durra-caudatum & 3.00 & \pm & 0.14 & 0.24 & \pm & 0.02 & 1.10 & \pm & 0.08 & 2.54 & \pm & 0.12 & 0.39 & \pm & 0.07 & 0.54 & \pm & 0.07 \\
\hline caudatum & 3.65 & \pm & 0.18 & 0.26 & \pm & 0.04 & 1.25 & \pm & 0.08 & 2.20 & \pm & 0.17 & 0.26 & \pm & 0.02 & 0.63 & \pm & 0.05 \\
\hline subs. verticilliflorum & 3.48 & \pm & 0.25 & 0.48 & \pm & 0.05 & 1.21 & \pm & 0.13 & 2.87 & \pm & 0.72 & 0.34 & \pm & 0.05 & 0.60 & \pm & 0.18 \\
\hline kafir & 3.68 & \pm & 0.48 & 0.27 & \pm & 0.05 & 1.28 & \pm & 0.21 & 2.48 & \pm & 0.19 & 0.28 & \pm & 0.03 & 0.65 & \pm & 0.09 \\
\hline durra & 3.86 & \pm & 0.31 & 0.50 & \pm & 0.11 & 1.90 & \pm & 0.29 & 3.35 & \pm & 0.13 & 0.30 & \pm & 0.04 & 0.59 & \pm & 0.07 \\
\hline subs. propinquum & 2.01 & \pm & 0.15 & 0.09 & \pm & 0.02 & 1.04 & \pm & 0.11 & 0.07 & \pm & 0.01 & & & & 1.41 & \pm & 0.00 \\
\hline $\begin{array}{l}\text { guinea-margaritiferum } \\
\text { SEM }\end{array}$ & 2.97 & \pm & 0.18 & 0.77 & \pm & 0.13 & 4.58 & \pm & 0.56 & 3.24 & \pm & 0.22 & 0.28 & \pm & 0.07 & 1.24 & \pm & 0.03 \\
\hline$P_{\text {Landrace }}$ & & & & & & & & & & & & & & & & & & \\
\hline
\end{tabular}

LAGB = live aboveground biomass; DAGB = dead aboveground biomass; RB = root biomass; $\mathrm{STI}=$ stress tolerance index 
Appendix S6. Mean proline content for control and $\mathrm{NaCl}$ conditions. Data shown are means \pm the standard error of proline (gfw-1) for a subset of accessions. Different letters represent significant differences when comparing accessions and treatment $(\mathrm{p}<0.05)$.

\begin{tabular}{|c|c|c|c|c|c|c|c|c|}
\hline \multirow{4}{*}{$\frac{\text { Landrace }}{\text { caudatum }}$} & \multirow{4}{*}{$\begin{array}{l}\text { Accession } \\
\mathrm{Sb}-1\end{array}$} & \multirow{2}{*}{\multicolumn{7}{|c|}{$\begin{array}{c}\text { Mean proline nmoles } \text { gfw }^{-1} \\
\text { Treatment }\end{array}$}} \\
\hline & & & & & & & & \\
\hline & & \multicolumn{2}{|c|}{ Control } & & \multicolumn{4}{|c|}{$75 \mathrm{mM} \mathrm{NaCl}$} \\
\hline & & 0.09 & \pm 0.01 & $\mathrm{ab}$ & 0.21 & \pm & 0.05 & $\mathrm{abc}$ \\
\hline durra & $\mathrm{Sb}-10$ & 0.11 & \pm 0.01 & ab & 0.09 & \pm & 0.03 & a \\
\hline durra-caudatum & $\mathrm{Sb}-15$ & 0.07 & \pm 0.01 & $\mathrm{a}$ & 0.13 & \pm & 0.02 & ab \\
\hline durra-caudatum & $\mathrm{Sb}-16$ & 0.26 & $\pm \quad 0.07$ & $a b c$ & 0.32 & \pm & 0.13 & $\mathrm{abc}$ \\
\hline kafir-caudatum & $\mathrm{Sb}-17$ & 0.19 & $\pm \quad 0.01$ & $\mathrm{ab}$ & 2.63 & \pm & 1.13 & $\mathrm{c}$ \\
\hline caudatum & $\mathrm{Sb}-7$ & 0.10 & $\pm \quad 0.02$ & a & 1.35 & \pm & 0.76 & $\mathrm{bc}$ \\
\hline \multirow[t]{5}{*}{$\begin{array}{l}\text { subs. } \\
\text { verticilliflorum }\end{array}$} & $\mathrm{V}-1$ & 0.15 & \pm 0.00 & $\mathrm{ab}$ & 0.07 & \pm & 0.02 & $\mathrm{ab}$ \\
\hline & SEM & \multicolumn{7}{|c|}{0.038} \\
\hline & $\mathrm{P}_{\text {Accession }}$ & \multicolumn{7}{|c|}{$\mathrm{p}<0.001$} \\
\hline & $\mathrm{P}_{\text {Treatment }}$ & \multicolumn{7}{|c|}{$\mathrm{p}<0.001$} \\
\hline & $\mathrm{P}_{\text {Accession*Treatment }}$ & \multicolumn{7}{|c|}{$\mathrm{p}<0.01$} \\
\hline
\end{tabular}


Appendix S7. Pearson correlation matrix (75 mM NaCl).

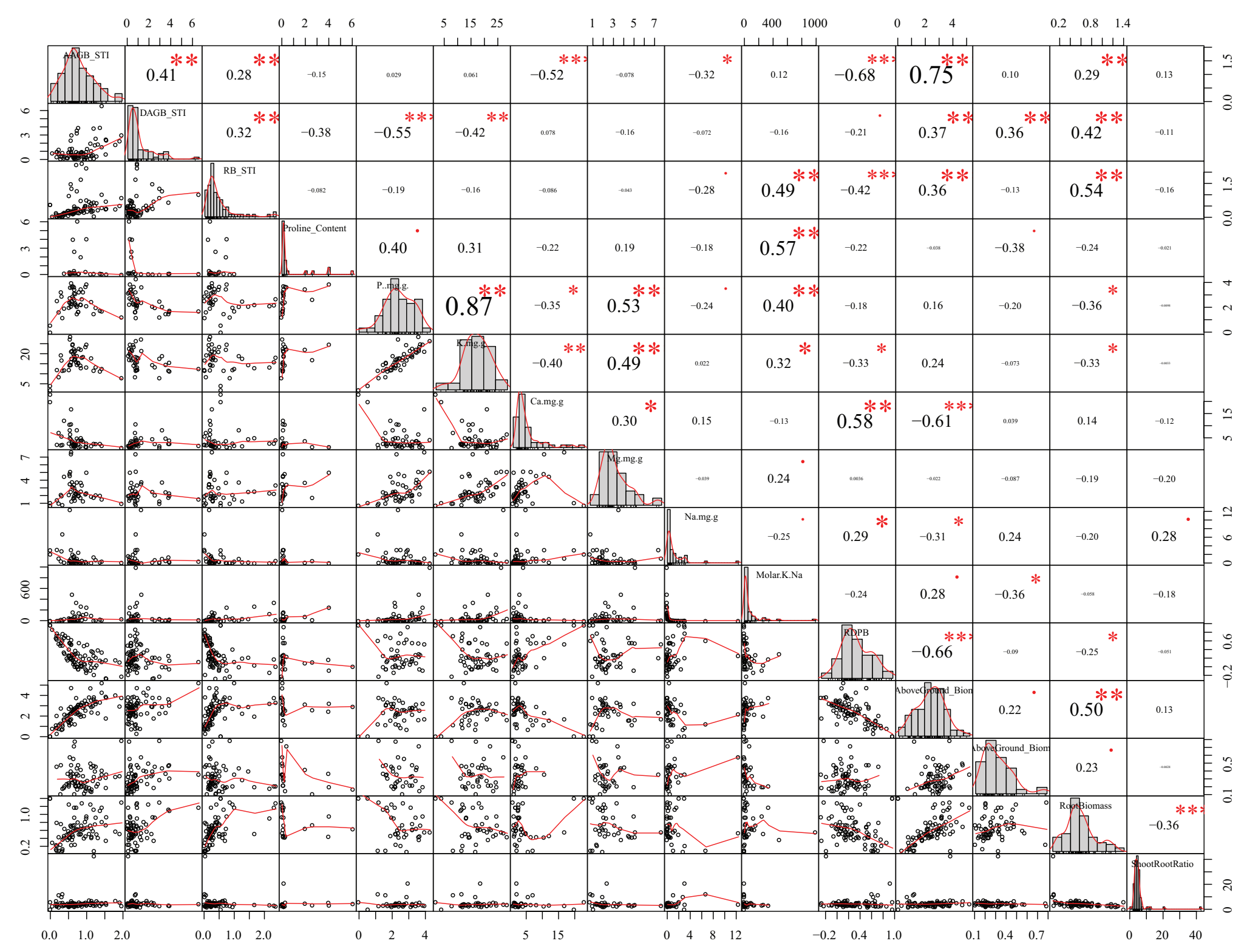


Appendix S8. Correlation between (A) $\mathrm{Na}^{+}$accumulation and RDPB (B) $\mathrm{Na}^{+}$accumulation and live aboveground biomass STI
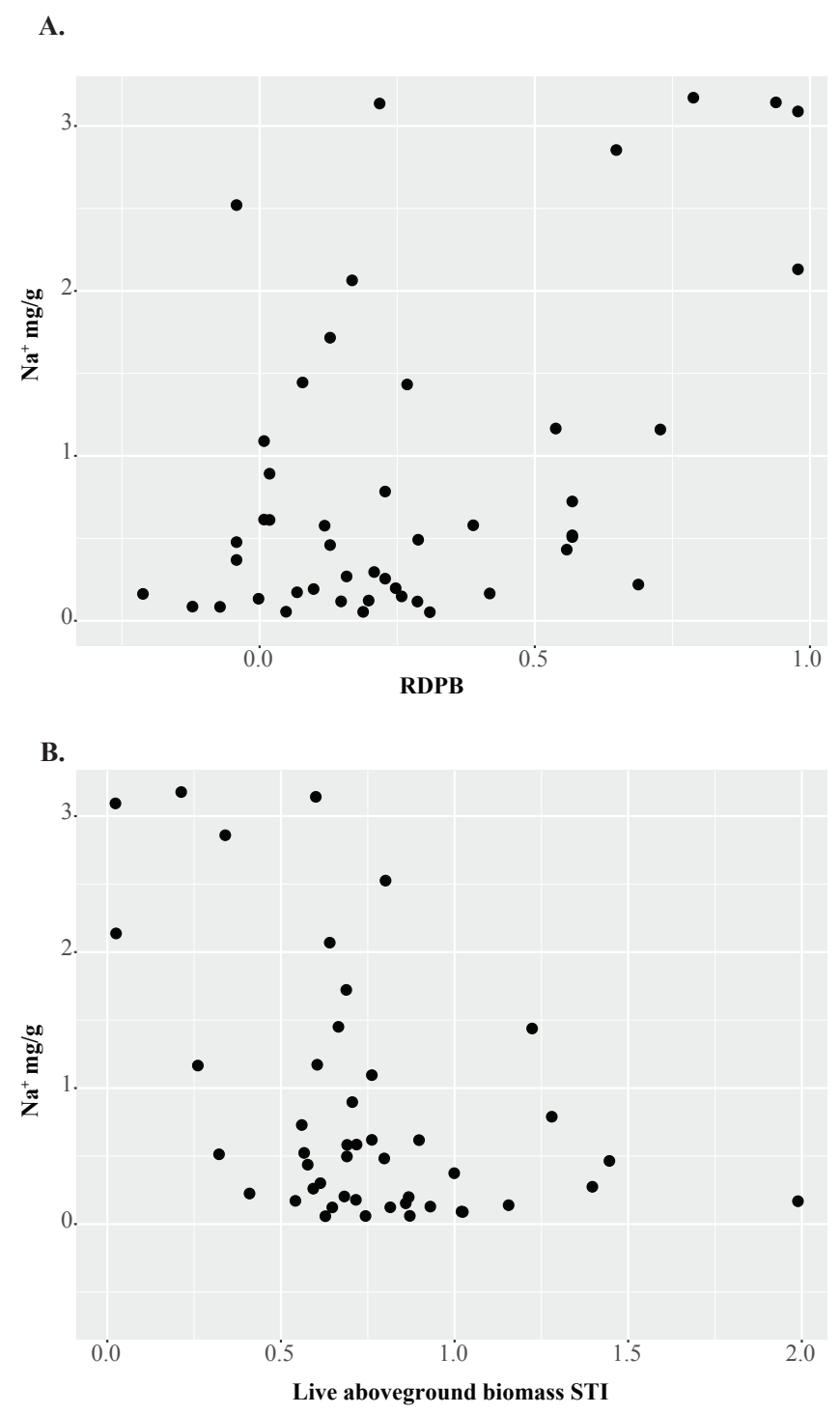
Appendix S9. A neighbor-joining tree constructed by Mace et al. (2013) using SNP data. (A) STI rank scores for live aboveground biomass overlaid on neighbor-joining tree (B) STI rank scores for dead aboveground biomass overlaid on neighbor-joining tree (C) STI rank scores for root biomass overlaid on neighbor-joining tree. Smaller STI rank scores (yellow) indicates sensitivity, whereas larger STI rank scores (red) indicates tolerance. Figure modified from Mace, E., Tai, S., Gilding, E. et al. Whole-genome sequencing reveals untapped genetic potential in Africa's indigenous cereal crop sorghum. Nat Commun 4, 2320 (2013). https://doi.org/10.1038/ncomms3320

A.

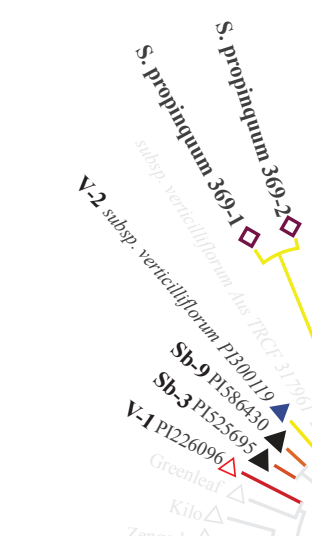

D-1 subs. drummondii $\triangle$ Sb-10 P1585749

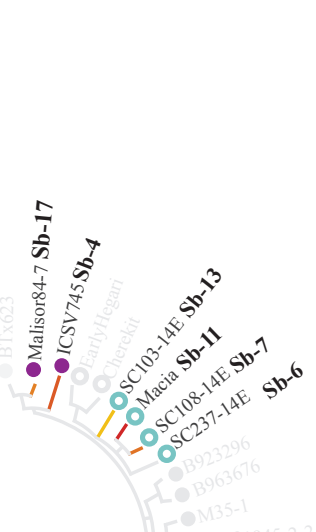

D-1 subs. drummondii $\triangle-$
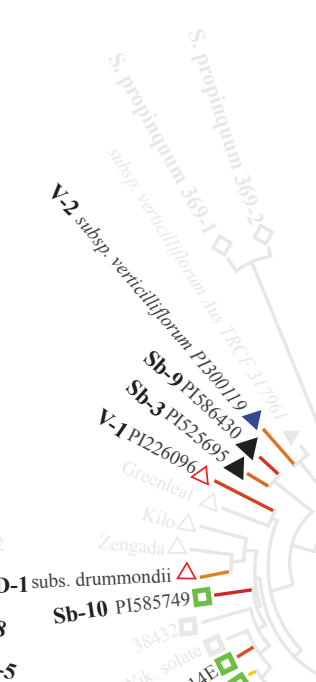
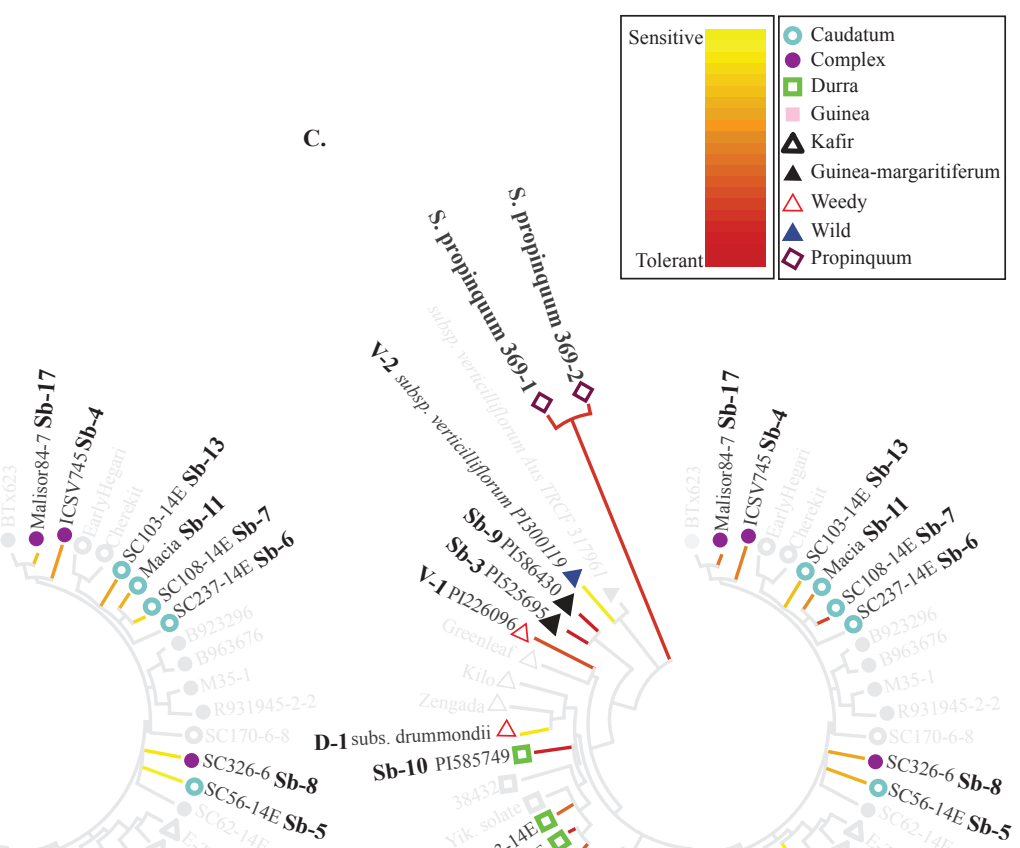
D-1 subs. drummondii $\triangle$ Pb-10

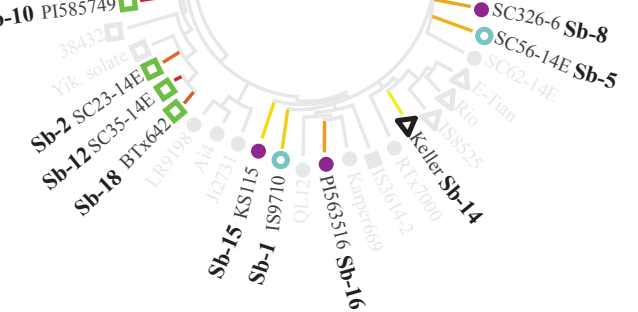




\title{
CHAPTER 4
}

\section{VARIATION IN THE EXPRESSION OF DETOXIFICATION GENES SUGGESTS THAT EARLY WATER ACQUISITION COMBINED WITH SODIUM EXCLUSION LEADS TO INCREASED SALT TOLERANCE IN SORGHUM BICOLOR}

\author{
Ashley N. Henderson; Katelyn Delaney; Jennifer S. Hawkins
}

\begin{abstract}
Soil salinity hinders plant growth, development, and function. For agriculturally and economically important crops this directly results in decreased biomass and grain yield making it difficult to increase production on marginal soils. Reductions in crop production are a result of an initial osmotic stress followed by an ionic stress, making salinity tolerance a complex polygenic trait. In this work, two accessions of Sorghum bicolor were germinated and grown in optimal conditions. Once seedlings reached the fifth leaf stage of development, seedlings were treated with $150 \mathrm{mM} \mathrm{NaCl}$ and above- and belowground tissues were collected for gene expression analysis. Three genes (SOS1, NHX2, and HKT3) that have been previously shown to play a role in salt detoxification via $\mathrm{Na}^{+}$extrusion, sequestration, and transport were assessed at eight time points. Upon the addition of non-saline water, we observed gene expression changes suggesting osmotic adjustment indicative of water acquisition in the tolerant accession. Further, in response to $150 \mathrm{mM} \mathrm{NaCl}$, we observed a delayed response in the tolerant accession indicating $\mathrm{Na}^{+}$exclusion at the root level. Taken together, our results suggest that the variation in tolerance observed between two accessions of Sorghum bicolor are a result of an initial osmotic adjustment followed by prolonged sodium exclusion and efficient extrusion, sequestration, and transport.
\end{abstract}

Keywords - Sorghum bicolor, SOS1, NHX2, HKT3, salt stress, $\mathrm{Na}^{+}$extrusion, salinity stress tolerance, vacuolar $\mathrm{Na}^{+}$sequestration, salt detoxification 


\section{Introduction}

Soil salinity is a constraint for agriculture especially in arid and semi-arid regions where environmental conditions impose stress on plants. These regions are prone to drought due to a lack of consistent rainfall and therefore require irrigation for adequate crop production. Over-irrigation, however, results in increased soil salinity due to a combination of poor water quality and insufficient drainage (Munns \& Tester, 2008; Food and Agriculture Organization (FAO), 2009; Parihar et al., 2015; Singh, 2015; Munns et al., 2019a). The resulting salt intensification impedes plant performance, both in terms of biomass accumulation and grain yield.

Reductions in plant performance on saline soils is hindered initially via osmotic stress, followed by a secondary ionic stress. Osmotic stress simulates drought-like conditions because the accumulation of salts in the soil alters the water potential. Consequently, when the soil water potential is lower than the plants osmotic potential, plants are unable to extract water and nutrients (Munns \& Tester, 2008; Negrão et al., 2017). Plants mitigate osmotic stress by accumulating and producing compatible solutes, such as amino acids, betaines, and sugars, that aid in osmotic adjustment, therefore improving the ability to take up water (Negrão et al., 2017; Turner, 2018). During water uptake, ions enter the plant through high-affinity $\mathrm{K}^{+}$transporters (HKT) and non-selective cation channels (NSCC) (Tyerman \& Skerrett, 1998; Munns \& Tester, 2008; Deinlein et al., 2014; Hanin et al., 2016), and as $\mathrm{Na}^{+}$and $\mathrm{Cl}^{-}$ions accumulate, an ion-dependent stress commences that disrupt normal metabolic function, resulting in further decreases in plant performance.

Salinity tolerance is a complex, polygenic trait that can arise from either osmotic or ionic stress resistance (Munns \& Tester, 2008; Miranda et al., 2017). Mechanistically, this resistance can be attained by continual $\mathrm{K}^{+}$uptake/transport, $\mathrm{Na}^{+}$sequestration, and/or $\mathrm{Na}^{+}$ extrusion for which several genes families are known to play key roles (Maathuis \& Amtmann, 1999; Tester \& Davenport, 2003; Rus, 2004; Munns, 2005; Davenport et al., 2007; Gao et al., 2007; Munns \& Tester, 2008; Olías et al., 2009; Leidi et al., 2010; Li et al., 2011; Barragán et al., 2012; Wang et al., 2014; Miranda et al., 2017; Baghour et al., 2019). The HKT (high affinity potassium transporter) gene family has been extensively studied and is known to increase tolerance by unloading $\mathrm{Na}^{+}$from the xylem and loading it into the phloem (Figure 1) (Maathuis \& Amtmann, 1999; Urao et al., 1999; Tester \& Davenport, 2003; Munns, 2005; Ren et al., 2005; Sunarpi et al., 2005; Tran et al., 2007). This process excludes $\mathrm{Na}^{+}$from the leaves resulting in increased ionic tolerance, while also altering the osmotic potential. At the cytoplasmic level, mechanisms to maintain low $\mathrm{Na}^{+}$include ion extrusion and sequestration. The tonoplast-localized $\mathrm{Na}^{+} / \mathrm{H}^{+}$antiporter (NHX) gene family is essential for the latter (Figure 1) (Deinlein et al., 2014).

Sequestration of $\mathrm{Na}^{+}$into vacuoles aids in both lower concentrations of toxic ions in the cytoplasm, while also contributing to osmotic adjustment (Yamaguchi et al., 2013; Ahire et al., 2018). Therefore, although accumulation of $\mathrm{Na}^{+}$is toxic to plants, if compartmentalized, it can be beneficial for osmotic adjustment resulting in increased tolerance (Ahire et al., 2018), making the NHX gene family a pivotal player in both osmotic and ionic tolerance. The salt overly sensitive (SOS) signaling pathway is a welldefined pathway, crucial for $\mathrm{Na}^{+}$extrusion and ionic homeostasis. SOS1 is a plasma 
membrane-localized $\mathrm{Na}^{+} / \mathrm{H}^{+}$antiporter (Qiu et al., 2002; Yamaguchi et al., 2013) and has been the only $\mathrm{Na}^{+} / \mathrm{H}^{+}$antiporter shown to efflux $\mathrm{Na}^{+}$from the cytoplasm of plant cells (Figure 1) (Wu et al., 2019). With three main roles, SOS1 extrudes $\mathrm{Na}^{+}$from roots into surrounding medium, reduces the accumulation within the cytoplasm, and aids in unloading of $\mathrm{Na}^{+}$from the xylem to prevent accumulation in the shoot (Shi et al., 2000, 2003; Shi, 2002; Qiu et al., 2002; Zhu, 2003; Batelli et al., 2007; Olías et al., 2009; Ji et al., 2013; Lekshmy Sathee et al., 2015; Miranda et al., 2017; Baghour et al., 2019; Wang et al., 2019).

Sorghum bicolor (L.) Moench, commonly known as sorghum, is an important African grass used for food, fuel, and fiber. Compared to other important crops such as wheat, rice, and maize, Sorghum bicolor has been shown to have increased salt (Boursier \& Läuchli, 1990; Almodares \& Sharif, 2007) and drought tolerance (Mullet et al., 2014; Fracasso et al., 2016; McCormick et al., 2018; Guo et al., 2018) making it a valuable model system to understand the molecular mechanisms associated with the variation in response to these abiotic stressors. Here, we use two accessions of Sorghum bicolor that have previously been shown to vary in response to salt exposure (Henderson et al., 2019). We focused on three key genes that play a role in ion uptake, transport (Munns, 2005; Parihar et al., 2015), and detoxification (Figure 1) (Deinlein et al., 2014). We found that the tolerant accession exhibited gene expression changes suggestive of early osmotic adjustment in response to the addition of water followed by a delay in salt specific sensing and signaling, indicating effective exclusion at the root level.

\section{Materials and Methods}

\section{Plant Material}

Two accessions of Sorghum bicolor that were previously described and ranked as salt tolerant (PI58574902SD) and salt sensitive (PI57112801SD ) (Henderson et al., 2019) were germinated and grown in a controlled growth chamber. The salt tolerant accession (PI58574902SD) is referred to as Sb-10, and the salt sensitive accession (PI57112801SD) is referred to as $\mathrm{Sb}-1$ throughout this study, in accordance with previously used shortname designation in Henderson et al (2019). All seeds were obtained from the USDAGermplasm Resources Information Network (GRIN).

\section{Experimental Design}

Fifty-four seeds of each accession (three replicates per treatment and a total of two treatments at nine time points) were germinated in $5 \mathrm{~cm} \times 5 \mathrm{~cm} \times 25 \mathrm{~cm}$ tree pots (Stuewe and Sons, Tangent, OR, USA) filled with a 1:1 mix of silica sand \#2 and \#4. Growth chamber conditions were 12 -hour days at $30.0^{\circ} \mathrm{C}$ and 12 hour nights at $25.0^{\circ} \mathrm{C}$ with $30 \%$ humidity. Plants were watered daily with non-saline tap water from sowing to the fifth leaf stage of development. Twice a week, all plants were treated with a 10-20-10 N-P-K fertilizer (Jacks water soluble fertilizer, Allentown, PA) diluted to $200 \mathrm{mg} \mathrm{N} \mathrm{L}^{-1}$. When $90 \%$ of the seedlings were at the fifth leaf stage of development, the treatment and tissue collections began. 
A destructive harvest included collection of the roots, the second leaf, and the newest fully emerged leaf, referred to as the top leaf throughout this study (either $4^{\text {th }}$ or $5^{\text {th }}$, youngest). Three biological replicates of both accessions were collected prior to treatment (time point 0 ). Half of the remaining replicates of each accession were treated with nonsaline tap water $(0 \mathrm{mM} \mathrm{NaCl})$ and the other half were treated with saline water $(150 \mathrm{mM}$ $\mathrm{NaCl}$ ). This concentration of sodium chloride was previously shown to inhibit growth and performance without causing death. Plants were watered to complete saturation. At 30 minutes post treatment, three replicates from the control group (tap water) and three replicates from the treatment group $(150 \mathrm{mM} \mathrm{NaCl})$ for each accession were collected. Additional collections were performed at 2 hours, 3 hours, 6 hours, 12 hours, 24 hours, 72 hours, and for each tissue. All samples were collected in RNAse free tubes, immediately flash frozen, and transferred to $-80^{\circ} \mathrm{C}$ to preserve RNA stability.

\section{Gene Selection}

The reference gene, PP2A (SORBI 3004G092500), was chosen as it has been shown to remain stable in various tissues under abiotic stress (Sudhakar et al., 2016). The Sorghum genome encodes a single SbSOS1 gene (Miranda et al., 2017), six members of the NHX gene family (Miranda et al., 2017), and four orthologs of the single copy HKT1 gene in Arabidopsis (Wang et al., 2014; Li et al., 2019). Therefore, the target genes, SbSOS1 (SORBI 3008G192900), SbNHX2 (SORBI 3005G201000), and SbHKT3 (SORBI 3010G251700) were selected for qPCR. Primer sequences for SbPP2A (Sudhakar et al., 2016), SbSOS1 (Miranda et al., 2017), and SbNHX2 (Miranda et al., 2017) were previously developed and published, while forward and reverse primers for SbHKT3 were newly designed and optimized in this experiment (Table S1). All primers were designed to span exon-exon junctions in order to target cDNA specifically and prevent genomic DNA amplification (Supplementary Figure S1, Supplementary Figure S2, Supplementary Figure S3, and Supplementary Figure S4).

\section{Gene Verification}

Conventional polymerase chain reaction (PCR) was used to amplify gene products from cDNA and amplicon specificity was verified by Sanger sequencing (Supplementary Table S2). PCR using genomic DNA template was performed to confirm that primers were designed to amplify cDNA only (Supplementary Figure S5). Each reaction contained 5 pmoles of $\mathrm{F}$ primer, 5 pmoles of R primer, $5 \mathrm{ng}$ of template cDNA or DNA, $1 \mathrm{X}$ of $\mathrm{Mg}$ included Taq buffer, $0.2 \mathrm{mM}$ dNTPs, and 1.25 units of Taq. Thermocycler conditions were as follows: an initial denaturation at $95^{\circ} \mathrm{C}$ for 5 minutes, followed by 25 cycles of $95^{\circ} \mathrm{C}$ for 30 seconds, $57^{\circ} \mathrm{C}$ for 30 seconds, $72^{\circ} \mathrm{C}$ for $45 \mathrm{~seconds}$, and a final extension of $72^{\circ} \mathrm{C}$ for 5 minutes. PCR products were visualized on a $1 \%$ agarose gel with a $1 \mathrm{~Kb}$ Plus DNA ladder (Invitrogen, Grand Island, NY, USA). PCR products were sephadex cleaned and directly sequenced at the West Virginia University Genomics and Bioinformatics Core Facility using the ABI 3130xL Genetic Analyzer (Thermo Fisher Scientific, Waltham, MA, USA). Sequencing results were compared with the Sorghum bicolor reference genome and transcriptome to ensure primer specificity to the specific SORBI gene of interest. 


\section{RNA Isolation and cDNA Synthesis}

RNA safe handling was enforced from tissue collection through cDNA synthesis. Tissues were ground and RNA extracted following the MagMAX ${ }^{\mathrm{TM}}$ Plant RNA Isolation Kit (Thermo Fisher Scientific, Waltham, MA, USA) protocol. Following RNA extraction, samples were quantified on the nanodrop (Thermo Scientific NanoDrop 2000 Spectrophotometer, Waltham, MA, USA) and the quality was checked on the Agilent 2100 BioAnalyzer (Agilent, Santa Clara, CA, USA). cDNA was synthesized following the SuperScript ${ }^{\mathrm{TM}}$ III First Strand Synthesis System for RT-PCR (Invitorgen Life Technologies Corporation, Carlsbad, CA, USA) protocol and quantified on the Qubit 2.0 Fluorometer (Invitrogen Life Technologies Corporation, Carlsbad, CA, USA) with Qubit $^{\mathrm{TM}}$ ssDNA assay kit reagents (Thermo Fisher Scientific, Waltham, MA, USA). Samples were diluted to $5 \mathrm{ng} / \mathrm{ul}$ for use in qRT-PCR.

$q R T-P C R$

Luna ${ }^{\mathrm{R}}$ Universal qPCR Master Mix (New England Biolabs, Ipswich, MA, USA), which uses $\mathrm{SYBR}^{\mathrm{R}} / \mathrm{FAM}$ fluorescence, was used to quantify transcript levels of mRNA. qPCR was performed on an iQ5 Real-Time PCR thermocycler (Bio-Rad, Hercules, CA, USA) where each reaction had $1 \mathrm{X}$ of $\mathrm{Luna}^{\mathrm{R}}$ Universal qPCR Mastermix, 5 pmoles of F primer, 5 pmoles of R primer, and $5 \mathrm{ng}$ of template cDNA. Thermocycler conditions were as follows: an initial denaturation at $95^{\circ} \mathrm{C}$ for $1 \mathrm{~min}$, followed by 40 cycles of $95^{\circ} \mathrm{C}$ for 15 seconds, $55^{\circ} \mathrm{C}$ for 15 seconds, and $60^{\circ} \mathrm{C}$ for 15 seconds, and a final extension of $95^{\circ} \mathrm{C}$ for 10 seconds. Primer specificity was verified by melt curve analysis where temperatures ranged from $65^{\circ} \mathrm{C}$ to $95^{\circ} \mathrm{C}$ with $0.5^{\circ} \mathrm{C}$ increments for 5 seconds, and at the end of each temperature increment, the fluorescence of the plate was read. All biological replicates were performed in triplicate.

\section{Fold Change}

Relative expression was more appropriate than absolute quantification for our study given that we were interested in comparing the variation in two accessions that differ in long term salt tolerance rather than exact copy numbers of gene transcripts (Livak \& Schmittgen, 2001). Gene expression levels were analyzed using the $2^{-\Delta \Delta C \mathrm{CT}}$ method (Livak $\&$ Schmittgen, 2001). Relative expression values for SbSOS1, SbNHX2, and SbHKT3 genes were normalized with SbPP2A (internal control), and by using an untreated control as the calibrator. Ct values for technical replicates were averaged when the standard deviation was less than 0.25 .

\section{Statistical Analysis}

Relative expression was analyzed by a balanced two-way analysis of variance (ANOVA, significance assessed at $\mathrm{p}<0.05$ ), with accession and time point as factors and fold change as the response variable. If a significant difference was found, means were compared using Tukey's HSD test. Each gene of interest and tissue were independently assessed. Graphs were plotted in RStudio (ver.1.2.5019) (R Core Team, 2013) with the ggplot2 package (Wickham, 2016). 


\section{Results}

Plant response to the addition of non-saline water

Plant response to the addition of non-saline water was tested by comparing gene expression at 0 minutes (pre-watering) to gene expression at 30 minutes (30 minutes after the addition of tap water). With the addition of non-saline water, we observed gene expression changes in both above- and belowground tissues suggesting greater uptake and transport of ions, indicative of osmotic adjustment. For example, in the roots, both accessions displayed decreased SbSOS1 expression; however, Sb-10 also experienced an increase in SbNHX2 expression, indicating greater osmotic potential in the tolerant accession (Figure 2a). Simultaneously, in the aboveground portion of the plants, we observed changes in expression of the $\mathrm{Na}^{+}$transporter, SbHKT3. SbHKT3 is upregulated two- to four-fold in the second leaf of Sb-10, while it is downregulated approximately one- to two-fold in Sb-1, further supporting the results observed for roots, that there is increased transport in the tolerant accession (Figure 2b). In the top leaf, we observe an increase in expression of SbHKT3 in response to water for both accessions with a greater increase in expression in Sb-10 (Figure 2c). In addition, we observed increased expression of SbSOS1 and SbNHX2 in the top leaf, indicating increased extrusion and sequestration.

\section{Plant response to the addition of $\mathrm{NaCl}$}

Two hours after salt exposure, we observed 1) a significant decrease in SbNHX2 expression in the root tips of Sb-10 (Figure 3f), 2) decreases in SbSOS1 expression in the second leaf of both accessions (Figure 3e), and 3) decreases in SbHKT3 expression in the second leaf of both accessions (Figure 3e). For the tolerant accession (Sb-10), these trends suggest exclusion of $\mathrm{Na}^{+}$at the root level. For the sensitive accession (Sb-1), however, we observe almost a one and a half fold increase in SbSOS1 expression in the top leaf at this same time point (Figure 3d), and approximately a two-fold increase in SbSOS1 expression in the root tips at 30 minutes after exposure (Figure 3c). Increased expression levels of SbSOS1 at 30 minutes and two hours post salt exposure indicates the presence on $\mathrm{Na}^{+}$ions.

Expression of SbSOS1 in the tolerant accession is stable until 3 hours post exposure, at which point SbSOS1 is significantly downregulated in the root tips, indicating the first salt specific response (Figure 3i). At this same time point, in the same tissue, we observe an increase in SbNHX2 expression for both accessions (Figure 3i) suggesting increased sequestration. With the increase in SbNHX2 expression and decrease in SbSOS1 expression, this suggests both the presence of ions and preferential sequestration of ions, a mechanism that would aid in osmotic adjustment. We also observe increased extrusion in the tolerant accession compared to the sensitive accession in the second leaf. At 6 hours, however, we observe increased extrusion in both accessions, suggesting the removal of salts from the aboveground portion of the plant (Figure 3j,k). Interestingly, following the significant increase in SbSOS1 expression in the second leaf at 6 hours, we observe decreases in SbSOS1 expression for both accessions (Figure 4a,b) and increases in SbHKT3 expression (Figure 4b). These results suggest that both accessions are attempting to transport ions belowground where they can be extruded into the soil 
medium or sequestered into vacuoles. This is further supported by the significant increase in SbSOS1 and SbNHX2 expression, respectively, in the root tips at 72 hours (Figure 4i).

\section{Discussion}

It is well-known that salinity tolerance is associated with increased $\mathrm{Na}^{+}$exclusion and/or sequestration (Munns \& Tester, 2008; Munns \& Gilliham, 2015; Munns et al., 2016). While sequestration simply involves compartmentalization of excess sodium into vacuoles, $\mathrm{Na}^{+}$exclusion can be achieved by four main mechanisms, including 1) reduction in $\mathrm{Na}^{+}$uptake by the roots, 2) reduction in $\mathrm{Na}^{+}$loading in the xylem, 3) increased $\mathrm{Na}^{+}$extrusion, and 4) increased $\mathrm{Na}^{+}$retrieval from the shoot (Wu et al., 2019). Each of these mechanisms results in the exclusion of $\mathrm{Na}^{+}$from the aboveground tissues. In this study, we delineate the variation in the onset of $\mathrm{Na}^{+}$sensing and signaling in two accessions of $S$. bicolor that were previously shown to differ in long-term response to salinity stress, as indicated by expression variation of key detoxification genes.

Upon the addition of non-saline water, we observed variation in SbSOS1 and SbNHX2 expression in roots. SbSOS1, which codes for a plasma membrane-localized $\mathrm{Na}^{+} / \mathrm{H}^{+}$ antiporter, displayed a greater than two-fold decrease in expression in both the tolerant and sensitive accessions (Figure 2). At the same time and in the same tissue, we observed an increased expression of SbNHX2, which codes for a tonoplast-localized $\mathrm{Na}^{+} / \mathrm{H}^{+}$ antiporter, in the tolerant accession (Sb-10). With decreased extrusion (SbSOS1) and increased sequestration (SbNHX2), the osmotic potential within the plant would increase, assisting in the uptake of water by the roots. Interestingly, previous studies in barley have found higher correlations of tolerance with $\mathrm{Na}^{+}$sequestration rather than extrusion (Wu et $a l ., 2019)$. Therefore, this initial sequestration mechanism identified in the tolerant accession may be responsible for some of the long-term tolerance observed (Henderson et $a l ., 2019)$. Further, we observed variation in SbHKT3 expression in the second and top leaf (Figure 2b,c). Specifically, SbHKT3 expression was downregulated in the second leaf of the sensitive accession ( $\mathrm{Sb}-1$ ) while expression was upregulated in the tolerant accession (Sb-10) (Figure 2b). Lower levels of expression suggest decreased transport and uptake of ions, which would result in decreased water absorption. Therefore, the increased expression observed in Sb-10 in both tissues (second leaf and top leaf) suggests the initiation of aboveground processes that alter the osmotic potential and promote the transport of water and nutrients. Together, these results indicate that the tolerant accession experiences the onset of osmotic adjustment at an earlier time point and in multiple above- and belowground tissues, even in the absence of excess $\mathrm{Na}^{+}$, promoting efficient uptake and transport water.

After 30 minutes of $\mathrm{NaCl}$ exposure, $\mathrm{SbSOS} 1$ expression in the roots of the sensitive accession increased, as would be expected in response to cytoplasmic sensing of salt (Olías et al., 2009). This result aligns with previous findings demonstrating that sensitive accessions are generally poor excluders of $\mathrm{Na}^{+}$and therefore experience an earlier onset of ionic stress. The delayed onset of SbSOS1 expression in Sb-10 until 3 hours post exposure suggests that the tolerant accession may be better at controlling $\mathrm{Na}^{+}$uptake and exclusion (Figure 3i). 
At 3 hours post-exposure, there is a shift in SbSOS1 and SbNHX2 expression in the roots, with SbSOS1 downregulated and SbNHX2 upregulated in both the tolerant and sensitive accessions (Figure 3i). This suggests that, in roots, ions are being sequestered into vacuoles, a process that acts as a cheap compatible solute that will aid in increased water uptake from the soil (Wu et al., 2019; Munns et al., 2019b). In contrast, significant differences between the tolerant and sensitive accession were observed in aboveground tissues at 3 hours post-exposure. For example, the tolerant accession shows increased levels of SbSOS1 expression, indicative of increased extrusion, in the second leaf, while $\mathrm{Sb}-1$ experiences lower levels in expression at this time point. We also observed evidence for decreased transport in the top leaf for Sb-1 and increased extrusion in the top leaf for both accessions (Figure 3g). This indicates that, in aboveground tissues, the sensitive accession is less effective at transporting or extruding sodium ions, which may result in toxic $\mathrm{Na}^{+}$accumulation in the cytosol.

SbSOS1 encodes a plasma membrane transporter that extrudes $\mathrm{Na}^{+}$from the cytoplasm to the apoplast and aids in loading $\mathrm{Na}^{+}$into the phloem to be exported to root tissue where it can be stored or effluxed (Munns, 2005; Sunarpi et al., 2005; Munns \& Tester, 2008; Lekshmy Sathee et al., 2015). At 6 hours post-exposure in leaves, SbSOS1 expression in the tolerant accession is upregulated approximately two-fold, indicating increased extrusion, possibly due to excess cytoplasmic $\mathrm{Na}^{+}$content (Figure 3k). $\mathrm{Na}^{+}$accumulation is less harmful to belowground tissues compared to aboveground tissues because as ions become deposited into the aerial part of the plant following water loss during transpiration, vital metabolic processes such as photosynthesis are disrupted (Morton et $a l ., 2019)$. When water is lost through transpiration and salts are left behind, normal metabolic processes are disrupted. Therefore, it is reasonable to assume that extrusion of ions and loading of ions into the phloem is an effective mechanism of tolerance compared to aboveground compartmentalization. Interestingly, SbHKT3 expression remains down regulated in leaves until 12 hours post-exposure, when it becomes significantly upregulated (Figure 4b). This increase in transport is likely a downstream response to the increase in extrusion observed at 6 hours (increased SbSOS1 expression, Figure 3k).

At 72 hours, there was an increase in both SbSOS1 and SbNHX2 expression in the roots of both accessions, with the sensitive accession exhibiting greater transcript abundance. This suggests that, by this point after exposure, plants are overloaded with $\mathrm{Na}^{+}$ions (ion dependent phase) and are attempting to both compartmentalize and extrude in order to avoid ionic disruption in the cytoplasm. The higher levels of transcript abundance in the sensitive accession (Sb-1) is likely a result of poor exclusion, extrusion, and sequestration (Wu et al., 2019).

Finally, the top leaf of the sensitive accession experiences earlier increases in SbSOS1 expression relative to the tolerant accession, suggesting greater amounts of $\mathrm{Na}^{+}$ accumulation in the aboveground portions of the plant. Since SbSOS1 is specifically upregulated by salt stress and no other osmotic stressors such as drought, cold, or abscisic acid (Shi et al., 2000; Shi, 2002; Wu et al., 2019), this finding provides strong support for the presence of $\mathrm{Na}^{+}$in leaf tissues of the sensitive accession. With $\mathrm{Na}^{+}$ions present in the newest emerging leaves; normal metabolic processes would be disrupted, and new growth 
would be limited. This finding is in accordance with previously reported results (Henderson et al., 2019) where Sb-1 was limited in new growth over long term sodium exposure.

\section{Conclusions}

In the work presented here, we find early onset of sensing and signaling after salt exposure in a salt-sensitive accession (Sb-1) of $S$. bicolor. We also observe numerous changes in gene expression throughout the time course for the sensitive accession, which suggests that salt sensitivity in sorghum is a product of 1) the inability to exclude ions 2) the existence of biological chaos resulting in an unorganized response, and/or 3) a leaky tonoplast, therefore requiring increased effort to maintain ion sequestration in vacuoles (Wu et al., 2019; Munns et al., 2019b). Together, these processes are related to the availability of energy, and therefore provide an explanation for the decreased biomass production observed for Sb-1 in our previous study (Henderson et al., 2019). We propose that the tolerant accession has higher tissue tolerance and is better at controlling uptake, exclusion, extrusion, and sequestration. With better control over these transport systems, fewer resources are diverted to the stress response, providing more available energy that can be utilized for new growth and development.

\section{Acknowledgements}

The authors wish to thank the WVU Genomics and Bioinformatics Core Facility (Ryan Percifield) for their assistance during data collection. We acknowledge Dr. Victoria Verhoeve and Dr. Timothy Driscoll for guidance in data analysis, the U.S. National Plant Germplasm System for supplying seed, and the West Virginia University Life Sciences Greenhouse for supplying space. This work was partially funded by the Eberly College of Arts and Sciences research award and the Biology Graduate Student Association graduate student research award, both awarded to Ashley N. Henderson. 


\section{Literature Cited}

Ahire ML, Anil Kumar S, Punita DL, Mundada PS, Kavi Kishor PB, Nikam TD. 2018. The vacuolar proton pyrophosphatase gene (SbVPPase) from the Sorghum bicolor confers salt tolerance in transgenic Brahmi [Bacopa monnieri (L.) Pennell]. Physiology and Molecular Biology of Plants 24: 809-819.

Almodares A, Sharif ME. 2007. Effects of irrigation water qualities on biomass and sugar contents of sugar beet and sweet sorghum cultivars.

Baghour M, Gálvez FJ, Sánchez ME, Aranda MN, Venema K, Rodríguez-Rosales MP. 2019. Overexpression of LeNHX2 and SISOS2 increases salt tolerance and fruit production in double transgenic tomato plants. Plant Physiology and Biochemistry 135: 77-86.

Barragán V, Leidi EO, Andrés Z, Rubio L, Luca AD, Fernández JA, Cubero B, Pardo JM. 2012. Ion exchangers NHX1 and NHX2 mediate active potassium uptake into vacuoles to regulate cell turgor and stomatal function in arabidopsis. The Plant Cell.

Batelli G, Verslues PE, Agius F, Qiu Q, Fujii H, Pan S, Schumaker KS, Grillo S, Zhu J-K. 2007. SOS2 promotes salt tolerance in part by interacting with the vacuolar $\mathrm{H}^{+}$ATPase and upregulating its transport activity. Molecular and Cellular Biology 27: 77817790.

Boursier P, Läuchli A. 1990. Growth responses and mineral nutrient relations of saltstressed Sorghum. Crop Science 30: 1226-1233.

Davenport RJ, Muñoz-Mayor A, Jha D, Essah PA, Rus A, Tester M. 2007. The $\mathrm{Na}^{+}$ transporter AtHKT1;1 controls retrieval of $\mathrm{Na}^{+}$from the xylem in Arabidopsis. Plant, Cell \& Environment 30: 497-507.

Deinlein U, Stephan AB, Horie T, Luo W, Xu G, Schroeder JI. 2014. Plant salttolerance mechanisms. Trends in Plant Science 19: 371-379.

Food and Agriculture Organization (FAO). 2009. Land and plant nutrition management service.

Fracasso A, Trindade L, Amaducci S. 2016. Drought tolerance strategies highlighted by two Sorghum bicolor races in a dry-down experiment. Journal of Plant Physiology 190: $1-14$.

Gao J-P, Chao D-Y, Lin H-X. 2007. Understanding abiotic stress tolerance mechanisms: Recent studies on stress response in rice. Journal of Integrative Plant Biology 49: 742-750.

Guo YY, Tian SS, Liu SS, Wang WQ, Sui N. 2018. Energy dissipation and antioxidant enzyme system protect photosystem II of sweet sorghum under drought stress.

Photosynthetica 56: 861-872. 
Hanin M, Ebel C, Ngom M, Laplaze L, Masmoudi K. 2016. New insights on plant salt tolerance mechanisms and their potential use for breeding. Frontiers in Plant Science 7.

Henderson AN, Crim PM, Cumming JR, Hawkins JS. 2019. Phenotypic and physiological responses to salt exposure in Sorghum reveal diversity among domesticated landraces. bioRxiv: 848028 .

Ji H, Pardo JM, Batelli G, Van Oosten MJ, Bressan RA, Li X. 2013. The salt overly sensitive (SOS) pathway: Established and emerging roles. Molecular Plant 6: 275-286.

Leidi EO, Barragán V, Rubio L, El-Hamdaoui A, Ruiz MT, Cubero B, Fernández JA, Bressan RA, Hasegawa PM, Quintero FJ, et al.2010. The AtNHX1 exchanger mediates potassium compartmentation in vacuoles of transgenic tomato. The Plant Journal 61: 495-506.

Lekshmy Sathee, Sairam RK, Chinnusamy V, Jha SK. 2015. Differential transcript abundance of salt overly sensitive (SOS) pathway genes is a determinant of salinity stress tolerance of wheat. Acta Physiologiae Plantarum 37.

Li W, Wang D, Jin T, Chang Q, Yin D, Xu S, Liu B, Liu L. 2011. The vacuolar $\mathrm{Na}^{+} / \mathrm{H}^{+}$antiporter gene SsNHX1 from the halophyte Salsola soda confers salt tolerance in transgenic alfalfa (Medicago sativa L.). Plant Molecular Biology Reporter 29: 278-290.

Li H, Xu G, Yang C, Yang L, Liang Z. 2019. Genome-wide identification and expression analysis of HKT transcription factor under salt stress in nine plant species. Ecotoxicology and Environmental Safety 171: 435-442.

Livak KJ, Schmittgen TD. 2001. Analysis of relative gene expression data using realtime quantitative PCR and the $2^{-\Delta \Delta C T}$ method. Methods 25: 402-408.

Maathuis FJM, Amtmann A. 1999. $\mathrm{K}^{+}$Nutrition and $\mathrm{Na}^{+}$toxicity: The basis of cellular $\mathrm{K}^{+} / \mathrm{Na}^{+}$ratios. Annals of Botany 84: 123-133.

McCormick RF, Truong SK, Sreedasyam A, Jenkins J, Shu S, Sims D, Kennedy M, Amirebrahimi M, Weers BD, McKinley B, et al.2018. The Sorghum bicolor reference genome: improved assembly, gene annotations, a transcriptome atlas, and signatures of genome organization. The Plant Journal 93: 338-354.

Miranda R de S, Mesquita RO, Costa JH, Alvarez-Pizarro JC, Prisco JT, GomesFilho E. 2017. Integrative control between proton pumps and SOS1 antiporters in roots is crucial for maintaining low $\mathrm{Na}^{+}$accumulation and salt tolerance in ammonium-supplied Sorghum bicolor. Plant and Cell Physiology 58: 522-536.

Morton MJL, Awlia M, Al-Tamimi N, Saade S, Pailles Y, Negrão S, Tester M. 2019. Salt stress under the scalpel - dissecting the genetics of salt tolerance. The Plant Journal 97: $148-163$.

Mullet J, Morishige D, McCormick R, Truong S, Hilley J, McKinley B, Anderson R, 
Olson SN, Rooney W. 2014. Energy Sorghum--a genetic model for the design of C4 grass bioenergy crops. Journal of Experimental Botany 65: 3479-3489.

Munns R. 2005. Genes and salt tolerance: bringing them together. New Phytologist 167: 645-663.

Munns R, Day DA, Fricke W, Watt M, Arsova B, Barkla BJ, Bose J, Byrt CS, Chen Z, Foster KJ, et al.2019a. Energy costs of salt tolerance in crop plants. New Phytologist.

Munns R, Gilliham M. 2015. Salinity tolerance of crops - what is the cost? New Phytologist 208: 668-673.

Munns R, James RA, Gilliham M, Flowers TJ, Colmer TD. 2016. Tissue tolerance: an essential but elusive trait for salt-tolerant crops. Functional Plant Biology 43: 1103.

Munns R, Passioura JB, Colmer TD, Byrt CS. 2019b. Osmotic adjustment and energy limitations to plant growth in saline soil. New Phytologist.

Munns R, Tester M. 2008. Mechanisms of salinity tolerance. Annual Review of Plant Biology 59: 651-681.

Negrão S, Schmöckel SM, Tester M. 2017. Evaluating physiological responses of plants to salinity stress. Annals of Botany 119: 1-11.

Olías R, Eljakaoui Z, Li J, Morales PAD, Marín-Manzano MC, Pardo JM, Belver A. 2009. The plasma membrane $\mathrm{Na}^{+} / \mathrm{H}^{+}$antiporter SOS1 is essential for salt tolerance in tomato and affects the partitioning of $\mathrm{Na}+$ between plant organs. Plant, Cell \& Environment 32: 904-916.

Parihar P, Singh S, Singh R, Singh VP, Prasad SM. 2015. Effect of salinity stress on plants and its tolerance strategies: a review. Environmental Science and Pollution Research 22: 4056-4075.

Qiu Q-S, Guo Y, Dietrich MA, Schumaker KS, Zhu J-K. 2002. Regulation of SOS1, a plasma membrane $\mathrm{Na}^{+} / \mathrm{H}^{+}$exchanger in Arabidopsis thaliana, by SOS2 and SOS3 . Proceedings of the National Academy of Sciences 99: 8436-8441.

R Core Team. 2013. R: A language and enviornment for satistical computing. Vienna, Austria: R Foundation for Statistical Computing.

Ren Z-H, Gao J-P, Li L-G, Cai X-L, Huang W, Chao D-Y, Zhu M-Z, Wang Z-Y, Luan S, Lin H-X. 2005. A rice quantitative trait locus for salt tolerance encodes a sodium transporter. Nature Genetics 37: 1141-1146.

Rus A. 2004. AtHKT1 facilitates $\mathrm{Na}^{+}$homeostasis and $\mathrm{K}^{+}$nutrition in planta. Plant Physiology 136: 2500-2511.

Shi H. 2002. The putative plasma membrane $\mathrm{Na}^{+} / \mathrm{H}^{+}$antiporter SOS1 controls long- 
distance $\mathrm{Na}^{+}$transport in plants. The Plant Cell Online 14: 465-477.

Shi H, Ishitani M, Kim C, Zhu J-K. 2000. The Arabidopsis thaliana salt tolerance gene SOS 1 encodes a putative $\mathrm{Na}^{+} / \mathrm{H}^{+}$antiporter. Proceedings of the National Academy of Sciences 97: 6896-6901.

Shi H, Lee B, Wu S-J, Zhu J-K. 2003. Overexpression of a plasma membrane $\mathrm{Na}^{+} / \mathrm{H}^{+}$ antiporter gene improves salt tolerance in Arabidopsis thaliana. Nature Biotechnology 21: $81-85$.

Singh A. 2015. Soil salinization and waterlogging: A threat to environment and agricultural sustainability. Ecological Indicators 57: 128-130.

Sudhakar PR, Srinivas DR, Sivasakthi K, Bhatnagar-Mathur P, Vadez V, Sharma KK. 2016. Evaluation of Sorghum [Sorghum bicolor (L.)] reference genes in various tissues and under abiotic stress conditions for quantitative real-time PCR data normalization. Frontiers in Plant Science 7: 529-529.

Sunarpi, Horie T, Motoda J, Kubo M, Yang H, Yoda K, Horie R, Chan W-Y, Leung H-Y, Hattori K, et al.2005. Enhanced salt tolerance mediated by AtHKT1 transporterinduced $\mathrm{Na}^{+}$unloading from xylem vessels to xylem parenchyma cells. The Plant Journal 44: $928-938$.

Tester M, Davenport R. 2003. $\mathrm{Na}^{+}$tolerance and $\mathrm{Na}^{+}$transport in higher plants. Annals of Botany 91: 503-527.

Tran L-SP, Urao T, Qin F, Maruyama K, Kakimoto T, Shinozaki K, YamaguchiShinozaki K. 2007. Functional analysis of AHK1/ATHK1 and cytokinin receptor histidine kinases in response to abscisic acid, drought, and salt stress in Arabidopsis. Proceedings of the National Academy of Sciences 104: 20623-20628.

Turner NC. 2018. Turgor maintenance by osmotic adjustment: 40 years of progress. Journal of Experimental Botany 69: 3223-3233.

Tyerman SD, Skerrett IM. 1998. Root ion channels and salinity. Scientia Horticulturae 78: $175-235$.

Urao T, Yakubov B, Satoh R, Yamaguchi-Shinozaki K, Seki M, Hirayama T, Shinozaki K. 1999. A transmembrane hybrid-type histidine kinase in Arabidopsis functions as an Osmosensor. The Plant Cell 11: 1743-1754.

Wang T-T, Ren Z-J, Liu Z-Q, Feng X, Guo R-Q, Li B-G, Li L-G, Jing H-C. 2014. SbHKT1;4, a member of the high-affinity potassium transporter gene family from Sorghum bicolor, functions to maintain optimal $\mathrm{Na}^{+} / \mathrm{K}^{+}$balance under $\mathrm{Na}^{+}$stress. Journal of Integrative Plant Biology 56: 315-332.

Wang J, Xu X, Ma D. 2019. Establishment of an efficient alfalfa regeneration system via organogenesis and the co-expression of Arabidopsis SOS genes improves salt tolerance in 
transgenic alfalfa ( Medicago sativa L.) (C Willenborg, Ed.). Canadian Journal of Plant Science 99: 348-363.

Wickham H. 2016. ggplot2: Elegant Graphics for Data Analysis. Verlag, New York: R Foundation for Statistical Computing.

Wu H, Shabala L, Zhou M, Su N, Wu Q, Ul-Haq T, Zhu J, Mancuso S, Azzarello E, Shabala S. 2019. Root vacuolar $\mathrm{Na}^{+}$sequestration but not exclusion from uptake correlates with barley salt tolerance. The Plant Journal: 1-13.

Yamaguchi T, Hamamoto S, Uozumi N. 2013. Sodium transport system in plant cells. Frontiers in Plant Science $\mathbf{4}$.

Zhu J-K. 2003. Regulation of ion homeostasis under salt stress. Current Opinion in Plant Biology 6: 441-445. 


\section{FIGURES}

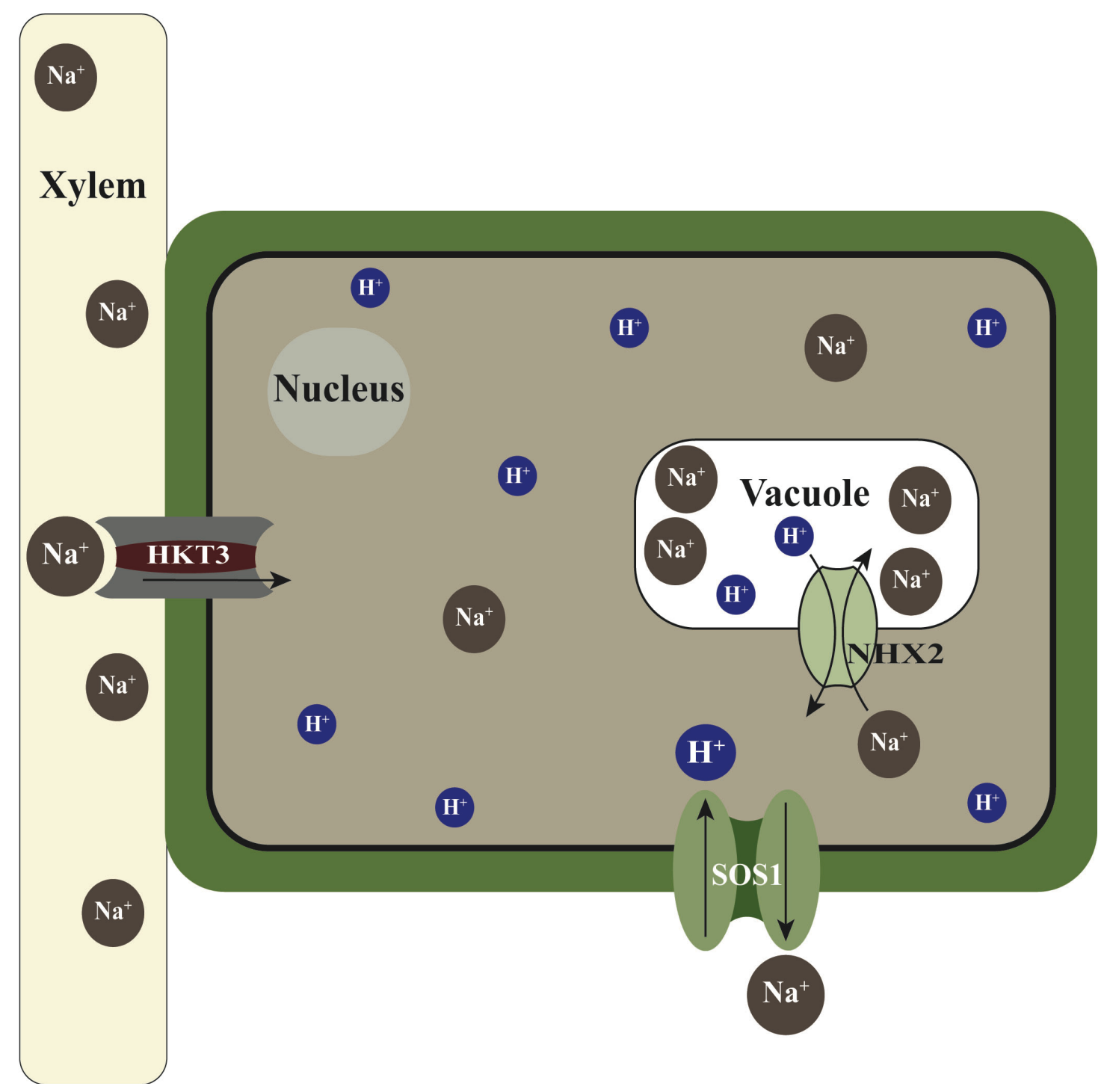

Figure 1. Overview of SOS1, NHX2, and SbHKT3 genes and their role in sodium detoxification. SOS1, a plasma membrane-localized $\mathrm{Na}^{+} / \mathrm{H}^{+}$antiporter, extrudes $\mathrm{Na}^{+}$ from the cytoplasm of above- and belowground plant cells. NHX2, tonoplast-localized $\mathrm{Na}^{+} / \mathrm{H}^{+}$antiporter, compartmentalizes $\mathrm{Na}^{+}$into the vacuoles of plant cells to maintain ion homeostasis in the cytoplasm of above- and belowground plant cells. SbHKT3 is a high affinity $\mathrm{K}^{+}$and $\mathrm{Na}^{+}$transporter that aids in uptake and unloading of $\mathrm{Na}^{+}$from the xylem. SbHKT3 is expressed only in aboveground plant cells. 


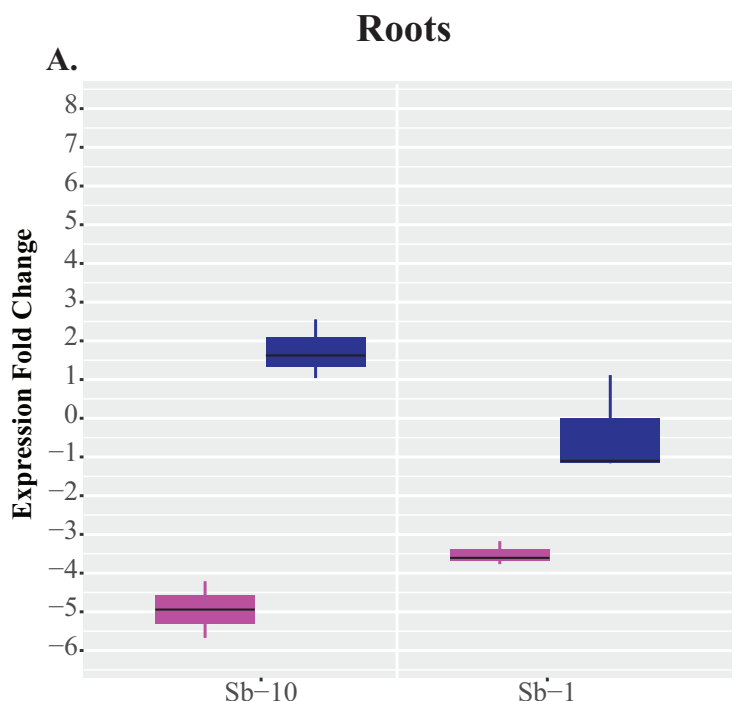

$\mathrm{Sb}^{-}-10$
B.

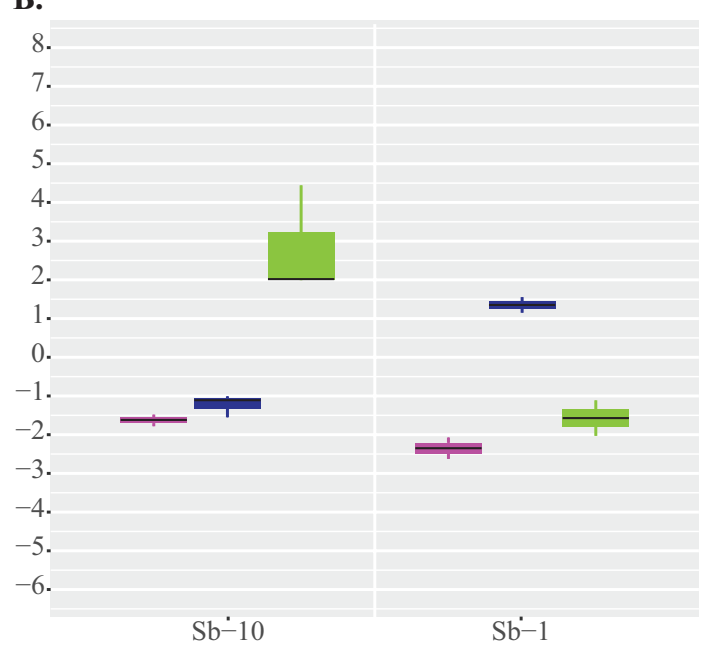

Accession
C.

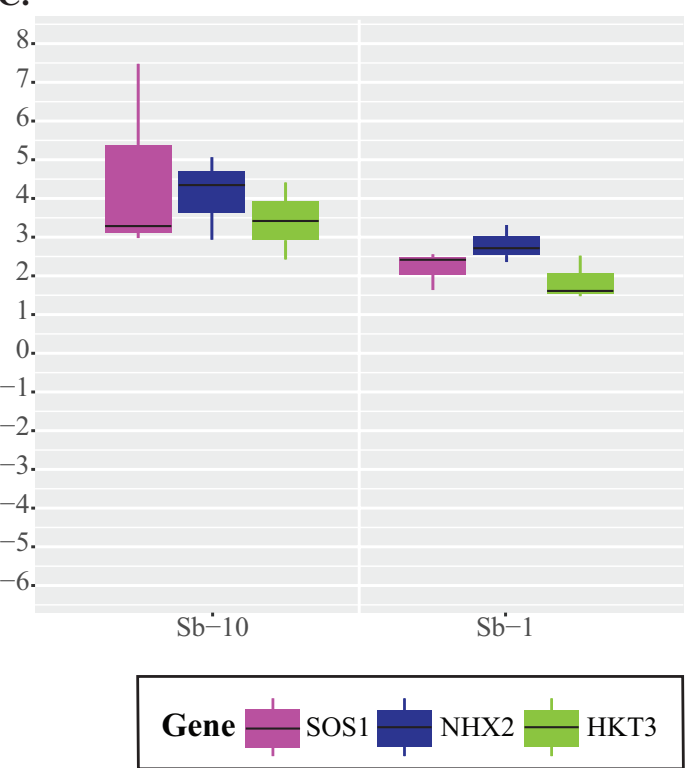

Figure 2. Gene expression changes for SbSOS1, SbNHX2, and SbHKT3 after the addition of non-saline water. Plants were watered with non-saline at the $5^{\text {th }}$ or $6^{\text {th }}$ leaf stage of development and relative expression of SbSOS1, SbNHX2, and SbHKT3 were calculated in the root tips, $2^{\text {nd }}$ leaf, and top leaf 30 minutes after the addition of water. Boxplots display the interquartile range, with the black line representing the median. Whiskers represent the largest and smallest value within 1.5 times the interquartile range above and below the 75th and 25th percentile. No outliers were detected. (A) Expression fold change of SbSOS1 and SbNHX2 in the roots after the addition of H20. Both accessions experienced a decrease in SbSOS1 expression, however SbNHX2

expression increased in Sb-10. (B) Expression fold change of SbSOS1, SbNHX2, and SbHKT3 in the 2nd leaf after the addition of H20. SbSOS1 decreased for both accessions, while SbNHX2 decreased for Sb-10 and increased for Sb-1, and SbHKT3 increased for Sb-10. (C) Expression fold change of SbSOS1, SbNHX2, and SbHKT3 in the top leaf after the addition of H20. SbSOS1, SbNHX2, and SbHKT3 increased for both accessions with a greater increase in Sb-10 after the addition of non-saline water. 


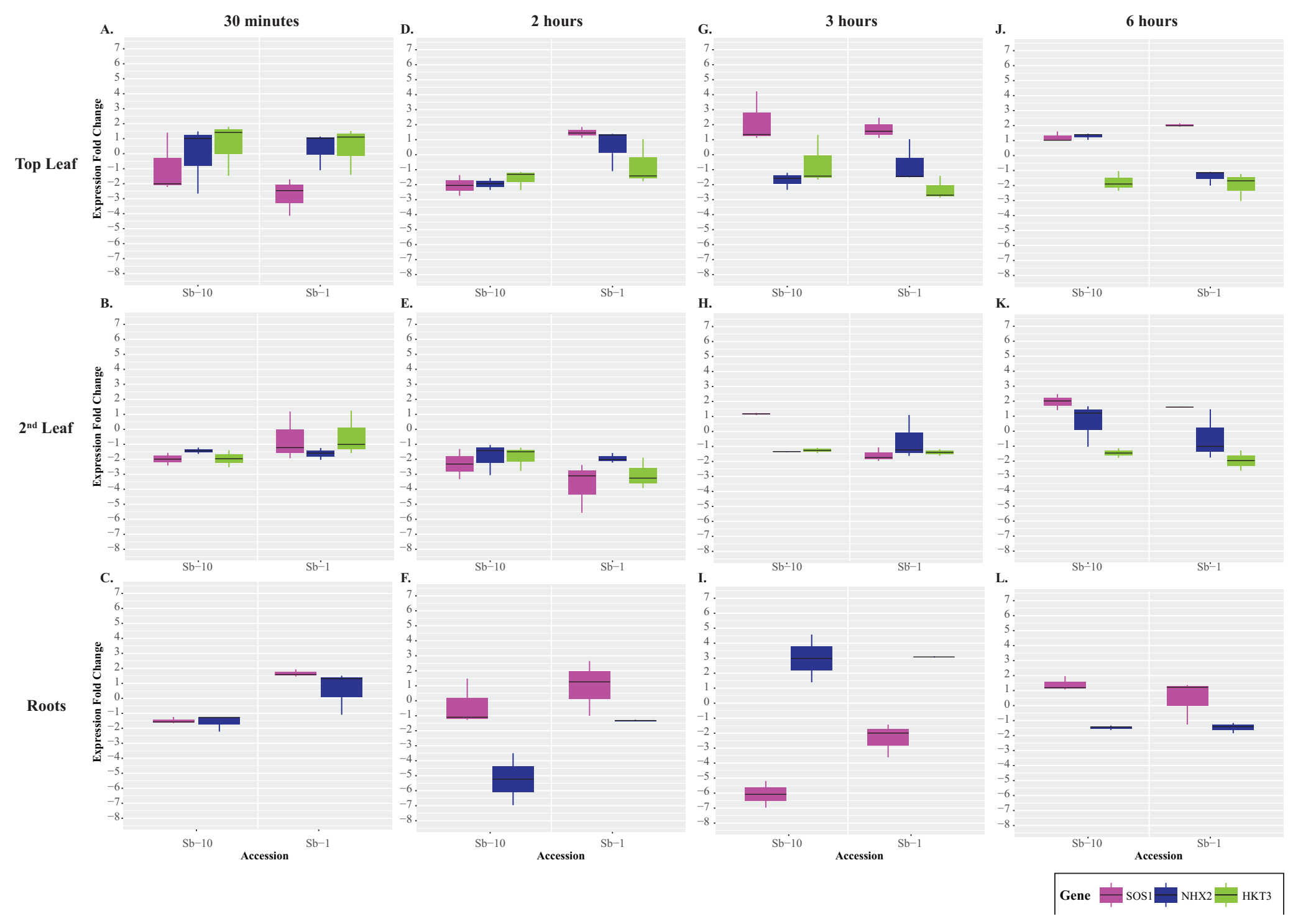


Figure 3. Gene expression changes for salt detoxification genes at 30 minutes, 2 hours, 3 hours, and 6 hours after salt exposure. Plants were watered with $150 \mathrm{mM}$ $\mathrm{NaCl}$ at the $5^{\text {th }}$ or $6^{\text {th }}$ leaf stage of development and relative expression of SbSOS1, $\mathrm{SbNHX} 2$, and SbHKT3 were calculated in the root tips, $2^{\text {nd }}$ leaf, and top leaf 30 minutes, 2 hours, 3 hours and 6 hours after exposure. Boxplots display the interquartile range, with the black line representing the median. Whiskers represent the largest and smallest value within 1.5 times the interquartile range above and below the 75 th and 25 th percentile. No outliers were detected. (A)-(C) Gene expression changes for SbSOS1, SbNHX2, and SbHKT3 30 minutes after the exposure to $150 \mathrm{mM} \mathrm{NaCl}$ in the top leaf, second leaf, and roots, respectively. (D)-(F) Gene expression changes for SbSOS1, SbNHX2, and

SbHKT3 2 hours after the exposure to $150 \mathrm{mM} \mathrm{NaCl}$ the top leaf, second leaf, and roots, respectively. (G)-(I) Gene expression changes for SbSOS1, SbNHX2, and SbHKT3 3

hours after the exposure to $150 \mathrm{mM} \mathrm{NaCl}$ the top leaf, second leaf, and roots, respectively. (J)-(L) Gene expression changes for SbSOS1, SbNHX2, and SbHKT3 6 hours after the exposure to $150 \mathrm{mM} \mathrm{NaCl}$ the top leaf, second leaf, and roots, respectively. 

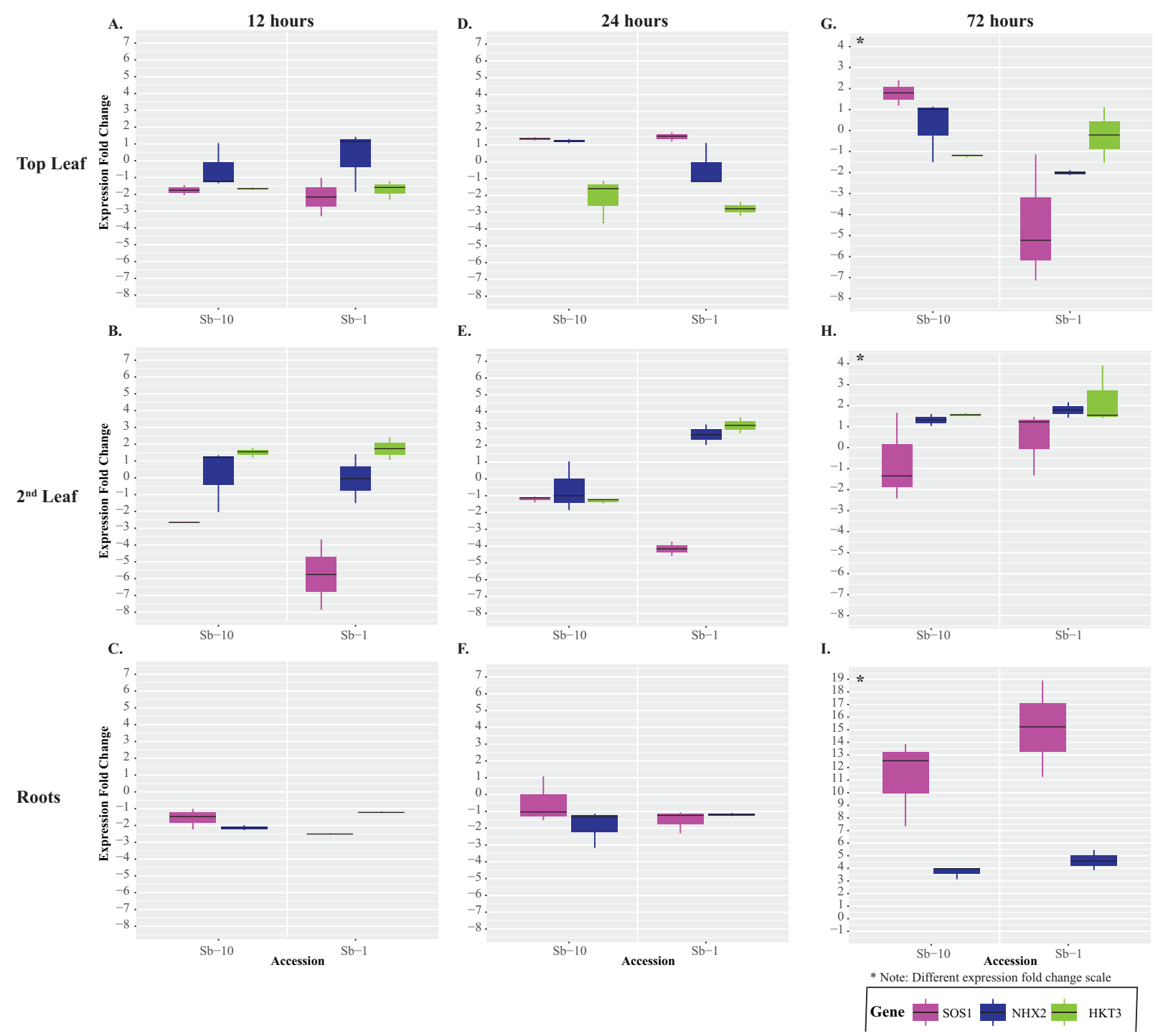

Figure 4 Gene expression changes for salt detoxification genes at 12 hours, 24 hours, and 72 hours after salt exposure. Plants were watered with $150 \mathrm{mM} \mathrm{NaCl}$ at the $5^{\text {th }}$ or $6^{\text {th }}$ leaf stage of development and relative expression of SbSOS1, SbNHX2, and SbHKT3 were calculated in the root tips, $2^{\text {nd }}$ leaf, and top leaf 12 hours, 24 hours, and 72 hours after exposure. Boxplots display the interquartile range, with the black line representing the median. Whiskers represent the largest and smallest value within 1.5 times the interquartile range above and below the 75 th and 25 th percentile. No outliers were detected. (A)-(C) Gene expression changes for SbSOS1, SbNHX2, and SbHKT3 12 hours after the exposure to $150 \mathrm{mM} \mathrm{NaCl}$ in the top leaf, second leaf, and roots, respectively. (D)-(F) Gene expression changes for SbSOS1, SbNHX2, and SbHKT3 24 hours after the exposure to $150 \mathrm{mM}$ $\mathrm{NaCl}$ the top leaf, second leaf, and roots, respectively. (G)-(I) Gene expression changes for SbSOS1, SbNHX2, and SbHKT3 72 hours after the exposure to $150 \mathrm{mM} \mathrm{NaCl}$ the top leaf, second leaf, and roots, respectively. Note: $y$-axis (expression fold change) values are different in panels $G, H$, and $I$. 


\section{Supplementary Tables}

Supplementary Table S1. Target gene and primer sequences. Primers SbPP2A, SbSOS1, and SbNHX2 used for qRT-PCR were previously published ${ }^{7,40}$. Primers for SbHKT3 were designed.

\begin{tabular}{|c|c|c|c|c|}
\hline $\begin{array}{c}\text { Target } \\
\text { gene }\end{array}$ & Primer sequences & $\begin{array}{l}\text { Amplicon size } \\
\text { (bp) }\end{array}$ & Accessing number & Gene product \\
\hline PP2A & $\begin{array}{l}\text { Fwd 5' AACCCGCAAAACCCCAGACTA 3' } \\
\text { Rev 5' TACAGGTCGGGCTCATGGAAC 3' }\end{array}$ & 138 & SORBI_3004G092500 & $\begin{array}{l}\text { serine/threonine-protein } \\
\text { phosphatase }\end{array}$ \\
\hline SOS1 & $\begin{array}{l}\text { Fwd 5' GGTGTAGTAAAGTGGACGAGTC 3' } \\
\text { Rev 5' ATCAGCACCTCATACAGTCCC 3' }\end{array}$ & 98 & SORBI_3008G192900 & $\begin{array}{l}\text { salt overly sensitive } \\
\text { pathway, antiporter/ plasma } \\
\text { membrane }\end{array}$ \\
\hline NHX2 & $\begin{array}{l}\text { Fwd 5' CTTTTAGGCAGCAGGTTATTG 3' } \\
\text { Rev 5' GGTCAGTAGCCCAAAGACT 3' }\end{array}$ & 179 & SORBI_3005G201000 & $\begin{array}{l}\text { antiporter/vacuolar } \\
\text { compartmentalization }\end{array}$ \\
\hline HKT3 & $\begin{array}{l}\text { Fwd 5'CGT GAT CTT CGA GGT GAT CAG TG 3' } \\
\text { Rev 5' TGT CAT GGC AGG CGG TGG TC 3' }\end{array}$ & 105 & SORBI_3010G251700 & $\begin{array}{l}\text { high affinity potassium } \\
\text { transporter }\end{array}$ \\
\hline
\end{tabular}


Supplementary Table S2. Sequence data for SbPP2A, SbNHX2, and SbHKT3 PCR products. Sanger sequencing results for SbPP2A, SbNHX2, and SbHKT3 PCR products. Nucleotide sequences were BLASTN to verify amplification. SbSOS1 primer pair was published and the PCR product was not a high-quality sequence due to small amplicon size. SbSOS1 data was omitted.

\begin{tabular}{|c|c|c|}
\hline $\begin{array}{l}\text { Target } \\
\text { gene }\end{array}$ & $\begin{array}{l}\text { Accessing } \\
\text { number }\end{array}$ & Sanger sequencing results \\
\hline PP2A & SORBI_3004G092500 & $\begin{array}{l}\text { ATAATKCTGGTGGTGACCTTACTTACTGGTGTTGATGCTCCTCTCTTCTGCAACATCAGG } \\
\text { GTCTGTAGATCTTCTGTCCTTAGATATGGGTTCCATGAGCCCGACCTGTAAAAAC }\end{array}$ \\
\hline SOS1 & SORBI_3008G192900 & - \\
\hline NHX2 & SORBI_3005G201000 & $\begin{array}{l}\text { TKTCGGCYATGAGAGTGCTGTGTCATTGCGTTGGCTTACAATAAGTTCACAAGATCAGG } \\
\text { CCATACTCAGCAACCTAGCAATGCTATCATGATCACAAGCACAATCACTGTTGTTCTTTT } \\
\text { CAGCACAATTGTCTTTGGGCTACTGACCCAAATAAATTGTCTGAAAAAAAAAAGTGATG } \\
\text { TKYRTYTRAWATGATACATTGYTKGTTGCTKAKTAGGKKYRTCTTGGGAAMTTATTGTA } \\
\text { GCCACGCYTGGAACGCACTCCAGAMMCCCCMCCAAACATWACCTGCKCCCTAAAARG } \\
\text { AWYS }\end{array}$ \\
\hline HKT3 & SORBI_3010G251700 & $\begin{array}{l}\text { CAWTTTGCGGKCGYGAGCAGCTGTAGCCAGTGGACAACCCCACGTTTCCATAAGCAC } \\
\text { TGATCACCTCGAAGATCACAAACCWSTTKWRASARRASYCRSAGAGWTYYWKRARW } \\
\text { KWCRAYTKMYCGWCARSAWCGGGGKGCGWSMGCSWCAGTGSSCAGCGYGAGGAGM } \\
\text { AMGWWAT }\end{array}$ \\
\hline
\end{tabular}


Supplementary Table S3. Analysis of variance results. F-statistic for 2-way ANOVA. $(* * *)$ represents a $\mathrm{p}$-value $<0.001,(* *)$ represents a $\mathrm{p}$-value $<0.01,(*)$ represents a $\mathrm{p}$ value $<0.05$, and $(+)$ represents a $p$-value $<0.01$.

\begin{tabular}{|c|c|c|c|c|}
\hline & & SOS1 & NHX2 & HKT3 \\
\hline \multirow{4}{*}{ Root Tip } & Genotype & $4.7803 *$ & $8.1063 * *$ & \\
\hline & Timepoint & $56.9923 * * *$ & $25.9038 * * *$ & \\
\hline & $\mathrm{G} \times \mathrm{T}$ & $2.6798 *$ & $2.8878 *$ & \\
\hline & RSS & 0.7626 & 0.4952 & \\
\hline \multirow{4}{*}{ Leaf 2} & Genotype & $6.9813 *$ & 0.6428 & 0.0048 \\
\hline & Timepoint & $14.5000 * * *$ & $4.6725 * * *$ & $8.352 * * *$ \\
\hline & $\mathrm{G} \times \mathrm{T}$ & $3.0827 *$ & $2.6804 *$ & $4.7009 * * *$ \\
\hline & RSS & 0.66467 & 0.6316 & 0.78629 \\
\hline \multirow{4}{*}{ Top Leaf } & Genotype & 0.5622 & 0.4392 & 2.5632 \\
\hline & Timepoint & $8.3479 * * *$ & $13.6257 * * *$ & $9.6173 * * *$ \\
\hline & $\mathrm{G} \times \mathrm{T}$ & $3.6537 * *$ & $2.9417 *$ & 0.8142 \\
\hline & RSS & 1.37502 & 0.6678 & 0.79947 \\
\hline & $0.001 * * *$ & $0.01 * *$ & $0.05 *$ & $0.01+$ \\
\hline
\end{tabular}


Supplementary Table S4. Effect of salt exposure on gene expression of SbSOS1 and SbNHX2 of Sorghum bicolor accessions in root tips. Plants were exposed to $150 \mathrm{mM}$ $\mathrm{NaCl}$ at the $5^{\text {th }}$ or $6^{\text {th }}$ leaf stage of development and relative expression of SbSOS1 and SbNHX2 were calculated in the root tips at nine different time points after exposure. Means followed by different letters are significantly different at $\mathrm{P}<0.05$. Values are mean $+/-$ SE with $n=3$.

\begin{tabular}{|c|c|c|c|c|c|c|c|c|c|c|c|c|c|c|c|c|}
\hline \multirow[b]{3}{*}{$0 \mathrm{hr}$} & \multicolumn{8}{|c|}{ SOS1 } & \multicolumn{8}{|c|}{ NHX2 } \\
\hline & \multicolumn{4}{|c|}{$\mathrm{Sb}-10$} & \multicolumn{4}{|c|}{$\mathrm{Sb}-1$} & \multicolumn{4}{|c|}{$\mathrm{Sb}-10$} & \multicolumn{4}{|c|}{$\mathrm{Sb}-1$} \\
\hline & -0.69 & \pm & 0.11 & $\mathrm{ab}$ & -0.55 & \pm & 0.09 & $\mathrm{ab}$ & 0.21 & \pm & 0.08 & cde & -0.02 & \pm & 0.08 & bcd \\
\hline $0.5 \mathrm{hr}$ & -0.17 & \pm & 0.09 & bcd & 0.22 & \pm & 0.09 & d & -0.19 & \pm & 0.08 & $\mathrm{bc}$ & 0.09 & \pm & 0.08 & bcd \\
\hline $1 \mathrm{hr}$ & 0.02 & \pm & 0.09 & $\mathrm{~cd}$ & -0.04 & \pm & 0.09 & $\mathrm{~cd}$ & -0.21 & \pm & 0.14 & abcd & -0.09 & \pm & 0.10 & bcd \\
\hline $2 \mathrm{hr}$ & 0.01 & \pm & 0.09 & $\mathrm{~cd}$ & 0.17 & \pm & 0.09 & d & -0.69 & \pm & 0.10 & $\mathrm{a}$ & -0.12 & \pm & 0.10 & bcd \\
\hline $3 \mathrm{hr}$ & -0.78 & \pm & 0.11 & $\mathrm{a}$ & -0.34 & \pm & 0.09 & $a b c$ & 0.40 & \pm & 0.10 & def & 0.49 & \pm & 0.14 & def \\
\hline $6 \mathrm{hr}$ & 0.13 & \pm & 0.09 & $\mathrm{~cd}$ & 0.04 & \pm & 0.09 & $\mathrm{~cd}$ & -0.16 & \pm & 0.08 & $\mathrm{bc}$ & -0.16 & \pm & 0.08 & $\mathrm{bc}$ \\
\hline $12 \mathrm{hr}$ & -0.17 & \pm & 0.09 & bcd & -0.40 & \pm & 0.15 & abcd & -0.33 & \pm & 0.10 & $\mathrm{ab}$ & -0.09 & \pm & 0.14 & abcd \\
\hline $24 \mathrm{hr}$ & -0.06 & \pm & 0.09 & $\mathrm{~cd}$ & -0.16 & \pm & 0.09 & bcd & -0.23 & \pm & 0.08 & $a b c$ & -0.08 & \pm & 0.08 & bcd \\
\hline $72 \mathrm{hr}$ & 1.04 & \pm & 0.09 & e & 1.17 & \pm & 0.09 & e & 0.57 & \pm & 0.08 & ef & 0.66 & \pm & 0.08 & f \\
\hline SEM & & & & & & & & & & & & & & & & \\
\hline $\mathrm{P}_{\text {Accession }}$ & & & & & & & & & & & & & & & & \\
\hline $\mathrm{P}_{\text {Timepoint }}$ & & & & 2.0 & & & & & & & & & & & & \\
\hline $\mathrm{P}_{\text {Accession*Timepoint }}$ & & & & & & & & & & & & & & & & \\
\hline
\end{tabular}


Supplementary Table S5. Effect of salt exposure on gene expression of SbSOS1, SbNHX2, and SbHKT3 of Sorghum bicolor accessions in the second leaf. Plants were exposed to $150 \mathrm{mM} \mathrm{NaCl}$ at the $5^{\text {th }}$ or $6^{\text {th }}$ leaf stage of development and relative expression of SbSOS1, SbNHX2, and SbHKT3 were calculated in the second leaf at nine different time points after exposure. Means followed by different letters are significantly different at $\mathrm{P}<0.05$.

Values are mean $+/-$ SE with $n=3$.

\begin{tabular}{|c|c|c|c|c|c|c|c|}
\hline & \multicolumn{2}{|c|}{ SOS1 } & \multicolumn{3}{|c|}{ NHX2 } & \multicolumn{2}{|c|}{ HKT3 } \\
\hline & $\mathrm{Sb}-10$ & $\mathrm{Sb}-1$ & $\mathrm{Sb}-10$ & & $\mathrm{Sb}-1$ & $\mathrm{Sb}-10$ & $\mathrm{Sb}-1$ \\
\hline $0 \mathrm{hr}$ & $-0.21 \pm 0.09^{\text {bcde }}$ & $-0.37 \pm 0.11^{\text {abcde }}$ & $-0.08 \pm 0.08$ & $\mathrm{abc}$ & $0.13 \pm 0.10^{\mathrm{abcd}}$ & $0.42 \pm 0.10^{\mathrm{de}}$ & $-0.18 \pm 0.12^{\mathrm{abc}}$ \\
\hline $0.5 \mathrm{hr}$ & $-0.29 \pm 0.11^{\text {abcde }}$ & $-0.10 \pm 0.09^{\text {bcdef }}$ & $-0.15 \pm 0.10$ & $a b c$ & $-0.20 \pm 0.08^{a b c}$ & $-0.27 \pm 0.12^{\mathrm{abc}}$ & $-0.03 \pm 0.10^{\mathrm{abcde}}$ \\
\hline $1 \mathrm{hr}$ & $-0.01 \pm 0.09^{\mathrm{def}}$ & $0.05 \pm 0.09^{\mathrm{def}}$ & $0.15 \pm 0.08$ & bcd & $-0.07 \pm 0.08^{a b c}$ & $-0.01 \pm 0.10^{\text {abcde }}$ & $-0.01 \pm 0.10^{\mathrm{abcde}}$ \\
\hline $2 \mathrm{hr}$ & $-0.32 \pm 0.11^{\text {abcde }}$ & $-0.54 \pm 0.09^{\mathrm{abc}}$ & $-0.22 \pm 0.08$ & $\mathrm{ab}$ & $-0.28 \pm 0.08^{\mathrm{a}}$ & $-0.24 \pm 0.10^{\mathrm{ab}}$ & $-0.46 \pm 0.10^{\mathrm{a}}$ \\
\hline $3 \mathrm{hr}$ & $0.07 \pm 0.11^{\mathrm{def}}$ & $-0.19 \pm 0.09^{\text {bcdef }}$ & $-0.13 \pm 0.08$ & $a b c$ & $-0.09 \pm 0.08^{a b c}$ & $-0.10 \pm 0.12^{\text {abcde }}$ & $-0.14 \pm 0.12^{a b c d e}$ \\
\hline $6 \mathrm{hr}$ & $0.28 \pm 0.09^{f}$ & $0.21 \pm 0.11^{\text {ef }}$ & $0.10 \pm 0.08$ & abcd & $-0.03 \pm 0.08^{\mathrm{abcd}}$ & $-0.15 \pm 0.12^{\mathrm{abcd}}$ & $-0.27 \pm 0.10^{\mathrm{ab}}$ \\
\hline $12 \mathrm{hr}$ & $-0.42 \pm 0.11^{\mathrm{abcd}}$ & $-0.74 \pm 0.09^{\mathrm{a}}$ & $-0.03 \pm 0.08$ & abcd & $-0.01 \pm 0.10^{\mathrm{abcd}}$ & $0.18 \pm 0.10^{\text {bcde }}$ & $0.20 \pm 0.12^{\text {bcde }}$ \\
\hline $24 \mathrm{hr}$ & $-0.07 \pm 0.09^{\text {cdef }}$ & $-0.62 \pm 0.11^{\mathrm{ab}}$ & $-0.08 \pm 0.08$ & $\mathrm{abc}$ & $0.41 \pm 0.10^{\mathrm{d}}$ & $-0.11 \pm 0.10^{\mathrm{abc}}$ & $0.50 \pm 0.12^{\mathrm{e}}$ \\
\hline $72 \mathrm{hr}$ & $-0.10 \pm 0.09^{\text {bcdef }}$ & $0.04 \pm 0.09^{\mathrm{def}}$ & $0.11 \pm 0.10$ & abcd & $0.24 \pm 0.10^{\mathrm{cd}}$ & $0.19 \pm 0.12^{\text {bcde }}$ & $0.31 \pm 0.10^{\text {cde }}$ \\
\hline SEM & \multicolumn{2}{|c|}{0.095} & \multicolumn{3}{|c|}{0.090} & \multicolumn{2}{|c|}{0.106} \\
\hline $\mathrm{P}_{\text {Accession }}$ & \multicolumn{2}{|c|}{0.013} & \multicolumn{3}{|c|}{0.429} & \multicolumn{2}{|c|}{0.945} \\
\hline $\mathrm{P}_{\text {Timepoint }}$ & \multicolumn{2}{|c|}{ 2.94E-08 } & \multicolumn{3}{|c|}{ 8.70E-04 } & \multicolumn{2}{|c|}{$9.93 \mathrm{E}-06$} \\
\hline $\mathrm{P}_{\text {Accession*Timepoint }}$ & \multicolumn{2}{|c|}{0.012} & \multicolumn{3}{|c|}{0.024} & \multicolumn{2}{|c|}{0.001} \\
\hline
\end{tabular}


Supplementary Table S6. Effect of salt exposure on gene expression of SbSOS1, SbNHX2, and SbHKT3 of Sorghum bicolor accessions in the second leaf. Plants were exposed to $150 \mathrm{mM} \mathrm{NaCl}$ at the $5^{\text {th }}$ or $6^{\text {th }}$ leaf stage of development and relative expression of SbSOS1, SbNHX2, and SbHKT3 were calculated in the top leaf at nine different time points after exposure. Means followed by different letters are significantly different at $\mathrm{P}<0.05$. Values are mean $+/-\mathrm{SE}$ with $\mathrm{n}=3$.

\begin{tabular}{|c|c|c|c|c|c|c|c|c|c|c|c|c|c|c|c|c|c|c|c|c|c|c|c|c|}
\hline \multirow[b]{3}{*}{$0 \mathrm{hr}$} & \multicolumn{8}{|c|}{ SOS1 } & \multicolumn{8}{|c|}{ NHX2 } & \multicolumn{8}{|c|}{ HKT3 } \\
\hline & \multicolumn{4}{|c|}{ Sb-10 } & \multicolumn{4}{|c|}{ Sb-1 } & \multicolumn{4}{|c|}{$\mathrm{Sb}-10$} & \multicolumn{4}{|c|}{ Sb-1 } & \multicolumn{4}{|c|}{$\mathrm{Sb}-10$} & \multicolumn{4}{|c|}{ Sb-1 } \\
\hline & 0.62 & \pm & 0.12 & d & 0.33 & \pm & 0.12 & $\mathrm{~cd}$ & 0.60 & \pm & 0.08 & e & 0.44 & \pm & 0.08 & de & 0.51 & \pm & 0.11 & $\mathrm{c}$ & 0.26 & \pm & 0.09 & $\mathrm{bc}$ \\
\hline $0.5 \mathrm{hr}$ & -0.17 & \pm & 0.12 & $a b c$ & -0.41 & \pm & 0.12 & $\mathrm{ab}$ & -0.08 & \pm & 0.08 & $a b c$ & 0.01 & \pm & 0.08 & $a b c$ & 0.08 & \pm & 0.09 & $a b c$ & 0.03 & \pm & 0.09 & $a b c$ \\
\hline $1 \mathrm{hr}$ & -0.21 & \pm & 0.15 & $a b c$ & 0.09 & \pm & 0.12 & abcd & 0.26 & \pm & 0.10 & cde & 0.14 & \pm & 0.08 & bcd & 0.01 & \pm & 0.09 & $\mathrm{abc}$ & 0.04 & \pm & 0.09 & $a b c$ \\
\hline $2 \mathrm{hr}$ & -0.29 & \pm & 0.12 & $a b c$ & 0.16 & \pm & 0.15 & bcd & -0.28 & \pm & 0.08 & a & 0.07 & \pm & 0.08 & abcd & -0.18 & \pm & 0.09 & ab & -0.13 & \pm & 0.09 & $\mathrm{ab}$ \\
\hline $3 \mathrm{hr}$ & 0.27 & \pm & 0.12 & $\mathrm{~cd}$ & 0.21 & \pm & 0.12 & bcd & -0.22 & \pm & 0.08 & ab & -0.11 & \pm & 0.08 & $a b c$ & -0.09 & \pm & 0.09 & ab & -0.35 & \pm & 0.09 & a \\
\hline $6 \mathrm{hr}$ & 0.07 & \pm & 0.12 & abcd & 0.31 & \pm & 0.12 & $c d$ & 0.11 & \pm & 0.08 & abcd & -0.13 & \pm & 0.08 & $a b c$ & -0.22 & \pm & 0.09 & ab & -0.27 & \pm & 0.09 & $\mathrm{a}$ \\
\hline $12 \mathrm{hr}$ & -0.24 & \pm & 0.15 & $a b c$ & -0.26 & \pm & 0.15 & $a b c$ & -0.06 & \pm & 0.08 & $a b c$ & -0.02 & \pm & 0.08 & $a b c$ & -0.22 & \pm & 0.11 & ab & -0.22 & \pm & 0.09 & $\mathrm{ab}$ \\
\hline $24 \mathrm{hr}$ & 0.14 & \pm & 0.12 & abcd & 0.17 & \pm & 0.15 & bcd & 0.09 & \pm & 0.08 & abcd & -0.03 & \pm & 0.08 & $a b c$ & -0.28 & \pm & 0.09 & a & -0.44 & \pm & 0.11 & $\mathrm{a}$ \\
\hline $72 \mathrm{hr}$ & 0.23 & \pm & 0.12 & bcd & -0.54 & \pm & 0.15 & $\mathrm{a}$ & -0.04 & \pm & 0.08 & $a b c$ & -0.30 & \pm & 0.10 & a & -0.08 & \pm & 0.09 & ab & -0.07 & \pm & 0.11 & $a b c$ \\
\hline SEM & & & & 0.1 & & & & & & & & 0.0 & & & & & & & & & & & & \\
\hline $\mathrm{P}_{\text {Accession }}$ & & & & 0.4 & & & & & & & & 0.5 & & & & & & & & & & & & \\
\hline $\mathbf{P}_{\text {Timepoint }}$ & & & & 6.84 & -06 & & & & & & & 1.32 & -08 & & & & & & & 1.13 & -06 & & & \\
\hline $\mathrm{P}_{\text {Accession*Timepoint }}$ & & & & 4.42 & -03 & & & & & & & 0.0 & & & & & & & & 0.5 & & & & \\
\hline
\end{tabular}




\section{Supplementary Figures}

\section{Supplementary Figure S1. SbPP2A gene sequence and primer location.}

Nucleotide sequence for SbPP2A gene. Forward primer indicated by cyan highlighting. Reverse primer indicated by magenta highlighting. Exons indicated by orange highlighting. Introns indicated by white highlighting.

1 AgTTATAATTTTAAAGTTATTTTTAATAATTTACTTAAAGTTAGGCCCTTTTTTGTACCG 60

61 TTCTGCTTCATCGACGAAACTTTTAAATTTTTAGCTATTTAGAAAAAATGTTTGACAAA 120

121 AAAACTTCATGCATGACTAGGAGAGGAAAATGAAAAAGAAAGTTATGAAAAACTACTTTT 180

181 TTTTAGTTTTACCTGTCTCAATTTTTTTTGATGAGAACATACAAAAGAGCTTCGTACCAC 240

241 GAGCTATTTTGAAAAAGATATTTAATAAAAGAAACCCAGTTTACAACCGCTTATAAAACT 300

301 GTGCCAAATAGATCTTAAAAGTTTGATCATATCAAATCAAATATAAAATTACATTATTTT 360

361 TTTTGATGGAGTATTTGCCGTTTGGAGATGCTCGAAACAACTATCCTCTTTGAAAATTGA 420

421 AACGCTGGCATGCCACCTACGACTACGAAGTCTTTGTTGACCAGCTCCCGTGGCCCCCCC 480

481 TGGCAATTACAATTCCATCCCTCCAAAACAACGAAACCACACACGACCCCCCAGCCCGAC 540

541 CTGCCCGCTCTCTGCACACCTGGAACGAGGTGTTACCGTCCCGAGAAAGAAGAGCCGAGG 600

601 AAAAATCTCGCACTCGCAAAACAAACAAAGCAGCGTGCCCCCCAAAAAATGGAGGCATGA 660

661 GCTCCGCCTCCTCCCCGTCTCTCGCCGATCTCCCCCAAACCCTAGCCCCGACCTGACCGC 720

721 CGGCGGGCCCGCCGGCCGGCCGGAGAAGGACTCGCCCCCCAACCCACTCACCCACCCACC 780

781 CAACCTCTGCCGCGGGCTGGAGGGGGGAGCGGGGCGGCGGACGAGATGCCGTCGCACGGG 840

841 GATCTGGACCGGCAGATCGCGCAGCTGCGCGACTGCAAGTACCTGCCCGAGGCGGAGGTC 900

901 AAGGCGCTCTGCGAGCAGGCCAAGGCCATCCTCATGGAGGAGTGGAACGTGCAGCCCGTG 960

961 CGCTGCCCCGTCACCGTCTGCGGCGACATCCACGGCCAGTTCTACGACCTCATCGAGCTC 1020

1021 TTCCGCATCGGCGGCGACGCTCCCGACACCAACTACCTCTTCATGGGCGACTACGTCGGT 1080

1081 GCGTGGCTACGCTCCCCTCGCCCTCACTTTTCTCCCACGCGGCTCTGTCCTGCTCACGGT 1140

1141 TTCTCTCTCTCTCCGTTAGCTCGCGCGCGGAGCTGTGCTGATGCCTGACTCGGCCGATCT 1200

1201 GTGATATGGGACGTTTGGTGCCGCTGAAGTAGGGGAGTTTTAGATCATGCGGTATACCTG 1260

1261 AAAGGTGGTTGGTTTTTGTGCGTCTGGCCGGATTGTTGGAAGAATCTGGTTATCCGGAAA 1320

1321 TTAGGGAACGTCTTTACTGCTTAACATATAGTCTACTGGAGTTCTTGTAGTTTGACTTGT 1380

1381 TATGGGTTGCTTTTGGGTCTAGCGTGCTAGGATCTTGTTGCCGCTGTTGCCTTTTAGCTC 1440

1441 ATTTAGTACCAAGAAAATAATTCTCATATATCAGCGTTTGAATTCCTCCTCCAGCAGTTT 1500

1501 CATAAGAATTTTGAGTGTGCTTCAGATTTCAGAGAGTGGTTGATTTGTTGGCCTGTTGTT 1560

1561 TTTGAGCTGATCCCTGTTGTTTTTGAGCTGATTCCTGAGCTTGTCAAAGGGTGCCACTTA 1620

1621 GGTCCACAAACTTTGAAAATGTATTTCTAGGTACCTAAACTTGTTAAGTGGTGCACCACA 1680

1681 TGGCCGAAACTTGTTAAATGATGCATCGCAAGTCCATTTTCAGACCATGCCAACCACTGT 1740

1741 GGTGCATCACTTAACAGGTTCAAGGACCCAGAAATGCGTTTTTAAAGTTCATGAACTAAG 1800

1801 TGGCACCCCTTAACAAGTTCAGGGGCCACTCATGCATTTAAATCATATGCAAATGCCATT 1860

1861 TATTTGAATGCTTGAAGGTAATTTTATAATTTCATTTTGTGTTGAGGGGATAAATAATTT 1920

1921 AGTAGACATTCATTACTTTATTTCATTTGTAGTACAAGTACCATAAGTGTCATATTTGTT 1980

1981 AATTTGATTATGTGTCTCTTGATTGCAGATCGTGGCTACTATTCAGTTGAAACAGTTTCT 2040

2041 CTGTTAGTGGCTTTGAAAGTCCGTTACAGAGATAGAATTACAATACTTAGAGGAAATCAT 2100

2101 GAGAGCAGACAAATCACTCAAGTGTGAGTTTATATCTACTAGTATTTGGATTTTGTATTG 2160

2161 CAACTCGTAATTGCTACTCCCACTTTTATTATTAGTACTTCCACAGTAGCTACAAGTATT 2220

2221 TGAGATGGATTTTCCCCCAGCATACTTGATCATTTTGTCTTCTTATTTCTCAAGTAACC 2280

2281 TGTCTACAATAGTAAATATTCAATAATTTGGAAATGGATAGTTCCACGTAAAGCTCACGT 2340

2341 TCGTGTAGATAAGGCTTCACAAACACTCGTTTGACAAGTTATCTTCTGTATGCTGGACTA 2400

2401 GGACAGTGAAATTGTGTTGATTAACATGGTAAACTATAATTTTAGTGTTCTGTCAACAC 2460

2461 GCTTGGCATTGTCAACTACAATGTTACATTAGGCGCTAGGCGATCTCTAGGCGGTGACCT 2520

2521 TCCGCCTAGAGCTTAGGTGAGCCTAGGCGTTTCCTAGGCGTTCCTCAAATATAGATGTGT 2580

2581 ACACATATATTAACTCAAAAGAAAAGAAGAAACAGGAGACTGCAGACCTAGGTTGCATAG 2640

2641 AACGGCCCATCAAAAGCATCCCACTCCACCTTATACATTCCCAACTTAACCATCCACCCT 2700

2701 CTGACCTCCCAGACGCACCTGCCTTCACCACTGCCAGCCTCCTCCCTTCCACCTCCACTG 2760

2761 CTGCCCGCCTCTTCCTGGCCGTGCCTGCCACCTCCACCGCCGCCTGCCTCCTTCTGGCCA 2820

2821 CGCCTGCTACCTCTGCCATCACCCACTGTCCCTGCCTCCCCTGCTGCCACTGGTGCCCGT 2880

2881 TGTCCCCGCCTCCCCTGCTGCTCCTGCCTCATCCCGTCGCCGCCCTCTTTTCATATATTC 2940

2941 CTGCCTACTTCCCTGCCGCTCAACATCTCTGCCTGCAGGGATCTGCACGTATGGACACTG 3000

3001 GGTTTCCACTGAGGGCCTGCCTGCACCCCAAGGTGCCCCGGCACCCCTCCGCCTCGCCTA 3060

3061 CTCGCGAGTAAGCAGCCACGGAATATCGCCTTTTGGAACACTACGTTGTTGCATGAAGAC 3120

3121 ATCCAGCTAGGTCTGTGGCCATCTGATTGCCGTCAATTTCGTGCCCTAACAAGGCACTGC 3180

3181 TAACTGTCTCCTGTGTTCTTCCTTAAACCTTCCATGGGTTTAACTACAGTTAATATGTCG 3240

3241 CAATGTCCTAGGTCATTGAAATGAACTCCACTTGTTTGCATGACATGCACACAATGGACC 3300

3301 TGTACACCTTTTTTTTTTTTGACAATTGGACCTGTACACCGTTGTGTTTCCAAGTTATTC 3360

3361 TGTGAACTTTGTAGTGTACGCCTGTAGTGCAACCGCACAATTGTTGACCTTGATTGGTTG 3420

3421 TTTCAGGTATGGCTTCTATGATGAATGCTTAAGAAAATATGGAAATGCAAATGTATGGAA 3480

3481 GTATTTTACAGACTTGTTTGATTATTTGCCTCTCACGGCTCTTATAGAAAATCAGGTATG 3540

3541 CAGCTTAATTTGTTATGGTTGATGCTATTATAGGCTTGCTAAATATATGCCTTTGACATT 3600

3601 TGAGAAACATCCATTTTGCAGGTCTTCTGTCTTCATGGTGGCCTCTCTCCGTCATTGGAC 3660

3661 ACATTGGATAACATTCGTTCTCTTGATCGCATACAGGAGGTAGGCACAACATTGCACTGC 3720

3721 TTTCATTATGAACCAGGTTTTCTTCATTGCCTCCAGTATATCATGCTGTGACTTCATGGA 3780

3781 TGTCTTGTATGCTGCAATAGTTTTAAATTGCTTAGTCGAGCCTAGTCATATGGGTAGCGG 3840

3841 TCAGGGGTCTGTTTGGTTTCATGGCTTATTTGTAGCCTGGTTAGAATTCTAGTCTGGGTA 3900

3901 GGCTTAACCTGCTTCTGTCAAGCCAATCTCTAGTTGTTTGGTTGTCCGTGTTATCTAGGC 3960 
3961 CTGGCTAGCACAGGGTGTGTTTGGTTGCCTGGATTGTTTTGGATAGGATCACCTCTTATC 4020 4021 CATGTGAGTAAGTTTACCCTCATTCAGGGATTTCATCAAACACGTTGTAGGCATCCTAAC 4080 4081 AGCATGACGAGCATGGTGAGCAGTGCTGGGAACGCTGGCGTGCCTTGGTCATCCACCTCC 4140 4141 TTGGTGCGGCCCTCTACACACCACCCCAGTCGGCTTTGTCGTCTCGTGTACCCCAGTCGG 4200 4201 CGAGAAGGCGGTCGACCATGTAGAGCACGTCATCCCCGTCGACGGCCATGGCCTCGTCAG 4260 4261 GAGCCAGGGACCTGAGCAGCCCCATTGCGCGCGGGTGACGGTGGGGAGCCGCTGCAGCGC 4320 4321 CTCCTGCTCGTCCTCCGCCTCCCGCCACGATCTCGAGCGCGAGAACACCGCCTCCGCCGC 4380 4381 CCACATCTCGCCGCTGATGGGTCTCCCCTGCCCCGCGGTGGTAATGGTGGGCTGGGGAGG 4440 4441 GAGGGGTGGATCCACCACGGTGGTAATGGCGAACTGGGGAGAACGTCGTAGGTGCCTCCC 4500 4501 TGAGCTTCCTGTCGCCATGGCCGCGGCAAGGAGGACGAACAGGGATGAGCTTCCCGCTTT 4560 4561 CCGTCGACCTCCCCCACCCCCCCACCCCCCCCCCCCCCCCCCCCCGGCGACGAGCAGAGC 4620 4621 AGGGGACCACCCACTGGCGGGGAGGGGAGGAGTTGGCGGACCTCGCTGCCTTTTGGCTCA 4680 4681 CTGCGTGTGAACTGTGAAGGACCAGGAGGTGAGGGGATGAGAGACGGAGCACTGGCCAAG 4740 4741 CCATTCTCCAGAAAAACGGACCGGCAACCTGTTCTCTGGGAGCCAGGCTAAGGCCTGTAG 4800 4801 GGCGGCCAGCAGAAGCCTGGCTAAGGCCCAAAGTCATGAAACCAAACAACCCAATGTTAG 4860 4861 CCCCAGCTGGCCTGTCCAAAGGTTGGCCTGGTAACCAAACAGGCCCCAGGTTCAATTGGT 4920 4921 CGGTGGCTAGTCAGCTAGTCGGGCAGTATAATTGTCCTGCCTACTTGCACTGCTTGTGCG 4980 4981 AAGAAATTAAAAATGCCATCCTTAATCTATTGTTTGCTATTGGAGAAGTGAACATCATTC 5040 5041 AGTGCAAAGTCTTCCCAACATTTTAGACAGATTCAGTGAAGCCCCTATTCTCCCAGTGCA 5100 5101 AATTATGCTGCGACATCCTATAGATATAAATCAAACATAATCCTATTCATGATTAGACAA 5160 5161 AAACATCTAATGGACTTTAAACACGAAGTGCCAATTGATATTTCCTACCGAGGCATAAAT 5220 5221 AGCGGATTTGGTGGATGAGGATGAATATCCAAAGTAATATTTCCAACTTCATAAGAGTCA 5280 5281 CTGACCCTTGCCAAAGAAATGTGGGGCATAGAAAAAGTCCAATATATATACTCTTGTTGG 5340 5341 CATAGCTGTTACAAGTGGAGAAGGAAAATTAATGCATGTTCATTACTAATGTACTACTTT 5400 5401 GTTTAGCCTTAATGGGAAGTGGGAGTGGTGATAGCACCGTGAATGTGAAAAGATGTTCGC 5460 5461 TGCAAGCTAAATTGATTAATTAATAGGAGAGGAATGGGGTAAATGGATTGCATGGTTGAG 5520 5521 CAGCTAGGAATGCAATTTATTTGGAGTTCATCGTTGTCTCTTCATTTTCTGATTATATTT 5580 5581 AATGGGATTGTAATTTAGTGACCGAGCTTAGTAACTTGGTGGGGCTTGTGGCATGACGTG 5640 5641 GCTTCACAAAATTGCAGAGAAATCTGCTAGTGGGGTTCTCCTAGTTAGGTATAGTAGATA 5700 5701 GTAGATTATAGATTCTAATATTGTTATATCAGTCCTAACTATATAGGATGACTAACCGAC 5760 5761 TAGGCTTGACTAATCAGGCTGGCAACTAGTGTCAACTGAATGATTTGATAAAATTGCTTA 5820 5821 GTAACACTGATATGCTGTAGGTAGTTTTGTGATGTTGGGAGAATTAACATATTTATGTAT 5880 5881 TTTTGGGTATGTGCAACTAGTAGATCAGCCATGTCCGATGTGGTCCTAATGTTTACTGTT 5940 5941 TATGTACAGAACTGTGGATCCTTAATACCGATTAAGGTACAAACATGGTGCTCTAACCAT 6000 6001 GATACAGTTATTTATCTAGACAGATGCCGCCATATTTAATTATCTCAAGTCATGCCGATA 6060 6061 CAATTTTGTAACGACATTTTGATTTTAGAGGGACACTTAACATCGTTTAATCTTCTCATG 6120 6121 GAATGGGCTTACCTAAGGAGAACTAAAGCACGACAACTAAAAATCAGCAAATATAGGCAC 6180 6181 GTGGTTGAATCATGAAAGTTTATATTGAAAGCTGACATTTTCCAACACTTATTCTGTCAC 6240 6241 TTTGCACGTGCACTTAGCAATACAAGGGATTTACCTTGATCTATACTTGGTACCATTTAG 6300 6301 TGTTAATCAGTGACTGATTTGAGGTATCATTTTTCTCAAACGATGCAGGAGAAGAAAGGT 6360 6361 ATGAGGGCAAGCTAAAACAGCCCCACCCAAACACACCACAACCGGCTATCTAAAAAAAAC 6420 6421 ATTCGCCACTGACTGAAGTAGAGATCACAACCAAGGGGTTTAACCTACCAACTAGAACCT 6480 6481 AAAAGTTATGGGGCAAATGACCTAAAGAGCGATCCTGGAGATTAGAAGCACCCACCATGC 6540 6541 ACCATATACTACACTCATCAACCACTGTTTTTAGGAGACCCAGAATGTTTGGCAAATCTC 6600 6601 CATCAGACACACAGGCATTCCTATGTTTACTTCCTAGGCCACTAAAAGGGCCAAGGAGTT 6660 6661 CAGCCCCTTGTGGCATCTCCTTGGGAATATTTCTGAATTCTGATAGTGTTCCTCACTATC 6720 6721 TAATAGCCTGTTTGGTTTGGAGATTGAATCCATTCCGATGGGCTGGTCAGGCACCAAAAA 6780 6781 GAATCAGCTTGTCTGACGTTTTTTGCGGAATGACTTTGCCTGAGAGATGAGCTCGCTGTT 6840 6841 GGTTCATGGGAACGCCGCACGTGGAACAGTTCCATGATGAACGAGTTGATGACGCAACAC 6900 6901 AAACCAAATGGTCTCAGCTAGGCTTGGATTTTGGATCGGATGATTCCGAACTGCTTCATG 6960 6961 ACGCAAACCAAACATGCTGTAAAGAAGTGAGTTGCATCAACTGGAGGTGCAACTGCAACC 7020 7021 ATGGAAACTTTCTTAAAAACCATAGTCAAGACCTGCAGGTTGAACACACAAGAGATTAAG 7080 7081 ACGTGCTAAATTGCTTCCTCAGCCTGATCACGAAACAGGTAGGCAGGCTGATGAGGCAAT 7140 7141 CGGTGCTTTGCAATGCAATCAGCCATCCAATACCGGTATTGATGGCTAACGAAAGAAGAA 7200 7201 TTTGCATCTTAGAGCCCCCCCAGCTCTTAAAAATTCTTTTCCAAGGACCAAACTTGATAG 7260 7261 TTCCCAAGAAGAAGGCAGCATGGGAATATGGGATGATTTGCCAGTGGAGCCATATTAAGT 7320 7321 CTGCTTCCGTAGGTGCTTATTGCTTGATAGTTCCCAAGAAAAAGACAGCATGGTGCTTGA 7380 7381 GGCTGACATCTCACTATTAGTGAAGTGACCAACCAGTAGTCATTTGCAATGAGGTTTGCT 7440 7441 TATtGCTTATAATATTGCCAGCACATGCATATTTGTTTGTGAAACATTTGCATCTGATAG 7500 7501 TGAACTATTTTAAGAAGGTACTTCGAATTTCTGTTGCTATGATTACAGGGTTTGTTAGA 7560 7561 ACCTATTTTTTTTTGAGGCCACCGTACTTTGTTATGCACATTATTATGTGTATAACTAAC 7620 7621 CTGATAGTGCCCCTTGCCCTGAATGTTGAGGTGATGCTTATGGGTGCTAGGAAATGGTGC 7680 7681 CCAATGTGATGGATCTTGAATTGATAGTTTGCTAATTCTTGCGCTGTATTAATTGAATGC 7740 7741 ATTATACATCTAATCTTTTTAATCCTCAACTCATATACCTAAAAAAAATGTGTGCAGGTT 7800 7801 CCTCATGAAGGACCCATGTGTGATCTTTTGTGGTCTGACCCAGATGACCGATGTGGATGG 7860 7861 GGAATTTCACCAAGAGGAGCAGGTTACACATTTGGGCAAGACATTGCGCAGCAGTTCAAC 7920 
7921 CATACAAATGGTCTCTCTCTCATTTCAAGGGCCATCAACTTGTAATGGAAGGATTTAAT 7980

7981 TGGTGCCAGGTAGGTCTTCAGAATGTAGCGTTGCATTTTCAATTTGTTTATTTGCTCAAC 8040

8041 CAATTGGATTGTTATCATGAAAAAGTACACTAAATTGTGAATATAATCTTTGTAGTTCCT 8100

8101 CTCTAGCTCAGCTTGCAGTTACGATATGACCATTGTGGATTTCTTTTCTCATAGAACTTA 8160

8161 CTCCCTTCGTTCCAAATTATAAGATGTTTTGGCTTCTCTAGATACATTGTTTTTGTCAAT 8220

8221 AGAAAGACTTGCAAACAATAGCCTTTGTTGTGAGCATAGCCCTAGGCACCCTTGTGGTTG 8280

8281 CAACTTGCTGATTATTTATCTTTGGTGTGCTGCCCTTTGAATGTTATTTTGCCCAGATAC 8340

8341 TATCCCACTGGAAGCTTAAATGGTTATTGTTATAATTTTTGCAGGATAAGAATGTAGTCA 8400

8401 CAGTCTTCAGTGCGCCTAACTATTGTTACCGATGTGGTAACATGGCTGCTATTCTTGAAA 8460

8461 TTGGGGAAAACATGGACCAGAACTTCCTTCAATTTGACCCGGCACCTCGGCAAATTGAGC 8520

8521 CAGACACAACCCGCAAAACCCCAGACTACTTTTTGTAATTGTGGTGGTGACCTTAACTTA 8580

8581 CTGGTGTTGATGCTCCTCTCATCCGCAACATCAGGGTCTGTAGATCTTCTGTCCTTAGAT 8640

8641 ATGGGTTCCATGAGCCCGACCTGTACGTCTCCCAATTCATTTGTTTGGAGATTTTGTTGC 8700

8701 TGCTTTCTCGATCTTTATACAAGATGTTAAAAGTTAAGTGCCAGTGGATTTTTCTTTTCG 8760

8761 TTTCTGTTGTACGTCGACTTTGTATTATTTGTAGACAGTGAATGGAAGTCACAGTAGCAA 8820

8821 CGCCCCTGCTATGTTTTTATTTCGGCTTAGGGATGTGTCATCCGCGTGGCTGAATAAATT 8880

8881 CTGTCAGATTTAGTCGCGGAATCCCAATCTGATTTGCTGTTTCATTCTACATTCATGTG 8940

8941 ATGCTAAAATGGTTTCACGATCTAATGTGCGTATAATGTTGGTTGGCGCCTTGCCGTTTC 9000

9001 ATTCTACATACATGTGATGGCTACAATAGTTTCGCAGTGTTTCTAGTACCATTTATGGTA 9060

9061 CATCCAGATCATTCAGTATGTACAGATGAGATGACGCATAATCCACAGCTCTATTCATTT 9120

9121 TTAAAAATCCACTGGGTGAAAACTAGGACAAGAATTTCGTTATCTCAACCGCACAGTAGA 9180

9181 TGATGACGTTTAATCACGAGAAGAAATCAGAACACATGAAATCATAAGCGTGAACAGGAT 9240

9241 GTTTGGCCTTGCATCGTTTCTCTTGGTTAGCAGTGGGACATCGAACGCTCAGTTCAGTTC 9300

9301 CAGCGTCACATGTCCTGGCTTTACAACATGCAAATGGGCATGTCAGTGCACATCTAACTT 9360

9361 CGATTGATCAGGCTTCGTACCATGTCAGTGAACTCGCGATCAACAGCCTGCTTGGTAAGT 9420

9421 CCCCCGGGCAAGGTGCAATGTACGTCAGCTTCTTCCTAGAATGTAGAATGTTAGTTCTTG 9480

9481 GTGCACACTGATAATCTAAAAACTCGCATATTAGCGCTGTCTCCTAAG 9528

FOR

REV 


\section{Supplementary Figure S2. SbSOS1 gene sequence and primer location.} Nucleotide sequence for SbSOS1 gene. Forward primer indicated by cyan highlighting. Reverse primer indicated by magenta highlighting. Exons indicated by orange highlighting. Introns indicated by white highlighting.

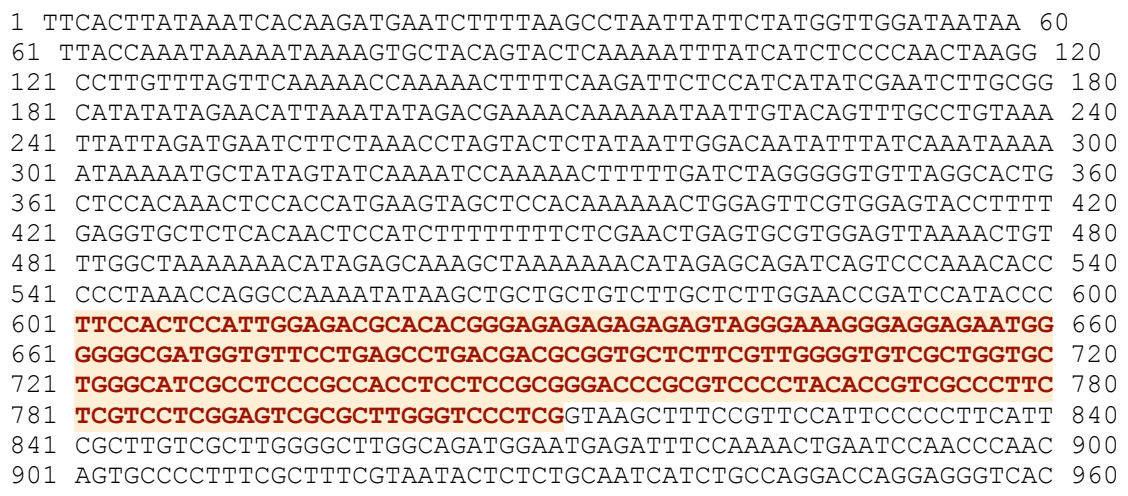

1 TTCACTTATAAATCACAAGATGAATCTTTTAAGCCTAATTATTCTATGGTTGGATAATAA 60 61 TTACCAAATAAAAATAAAAGTGCTACAGTACTCAAAAATTTATCATCTCCCCAACTAAGG 120 121 CCTTGTTTAGTTCAAAAACCAAAAACTTTTCAAGATTCTCCATCATATCGAATCTTGCGG 180 181 CATATATAGAACATTAAATATAGACGAAAACAAAAAATAATTGTACAGTTTGCCTGTAAA 240 241 TTATTAGATGAATCTTCTAAACCTAGTACTCTATAATTGGACAATATTTATCAAATAAAA 300 301 ATAAAAATGCTATAGTATCAAAATCCAAAAACTTTTTGATCTAGGGGGTGTTAGGCACTG 360 361 CTCCACAAACTCCACCATGAAGTAGCTCCACAAAAAACTGGAGTTCGTGGAGTACCTTTT 420 421 GAGGTGCTCTCACAACTCCATCTTTTTTTTCTCGAACTGAGTGCGTGGAGTTAAAACTGT 480 481 TTGGCTAAAAAAACATAGAGCAAAGCTAAAAAAACATAGAGCAGATCAGTCCCAAACACC 540 541 CCCTAAACCAGGCCAAAATATAAGCTGCTGCTGTCTTGCTCTTGGAACCGATCCATACCC 600 601 TTCCACTCCATTGGAGACGCACACGGGAGAGAGAGAGAGTAGGGAAAGGGAGGAGAATGG 660 661 GGGGCGATGGTGTTCCTGAGCCTGACGACGCGGTGCTCTTCGTTGGGGTGTCGCTGGTGC 720 721 TGGGCATCGCCTCCCGCCACСTCCTCCGCGGGACCCGCGTCCССTACACCGTCGCCCTTC 780 781 TCGTCCTCGGAGTCGCGCTTGGGTCCCTCGGTAAGCTTTCCGTTCCATTCCCCCTTCATT 840 841 CGCTTGTCGCTTGGGGCTTGGCAGATGGAATGAGATTTCCAAAACTGAATCCAACCCAAC 900 901 AGTGCCCCTTTCGCTTTCGTAATACTCTCTGCAATCATCTGCCAGGACCAGGAGGGTCAC 960 961 TCCGATCCTTGTTACAGTAAACACCCTTTGATTTCCACCAATAAATGAAAACGATAGAGA 1020 1021 GACTTATTATTAGCTGCTGCTGCTACTACTACCATTACAGTAGGGAGTGACTTTCTATTT 1080 1081 CAGCTCAGTTGGATCAGGATACTACTACTACTAAGTACTACTAGTAGCATTTTTTTATGT 1140 1141 AAATGTAAATACTCTCTCGATCCCTAAATAAATCAACTTCTCTAGAGTTGTCATGAGTTT 1200 1201 TACTTTCGTAACTTCGACCAACTTTATAGATCTACTATGAGATTAAATGAAGTGGTGTAT 1260 1261 CTAATGACACTAATTTTGAAAATGGCACAAATTTTGTCTCATATATGTTGGTATTCCTCT 1320 1321 CTTCTATAAATTCCATCACTTAGTAAAACTGTACAAGTTGGTTTATTTAGGGACAAAGGT 1380 1381 AGTAATATAATGGCCCTGGCCCCTGCCCCAGTTTAATTTCTCTATTATACTTGCTCTGCT 1440 1441 ACTAAGTAGTAAGAGCATCTCCAAGAGCTTGATATAATTTACTTGCTAAACTAATAGATC 1500 1501 TAGCAAGTTAATAAAAGAAATAGCAACTTTAAATTTTGTTCTTCTCCAACAGTAACCTAT 1560 1561 AATAGCTTTCTAAAATTTTAAAATTTATAGTAGGGTCCACATCTATTTGTTATTTTTTGG 1620 1621 TTTACTAGAGACGATCATATCTTTTACTAGAGGGATAGGGAGTTCACTCCACTTTGCAAA 1680 1681 CTTATGAGTTGAGGAGGATATTTGACAACCTTTTATTTTTAAGTACCTTTTTACCAAACT 1740 1741 GTTGGAAGAGACTTTTTTTTTTCTATTTTTGCTAAAAAATTAAGATAGACTCCTGGAGAT 1800 1801 GCTCTAATATTCTCTTTCTCTGGTGACCTCCAGAATACGGAACACAACATGGTCTAGGCA 1860 1861 AACTTGGAGCTGGAATTCGTATCTGTAAGTTTCTTATACTGATTGATACTTCAGTTCCTT 1920 1921 CCACATGTATGTGTAGGTACCTAATTAATTCAATTCCCTACCTGCTTTTATTTCATTCAT 1980 1981 CATTCAGTTAATTATTTCCCTTCCAATTAATTTGCAGGGGCTAACATAAACCСTGATCTT 2040 2041 CTGCTGGCTGTCTTTTTACCTGCССTCСTCTTTGAAAGCTCCTTCTCCATGGAAGTACAC 2100 2101 CAAATAAAGGTACATCATGTGATGTCTGTTTATCCTCCGTGGATGCACGATGTGGGAGTA 2160 2161 AACTAATATGTGATCACAATAGTGCTTGTTCACACCCAAAAGTTTTCTTTTCTGTCTAAA 2220 2221 TCGTTTCAGTTTCTTTCTTAAATCGTTACTGACAACACTGGATGGCCCTACTTCTGCCTG 2280 2281 CTGTACCTCTCTGTTATGCTGTTCATTACTTCATTTATGTGCTAATCCTCAGTTATTACT 2340 2341 TCTGGCTTTAGACGCTCTATGCTTCCTAGCAGACAACCACTTTGGTGCAGGTTCAAAATC 2400 2401 TGTAATGAGAGTAGCACCTTCATATTCAATTACCTCACCCCAAAGCCAGCCACTACACAT 2460 2461 TCAAAGAAATGATGACAAATATTCTTCTAACCTCCACAAAAGAGACAGCTACAGTCCTCT 2520 2521 ACCATCCTTCTTTTTGGCTAAGTTATCTGTAGACAAGAGTTCTTCGATAAGAGCACAAAA 2580 2581 AAAACGTGAACCCTCAGGGGATCCTAAGTTTGCAAACTGCAGGGGTCTAATACACAGGAG 2640 2641 TCACACCAAGCTGGGTTCTGCCCCCCCCCCCCCCCCTGCGGCCTGTTGCGTTGTTTTCAA 2700 2701 GGACCCTAGAACATCTGCATGGGTGTACCCACACCAATATTCTTTCTTACTATTGGTATT 2760 2761 CTATTCTTCCACCATTCGTAGGCTTCTTCAAGTCAAGGACAAAAGCCTGAATACTGTGCA 2820 2821 CAACAAACAATACTAGTAGCTGGAGTAGCTAGCTAGAGCTCATGCAGTCCCTTCTTTTTT 2880 2881 TTTTTGCCCTACTTTACTGCTCGTTGTATTGCGGCATCCAGGCAGCCACAATCGCTACTG 2940 2941 TGGCTACAGCTGGAGGATCACAAATATACAAAATGCATGACATTCAGTTTAGCCTCGAAT 3000 3001 TAGCCCCCCCCCCCCTCCCCCTCTGATTTGTCGGCACACTCCACCACTGCCAGAAACTGA 3060 3061 TGGTCCTATATAGAGGTTGCGAGTAGTACAGTAAACCCCACCTGAAGTGTGTTGCCAAAT 3120 3121 AATTTCATCCTCATTATCTGTTAGCACAAGGGTGGAGGCTATCTGAATCAACTCATCCCA 3180 3181 TTGCCTCATGAGTAATCCCACAGATCGTCTACGGTTAGTGCTATCCCACAGATCAGCAAT 3240 3241 TATTGTCGAATGCTCATTCAGAATCACATAAAGCTCTCAAAACATAAGGGCCAAATTACA 3300 3301 TGGCCCTAACCAATTGTCCTGCCAACATCTAACTTGCTTGCCATTACCAGCCAGCCATCT 3360 3361 AAACCCCATTTTAGCAACCTCAGCAGCCCACTGGAAACCCTTCCAATGGAATTACGATTC 3420 3421 ATATTCCCTAAAAAATCAGCAGATCTATATGAAAGCAACCAATTAGTCTTGTAAATCCTG 3480 3481 TTCTGTGGTTCTCAATCTGATCTTGTGTACTGCTGTATACTCCATCTTCATCTGATATGG 3540 3541 ACGATCTTACACTCTCTTCTGATTATCTTGTTTTTATACCACAATACATTATCATCTAAA 3600 3601 ATGCCTTGTCTGAATAGAATCATGTGGGGAACCTCTCCTCTGGTTGTGCCAAAAAAAAAA 3660 3661 AAATCTGTGTGAACATCATATTTGTTTTCTCTACTGTCACTGCTTCTAATAAGTAATCAA 3720 3721 TAGTAGAGTACTCTTAATAGTACTTGCTATTGATCTTTTTGCTGTGATTTCCTTTATTGA 3780 3781 CGTAGCACAACTGGTCCATATATGCTTGTTGAGTGCTGAATACGATGCTTATTTTGCAGA 3840 3841 GATGTATGGCACAGATGGTGTTACTTGCTGGACCAGGTGTGGTAGTATCAACAGTTTTAC 3900 3901 TTGGTGCTGCCGTAAAGGTATGTGCTTAGAGAAACAATGAGACATTGGTTTTAATATTCC 3960 
3961 AATGCTTCCTAATTTGTGTCCCACAGCTCACTTTTCCTTACAACTGGAGCTGGAAAACAT 4020 4021 CATTGTTGCTTGGCGGACTGCTTAGTGCAACTGATCCAGTTGCTGTGGTTGCACTGCTAA 4080 4081 AAGAACTCGGAGCAAGTAAAAAGCTTAGTACAATCATTGAGGGTGAATCCTTAATGAATG 4140 4141 ATGGGTAAGCTACTGTAGTATTGGACTCTAGAAGCGGTTGGACTTTCTGTTCTAGTCACC 4200 4201 GCTGTACATTAATAAATAAATCACGCTTCATGCTAAAATTAAATTTGAAAGTATTTACAC 4260 4261 TACCGTGCTAATAACAGAAGTTGTCAAAGCTTTTATATTCAACAGTTATATTGGGAATGT 4320 4321 AAATTTTGTGCTCTATTTATGTAAGCTAAAATATGGAATTCAAGATTTAATGAACTATG 4380 4381 CAATGACCTGTTGGACACAAATCACAGGATTGGGGCTAGTTTTTTCATTTCATTAGCCTT 4440 4441 ACCACAACTATGGCAAGGTTGGGGATACATATAGGGTAGCTTGCTTGGTTCTTAAGAAAG 4500 4501 GATTACAACATATTCTAGAGATGCTAAAGTAGATGTTACAAAGATAAGGTGCTGACACAA 4560 4561 CAGCCACCAACTACTCTAGATAAATATCCTAGGTAGATAAGCATTGGACTTATGCTTTCA 4620 4621 TTCTCCCCCTAAGTATTGTGCAGCGCCTTCTGGAGAATTTGAACCATCCCAATCCTTGCG 4680 4681 CGAAGCTCCTGGAACTTGACCCGCCCAAGGGACTTGTTGAGAAGGTCAGCAAGCTGATCC 4740 4741 TGGGTGTTGATGTAGCCGGCCTTGATGCTTCCCTCATCCAAACAGCTTCCGATGAAGTGA 4800 4801 TACTTGATGCGGATATGTTTGCTGCGCTCATGGAAGACGGGGTTCTTCGCCAAGGCCAAG 4860 4861 GTGGACTTGCTGTCCACCCTGAGCTCCACTGCTTCAGCGTCTCTGCCCAGGAGATTGCCC 4920 4921 AGCAGCTGAGCCAACCAGAGAGCTTGAGTCGAAGCGGTTGTGGCAGTGATGTACTCCGCT 4980 4981 TCGCAACTGGACAGAGCCATCACTTGTTGCTTGAGTGACAGCCAGCTGATCAAACACTTG 5040 5041 CCGAGGAAGAACAGCGTACCGCTGGTGCTCTTGCTCGGGTCGATGTCGCAGGCGAGGTCG 5100 5101 CTGTCGCTGTACCCGATGAAGTGTTCCGCACCGGAACACCTCAGGTAGTGCAAGCCGTAG 5160 5161 TCGGTGGTGCCCTCGACATAGCAGAAGATCCTCTTGACAGCCTGCAGGTTCTCTGTTGTC 5220 5221 GGTCGTTGCACGAACCGGCTGACATAACCAACAACGAACGCCAAGTCCGGCCGCGTGTGG 5280 5281 ACGAGGTAGCGAAGGCTGCCCACCGGTACTATGTGGCGTCAGCCTCCTTGGCCGTGCTGT 5340 5341 CGTGGCTCAGCTTTAGCCTCTCCGCCTCTCCTCCATAAGAGTGTAGGCTGGGTTGCAGCC 5400 5401 GATGAGCCCACCCAACTTGATGATGCGCTTGGCGTAGGCGGTCTGGCGAAGGGAGATGTC 5460 5461 GGAGCTATCCTAGTGGACCTCGATCCCCAGGTAGGAGAGAAGGCCCAAGTCACTCATCTG 5520 5521 GAAGGTCGCCTTCATCTCCTCCTTGAACGCCTGCACCTCAACCTCCTTGGTGCTGGTGAT 5580 5581 CACCAAGTCGTCGACGTAGACGCCTACCAACAGGGCATTGCCATCCTTACCCCGTCGGTA 5640 5641 GACAGCAGCTTCATGAGGACTTTGTTGGAACCCCATTTGCTTGAGGGTGGAGTCCAGCTT 5700 5701 GGCATTCCAAGCTCGAGGCGCCTGCCGCAAGCTGTAGAGGGCCTTGCGCAGGCAAAGAAC 5760 5761 CTTGTTCTCCTTGTCGAGGATGATGAATCCTAGCGGCTGGTGGACGTAGACCTCCTCCTT 5820 5821 CAGGTCACCATTGAGGAAGGCAGACTTGACGTCCATGTGGTGCACACGCCAACCTTCCTG 5880 5881 GACCGCTAGCGCGAGGAGGAGACGAACGGACTCCATCCGCGTGACGGGCGCGAAGGCGTC 5940 5941 GTCGAAGTCGACTCCCTCCTGCTGGACAAAACCGCGCGCCACCAGACGTGCTTTGTGCTT 6000 6001 GATCACTGCCCTGGCCTCATCCTTCTTGAGCTTGTAGACCCACTTAAGGGTGATGACGTG 6060 6061 GTGACCGGCAGGAAGATCCGCCAGCTCCCACGTCCGGTTCCGCTCGACCGTGTCCATCTC 6120 6121 CTGCTGCATCGCGGCCGCGTCTCCCTCCGCCTCAGCAAAGGAGCGAGGCTCGCCGTCTTC 6180 6181 GTGTGCTAGGTGCAGCTTCGCCTCGAAGTCATGAATCACCAGTCCAGGGACGGGCTGATC 6240 6241 ACCAAAGATGTTGTCCAAGGTGCAGTAGCGCAGAGGCTCGTTGTCGTGGTACGCATCGAT 6300 6301 GCGATCCTCGTGGACGGACAGCGGAGTGGCAAACTCCACCGTGCACTGCTCATCACGGAC 6360 6361 TGAAGCTGTCGGTGCCGATCCTAGAGGTGTGGGTGCTGGTGCCGGTGTGGGAGTGTGCAG 6420 6421 AgCCGGTGTAGATGGGGCACCACCGGTGTAGGAGAGCAGGGCGTAGCCAGTGTGGAACTC 6480 6481 GCTGGTGGTGTAGGTGGTGGAGGACTCGCTGAAGGTAATGGCGAGCCGGGTGCCGAGGTG 6540 6541 GACAAGCTCGGTGAGGATGAGCTGCTAGCTCCCCTAGCTCCCCCGAAGTGGACGTAGTCG 6600 6601 ACAACAAAGTCTAAGTCGAAGTCGAGCCATCGTCCACCGCCTTGTCCCAAGCCCAGCCTC 6660 6661 GCCCTTCATCGAACACGACGTCCCGGGAGATGCGGACGCGCTGTGTCGCAGGGTCGAGGA 6720 6721 TGCGGTAGGCCTTGACGCCCTCCGCGTAGCCGATGAAGACTCCCGTCGTGGTTCCCTACG 6780 6781 TTGCGTCCGCCGAAGCCGCCCAGGTCTGAGTCCGTGTTGAGGCCGCGTCGGTCCCCTGCG 6840 6841 CCCCGCAGGGCCGTGTCCAGGTCGCGGTTGCGCCCACCTCAGCGCAGGTCGAGGACGCTG 6900 6901 CGTCCACTTAGGTCCAAGTCGCGCCCTTCTGCGAGCTGGTCTGCGTCCGCGTCCACTTGC 6960 6961 TCGCCCCGCGCACCTGTGTGGACCCGCTCCCAACACGCGTTGATGTCACGTCCCGCGCGG 7020 7021 CCCGCATCCGCTCAGTCCACCTCTGCGCCTTGCCGCTCATGGACGAGGCCGCCATCTGCT 7080 7081 TCCGTCAGGCCAGCTGCCTGCGCTGCCGCTGCTTGAGCCGCAGCGGCCGCGACCGCGGCC 7140 7141 TCCTCGGCGGCAGCCAGCCGCAGCCGCCCGCTCTGCCGCCTCCCGCTCACGTCTCTCTGC 7200 7201 TGTGAGCAGCTCTGCGTTCCGCACGTCCTCCCCTGCAGCTTGCCTGCGCCGTACGCTTGA 7260 7261 AgTGGTGGAGCGATTGGAAGAGGAAGAGGAGTAGGAGCGGACGGACATGGCTGGATTGGG 7320 7321 ATTGGTAACGGGGAAAAACCCCAGGTAAGAGACTAGGTCTAGATACCAATTGTTGGACAC 7380 7381 AAATAACAGGATTTGAGGCTAGGTTTTTCATTTCATTAGCCTTACCACAACTATGGCAAG 7440 7441 GTTGGGGATACATATAGGGTAGCTTGCTTGGTCCTTAAGAATGGATTACAGCATATTCTA 7500 7501 GAGATGCTAAAGTAGATGCTATAAAGATAAGGTGCTGACACAGCAGCCACCAACTACTCT 7560 7561 AGATAAATATCCTAGGTAGATAAGCACTGGACTTATGCTTTCATGACCTATGTACTATGG 7620 7621 TATTCACTCTCCTCATTGTATGTATTAGCTACATATTAGGTATTGTGGTGCATACATGAT 7680 7681 ACCTAGAAATATAGAAgTTTTCAACTTCAgTTAATATACAGTTATAGAATCTGTGAgAgC 7740 7741 TACCTCATGCTAAATGATCAGGCAGAACTCCTGCCGGTTGTTTAAACTCACTCTTCTTCT 7800 7801 CTATTAATATATTGCCGAGCAGAACTCCTGCCGGTCATTTAAAAAAAACTCATGCTAAAT 7860 7861 GACCTCGAATTCTACAGGACCGCTATCGTTGTCTATCAGTTATTCTATCGAATGGTGCTT 7920 
7921 GGAAGAACCTTTGATGCTGGCTCAATAATAAAGTTCTTGTCTGAAGTTTCACTTGGAGCG 7980 7981 TATGTGGAATTTCTTTTTTACATTCAGAATGAATTATATGGATATGTGTGTATAATGCTG 8040 8041 ATTAGTACCTTCTTTGATCAGTGTTGCTCTGGGCCTTGCATTTGGAATCATGTCAATACT 8100 8101 GTGGCTAGGCTTTATTTTTAATGATACAATCATAGAGATTGCACTTACTCTTGCTGTCAG 8160 8161 СтATATAGCTTTCTTCACTGTAAGACCATGCCACTCAGAAGTCCTTACTTCCCTCTATTT 8220 8221 TCTTGGAGACTTTGCTTTTGCTAATGTTCATTTGTATCAGGCGCAAGACTCACTCGAGGT 8280 8281 СTCTGGTGTTTTGACCGTCATGACACTGGGAATGTTAGTAAACTTGTATCCACAAATAGT 8340 8341 TTTTGCATGTTATTTAATATCATTTCTCTCATATTGACCGTGTTACCTGGCAGGTTCTAT 8400 8401 GCAGCTTTTGCAAAAACTGCTTTTAAGGGTGAAAGTCAGCAAAGTTTACACCATTTCTGG 8460

8461 TATGTATCTTATAGAAACAAGTCAGCCTCCAAACTAGAGGTCCTACTGCCGTGCTATGCC 8520 8521 GGTATCACTGTGTTTGCATAACTGGGGAAGCTAAACAAGGAGTCAGCCAGGGTGGTGGAA 8580 8581 TTGGAATTGCTGGTGAACTACTTATTGCACTACGGGAACTAATTTGAGGGTCTGTCATAG 8640 8641 CTATTTACTAGCCATGTTAATTTGGGATCTGTAACCAACAAAAAGAATCATTACAGAAAC 8700 8701 TTATAAAACCATAACGACATAAATACACAATCATTTAATACCATTTTTTTGCATGGAACA 8760 8761 ATTCTGGCACTTAGTGTCTCTGTGATTCTTATCCTAATTTTGTTGATGAATAATATGCCA 8820 8821 GTGGTGGTTACCAAAAGTACTGACAGAGGTTGAACCTGTTAGGTTTCACGCACCAACCCC 8880 8881 AGATGAACCCAAAAACTTAAGCCATTGGGAAGAGGTGGCCAATCCACTTATACACTTCAA 8940 8941 CACTCCCACTCATGGGCAGCCACAGACAAGGCGTAAACGTGGAAATAAAGGAGTGGAGGA 9000 9001 CTTAAATGATGTCTCTACTAGAATTCAAACTCGAGATCTTTGGTTTTGATACCGTGTTAG 9060 9061 GTTTCATGCAATAACCAAATGAACCCAAAAGCTTAAGCCATTGGGAAGAGGTGGGCAATC 9120 9121 CACTTATACACTTCAACAGAACAAGCTCATATTCCATTCATATGGAGTAAACCAGATTAC 9180 9181 AGTGATTTAAATAGGAGCTAGACTAACACAAGAGAGGAGAAAGAGGGAAGCTCTCAGGCG 9240 9241 ACAGTCCAGGCATCAGCCGACTAGCAGTAACTGGAGAAGTAAACACTAGCAGTAAAGAGG 9300 9301 GGAAGTAAACAGGGGAGGTTCCTAGGCAACAGCCGGCTAGTAATATAGGAAGCAGTAAAC 9360 9361 ATGCTAACAAGTACTATGAAATCTTTTCAGTTGACACTAAGGCCTTGTTTAGTTCGTGAG 9420 9421 TGAAAAGTTTTTGGGTGTCCCATCGGATGTCAGAAGGGATGTTCGGATATTAATTGAAAA 9480 9481 ACTGATTACATAACTCGCCTGGAAACCGCGAGCCGAATTTATTAAACCTAGTTAATGTGT 9540 9541 CATTAGCACATGTGTGTTACTATAGCAATTATGGCTAATCATGGACTAATTAGGCTTAAA 9600 9601 AGATCTGTCTCGCAGTTTTCATGCAAACTGTGCAATTAGTTATTTTTTTATCTATATTTA 9660 9661 ATGCTCCATGCATGTGTCCAAACATTCGATGGGACAGGGTGAAAAGTTTTTGGGTGGGAA 9720 9721 CTAAACAGGGCCTAAATTAAGGTATCCTAATCTGGGTATTACTAGGAACACATCAAATTA 9780 9781 TTGACTTCTTTTCTTCTGTAAATCATGTACATGATCTTGCATATATGCTCTGCAAGATAG 9840 9841 TTCTTTACTTTTCTGATATATGAGTATTCAGCTGATCCGAGTTTCATGTTTGCTTTGTTC 9900 9901 TTACTCTTGTATTCAGGGAAATGGTTGCTTACATTGCAAACACACTTATTTTTATACTGA 9960 9961 GGTATTGGCAGCTCTTCTGTACACATGGGAAAAAAAAACTTTCTCTGGTTTTTTCTCTGG 10020 10021 CAGCTCTCTGTCCACTCCTGCTTGCTTTGATCTTATGCTTCATAATGACACAGTTGTAAA 10080 10081 GTTTCTCACATGTGAATTCCCTTCAGTGGGGTTGTTATTGCAGATGGCGTTCTACAAAAT 10140

10141 AATGCCCACTTTGAGAGGCACGGTATGCACCATGTACATCCTGAAATTTATTTCTATATG 10200 10201 TCCTTTAGGTCGAGGTCAGTTTTTTCCAATCTAGTACTGGTGCGTCTGCTTTTATAAGCC 10260 10261 TATGAGTGAGTGGTCTGTGTTATAAGGGTTTCTCTGAACCCCCTTTTCTCTTCTTAAATA 10320 10321 TAATATAATGATGCACACATATTCAGGAGAAAAAAAAATCTGTCCAAGTGAAATATACAA 10380 10381 AAGCCACCTCACCCTTGACCATGACATGTTCAGATAATCCATTTGGCTTCTACTGAATTG 10440 10441 GCTTTGATTTTTGTTACATGTTTTGATATTATGGTGAGTTGAACCTAATTGATCACCACG 10500 10501 TCCCATTCAATATATGGATATTGGAACTATTACAAATCAAATCACAGTTCACAGCAGAAT 10560 10561 AATATGAAATAGAAAGATCCAATTCTTACTATGAGCAAATCAGTTTTCCTGTTTGTTATG 10620 10621 GACTCGTTGGTCAAAGAAGGATGAGAAAGAAGGCAGCTGTTAGAATAAGTGGCCAACCAA 10680 10681 TCCCTATTCCAAGCCCAAAGGGGTAAGACCCCCCCCCCCCCCCCCCCCCCCCCCCGCGCG 10740 10741 CGCGCAAACTCATGGTGGGTCAACCACACAGCTGCGCATCATTCTATTAAGAAGTGATGA 10800 10801 AAAAAATAGGGAATCTGATCCTTAGGATGTCAGCGCACCCGAGAATATGTTTCAAGAGGC 10860 10861 GACCAGCAGAAGTTCAAGGATCCTAGCATTCTGCATGGGAGGCAGTCAGGAGGGAAATAC 10920 10921 CTCTGGCCCCAGCCAACGACCATAATTTATGCTCATCTCTAGCAATGATCACAATTCTTC 10980 10981 CAATATGAGGGGCTGCTCCATCAAAAACACACCTGTTGCGATGAGTCCATACAGTCCAGC 11040 11041 TCCAAGAATTATGAGAGAATTGATTCCATGTGAGATTCTGTCACTGGTACCACTAGTCGC 11100 11101 TCTATCCCACCAATCTAAAAAGGATAGTTCAGTGGGCTGAGGAGAGAGGGATTGTAGGCC 11160 11161 AACTTGTGACAAGAATCGGAACCAGAACTCTCTTGTGAAGACACATCCAATGAGGAGATG 11220 11221 ATCAATGGTTTCGGATGCTTGGTCACACAAAGGACAGCACTTAGGATGAGGGAGACCTCA 11280 11281 GCGAGCTAAACGATCTGCTGTCCAACATCTATTATGAGCAACCAGCCACAAAAAGAAGCG 11340 11341 ACATTTAGGTGGCGCCCAAGTCTTCCAAATTTTCTCCCACGGTCTGAAAGGAATAGAACC 11400 11401 CAAAAATAGGCCCTCATAAGCTGATTTAGCGGAATACTGCCCATCTGAAGCAAGTTGCCA 11460 11461 CACATGTTTATCTTCTACTTCAGGCTGCAGCTCAAAGTCTGATTAGAGGTCCCATAGGCG 11520 11521 GAAAAACTCAGTGATAAAACCAACCATGCGAGCTCCCTGTAAATCTGAAATCCATGTATG 11580 11581 GTTGGAGAGGGCTTCTTGCACCGTCCTCTTCCTGCGTCTCCTTATAGCAACAGCAGCGAA 11640 11641 GAGGCGAGGTGCCACATCTGCAATGCATTGACCATGAAGCCATTTATCTGTCCAGAAAAG 11700 11701 GGTTGTTGCTCCATCTCCAACCTCAGAATAAATTGCCGCTGCAAAGAAGACCCTTACTTG 11760 11761 TTCAGGAACCTGGATTGGGAGGTCTGCCCATGGGCGATCAGGTTCTGTTTTTTGTAGCCA 11820

11821 GAGCCAACGCATTCGCAAGGCCCAGCTAAGGGACTTGAGATCTGCAATTCCTAATCCACC 11880 
11881 CAATTCAATTGGTCAACATACTTTTGTTACGTACCTTTGGGATCACGAAGTACAAGCACT 11940 11941 CCAGAGATGGAGTCGTACATATATATAGAGAGCCCCCTGGCTATATATAGATAGAGCCGG 12000 12001 CTATATATAGATAGAGCCTATAGATAGGCCTATTGACTTGATCTTCATCATATACTTAAC 12060 12061 ACCCCCСTTCAAACTCAAGGTGGAAGCGGAGGAATGGAAGCATTGAGTTTGATCAAGTGA 12120 12121 AgTCGATGCTGCTCTCGAGTTTGTGCTTTAGTGAAAAAGTCAGCCAATTGCAACTCTGAA 12180 12181 GGCACATACTGGAGAGCAATAGTTTTCTGTTGACAATGAGACCGAGTAAAGAAAGCATCC 12240 12241 ACACCAATATGCTTTGTAAGTTCATGCTTCACAGGATCATTGGCAATCTGTATGGCCCCT 12300 12301 GTATTATCACAGAAAAGAGGTGTGGCAACATTACAAGAAACACCAAAATCTGCCAACAAC 12360 12361 CATCGCAGCCATACAATCTCTGCAGTAGTGGTAGCAAGGGCTCGAAGTTCAGCCTCTATA 12420 12421 CTAGAACGAGATACAACTGCTTGTTTCTTGGACTTCCATCCAATGGTAGAAGAACCAAGA 12480 12481 AGAATACAGTATCCTATGATGGAGCGTCGATCATTTGGGTCACTCGCCCATGTGGAGTCC 12540 12541 GAGTAAGCATGAAGCTGAAGCGGACTGTCATGTGCATAGAATAAACTCTGAGATGATGTT 12600 12601 CCCCGTAAATATCGTAGCACACGAAGTAGATGTCCAAAATGAATAGAAGTTGGGGCACAA 12660 12661 ACAAATTGACTCAAAATATGGACAGCATGAGCAATGTCTGGCCTGGTGACAGTAAGATAA 12720 12721 ACAAGGCTGCCCACAATATGTCGATATCGAGAGGGATCCTGAAGAGGCACCCCATCAGTG 12780 12781 AgACGAAGCTGCAAGTGAAGATCCATAGGAGTAGCAGCAGTCCGGTCATCAGAGATGTCT 12840 12841 GAACGAGCAATAAGATCCTGTATGTACTTAGACTGAGAAAGATGATATCCCTTAGTGGAC 12900 12901 TTCTTGACCTCAATGCCTAAGAAATAACTGAGAGGACCCAAATCCAACATCTGAAATTCA 12960 12961 GCACTAAGTTGTTGCTTCACATGGGAAATATGATCCTCATCATCGCCCGTAATCAGCATA 13020 13021 TCATCAACGTAGAGAAGAAGCAACGTACGACCACGCGGTGATAAATGAACAAATAGAGCC 13080 13081 GGATCATGATCACTAGCTGAGAAGCCAGCAGCCTGTATCACTGAGACAAAACGCTCATGC 13140 13141 CAAGCATGAGGAGCCTGTTTAAGACCATATAAAGCACGGCGAAGACGACAGACATATCCT 13200 13201 AGGGGAGCAACAACTCCTGGGGGTGGCTGCATATAAACTTCTTCAGTCAAATCACCATTA 13260 13261 AgAAAGGCATTCTTGACATCCATTTGAGATATGGACCAGGAAGAAGCTGAAGCAACTGCA 13320 13321 ATCAATGTACGAACTGTTGTCATATGAGCAACAGGTGCAAAAGTCTCATCATAATCTAGA 13380 13381 CCCTGAGTCTGCTGAAAACCTCTAGCAACAAGACGAGCCTTATATCTCTCTATAGAGCCA 13440 13441 TCTGACTTGGTCTTAACTTTGAATACCCACTTAGATGTAATAGGTACTGTGTGCAATGGC 13500 13501 AGTGGAACAAGATCCCAAGTGGCTTGACGATCAAGGGCAGCAAGTTGCTCAGACATAGCT 13560 13561 AGCTGCCATTCTGGAATTGAGAGGCTTCCTGATAAGTGGATGGCTCATCAACAATAGCA 13620 13621 TGCACTTGGGGAAAACCATACTTCTCTTCAGGATGAATAGTACTGTGGTCTCGGAGATTA 13680 13681 TACCGTGGAGCAACCTGTAACTCATCAACATGTGAATCATCAATGTTATTATTAGAAGCA 13740 13741 TCTGCAGCGGGCTCATCAGGACTAGCCATGGTGGAGGGAGAACTAGGCTGAAGCTGGGAG 13800 13801 GAACGACGGTTGTAGACACGTGTAATAGGTGGTTTTGAAAAAGAATGTGATGGAGGCGAG 13860 13861 GATGTTGTAGGAGGTAAAGGTGGTGTGATGGAAATACGTGGATCAGATGGGGCGGAAGCA 13920 13921 TCATCTGTGGATGAATTTAGAGGAAGGATCAAAAAGGAGGTGGACTCTATGGGAGAATAT 13980 13981 GAAGGCTTAGTGGAAGGGTTATAAAAGAAAGGATGGTCCTCAACAAAAGTAACATCACGA 14040 14041 GAGATGCGTATGCGACGGGAAGAAGGATCATAGCATCGATCTTATGCTCAAAACTATATC 14100 14101 CCAGGAAAACACACTCAACAGACTGGGCAGTCAATTTCGTGCGCTCACGAGGGGCAAGCA 14160 14161 AAACATAGCATGTGCATCCAAAAACACGAAGATGGTCATATTTTGGAGGGGTACCATAAA 14220 14221 GTACTTCACAGGGCATCGGTCAGACAACTTGGATGATGGTTGCCTATTGATGAGATAAAC 14280 14281 AACAGTGGAAACAGCTTCACCCCAAAAATGAGAAGGAACAAAGGATGAAATCAAAAGGAT 14340 14341 GCGAGCTGTCTCTATGAGATGGCGATGTTTGCGTTCAGCAACGCCATTCTGAGCATGAGC 14400 14401 ATCTGGACAAGAAAGCTGTGCAAGGGTACCCTCAGAGGACAAAAAATGGCGAAAAGCAGC 14460 14461 AGACAAATATTCACCCCAGAGTCTGAGCGAAGAATTTTAATCGGAGCAGAAAATTGTGTG 14520 14521 TGAACCATTCGAGCAAAAGTTTGATAAATGGAACACAACTGTGAACGATGTTTCATAAAA 14580 14581 TATATCCATGTATAGCGAGAAAAATCATCAATAAAAATGACATAATATTTGTGACCAGAC 14640 14641 CACCCTTTGTAGCAAAAGGTGCAGGACCCCATACATCTGAATGAATAAGATCAAAAGGTC 14700 14701 TAGCAGATTGAGAAACACTAGAAGAATAAGGAAGTTGTATTTGTTTGCCAAGTTTACAAC 14760 14761 CCTTACAATGAAAACTAGACTCAATAGATGTATGACCTAAACAACCTTTATTAATCATGA 14820 14821 AGGACAAACGAGACCCACAAAGATGACCAAGACGATGATGCCACTGGGCAAAGGAGGCAG 14880 14881 AgGACGATGCAGCGGATGAGGCATGGGTTGTAGGTGCAACTGACGAAGGAAGACGTAGGG 14940 14941 TGTCTAGAACATAAAGGCTAGAAGCACCCTTACGGCGATGGCCAGTCCCAATCACTTTCC 15000 15001 CGCTGCGACGGTCCTGAATAAAACAAGATGAGTCATCAAAACCAACGAAACAATTCTGGT 15060 15061 CGGTAACTTGACCAACTGACAAAAGATTCATAGACAACTGAGGTACAAAGGAAACATTAG 15120 15121 GTACAGAGAAATGATTGTTGCAAAGTGAACCCTGATGAGTAATATGACAAGAAATATCAT 15180 15181 CAGCTGTCTGAATAGAAGTGCCATCAGTGACCGGCTTGCAGGCAACCAGCTGGGACTGAT 15240 15241 CAGATGTCACATGAAATGAGGCTCCAGAATCAAGCATCCAAGACGAAGGAGCACTGACAG 15300 15301 TCGAGGAGGCAGCAACAGAAACAGTACCACTAGCTGAACCTCTAGGAGTGGAACCAGTAC 15360 15361 CACGGCCACGACCACGAGCAGCACGCCGTGCACGGTACTCAGCCAACTTCTCTGGATGAT 15420 15421 GAGAGAAACAATTGTTTGAAAGATGACCAGTCCTGCCACAATGCTTACAGGGATCTGCAG 15480 15481 AAGTATTGTTGGGTGTACTAGTCCTCCGAGAAGCTGCCAACACACCAGGAGACATTGTAG 15540 15541 ATGACAGGGACTTGAGACGAGTTTCTTCTGCAAGTAAGTCTGACAGAGCATTTGCCATAG 15600 15601 TGAGATCAGAAGAACTATGAAGTAACCATGTACGGATGGAATCATACTCAGCTCGAACTC 15660 15661 CCATGACAAATCTATAGGTGAAGAACTTCTCAATAAATTTATGTGCTGGACAAGAAGCAG 15720 15721 CTGAACATTCAGGTACCATGGAAGTCAATGATCCCATCAGTCGATCAAAAGCAGAATAGT 15780 15781 ACTCATCAATGGACATTTCATTCTGCTCAATGACATGAGTTTGCTGCATAAGACTATGTA 15840 
15841 AAAGAGCCCCACTGTCCTGTACATAGCGCTGCTTTAGATTTTCCCATATGGCCTTAGCAG 15900 15901 TTTCGAACTTAGATAGACTCATAATCAAAGACTGTTTAGTACTATTGACCATAGCAGCCA 15960 15961 TCACTTTGCCATCATTGATACCCCAACCTTAGCCTTAGGGGCATTATCAGTTAGATGATG 16020 16021 CAGTAAACCATGACCTCGTAATGCAGTTTCCACGCAGAAAGCCCATTCAGGATAATTTGG 16080 16081 ACCCTCTAAAGTAATACGGATGACAATTGCATTGAGCTGAGACTGAGACATGATTGACAA 16140 16141 GAACTGCTAACAGCTGACCAAAGATGAGGGAGGCAGCAATCTGTTACCACAGTGGTATAA 16200 16201 GCAGCAGACGACCCCCTCTGTTTGCTGGACGTGCAGGACCTCCTCTGCCAACAACAGGCA 16260 16261 GACAGAGCAGGGGAGGCAACAGGCAGACGAAGCGGGGGAGGCACAGACGGAGCAGAGGAG 16320 16321 TCGGCAGGCGGACAGAGTCGCGCAGAATCGCGCACCCCGCGACGGGCGAGTCCACGCGCG 16380 16381 CGCACCCCGCTACGGATGAGTCCGCACACGTGAAGAAGACTCGGGCGGACGCCCGCGATC 16440 16441 ACGATCACGATCACGATCTCCGCACGCTGAAGAAGCCTCGGGACAATCGACGAGGGACAC 16500 16501 AGCGATAAGCCGCGCGAAGACGGCGACGAGGGAACGCGGCGACGGGCCGTGCGATGAAAG 16560 16561 GAGGATCCCAAGGAGAAAGAACTGGATCGTGGGTCAGATTAATCTAATCCTAACCCTAAT 16620 16621 CCCATAGCTCTGGTACCATGTTACGTACCTTTGGGATCACGAAGTACAAGCACTCCAGAG 16680 16681 ATGGAGTCGTACATATATATAGAGAGCCCCCTGGCTATATATATAGATAGAGCTGGCTAT 16740 16741 ATATAGATAGAGCCTATAGATAGGCCTATTGACTCGATCTTCATCATATACTTAACAACT 16800 16801 TTGACCCACGCAACCAGACAGTGCCCTCCCTGTGCATCCCTTCGACCTTTCCAAAGAAAA 16860 16861 CCACGCCTAATTTTATCCACTGCTTTGATGGCTCATGGTGGAAGATCAATAGCCATGAGC 16920 16921 ATATAGATAAGCATGCCAGTGAGCACTGATTGTACTAGAACTTTTCTCCCAATTTTGGTC 16980 16981 ATCAGATTCGCTTTCCAGCCCGGAAGCTGATCGGCAATGCGGTCAATAATTGGCTGCACT 17040 17041 TGCTCCTTAGTACTGCACTTGCTCCTTAGTAAGTTTCTTCAGGGAGAGGGGCAAACCCAG 17100 17101 ATATTTGCATGGAAAACTAGCAAGTTCACATGGCAGCAGGTTCTGTATAGTTGACATCTC 17160 17161 AGTTTCACCACATCTAATGGGTAGCACACTACTTTTCTGTAAGTTTGTCTTGAGCCCTGT 17220 17221 TGCCTCTCCAAACAGATCAAGAATGCCCATTGTTAAATTGATATCCCCAGCCACTGGTCT 17280 17281 AAGAAATAACACCACATCATCTGCATAAATAGAAATCCGGTGCTGCAAGGCCCGCCTTGA 17340 17341 CAGTGACATCAACAATCCCTCAGCCTCAGCCTTGGAAATCATATGCCCTAAAACATCCAC 17400 17401 GACCAAGATGAACAACATCGGGGAGAGGGGGGCGCCCTGCCGTAATCCACGCCGATGGAT 17460 17461 GATATGATCTCCAGGGCTTCCATTCAGTAGCACTTGGGTGGATGAAGAGTAAAGCAGACC 17520 17521 ACTGATTATCTCCCTCCAAACTTGTCCAAAGCCAAGCTGCTGCAAAATTTCAAGGAGGAA 17580 17581 GGACCAAGCCACGGAGTCAAATGCTTTTGAAATATCCAATTTGAGAAGAATACGTGCCTG 17640 17641 TTTCTGTTGATTAAGAAATCTCGCTGTCTGCTGCACTAGCATGAAATTATCTGTAGGGAC 17700 17701 TGGAAAGAAGAGCTGAGAAGAACCGGAGTGGTTGTTCTGCTTGAATAGGCTTCATGGGCC 17760 17761 ACAGCTCAGAGATTCAAGGTAGTAGTTCCTTGAAAGATAAGAAGCTAGCACTTCGAGGAA 17820 17821 GTAACCGAGCAATCGAGCGATCAAGCTGCCATATTTTTTGCTCCCCCTTAGTCCAGATTA 17880 17881 CTAATTAACAGTCCTCCAAGGCAAGGGTATCTGTCTTGCTAGCTTGCTTTCTTATCTCTT 17940 17941 GCTTCCTCTCCGGTGGCAGCCCGGCGGGCTGTCTTACCACCCCTCGCTTCCGATCTCGGG 18000 18001 GTGGCGCTTAGGCAGGCCTATTCCCTAGTGCTGGTTTCAAAGCGTCCTTTTATGAATGCG 18060 18061 CTCTGAATGGGAGATATAATTTGCTGCAGCCTTGGAGCAAGACGGTTAGAAAGCAACTTT 18120 18121 GTGCTTAATTTGGCAAAGCTATGCACCAAGCTTATAGGTCTGAAATCCGGTGGGTTGTTC 18180 18181 GGCCCCTTCCTTCTTTGGGAGGAGTATGATGTATGCAGAATTGAGCACTCCAAAATTTGC 18240 18241 AAGTCTCCTACTCCAAACTGCAGAGATGGCTGCCATGACGTCTTCTTTTATGATGGACCA 18300 18301 ACAAGTTTTATGATGGAACCACCTCTTTTTTTTATTTTTTATTTTTATTCTTTTATATTT 18360 18361 ATGTTTTAGCTCTCATTAGCTCAGACTTTGATTCAACATACAGATATGCACCTGAATTAA 18420 18421 TCAACATCATCTCAGTTTTGCTCGTAACTGTTGGAGTATGAATGGTACAGGCCCATGTGG 18480 18481 CTAGGCCCATGAGGCCCTTGTATGGCAACTATATGGCCACCCTGGTTAGGGTTGGCCCAA 18540 18541 GTTAAGGAAAACCTAACACCTTTGTGAAAAAAAAAACTTTGGTGGGCTAAAGAAAAAATT 18600 18601 CTAGTTTTGACATGTGGTGTCCCATGTTCATCATAGTGGTACGGCTGATCAGTAGCTACT 18660 18661 ACGCTATTCTGTCTGCACCCACCTCTCCCGATTAACTTACGAGACCAAACCTAGAATCAG 18720 18721 TGTTTATGAAAGATGGTATGCTAATGCGAGTGCTTCTTTCGTTTCGTGTGTCGCTTCGAT 18780 18781 GGCCAAGACCACGATCATCATATCCCCGTATTGCGTTGCGTCATTGTGTCTCCATCCGTT 18840 18841 GTCTATCTCGCCTGGGCAACGCAAGACGCCAACGCCAACTCCAATGCATGCCATGCCCAA 18900 18901 CGACACAAAAAAATAAAATCCCCTCTGGCCTCTGCTCTGCTCTCTCCGGCCGCACCGCAC 18960 18961 CTCGACCGGTGGAAGCTTTTAGCGATGAAAATGGTACGGATGGATATTTTCCGATCGTAT 19020 19021 TTGAGACTAAATTAGTTTAGAGAAGTTCAGATCTATCCGTATTCAAGTCCGAATATTCAA 19080 19081 CATTCGATTATGTATCCATATTCGAATACTTAAATCGTATATTCGAATACTTTGATTCAA 19140 19141 CATACAGATATGCACCTGAATTAATCAACATCATCTCAGTTTTGCTCGTAACTGTTGGAG 19200 19201 TATGAGTGGTACAGGCCCATGTGGCTAGGCCCATGAGGCCCTTGTATGGCAACTATATGG 19260 19261 CCACCCTGGTTAGGGTTGGCCCAAGTTAAGGAAAACCTAACACCTTTGTGAAAAAAAAAA 19320 19321 AAAACTTTGGTGGGCTAAAGAAAAAATTCTAGTTTTGACATGTGGTGTCCCATGTTCATC 19380 19381 ATAGTGGAATGCATAAAAGGCTGGTATTTATACAACATGTTAATGAGCTATATATAAAAG 19440 19441 ATAATTGTTGAACTAACCCTGTATTAGATCCCTCTGCCCTGCTTCTGAATTTTAGTGCCG 19500 19501 TAGGGAACTTCTGATTCTACTTCAGTTAGCCTATACTTCAAACACTTGGCATTTGATTAT 19560 19561 GAAAAACATATGCTTGAACGTTTCATCTTGGGTTAGATATCATTGTGCAGCAAAATCATG 19620 19621 TTTTGTATATGATTTCATATATAAAATTTGATAACACTATTTGAAGTTTTGGTATGAGCT 19680

19681 TTTGTTCGAGATTAACCCTATTAAATCTTGTTGTATGCACATTGATTTTATATCTTGCTC 19740

19741 TTGTAGGCAGTTCATGGGGCTTCCTTCTGCTGCTCTATGTCTTTGTACAGATATCTCGAC 19800 
19801 TTATAGTTGTTGGTGTTTTGTACCCTTTGTTGCGTCAGTTTGGGTATGGGTTGGACTGGA 19860 19861 AAGAGGCCATGATTCTTGTTTGGTCAGGGCTGCGAGGGGCTGTTGCTCTGTCACTATCAT 19920

19921 TATCTGTTAAGGTAAATCAGTTTCATTTGTGTATCAATAAACCTTTTTCTCTGTGCTTCA 19980 19981 TTTTCATGTAAGTACATTAGTTTACTGCAGAGTTTTCTAATGCATTTATTGGAATATTTT 20040

20041 TACTAGCGTACCAGCGATGCAGTTCAACCTTACCTTAAACCAGAAGTTGGAACAATGGTA 20100 20101 CGCCCCTCTTGTGTGTGGAAGTGTCAAATGTCTAATATGAACTTTGCTAATGTTATATCT 20160 20161 TATGCAGTTTGTGTTCTTCACTGGTGGCATCGTGTTTCTGACATTGATTTTTAATGGCTC 20220 20221 AACCACACAATTTTTGCTACATATGCTCAGCATGGACAAATTGTCGGCCACAAAGGTTAA 20280

20281 TTTCATAAATTGTCATCTCCAATTCCAACTTGGCATTTATCTCCTTGTGTACCCACCTGT 20340 20341 CCTCTCCCTTCAACTAATTACTAGTGAAGTGGTGAAGGCATGTTTTATGTGCTGCGAATC 20400 20401 TGCCACTTAGCCTAGTGCCTCCAAGATCTCAAGGTTAATGGTCATCAATATACTCATCTC 20460 20461 ACAAAAGTTTGACACCCGTGCTATGTTGCAGACATTTACTTTATCTGTATGTATGCTAGC 20520 20521 ATGCCTAGTGCAAAATTACTTATGAATTGATTGAGATAATAGATCCTTTGCCAGCGACAG 20580 20581 CAGAAGATGAAAAGAAGAAGCCCTAAACCTGACTTATGCCCTACTACCATTTTATGAATA 20640 20641 CAACTTGTATTGTATAATAGCCCCATGGGGGAAATATATATGAGTACATGAGTACAAGAA 20700 20701 AAGGAATATTTACTCTTTAATTTAATGCTGGTTTGAAGTCACATTAAAGCAATGTATCTT 20760 20761 TCATCACAAAAGGTATATTAGCAATTCTTGCAACAATATGATTCAAAGAGAATCATGTGT 20820

20821 TTAAGTATGCACTTCTTTTGACAACTCACAAAAGTAGCAGAAAATCCAGAGCAGTTGATT 20880 20881 TTCCCTCTTTAGTTGGAAGTATTTATAACAAACAGACCTTTTGCTCCGAAGAACACCACC 20940

20941 AAAACATTGTTCCATTTGTAAACTGTAATTCCTATCTGAACAAGATTAGCATCAGACCTT 21000 21001 GTTGCGAAAAATATATTAATAATTTCACACATTGTGTTCAGGAAGCCTTTATCACTATCA 21060 21061 TTAACCATGCCTCTTATTCACCATCTTCTATCTGTCTAGGTTTGTTTTCTCTGCTGATTT 21120 21121 ATTGCTTTCATAGCACAACTGGTTCTCATTTATGAAAATACGTTCACTTATGCTCCAGAT 21180 21181 AAAGATTCCAATATGATTTTATGCAGCTTCGTATATTGAAATATACAAGATATGAAATGC 21240 21241 TAAACAAAGCATTAGAGTCTTTTGGTGAGCTAAGGGATGACGAGGAACTTGGACCTGCTG 21300 21301 ACTGGATTACTGTAAAGAAATATATCACATGTTTGAATGACCTAGACAATGAGCCAGAGC 21360 21361 ATCCCCATGATGTCAGTGGCAAAGATGATCACATGCATATCATGAACTTAACAGATATCC 21420 21421 GAGTGCGGCTTTTGAATGGTATGTTATCACTTATCAGGTTGTCTGATGGAATTTGATACA 21480 21481 GATAATATTTTTTTCATGAACACACCTGAGTGCATATTTCATTAAAAAGAAGAGCAAGTG 21540 21541 CAACCGCACATGTAGCTAGGCCCTTCCGTCTTTGTAGTTTGATGGTATTTATCTGTCTTC 21600 21601 TAAATGAATTGCTACTTTGCTAGTGATTGGCCTCCATTACTTTTGATATGATTTCTTTTG 21660 21661 TTGAGAAGTATTTTATCAGTTTGATATGTTGGGGTTGTGACTGATGTCGATTTGTCTTTC 21720 21721 CAATTTTACAGCCTTCTCATGCAATATGTGTTTATCCATAAACTGTTTGCTTACTGTTCC 21780 21781 CTCCATGGTTCTATCTTTTATACCTTCGCAACTTAATGTACAAAGTGTTGTTAATGAATG 21840

21841 TTAGTTAAAGGAGACAATTTATAAGGACATATTTTATAACAGGTGTGCAAGCTGCTTACT 21900 21901 GGGGAATGCTTGAAGAAGGACGAATAACTCAAGCTACAGCAAATATTCTGATGAGATCCG 21960 21961 TTGATGAAGCTATGGATCTTGTTTCCGAACAAAAATTATGTGATTGGAAAGGTTTAAAGT 22020 22021 CTAATGTCCAGTTCCCAAATTACTATAGGTTCCTTCAGATGAGTAGGTTACCACGAAAGC 22080 22081 TTGTCACATACTTCACAGTCGAAAGATTAGAGTCTGGATGTTACATCTGTGCTGCATTTC 22140 22141 TTCGTGCTCACAGAATTGCAAGGCGACAGCTACATGATTTTCTTGGTAATATATTGGGAA 22200 22201 CTTGATGTGTTATTTCCTGCAAATTGTCTATTATTTCTTGGGGGTGCTAGAAGAGAAGCA 22260 22261 GTACTAATCGCATATGTATGAGATTTACATGTATGGTGGACATTTTCTATAGCTGTACAT 22320 22321 TGTTGTTGCCATGTAGATCACAAATGGCAATAGAAAGCAGACTTTTAAGAAGGGTTTACC 22380 22381 TTCACCACAGAAATCTGTTACAGCATTTGGTTGTCAAACTGCTAGGTCATGTGGGGTGAC 22440 22441 AGAGCCAGCCTTCACTGCAAAACCACTTTATAGGGTGAAATTGTGGTTGAGTGTTACTTC 22500 22501 AACGAGGACAAACCTGGGGTAGCTCAATTTATTTATCAGTTTGAACTTTTTTTCTTGGAA 22560 22561 CTACGCAGGAGAGCTGTGTGTCATTTCATTAAGATAGAAAAAGATACAACGAACCGAGTT 22620 22621 ATATCAGTTTGAACTATGAAAGCTTCATTAAAGGTTCCACACACTATGGTTTTGATTGAG 22680 22681 TCCATCCTTCATTCTGTTTTGTAGATACCCTAAGCTCAATCTTCTGGTATGATGCTAATG 22740 22741 CACTTCACCAGTTTCGGTATTTATTATTTGTTTTCTTCTCTCTTCAGGCGATAGTGAGGT 22800 22801 TGCAAGAACTGTTATTGATGAAAGTAACGCTGAGGGAGAGGAAGCTAGAAAATTCTTGGA 22860

22861 AGATGTTCGAGTTACATTCCCGCAGGTTTGTGGTAACAATGTGCTTCTATCATTTCATTC 22920 22921 AACTGTTGTTGACCTTTCAGTTCCAACACAAAGTCTTTGTAACATATTCACCAAGCAGTC 22980 22981 CTGCATGTTTGAGGAAAAAAACAATCAGTTTTCTCTCCATAAGACTTGGAGAAGAAAGTA 23040 23041 CAAAACCAACATAATAATGAAGATAAAGATCATTGCATGACTAAACTAAAGAATCCTACT 23100 23101 GCTGATAAATTGCAGTGCCCTGGTTCTGAAATCATTTTCCCCCAAAATTTCAGGTGCTAC 23160 23161 GAGTGCTAAAGACACGACAAGTCACATATTCTGTGCTGACACACTTGAGTGAGTATATTC 23220 23221 AAAACCTCCAGAAGACTGGGCTGCTGGAAGAGAAGGAAATGGTCCAGTTAGATGATGCTC 23280 23281 TGCAGGTAGCTGGAATATTATTTAACTAAATATGCCTATACAACTCCAGTAAGCTAAGCT 23340 23341 AATTCACTTGGCAGACAGACTTGAAGAAGTTGCAGAGGAATCCACCAATAGTGAAAATGC 23400 23401 CAAGAGTCAGTGACCTTCTGAACACTCATCCTTTAGTTGGCGCGCTGCCTGCTGCTGTGC 23460 23461 GTGATCCTTTGCTAAGTAATACAAAGGAAACCGTGCGAGGACAGGGCACAACCCTGTATA 23520 23521 GGGAAGGCTCCAGGCCAACCGGTATATGGCTTGTTTCTATTGGTGTAGTAAAGGTCAGTA 23580

23581 TGCGCCTCAACAACACTAACAAAATTCTGTTGGGAACGAACTGTTGGTTCTAATGAGGCA 23640

23641 TTTTATCCCCCTTTTTATTTTACCAACAACAGTGGACGAGTCAGAGATTAAGCAGAAGGC 23700 END-F 23701 ATTGCTTAGATCCAATTCTATCACATGGAAGCACTTTGGGACTGTATGAGGTGCTGATTG 23760 R 
23761 GAAAGCCATATATCTGTGACATGACCACGGATTCAGTGGCACACTGTTTCTTCATCGAAA 23820

23821 CTGAAAAGATAGAAGAGCTGCGCCATTCAGATCCTTCGATTGAGGTTTTCCTGTGGCAGG 23880

23881 TAATACATAATTACTCCTACTAGTAAATAAAATAAATAAATAAATAAATGGTACTCGATG 23940

23941 GATGAATGTTGGCAGGAAAGCGCTCTGGTTCTTGCCAGGCTTTTGCTCCCTCGCATATTC 24000

24001 GAGAAAATGGGAATGCATGAGATGAGGGTTCTCATTGCTGAAAGGTCGACCATGAACATA 24060

24061 TACATCAAGGGAGAAGACTTGGAAGTGGAGGAGAATTGCATTGGCATTTTGCTGGAAGGA 24120

24121 TTCTTGAAGACCGACAACCTGACTCTAATCACGCCTCCAGCGGTGCTTCTGCCATCCGAT 24180

24181 GCTGACTTGGGTCTCGAGTCCTCAGGTCTCTTTATTTATTATAGTTATAATTATAATATA 24240

24241 TACTATATGTTTTTTGCTAATATATTTATAGATAATAATGAAGAAATAAAGAGTCAACAA 24300

24301 AAGGCTCTGATTTGACTCGCTCTCTCTGGTATAGACTACTGTCATACTGCACCTAGGTAT 24360

24361 CAGGTGGAAGCTAGAGCACGGATCATCTTCTTGGAGGAGGCAGAGGCCCATCTTCATCGA 24420

24421 AGTGCGTCGCGGCTGCTGCTGCCCCAAGGGCAAGGAGGAGGTCATGAGCCAACACGGAGC 24480

24481 ATGAGCAAGGAGCACAGCGGCTTGCTCAGCTGGCCCGAGAGCTTCCGGAGGTCCCGTGGC 24540

24541 AACCTAGGCCTAGCAGCTGAGATGCTGCCGGGCGGCTTGTCTTCCAGGGCCСTGCAACTG 24600

24601 AGCATGTACGGCAGCATGGTGATCCTCTCCTCCGGCCAGGGCCACTCTCACCGGCGGCAG 24660

24661 GGGCGTCATCGCGTGCAGGCGACGACAACAGACCAGAAGCAAAGCTCGTCCTACCCAAGG 24720

24721 ATGCCATCCATATCCAAAGAACGGCCTCTGCTCTCCGTGCAATCAGAGGGCTCCAACATG 24780

24781 AAGCGAGTGGCAGCTCTACCTCTCAGAGACGACGCTGCTGAGGTTGAGGCTCCGGCAGCC 24840

24841 CAGCAGCGGCGGCGGCGGAAGGCTATGCACTTGCAGGAGGACAACTCAAGCGACGACTCC 24900

24901 GCCGGCGAAGAAGTCATTGTCAGAGTTGACTCGCCCAGCATGCTCTCTTTCCGTCAGTCA 24960

24961 GCCGCCGCACCTCCGCCGCAGGACCAGTAGTCGTCGTCTCCTCTTTGCGCTGTCATACAA 25020

25021 ATATATCATATCCATTTCTCTTGTATTGTATTGTACAGAAAAAATAAAATAAACACATTC 25080

25081 TCTGCTCTATATTTTCTCTTCATAATCACTGAATAAAAAAACAGAATTCTCCTTAACATG 25140

25141 ATGCAGAAAATGCACTGCAAAAGCCACATTACAGACTCGTTTTATTGGATCGGACGGGTA 25200

25201 CGTTACGGCTGATCAGTAGCTACTACGCTATTCTGTCTGCACCCACСTCTCCCGATTAAC 25260

25261 TTACGAGACCAAACCTAGAATCAGGTTCAGGTACATACATCGGAATTCATTCATCTTCTT 25320

25321 CCCATGGACTAGGACACTGCTCCСCTGTACCTGTGGCTCATGCTGGTAGCAGCTGATGAA 25380

25381 AACTCAAAAATATACATCAAACAACAGCTAGGTCAGCAACCGACGATGTTAGGCCACGGT 25440

25441 TCGCCCATAGCATATCCCAGCAAGGTAGAGATTCTTGGCCCACTTATCCTGCGACAGCCC 25500

25501 AGAGGAACAAGTAAGGAAAAAAACACTGGTCAAGCTAGAGAGAGAGAGAGAGAGAGAGAG 25560

25561 AGAGAGAGAGAGAGAGAGAGAGAGAGAGAGACACGGCTCCCGTGTCCTACCTTGACATGT 25620

25621 TGACTGGGAAACTGTGTGGTCCGCAGAGTCTCTTGTGTCTCGTCTCTCGGACGACGCCTT 25680

25681 GGCTTGCTTAGGATCAGCGCAGACTGATCCATTGTGGCAGCCATTGCAGTGATACGAAAG 25740

25741 CCATTGTCCCAGCGTCTATGGATGCCCTCACTTGGGTACAAGAAGTCCAACTCCACAACC 25800

25801 TGCAAGAATTGCAATGCTAAGTCCATCAAGATCAAGGCACCCCCATCTTTGTTCATCACG 25860

25861 TACACGTAGTAGCACATTCCTCATCTTCAAGGCTATCCCGCAAATAAAATACCAGACCTA 25920

25921 ACAATCAATGAAGATGCACCTGAACATTTAGAAAATCACATTGCTACTAAAAACATTTTC 25980

25981 TACTGTCCTTTGCAAACAGTGCAGCATGAAAGAAAATATTAAAACCTCTAGCATAAGACA 26040

26041 CTTGGCTTTTTTCTTTTG 


\section{Supplementary Figure S3. SbNHX2 gene sequence and primer location.}

Nucleotide sequence for SbNHX2 gene. Forward primer indicated by cyan highlighting. Reverse primer indicated by magenta highlighting. Exons indicated by orange highlighting. Introns indicated by white highlighting.

1 GTCCCCACGCCCCGGAACGCGCCGCCCGGACCAGTCACTGACGCGTGGGGCCACGCTTAC 60

61 CCGGTGGGCCGCGTGGGTCCCGGGTTAACCGACCGTCCGAGAGCGACCTGCTGCCCGGTG 120

121 GGCCCAACGTGTAGCGCTTTTCTGGCCCCCACGTGTTCACCCACTGGCCTGTTGGCCACT 180

181 CCCCTCTCCCGCGCCGCGCGGCAGCAGCAACCGCCCCCCGTGCCACCGACACGTGGGCCA 240

241 TCCCCACCAAAGCCCGTCCAGTCGTCACCTCCCCCTCCCTTCGCGTCACTTCCGACCTCA 300

301 CCCCAAATATAAAAAGTTTTCAAAATTTACTATCGCATCGAATATTACGATATATACATA 360

361 AAATATTAAATATAGATAAAAACAAAAACTAATCATACAGTTTGACTGTAAATTGCGAGA 420

421 CGAATCTTTTAACCCTAGTTAGTCTATGATTGGACAATATTTTTTTTATCACAAACAAAC 480

481 GAGTGAAATTTAAAAAAAAAATCACATCTAAATAAGGCTGATATTTTGTTTGTTTATTAT 540

541 TTAATTATTTAATTTATTAATTTCCGCACAAAATCCCGTTCGAATCGTATCTCCTCCTCC 600

601 TCCTCCTCGCCTACGACTACGACGCCGTGGCGCGCCACCCGCCACCAGGCCCGCCGAACC 660

661 CTACGCCCCGTCCCCGAATCGGAGGAGCAACCGCCTCGCGGAGATTCCCTCCGATACCCG 720

721 CCCGCCCACGCCGGGATCTCCGCATCCGGATCCGACTTGCGTCATTGCCCCCCTGATATC 780

781 TCCTCCACGCACACAGTCCACCCCGGCTTCCAGAGTCCAGAGTCCTGACCACGGGCGAGC 840

841 GCACGAGCTCTCGCGCGCGTAGAGGCGCCGGATTTCGTCGATTCCGGCGACATAGCAGAT 900

901 CCATTGCCTTTCCTCGGATACAGTCCGGGCTGGGTGGGGGGACTCCTTTTCCGCCTAGCA 960

961 GGGTTGCGTGCGGGCGGCGGGGTTGCTTGGAAGGCAAGCCGAGGTGGGAATCGGGTGTTT 1020

1021 AGGGGGCGGCGGTGGTGGTAAAGGTACTAGGGTTGGGGGCGGTGATTAGTGGAGCTGCGA 1080

1081 GGAGGTCGATAGAGAGGTGGGGAACGATGGGGCTGATGGCGCTGGGCGACCCGCCGGCGG 1140

1141 ACTACGCGTCCATCGCGGCGGTGGGGCTGTTCGTGGCGCTCATGTGCGTCTGCATCATCG 1200

1201 TCGGCCACCTCCTCGAGGAGAACCGATGGATGAACGAGTCCATCACCGCGCTCTTCATCG 1260

1261 TGAGTCCATCCAACCGCCCCCTTTCTCGCTTTTCATGACCTGAGTTTATGCTCTCTCTCT 1320

1321 CTCACCCCTGTGGTATTGGTATTGCAATGTTGTCTGTCGGGAATTGAGGGGGTAATTGTG 1380

1381 GCCCTGTTGTTTGATGTGCCTGTGGCTTTGCAGGGGCTGGGAACTGGAGCGGTGATCCTG 1440

1441 TTCGCGTCCAGCGGGAAGCACTCGCGCGTGCTCCAGTTCAGCGAGGACCTCTTCTTTATT 1500

1501 TACCTGCTGCCGCCCATCATATTTAATGCAGGGTATGGAATTCTTGCAATTGATGCTATA 1560

1561 TGTTCTAGCGTTATGGTGCCATTATTTTATTTATTGTTGCAATTTATCGGTTTTTCCTAC 1620

1621 ATAAAGGATTATTGTTACAATTTATCAGTTTTTCCTACATAATAAAGGACAAATAAAGAT 1680

1681 GATTCTTCTGACAATTAAGAAGTTGAGTTGGGCCACACATTGGAGATTGAGAAACTTGCT 1740

1741 ATGATTTTAATAAGAACTGTAGTTCAAGAGAGCTGTTGCTACCATCCCTGTGCTTGGAAT 1800

1801 TTCTCCTTCTTTTCCTTCTAATTAAGACAGGAGAATCCTTAATTGGAAGGCAGAGCTCCT 1860

1861 TCTGTTTACGTTAAAAAACAGAAGCATTACATGTACTTTGTTACTGTTTTAGGACCTCTT 1920

1921 TGGATAGGTTTTGTCTTTGGAGCTTTCTGAGCTAAAATCCAAAAAAGATTCCCTCTTCTA 1980

1981 AACACTTTGGTAGCAAAGCAACTACGGTGTGCTATTAAATAATAAATCTGCAATTATTCC 2040

2041 TCTGAGTATTTCGCATTAAGAGTGTAGGTGATATGCCATGTATAATTTAGTGAATATCTG 2100

2101 GACTAGGAACCTATATGTATAACTCACTCATAATTCTCCATTTTTTCTGTGTAAGCCAGg 2160

2161 TTCCAAGTGAAGAAGAAACAGTTCTTTCGAAACTTCATTACTATTACACTGTTTGGTGCA 2220

2221 GTTGGCACCTTGATCTCTTTTACTGTAATATCCCTTGGTAAGTTTGCTCCCAAATTTCAT 2280

2281 TTTTACCATGATTGTCAATTTCTGGGTTTCTGCCTGCCTTAACTCACATTTGATTTCACA 2340

2341 GGTGCTCTAGGACTAGTATCAAGGCTTAATATTGGCGCACTTGAGCTTGGGGACTATCTC 2400

2401 GGTAAATTCATTACCCAAAGTATAAGCACTTCCATTGCCCATATACAGTTCTTTCTTTCT 2460

2461 GACTCATCTATACCTTAAATTTCAGCACTTGGGGCAATATTCTCGGCCACAGACTCGGTG 2520

2521 TGCACCTTGCAGGTGTTAAGCCAAGATGAGACACССTTCTTGTACAGCCTCGTGTTTGGT 2580

2581 GAAGGTGTTGTCAATGACGCAACTTCTGTTGTGTTGTTCAATGCAATCCAGAACTTTGAT 2640

2641 CTTGGAAATATCAGTGGTGCCAAATTACTTAACTTTATTGGCAGTTTCCTTTATCTATTT 2700

2701 GGCACCAGCACCATTCTTGGAGTAGCTGTAAGTTATATGATGCTTCCGCCTCTAGCTTTG 2760

2761 CCTAAGTTTATTCTTTACTGACATGTCTTTTGGCTGCAGTCTGGACTTCTTAGTGCTTAT 2820

2821 ATCATCAAGAAGTTGTACTTTGGCAGGTTTGTACTTGACACAACACGATTTGTTTGATTG 2880

2881 AAATTGATGACATTTCTGTAACTTATGTTCCTCTGATTTGACATGCACCTCAGGCACTCA 2940

2941 ACCGATCGTGAAGTTTCCATTATGATGCTAATGGCTTATTTATCTTACATGCTAGCCGAA 3000

3001 GTGAGCACCCTGTACTCTTAACCTCTGTAGATATTGTGTATTTCAGAAAAGAAAATACAG 3060

3061 CTGTAAATTGTTATTGACGGGTTGCCTTTTTATGGTAGTTGCTTGATTTGAGTGGCATTC 3120

3121 TCACAGTGTTCTTCTGCGGTATCGTAATGTCCCACTATACCTGGCACAATGTAACAGAAA 3180

3181 GTTCCAGGGTCACAACCAAGTAAGTAGCTTCGTAGCTTCTGTGTGGACATTTTCCTTTGA 3240

3241 TCATGCATCCTTTGCTAATGCATATACTAATATACCATTGGATGGATCACAGACATGCCT 3300

3301 TTGCAACATTGTCATTTATCGCCGAGACTTTTCTGTTTCTCTATGTTGGCATGGATGCAT 3360

3361 TGGATATAGAGAAGTGGAAGATTGTCAGTCAAACTTACAGGCATGCTCTCTCCCTCTTTC 3420

3421 TCTCTCTCTTCATTGCTCAAGTAAGGTTTTTTTTTCCTGAATCTGTATGTTCTGTCATGT 3480

3481 GCAGCCCAGTAAAATCTGTTGCTTTGAGCTCCACTATTTTAGCCTTGGTGCTGGTTTCAA 3540

3541 GAGCTGCTTTCGTTTTCCСАTTATCATTTCTATCAAATTTGACCAAAAAAACTCCAAATG 3600

3601 GAAAGATATCTTTTAGGCAGCAGGTGAGTCTTTAACTTAGCAACATCTTAACTTCTTATG 3660 FOR

3661 TCCTCTTGAAACAGTTATGTTCCTTACTTGATAGTGATCATTCAGGTTATTGTTTGGTGG 3720 FOR

3721 GCGGGTCTCATGAGAGGTGCTGTGTCCATTGCGTTGGCTTACAATAAGGTAAATCTTGTG 3780

3781 TTTGGTCCATCTGTTTGTAAATTAAATTGTTCACTAGTGGTTTGATTTTCTTTCTTATAT 3840

3841 ATGCTTGAATACACTAGCCTCAAAAGATCTGTAGTGTTAAATGTTCAATTGTCTGTTGTT 3900

3901 AATGCCTTTATCTAACCAGTGGTTTTCTATTGTGCAGTTCACAAGATCAGGCCATACTC 3960 
3961 AGCAACCTAGCAATGCTATCATGATCACAAGCACAATCACTGTTGTTCTTTTCAGCACAA 4020 REV

4021 TTGTAAGTTTTTCCTCACCTAGTACACACAATATAACAACCTAGGTTGATTTTCAAACTT 4080

4081 ATATTGCAGACAAATACCAAACATAAGAACATGACGTGATAGGGGCATTCCTTTTCCTGC 4140

4141 TACAACATGGTTCTGAATAGAACAATTATCCTCTGTTCTTGCAGGTCTTTGGGCTACTGA 4200 REV

4201 CCAAACCGCTGATCAGGCTCTTGATCCCACCAAGGCACCTATCCAGGGAAGCCAGCGCCC 4260 REV

4261 TTTCTGAACCATCCAGCCCAAAGTCTTTCTTTGAGCAGCTGGCCACGAACAGCCCTGGTC 4320

4321 TCCCTGATATTGAGAACGGCATAAGCCTACGCCGCCCGACAAGCCTCCGTTTGCTCCTAG 4380

4381 CGAGCCCGGCACGGTCGGTCCACTATTACTGGCGCAAGTTTGACGACGGTTTCATGCGGC 4440

4441 CGGTTTTTGGCGGCCGTGGCTTCGTCCCCTTCCACCCTGGTTCACCGACTGAGAGCAGTG 4500

4501 TGCCGCTGCTTGCTGGCAATGGGAACTGAAACCAGCATACCGTGGTGACTGGGTTCAGCA 4560

4561 AAAGTTTTGTAAATTAACTTCGCTTATTAGGAATAATGAATTGGTGTAAATATAGGTAGT 4620

4621 AGATTCACTTGCTAAGCTTGTACATGCTGATGTAGGCTAGTTGCCTGACCAGAGACCACA 4680

4681 CGGCTCTTGATGAATTTGTATTTATGAATTACGTACTCTACATATTGGATCACAAAATAT 4740

4741 GTATCATCTCCGAATTAATAGATATATGTAAATTATCAATCCATTTTGGAGTGAATACTA 4800

4801 TGCTTGAAATATTCACGGGAGGATCTTTTGATTTGTATTCATCCCAAACACATCGAACGT 4860

4861 TTTTCAGGAAGGACGTCTCTTCCCAAGTAGCTAATCTATGAGGAATTTTATTGGCTATTA 4920

4921 ATGACAATTTACAAATAGCTAGTAAGATGACATATATAAATTAAAAAAATAAACACTATA 4980

4981 GTGGAGAGTTATGTGAGAGATATTTGCAGGAGATAGTGCTAGATTAGTTATTTGTAGTGG 5040

5041 AGAGTTATGTGAGAGAGATTTCCAGGAGATAGTGGTAGATTAGTTATTTGGAAGTCGCTA 5100

5101 GCTATTTGATCTCTCTTTTTATAGTCATTGGAAGTGTTACTTTTTTATTATTTCTATACC 5160

5161 TCATCTAGCTAGCTATTTATACGTTATCTTTAAAGACATTTTTATAGCTAATAGATTTTT 5220

5221 TTTTCTAAACTAACTATTTGATCTAAAGATTGTCTCTCTTGATTTGCACCCTGAAGGCCT 5280

5281 GAAAATCTCACCACTCACATCTTTCCGTATCCGTGACTGCAAGACGTATTTCACAAAACC 5340

5341 TCTCCATTTACGCCTTCTCATTCCCTTCTTCGTGGCCCCGTCGTCGGTCCGACCCCACGC 5400

5401 ATCCCGACTGGCAG

5414 


\section{Supplementary Figure S4. SbHKT3 gene sequence and primer location.}

Nucleotide sequence for SbHKT3 gene. Forward primer indicated by cyan highlighting. Reverse primer indicated by magenta highlighting. Exons indicated by orange highlighting. Introns indicated by white highlighting.

1 GAACCCGTGTCCATGGAGATGCAGATGATTGGTCCTGCTCCTGCAGCAGCGCGCGTCTCT 60

61 CCGGCAGCCTCGCTATCACAAAGCAATGGCCGGTCTCTGCCTCTCTGAAGTGGCCACCGT 120

121 TTCATTTGCTGGCGATCTCGACGCCGCCGGCGTATCATATCAGTATCACTCGCCGGAAGC 180

181 TTTCAGTTACTACTAGTGGCTGGGGTTGGCCTGCCTCTAGGAGCAGCCGGCTGCCACCCC 240

241 TGCCTTTCCGTTTTGCCTGATCTGGCCGTGGTTGCCCTCGGCGCCATGGCAGACGGTTGG 300

301 GCAAAGAGAGGCTCACCATTCACCACGCACGCATGTGCACAAGGCTCTGAACTCTAAACT 360

361 GAATTTTCTCCAGCCTTCTCTGTGCTGTGCGTAGTAGTTTCGCGCGTGTGTATTCAGTCA 420

421 TCTCATCTCACTCACGGCCGGCGTGCTCCATCTGCAGGCGCGCATGCCATTAAGTTCTGA 480

481 AAGCTGCCTGATGAGCCATGCTACTACACTTGCATTGCACACATGTCGTCCTCCACACCA 540

541 CTAATCTCTCTAAAGCCAATGCCATGGGCTGGCTGAAACAGTTACTTGCATTTCCATATG 600

601 ATCACTGCTCTGTCAAGCTAAGTTGTATATATAGTTATATTATATACACCCATTGAGATC 660

661 TCAGTAATCACTTGTACTAGGTTCCATATGTATTAGTACCAGTAAAAGTAAGTAGTTTTC 720

721 CATTGAAACAAGAGCTAGCTAGATCATCAGGCACTGGTCATTGCCCTCTCTAGCTACCAC 780

781 CACCATCTCCAATGCCTATTCGGTTCCATGTCTTGGCCAGCGCCGCGAGACACGCCGTCA 840

841 GCTCATCGGTGCTCGTCTGCCGGCTCATCGCСTACCACCTCACCCСACTGCTGCTCCACC 900

901 TGACCTACTTCCTCGCCGTCGACCTGCTCGGCTTCCTCGCCTTGGTCCTCCTCAAGCCAA 960

961 GCAACCCCGGGTACCGTCCGCGCTACATCGACGTGTTCTTCATGTCGACGTCCGCGGTCA 1020

1021 CCGTCACCGGACTAGCCACCGTCGAGATGGAGGACCTCTCCAGCGCCCAGCTCGTCGTCC 1080

1081 TCACССTCСTCATGCTCCTCGGCAGCGAGATGTTCGTCTCCTTGCTCGGTCTCGTCCTCG 1140

1141 AGTCGTCGCGCAACCGACGACAGCAGCAGCGCGACCATCAAGATCACGACAGCAGGGTCA 1200

1201 TGGCGGCGGCCGCCGTCCGCGACGAGCCGGATCTCGAGGAGGCGAATGGTCCGGCAGCAG 1260

1261 CTCCGTCTGCGGATTCGTCCGGCGATGGTGGTGATCGCAATCGCAAGGAGAGCTCCCGCG 1320

1321 ACGTCAGAAGTTTAGCGCTTGTGGTGTCGGCCTACATGGCCGCGATCCTCGTCGTCGGCT 1380

1381 CCGTGCTGGTGTTCGCGTACGTCGCCACCGTCCCGACCGCGCGCGACGTGCTGGCGAGGA 1440

1441 AGCGCCTCAGCGCCGCGCTCTTCTCGGTGTTCGCCACCGTCTCTTCCTTCACCAACGGCG 1500

1501 GCCTGCTCCCGACAAACGAGAGCATGGCGGTGTTCGCCCCGAACCGTGGTCTGCTCCTGC 1560

1561 TGCTCGCGGCACAGATCCTCGCCGGCAGCACGCTGCTGCCGGTGTTCCTCAGGCTGGTGG 1620

1621 TGAGCGCCACGAGAGGGCTGGCGAGGGCGTTGTCCTTGTTCACCGGGCGAGGAGGGTCCG 1680

1681 TCGAGGAGCTCGTGCCCATGGACATGGAGAAGAGCGCCGCGGCGGCGGGGTTCGGCCACC 1740

1741 TGCTGCCGTCAGGTTCGCGGGCGGCGTCCCTCGCCGCCACGGTGGTCGCCGTCGCGACCG 1800

1801 CCGCCGCGGCTCTCCTCTGCTGCCTGAACTGGAACTCCGCGGTGTTCGCGGGGCTCACCA 1860

1861 CCGGAGAGAAGCTCACCAACGCGGTGTTCATGGCCGTGAACGTGCGGCAAGCCGGGGAGA 1920

1921 ACTCCGTCGACTGCTCCCTCGTCGCGCCGGCCGTGCTGGTGCTGTTCCTCGCCATGACGT 1980

1981 ACGTCAGTCACGATGCTCCTCCGCGCGAAATTGAAGCATACTACGCAACAATATGTTGTT 2040

2041 CGATCATTGACAGATTTTGGCATGCCGACCGACGATTTTCAGGTGCATCCCGGCGTCGGC 2100

2101 GACATTGTTGTCGGTGCAGGACGACGGCGGCAAAAGACAAGGAGCGGCGCCGGAGAACC 2160

2161 GGAACGCAAGGATGGAGCCGAGAAGAAGAGGAGGAGGAGACTGTCGCTGAACAGCATGCT 2220

2221 GCTGTCACCGCTGGCCTGCAACGCCGCGGCGGTAATGCTCGCCTGCATCACCGAGAGGCG 2280

2281 ATCGATCGCCGGCGACCCGCTCAACTTCTCCACGTTCAACGTGATCTTCGAGGTGATCAG 2340 FOR

2341 GTGAGGTGCACACATGCACGATCGACGAACATCACAGTTCACAAACCATCTCATCAGAAG 2400

2401 CTTCGTTCTCTGAAACTGACATATGGATTCCTGCATGTGTGCAGTGCTTATGGAAACGTG 2460 FOR

2461 GGGTTGTCCACTGGCTACAGCTGCTCGAGGCTGCCGCCGCCGCCGGCGACCACCGCCTGC 2520 REV

2521 CATGACAAGCCATACAGCTTCTCCGGGTGGTGGAGCGACCAGGGGAAACTGCTCCTTGTT 2580 REV

2581 CTCCTCATGCTCTACGGGAGGCTCAAGGGCTTCCATGGACAGCGACGCAGGAGGTGAACT 2640

2641 TTATTTGGTGATCGATGACCGATGATGAAGGCCAATGCCGGGATTGGTCGGGGATCAAAC 2700

2701 TTGAAATTCTTCAAGATTCCATGGGCGATAAGAATGAAATTCAGAGTGAAATGCGATTG 2760

2761 GAAGAAGGATACACACTCCGTGGAGAAATATATATAGAATATAGATTGTAAGTTTTTCTA 2820

2821 GAGGTCATAGATAGGGTACTTCTTTTTTGAATAGAGATTATGCTGTTCTCAATTTTGAGG 2880

2881 ACAACAATAGGAATTAGGAAAAAAGTCTATTTGACCCСTCAACTTTCACGGTCATCTGAT 2940

2941 TTCTCTTCTTCATCTACAAAACTAGATTTTTGTCATCСTAAACTTTTATATAAACCGTTT 3000

3001 GTTTGGTCAATTGGCACATGTCAGTCGTCCTATGTGGCGCCATGATAACCATGAGCGGG 3060

3061 TTAATTCGAACTAATTGATGGTTGGTGGGTTTGCATATCAGACTATAAAATATTTTCCTC 3120

3121 AAATAAATACACAAATATTTTTCCATAGAAAAGTTAAAATCCTAAACTTGTAAAATCGGG 3180

3181 TTTAATCATAGAAAAATATTTTAGCATAATTTTCCTAAAATCATGATGTATCTTATAGTG 3240

3241 ACTAACTTGGAACACTTTGAGTCTTATATGTACCCATGTCCCATTTTGTTGTTTATTTAC 3300

3301 CGGTAGATGCCCTTACTATCTATTACAGTTAGTCTACATTGAAGACTCGAACTTTATAAA 3360

3361 GGTTCAAATGACTTTGGCGACAACACAATTTCCATGTAACTATAGCATACTTGATTCTAT 3420

3421 ATATGATCATCTTAGTATGAAAAAGTATGGAGGGTGAAGTGTGGATAACAAGACCCACAA 3480

3481 GTATATCAATGAAAAGAACAAAGTAATGCACAACAATTTCATGAAAACTAGAGTATGTGT 3540

3541 CACACTGGCCTTTTTATGTGTTCTGGGTGGCAAAGTTGACTAATTATAGATAACAAGAG 3600

3601 CATATACTAGAAAATAAACACAAAAAGGGT 
Supplementary Figure S5. DNA and cDNA PCR for gene verification.

Agarose gel (1.0\%) electrophoresis verifying PCR amplification with $1 \mathrm{~Kb}$ plus DNA ladder.

(A) PCR run with DNA. Primers span introns.

(B) PCR runs with cDNA. Sizes are expected for genes listed.

A.

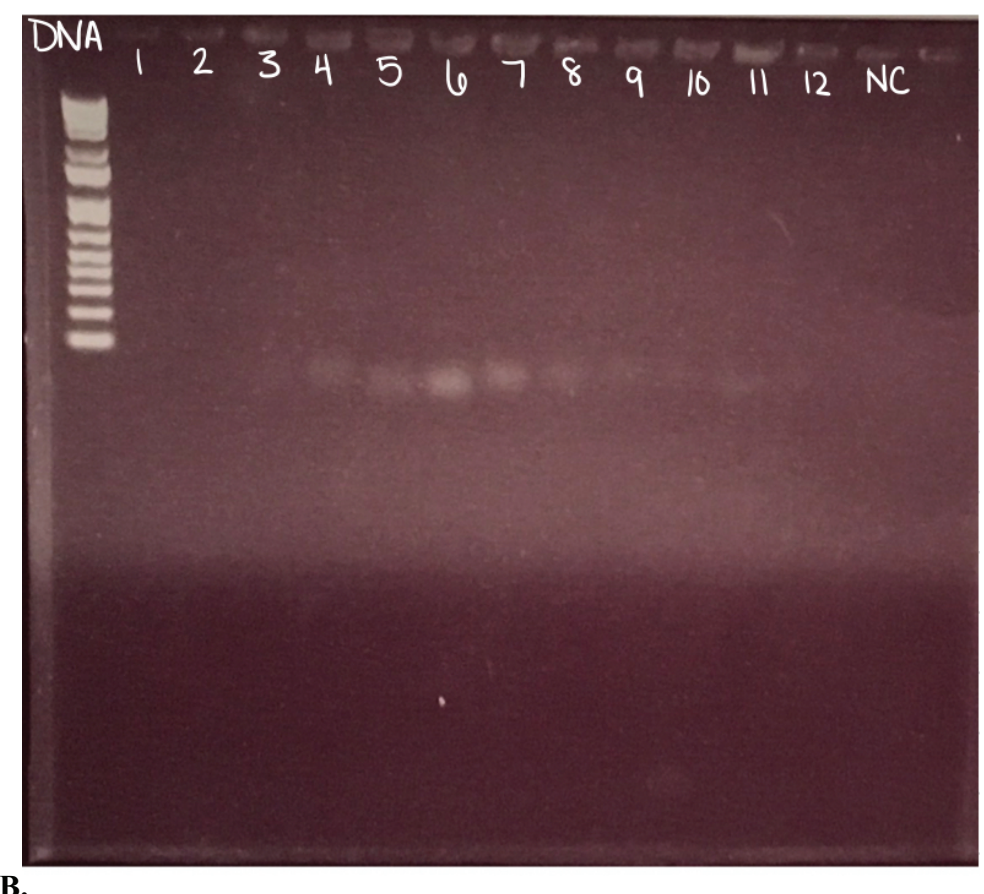

B.

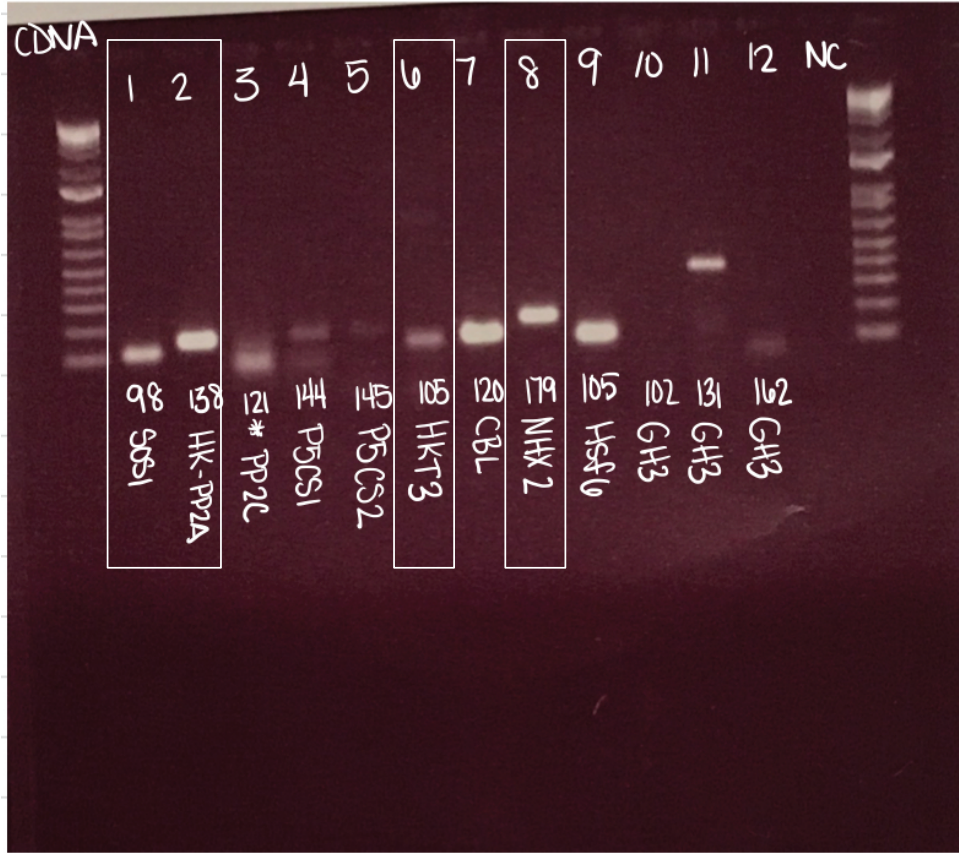




\title{
CHAPTER 5
}

\section{DOMESTICATION \& DETOXIFICATION: EARLY SENSING, SIGNALING, AND OSMOTIC ADJUSTMENT AID IN THE INCREASED SALINITY TOLERANCE OF SORGHUM BICOLOR}

\author{
Ashley N. Henderson; Rajanikanth Govindarajulu; Jennifer S. Hawkins
}

\begin{abstract}
Soil salinity is an intensifying problem affecting lands used to produce agronomically important crops. Salt stress impedes crop production via both osmotic and ionic stress. Such stress slows plant growth and disrupts normal metabolic processes, resulting in decreased biomass and increased leaf senescence. Therefore, the ability to maintain biomass in response to salt exposure is indicative of tolerant genotypes. We used a recombinant inbred line (RIL) population derived from Sorghum propinquum and Sorghum bicolor (Tx7000), two genotypes shown to differ for tolerance to salt exposure, to map regions of the genome associated with salt tolerance. Low coverage Illumina sequencing was used to generate a high-density genetic map that covered the 10 Sorghum chromosomes with 1692 Mendelian segregating markers. Eighteen total QTL were detected for dead aboveground biomass, live aboveground biomass, total aboveground biomass, root biomass, total biomass, rank score, and height in two environmental conditions (control and salt), and when stress tolerance index (STI) values were mapped. Candidate genes associated with salinity tolerance include genes associated with osmotic and ionic stress. Most interestingly, however, was the enrichment of aquaporins in salt specific QTL suggesting that better water acquisition and transport may be responsible for the greater salinity tolerance observed in $S$. bicolor.
\end{abstract}

Keywords - abiotic stress, aquaporins, bin mapping, genetic architecture, recombinant inbred line, salt stress, Sorghum bicolor, Sorghum propinquum, stress tolerance index, quantitative trait loci 


\section{Introduction}

Saline soils are an intensifying problem that directly affects the production of agriculturally important crops. Soil salinity is an abiotic stressor where soluble ions, such as $\mathrm{Na}^{+}$and $\mathrm{Cl}$, accumulate in the soil surrounding root rhizospheres. These ions cause a decrease in the soil water potential, making it difficult for plants to absorb water without altering its own potential. With salinity affecting more than $6 \%$ of the total land and $20 \%$ of the irrigated land used for crop production, it is imperative to identify ways to maintain and even increase crop productivity in saline environments in order to meet population demands (Rengasamy, 2006; Food and Agriculture Organization (FAO), 2008, 2009; Hasegawa, 2013; FAO, 2017; Yang et al., 2020). Research over the last 20 years has focused on unraveling the key mechanisms of tolerance, and the results suggest that tolerance is a result of: 1) ion exclusion, 2) tissue tolerance, and 3) osmotic tolerance (shoot ion-independent tolerance) (Munns \& Tester, 2008; Carillo et al., 2011; Fan et al., 2015; Genc et al., 2016; Negrão et al., 2017; Munns et al., 2019). Ion exclusion is the absence of salt ions from the shoot of the plant, whereas tissue tolerance is the sequestration of ions into specific tissues, cells, and subcellular organelles. Lastly, osmotic tolerance is defined as the ability to maintain water uptake and growth despite lower water potential.

Salinity stress negatively affects many economically important crops. Sorghum (Sorghum bicolor L. Moench), which is naturally drought and salt tolerant (Boursier \& Läuchli, 1990; Almodares \& Sharif, 2007; Almodares et al., 2007, 2008b,a; Mullet et al., 2014; Fracasso et al., 2016; McCormick et al., 2018; Guo et al., 2018; Henderson et al., 2019), ranks fifth for food, fuel, and feed production after wheat, maize, rice, and barely (Doggett, 1970, 1988). Compared to other C4 cereal crops, Sorghum requires minimal resources and delivers high yields (biomass, grain) making it a model species to dissect the various tolerance mechanisms. In a recent study, 18 diverse genotypes of Sorghum bicolor and four wild relatives were assessed for performance following salt exposure (Henderson et al., 2019). Genotypes ranged in maintaining as little as $30 \%$ to as much as $95 \%$ of their biomass after 12 weeks of salt exposure. Most of the individuals from the landrace durra ranked in the top 5 for most tolerant. Further, the most sensitive genotype, in terms of live aboveground biomass production, was Sorghum propinquum, which lost $95 \%$ of its biomass in response to stress. This wide range in biomass retention indicates continuous variation in salinity tolerance and suggests that tolerance is a quantitatively inherited trait.

Quantitative trait loci (QTL) mapping is a powerful tool that enables the association of quantitatively inherited phenotypes to candidate genomic loci (Kearsey, 1998; Lynch \& Walsh, 1999; Broman \& Sen, 2009). Given recent results that demonstrate extensive variation in response to salinity stress among sorghum genotypes and their close relatives (Henderson et al., 2019), the recombinant inbred line (RIL) population used in this study (S. propinquum by $S$. bicolor (Tx7000 - landrace durra) serves as an invaluable resource to dissect the genetic underpinnings of salinity tolerance. Here, we provide a high-density genetic map from $177 \mathrm{~F}_{3: 5}$ lines and identify QTL associated with numerous biomass-related traits that are indicative of salinity tolerance, such as dead aboveground biomass, live aboveground biomass, total aboveground biomass, root biomass, total biomass, rank score, and height. Eighteen QTL and 140 candidate genes previously shown to aid in osmotic and ionic stress alleviation were identified. 


\section{Materials and Methods}

\section{Plant Material}

A recombinant inbred line (RIL) mapping population derived from an interspecific cross of Sorghum propinquum (William Rooney, Texas A\&M University, College Station, TX) and Sorghum bicolor (inbred Tx7000, landrace durra) was used to investigate the genetic underpinnings associated with variation in salinity tolerance. The RIL population consists of 177 $\mathrm{F}_{3: 5}$ lines with $75 \%$ (132 RILs) of the individuals being $\mathrm{F}_{5}, 18 \%$ (31 RILs) of the individuals being $\mathrm{F}_{4}$, and 7\% (14 RILs) of the individuals being $\mathrm{F}_{3}$. Each line was derived by the single seed descent method (Brim, 1966; Snape \& Riggs, 1975).

\section{Experimental Conditions}

In a controlled greenhouse room, five seeds of each RIL were sown in $5 \mathrm{~cm} \times 5 \mathrm{~cm} \times 5 \mathrm{~cm}$ planting plugs filled with metromix soil. Conditions during germination were: $21^{\circ} \mathrm{C}, 75 \%$ humidity, and 4.5 vapor pressure deficit (VPD). During germination, seedlings were misted regularly with non-saline tap water and watered with a 20-10-20 N-P-K (J.R. Peters, Inc., Allentown, PA, USA) fertilizer diluted to $200 \mathrm{mg} \mathrm{N} \mathrm{L}^{-1}$ every $4^{\text {th }}$ day. Once all plants reached at least the third leaf stage (V3) of development (approximately 32 days post sowing), soil plugs were transplanted into $5 \mathrm{~cm} \times 5 \mathrm{~cm}$ x $25 \mathrm{~cm}$ treepots (Stuewe and Sons, Tangent, OR, USA) filled with silica sand $\# 4$. Treatment room conditions were: $27^{\circ} \mathrm{C} / 23^{\circ} \mathrm{C}$ (day/night) with 16 hours of daylight and $75 \%$ humidity. Following transplant, seedlings were watered to saturation with non-saline tap water daily for two weeks to provide a period of establishment. All plants were fertilized twice weekly with a 20-10-20 N-P-K (J.R. Peters, Inc., Allentown, PA, USA) fertilizer diluted to $200 \mathrm{mg} \mathrm{N} \mathrm{L}^{-1}$ for the remainder of the study. Following establishment, three of the five biological replicates were randomly assigned to a $75 \mathrm{mM} \mathrm{NaCl}$ salt treatment and two of the five biological replicates were randomly assigned to a $0 \mathrm{mM} \mathrm{NaCl}$ control treatment. Seedlings were watered once daily, in accordance with their assignment, to complete saturation for the duration of the experiment. Treatment began 51 days after planting and plants were treated for a total of 45 days.

\section{Phenotypic Measurements}

The following measurements were recorded at various developmental stages for each of the 177 lines: height $(\mathrm{cm})$, tiller count, rank score, root biomass $(\mathrm{g})$, dead aboveground biomass $(\mathrm{g})$, live aboveground biomass (g), total aboveground biomass (g), total biomass (g), and the shoot to root ratio. Height was taken from the base of the stem to the tip of the newest emerged leaf. Tiller count was the total number of tillers attached to the base of the stem. Rank score was a qualitative score that described overall leaf 'greenness', leaf health, and mortality, where plants that displayed no signs of stress received a low rank score, and plants that were extremely stressed or had died received a high rank score (Table 1). Rank score was assessed by the same person throughout the entirety of study to minimize bias. All biomass measurements were taken on tissue collected from a destructive harvest and dried in $65^{\circ} \mathrm{C}$ for a minimum of 72 hours. Root biomass was the total belowground biomass collected. Roots were rinsed in water to remove all dirt and sand. Dead aboveground biomass was all biomass (leaves, tillers, and/or stem) attached to the plant where more than $50 \%$ of the tissue was brown; whereas, live aboveground biomass was all biomass attached to the plant that was more than $50 \%$ green suggesting it was alive. Total 
aboveground biomass was the sum of live and dead aboveground biomass, while total biomass included live, dead, and root biomass. The shoot to root ratio was the total aboveground biomass divided by the root biomass. Mortality was scored as 1 if plants were alive and 0 if dead.

Phenotypes were measured at three time points: 0 days (51 days after planting, 0 days of treatment, referred to as pre-treatment), then 15 (short term exposure), and 45 (long term exposure) days after treatment began. Height and tiller count were taken at 0,15 , and 45 days after treatment began, with 0 days indicating immediately before treatment. Rank score was taken at 15 and 45 days after treatment began. All biomass was collected between 45-50 days after treatment and was immediately dried.

The stress tolerance index (STI) value for each trait was calculated using the following formula, where $\mathrm{Y}$ is the phenotypic trait, control is the trait measurement in $0 \mathrm{mM} \mathrm{NaCl}$ conditions, salt is the trait measurement in $75 \mathrm{mM} \mathrm{NaCl}$ conditions, and control average is the population average of the trait in control conditions (Negrão et al., 2017):

$$
\text { Stress Tolerance Index }=\left(\frac{Y \text { control }}{Y \text { control average }}\right) \times\left(\frac{Y \text { salt }}{Y \text { control average }}\right)
$$

For each RIL, the control value was averaged across control replicates and an STI value was calculated for each salt treated plant. The STI value accounts for the overall performance of the population and compares each RIL's ability to maintain performance under stress conditions. RIL's with large STI values indicate larger phenotypic values for a given trait and are often considered tolerant depending on the phenotype.

\section{Statistical analysis of phenotypic values}

All statistical analyses were performed on the control population, the salt treated population, and on stress tolerance index (STI) values. Three biological replicates of each RIL in the salt population and two biological replicates of each RIL in the control population were considered for QTL analysis. There were three biological replicates for STI values. Least square means for each phenotype in each population (control, salt, STI) were calculated for each RIL. Normality was assessed using both a Shapiro-Wilk test in RStudio (ver.1.2.5019) and Q-Q plots from the car (Fox \& Weisberg, 2019) package of R (R Core Team, 2013). Traits that were not normally distributed were transformed (Supplementary Table S1). Transformed values were used in statistical tests and in QTL analysis. Correlations of phenotypes within each treatment (control or salt) were assessed via a Pearson's Correlation analysis in R (R Core Team, 2013) using the PerformanceAnalytics (Peterson \& Carl, 2019) package (Figure S1)(R Core Team, 2013).

To determine if there was a treatment effect, both a non-metric multidimensional scaling (NMDS) analysis (Julkowska et al., 2019) and an analysis of variance (ANOVA) was performed. The NMDS ordinates RILs based on similarity/dissimilarity when all phenotypes were considered. The NMDS was generated using the vegan (Oksanen et al., 2019) package in RStudio (ver.1.2.5019)(R Core Team, 2013). The NMDS was paired with an analysis of similarity (ANOSIM) to statistically test if individuals cluster within a treatment or among treatments (significance assessed at $\alpha=0.05$ ). An analysis of variance (ANOVA) was used to 
test if control and salt populations differed for individual phenotypes (significance assessed at $\alpha$ $=0.05)$. All statistics were completed using RStudio ver.1.2.5019.

\section{Genetic map construction and QTL analysis}

A high-quality genetic map for the $S$. propinquum by $S$. bicolor (Tx7000) RIL population was previously constructed as described in Govindarajulu et al. (2020). In summary, using highquality nuclear DNA, the parent plants (S. propinquum and $S$. bicolor) were sequenced at $18 \mathrm{x}$ depth, while the RILs were sequenced at $2 \mathrm{x}$ depth. SNP data were aligned to the masked Sorghum bicolor reference genome ver 3.1 (Paterson, 2008). Loci were called as S. propinquum (A), S. bicolor (B), or heterozygous $(\mathrm{H})$ when SNPs were analyzed with the GenosToABHPlugin in Tassel ver 5.0 (Bradbury et al., 2007). The ABH formatted SNP data file was then used as input to SNPbinner (Gonda et al., 2019), which calculated breakpoints (Govindarajulu et al., 2020). Breakpoints were merged if they were shorter than $0.2 \%$ of the chromosome length. After removing heterozygous bin markers, duplicate bin markers, and markers that deviated significantly from the expected Mendelian ratio (1:1) at $\mathrm{P}<10^{-5}$ after Bonferroni correction, the kosambi map function in R/qtl (Broman et al., 2003) was used to construct a high density genetic map. A second map was constructed including all markers that deviated from the expected Mendelian ratio $(1: 1)$.

QTL analysis was performed in RStudio (ver.1.2.5019) using the qtl (Broman et al., 2003) package. QTL were first identified by a single interval mapping QTL model. Significant LOD peak scores were determined by comparing LOD peak scores after a 1,000 permutation test $(\alpha=$ 0.05) (Churchill \& Doerge, 1994). If QTL were detected by interval mapping (IM), phenotypes were assessed via a multiple QTL model. The multiple QTL model (MQM) tested for additional additive QTL, refined QTL positions, and tested for epistasis. Following MQM, a type III analysis of variance assessed the significance of the fit for the final model, the proportion of variance explained, and the additive effect. QTL with a negative additive value indicated that the trait was negatively influenced by $S$. bicolor alleles, whereas a positive additive value indicates the trait was positively influenced by S. bicolor alleles. Genes (Sorghum bicolor ver. 3.1) within a 1.0 logarithm of the odds (LOD) confidence interval for each QTL were identified.

\section{Results}

High quality genetic map

The resequencing and bin calling of the 177 RILs generated 4055 total bin markers (Figure S2); however, after removing distorted markers (Figure S3) and duplicate markers (Figure S4), our map covered the 10 Sorghum chromosomes with 1692 bin markers (Supplementary Table S2) and was $888.7 \mathrm{cM}$ in length (Supplementary Table S3). Chromosomes 7 and 8 contained no distorted regions and chromosomes 3 and 9 contained less than 10 distorted markers; however, the distorted region of $61.09 \mathrm{Mb}$ to $70.23 \mathrm{Mb}$ on chromosome 2 and the distorted region of 6.37 $\mathrm{Mb}$ to $59.45 \mathrm{Mb}$ on chromosome 5 indicate preferential transmission bias of $S$. propinquum alleles. Chromosomes 1, 4, 6, and 10 contain distorted regions favoring $S$. bicolor alleles (Supplementary Table S3). 


\section{Treatment Effect}

The control and salt population summary statistics of phenotypes are listed in Supplementary Table S4. With the exception of mortality, all other phenotypes were significantly different between control and salt treated populations (short term and long term exposure)(Supplementary Table S5). In response to salt exposure, plants were shorter (Figure 1a) and had less live aboveground biomass, root biomass, total aboveground biomass, total biomass, and percent of alive aboveground biomass (Figure 1b). In contrast, plants had a larger rank score, more dead aboveground biomass, and a larger shoot to root ratio (Figure 1b). These significant differences between treatment and control conditions, in addition to the clear and significant clustering $(\mathrm{p}<0.001$, ANOSIM $\mathrm{R}=0.16)$ of treatments in the NMDS analysis (Figure 2), are indicative of a decrease in performance in response to treatment.

\section{QTL Results and Phenotypic Responses}

Although variation among the control and salt population was observed in response to treatment, no QTL were detected for short term salt exposure (DAT=15). Therefore, the remaining sections will focus on QTL detected for long-term salt exposure (DAT=45). All genes detected in QTL when only considering Mendelian segregating markers are listed in Supplementary Table S6. All genes detected in QTL when including all markers that deviated from the expected Mendelian ratio are listed in Supplementary Table S7.

$\underline{\text { Total biomass }(\mathrm{TB})}$

In control conditions, plants ranged from $1.98 \mathrm{~g}$ to $12.18 \mathrm{~g}$ of total biomass, with a mean of 7.49 $\mathrm{g}$; however, in salt conditions, a 32\% decrease in total biomass was observed $(0.66 \mathrm{~g}-9.42 \mathrm{~g}$ with a mean of $5.11 \mathrm{~g}$, Supplementary Table S4). Three QTL were detected for total biomass with a common QTL detected on chromosome 4 in both salt conditions and when STI values were mapped (qTB45_4.S and qTB45_4.STI, respectively) (Figure 3a). An additional unique QTL was detected on chromosome 5 in the salt population (qTB45_5.S). Each QTL had a positive additive effect indicating that $S$. bicolor alleles positively influenced the total biomass and explained greater than 10 percent of the phenotypic variation. The QTL on chromosome 4 that was detected when STI values were mapped (qTB45_4.STI), explained the greatest amount of phenotypic variation $(\mathrm{PVE}=13.02)$ (Table 2). Of the 595 genes within qTB45_4.STI, candidate genes were associated with aquaporins, oxidative stress, salt tolerance, LEA (late embryogenesis abundant) proteins, and transporters (Supplementary Table S8). When including distorted markers, the peaks for the two QTL detected on chromosome 4 (qTB45_4S and qTB45_4STI) were not affected (Supplementary Table S9, Figure 3b).

Total aboveground biomass (TAGB)

In control conditions, plants accumulated an average of $5.00 \mathrm{~g}$ of total aboveground biomass ( $1.34 \mathrm{~g}-8.56 \mathrm{~g})$, however, in response to salt treatment, there was a $20 \%$ decrease in total aboveground biomass (average $=3.98 \mathrm{~g})$ (Supplementary Table S5). A single QTL

(qTAGB45_4.STI) was detected when STI values were mapped (Figure 3a). The QTL was located on chromosome 4 between $62.17 \mathrm{Mb}-66.68 \mathrm{Mb}$ with a peak at $62.29 \mathrm{Mb}$ (Table 2). qTAGB45_4.STI explained 12.34 percent of the phenotypic variation and had a positive additive effect indicating that $S$. bicolor alleles positively influence the total amount of aboveground biomass. qTAGB45_4.STI co-localized with qTB45_5.S and qTB45_4.STI. Therefore, the same 
595 total genes and candidate genes identified in the total biomass QTL were also identified for total aboveground biomass. When including distorted markers, the QTL detected on chromosome 4 for total aboveground biomass when STI values were mapped remained at approximately the same location, however, an additional QTL was detected for the salt population, explaining 9.49 percent of the phenotypic variation and having a larger additive effect of 0.40 (Figure 3b).

Dead aboveground biomass (DAGB)

In control conditions, dead aboveground biomass ranged from $0.06 \mathrm{~g}$ to $1.61 \mathrm{~g}$ (mean of $0.55 \mathrm{~g}$ ), whereas in salt conditions there was an increase of $45 \%$ with a mean of $0.80 \mathrm{~g}$ (Supplementary

Table S4). Two QTL (qDAGB45_2.C and qDAGB45_2.STI) were detected for dead aboveground biomass when control and STI values were mapped (Figure 3a). The QTL were both detected on chromosome 2 and explained 9.14 and 12.03 percent of the phenotypic variation, respectively (Table 2). RILs with S. propinquum alleles in this region positively influenced the amount of dead aboveground biomass. In qDAGB45_2.STI, there were 739 genes. Of the 739 genes, candidates included genes that encode aquaporins, $\mathrm{Na}^{+} / \mathrm{H}^{+}$transporters, LEA-like proteins, and CLB (calcium-dependent lipid-binding) proteins (Supplementary Table S8). When including all distorted markers, the two QTL on chromosome 2 remained, however, an additional QTL was detected on chromosome 9 in the control population. The range of the QTL detected on chromosome 2 when control values were mapped (qDAGB45_2.C) shifted and decreased significantly when distorted markers were included (64.40 Mb-67.54 Mb, peak @) 65.42), however, when STI values were mapped the QTL peak shifted and the range increased (13.85 Mb - 67.54 Mb, peak@62.28 Mb) (Figure 3b). The new QTL, qDAGB45_9.C, was detected between 55.47 and $57.91 \mathrm{Mb}$ with a peak at $56.32 \mathrm{Mb}$ and explained 9.71 percent of the phenotypic variation with an additive effect of -0.06 .

$\underline{\text { Live aboveground biomass (LAGB) }}$

In control conditions, live aboveground biomass ranged from $1.20 \mathrm{~g}$ to $6.95 \mathrm{~g}$ with an average of $4.45 \mathrm{~g}$ (Supplementary Table S4). In response to salt treatment, there was a decrease of $28 \%$ in live aboveground biomass with a range from $0.32 \mathrm{~g}$ to $6.22 \mathrm{~g}$ and an average of $3.18 \mathrm{~g}$ (Figure 1b). Two QTL were detected for live aboveground biomass (qLAGB45 4.STI and qLAGB45_5.STI) when STI values were mapped (Figure 3a). Both QTL had a positive additive effect indicating that $S$. bicolor alleles positively influenced live aboveground biomass. The QTL detected on chromosome 4 explained 15.35 percent of the phenotypic variation and the QTL detected on chromosome 5 explained 10.40 percent of the phenotypic variation (Table 2). In the $4.38 \mathrm{Mb}$ region where qLAGB45_4.STI was identified, there were 577 genes from which we identified several candidate genes. Candidate genes include genes associated with aquaporins, stress induced proteins, cation efflux proteins, and a calcineurin B subunit protein. In the region where qLAGB45_5.STI was identified, there were 1356 genes from which we identified candidate genes. Candidate genes included genes that encode proteins associated with photosynthesis, auxin signaling and response, stress response, potassium channels, and growth regulation (Supplementary Table S8). When distorted markers were included, the QTL on chromosome 4 (qLAGB45_4.STI) was still detectable, however there was a slight shift in the range and peak (Supplementary Table S9).

$\underline{\text { Root biomass (RB) }}$ 
Root biomass for plants grown in control conditions ranged from $0.48 \mathrm{~g}$ to $6.38 \mathrm{~g}$ with a population average of $2.50 \mathrm{~g}$; however, root biomass for plants grown in salt conditions was reduced by $55 \%$ and ranged from $0.09 \mathrm{~g}$ to $2.48 \mathrm{~g}$ with a population average of $1.13 \mathrm{~g}$ (Supplementary Table S4). A single QTL was detected for root biomass when STI values were mapped (qRB45_4.STI) (Figure 3a). qRB45_4.STI explained 9.09 percent of the phenotypic variation and had an additive effect of 0.08 indicating that individuals with $S$. bicolor alleles in this region positively influenced root biomass. There were 812 genes within the $6.26 \mathrm{Mb}$ region (Supplementary Table S6). Of these, there were several notable genes for their role in stress response, specifically genes that have been annotated as salt tolerance homologs (Supplementary Table S8). When including all distorted markers, the QTL detected on chromosome 4 was retained in approximately the same location (peak @62.46 Mb), however, the range of the QTL was reduced (62.17 Mb - 62.54 Mb)(Figure 3b).

\section{Rank Score (RS)}

Rank score was a qualitative measure used to describe overall plant health (Table 1). There was a 58\% increase in the rank score in response to treatment indicating that there was an overall decrease in the health of plants exposed to $\mathrm{NaCl}$ (Figure 1b). In control conditions, the average rank score of the population was $2.01(0.72-3.20)$ indicating that most of the individuals in the population were beginning to show signs of leaf tip curling; however, some individuals had dead leaves present but still were able to produce new leaves. In contrast, the rank score of the salt treated population averaged 3.19 with a range of 1.68 to 4.55 (Supplementary Table S4). This increase suggests that the production of new leaves was halted, most leaves were dead or began dying, and all individuals were displaying signs of stress. When STI values were mapped, a single QTL (qRS45_7.STI) was detected on chromosome 7 (Figure 3a). qRS45_7.STI explained 9.00 percent of the phenotypic variation and had a negative additive effect indicating that $S$. bicolor alleles are associated with a lower the rank score. Of the 134 genes located within qRS45_7.STI, there are genes that encode aquaporins and cation transporters (Supplementary Table S8). When all distorted markers were included a new QTL was detected on chromosome 4 (qRS45_4.STI). qRS45_4.STI ranged from $62.46 \mathrm{Mb}$ to $63.95 \mathrm{Mb}$ with a peak near $63.67 \mathrm{Mb}$ (Figure 3b). qRS45_4. STI explained 10.77 percent of the phenotypic variation and also had a negative additive effect of 0.19 indicating that $S$. bicolor alleles are associated with a smaller rank score.

\section{Height (HT)}

At the final recording of height, the control population ranged from $52.92 \mathrm{~cm}$ to $122.37 \mathrm{~cm}$ with a population average of $87.81 \mathrm{~cm}$. In response to treatment, the salt population displayed a $16.38 \%$ decrease in height, ranging from $46.32 \mathrm{~cm}$ to $112.47 \mathrm{~cm}$ with a population average of $75.46 \mathrm{~cm}$ (Figure 1a). Six QTL were detected for height with two common QTL in the control (qHT45_7.C and qHT45_9.C) population and when STI values were mapped (qHT45_7.STI and qHT45_9.STI) (Table 2). qHT45_7.S was also detected in the salt population; however, a unique QTL (qHT45_1.S) was detected in the salt population, explaining 12.07 percent of the phenotypic variation and having an additive effect of -4.36 . Of the 3644 total genes within qHT45_1.S, several candidate genes were identified, including genes associated with osmotic and ionic stress alleviation, such as SOS3- and CBL-interacting proteins, and vacuolar cation exchangers (Supplementary Table S8). When including distorted markers, all six previously detected QTL were retained, however, an additional two QTL were detected when STI values 
were mapped (Figure 3b). With the exception of qHT45_1.S, the positions of all other QTL (qHT45_7.C, qHT45_9.C, qHT45_7.S, qHT45_7.STI, and qHT45_9.STI) were unchanged. The range of qHT45_1.S significantly decreased $(7 \overline{6} .22 \mathrm{Mb}$ to $80.57 \mathrm{Mb})$; however, the peak remained close to its original location (peak@75.72 Mb). The two additional QTL detected when STI values were mapped (qHT45_1.STI and qHT45_4.STI) explained an average 9.82 percent of the phenotypic variation. Interestingly, qHT45_1.STI had a negative additive effect indicating that $S$. bicolor alleles negatively influenced plant height while qHT45_4.STI had a positive additive effect indicating that $S$. bicolor alleles positively influenced height. Further, qHT45_1.STI co-localized with the previously detected qHT45_1.S, which was only detected when salt values were mapped.

\section{Discussion}

In the present study, we screened $177 \mathrm{~F}_{3: 5}$ RILs derived from a cross between an inbred Sorghum bicolor (Tx7000; landrace durra) and its wild relative, Sorghum propinquum for performance in saline conditions. Because of Sorghum's importance in biofuel and forage production, salinity tolerance was assessed as the ability of the plant to maintain traits related to growth and performance in response to salt treatment. This tolerance can be achieved by various mechanisms including osmotic adjustment, $\mathrm{Na}^{+}$exclusion from the aerial organs of the plant, and overall tissue tolerance; however, $\mathrm{Na}^{+}$exclusion can also result from reduced $\mathrm{Na}^{+}$uptake, increased $\mathrm{Na}^{+}$ extrusion to the roots and/or soil media, or increased retrieval from the shoot (Wu et al., 2019). Ultimately, each of these tolerance mechanisms results in the maintenance of plant vigor similar to those plants grown in optimal conditions. In this study, we identified QTL associated with total biomass, total aboveground biomass, height, dead aboveground biomass, live aboveground biomass, root biomass, and rank score, in a control environment, a saline environment, and from STI values. Among the 18 QTL detected, 11 were either 1) unique to the STI values, 2) unique to the saline environment, and/or 3) explained more than 10 percent of the phenotypic variation (Table 2).

The data presented here, in combination with previous findings (Henderson et al., 2019), collectively demonstrates that there is increased tolerance to salinity stress in Sorghum bicolor compared to $S$. propinquum. For dead aboveground biomass, live aboveground biomass, total aboveground biomass, and total biomass, S. bicolor alleles were associated with tolerance. For example, the negative additive effect for the QTL detected for dead aboveground biomass indicates that $S$. bicolor alleles were associated with less accumulation of dead aboveground biomass. Similarly, the QTL detected for live aboveground biomass, total aboveground biomass, and total biomass all have positive additive effects indicating that $S$. bicolor alleles promote continued growth in stressful conditions. It is important to note that, in optimal conditions, S.propinquum produces more aboveground biomass compared to $S$. bicolor (Govindarajulu et al., 2020). Therefore, in response to salt, the ability for the lines with S. bicolor alleles to perform favorably supports the conclusion that $S$. bicolor possesses greater tolerance to salinity stress. Further, these results suggest that $S$. bicolor is better at handling both osmotic and ionic stress, because with osmotic adjustment, increased water can be taken up by the plant to support the production of new biomass and to limit necrosis due to cell dehydration, while increased ionic tolerance results in decreased leaf senescence resulting in overall greater aboveground growth. 
Because salinity stress is the product of both osmotic and ionic factors, their respective causes and consequences are often difficult to distinguish; however, these two stresses are often temporal in their action. When salts initially begin to accumulate in the soil, the osmotic potential of the soil water decreases, resulting in decreased water extraction by plant roots. This osmotic stress causes a sudden, short term loss of water, cell volume, and turgor from leaf cells. Plants that are tolerant to stress during the osmotic phase are better able to modify long distance signaling, limit stomatal closure, osmotically adjust, and continue cell expansion/lateral bud development, resulting in the continuation of both above and belowground growth (Munns \& Tester, 2008). One important mechanism that plants utilize to overcome the osmotic phase of salinity stress is via the production and accumulation of compatible solutes such as amino acids (i.e. proline), amines, betaines, organic acids, sugars, and polyols (Parihar et al., 2015) which aid in water acquisition and maintenance of cell turgor. For the QTL detected in this study, we identified various genes whose products are related to osmotic adjustment, including genes involved in proline production, aquaporins, CDPKs (calcium-dependent protein kinases), sensing and signaling, cell division, $\mathrm{Na}^{+} / \mathrm{Ca}^{2+}$ exchanger, leaf senescence, early response to dehydration, heat shock proteins, SAPK3 (stress-activated protein kinases), vacuolar proton exchangers, potassium antiporters, and stress response proteins.

Perhaps most striking was the presence of a large number of genes encoding aquaporins (Supplementary Table S6). Aquaporin genes are well known for their role in water transport (Sakurai et al., 2005; Alexandersson et al., 2005; Maurel et al., 2008; Liu et al., 2015; Reddy et al., 2015; Kadam et al., 2017; Hasan et al., 2017). In a previous study that characterized the aquaporin (AQP) gene family in Sorghum bicolor, SbAQP transcript abundance was affected by both salt and drought stress (Reddy et al., 2015). In response to salt stress specifically, most of the SbAQP genes were significantly upregulated. Reddy et al. (2015) hypothesized that increased SbAQP expression may be important in not only water uptake, but also in sodium dilution in root cells. In our study we identified 14 unique aquaporin genes, specifically, Sobic.001G208500, Sobic.001G389900, Sobic.002G124700, Sobic.002G125000, Sobic.004G295100, Sobic.007G039500, and Sobic.005G091600, which encode TIP3;1, SIP2;1, PIP2;2, PIP2;6, TIP2;1, NIP3;2, and SIP1;1, respectively (Supplementary Table S6). Given that osmotic stress is a result of water limitation due to the decreased water potential within the plant cells, we predict that the various genes encoding aquaporins detected in our QTL are important for osmotic tolerance.

Following osmotic stress, as soil salinity levels rise, plants begin to accumulate $\mathrm{Na}^{+}$and $\mathrm{Cl}$ - ions, which if not properly handled will become toxic within the leaves. The most common phenotype associated with ionic stress is increased leaf necrosis. Therefore, we used dead aboveground biomass and rank score as a proxy for ionic toxicity. RILs with greater amounts of dead aboveground biomass or larger rank scores were considered sensitive to ionic stress, whereas tolerant genotypes exhibit less leaf necrosis. For qDAGB45_2.STI, S. propinquum alleles positively correlated with greater dead aboveground biomass, possibly as a result of increased $\mathrm{Na}^{+}$accumulation in the aerial plant tissue. Larger amounts of dead aboveground biomass is often a result of the inability to exclude ions resulting in toxic accumulation, ionic disequilibrium, or tissue sensitivity (Munns \& Tester, 2008). Similarly, qRS45_7.STI also had a negative additive effect, indicating that $S$. propinquum alleles positively influenced the rank score, suggestive of greater susceptibility to ionic toxicity (Table 1). Candidate genes associated 
with ionic stress in these QTL include: calcium-dependent protein kinases, LEA-like proteins, aquaporins, heat shock proteins, $\mathrm{Na}^{+} / \mathrm{H}^{+}$antiporters, WRKY transcription factors, $\mathrm{K}^{+}$uptake, and cation transporters (Supplementary Table S8). Most interestingly, there were numerous genes within the two QTL that we considered most informative of ionic stress, specifically genes associated with $\mathrm{Ca}^{2+}$ sensing/signaling and $\mathrm{Na}^{+}$transport, which are important in limiting cytoplasmic ion toxicity. A notable candidate gene associated with ionic sensing and signaling identified in qDAGB45 2.STI is CDPK (calcium-dependent protein kinase) (Sobic.002G114800). CDPKs are a class of calcium sensors that, in response to most environmental stresses, have been previously shown to mediate abiotic stress via calcium waves that signal various physiological responses (Urao et al., 1994a,b; Knight et al., 1997; Cheng et al., 2002; Delormel \& Boudsocq, 2019). Further, two genes that encode $\mathrm{Na}^{+} / \mathrm{H}^{+}$transporters were identified as candidate genes. $\mathrm{Na}^{+} / \mathrm{H}^{+}$transporters are especially important in sodium exclusion from areas of the plant such as the cytoplasm and aerial organs. Lastly, genes associated with potassium uptake and distribution were identified. Potassium $\left(\mathrm{K}^{+}\right)$is an essential nutrient for plant growth and development (Maathuis, 2009; Ahmad \& Maathuis, 2014; Morton et al., 2019). Because of the similarity in size and structure of $\mathrm{Na}^{+}$and $\mathrm{K}^{+}$, both ions often share transport systems. $\mathrm{K}^{+}$, however, is essential for protein synthesis (Jones et al., 1979; Blaha et al., 2000), enzymatic reactions (Bhandal \& Malik, 1988), and signaling (Shabala, 2017), whereas $\mathrm{Na}^{+}$is not. Therefore, maintaining high $\mathrm{K}^{+} / \mathrm{Na}^{+}$ratios is important for salinity tolerance (Chen et al., 2005, 2007; Cuin et al., 2008; Shabala, 2013; Wu et al., 2018; Morton et al., 2019).

\section{Conclusions}

In a previous study comparing salt tolerance rankings among a diverse group of Sorghum genotypes and species, we concluded that the most parsimonious explanation for the phylogenetic distribution of variation in plant response to salinity is that tolerance was acquired early during domestication, specifically in the durra landrace, and then lost in improved lines in a lineage-specific manner (Henderson et al., 2019). The results presented here, specifically with respect to the enrichment of aquaporins in salt responsive QTL, indicate that the greater salt tolerance in Sorghum bicolor is likely a result of efficient water acquisition under stressful conditions. Therefore, since drought stress and salt stress share a common osmotic component, and since $S$. bicolor was domesticated and improved in arid environments, we hypothesize that salt tolerance in Sorghum is a byproduct of the drought tolerance acquired during domestication. As we also observed genes associated with sensing, signaling, and transport of $\mathrm{Na}^{+}$, it is possible that sorghum is able to maintain ionic homeostasis, while also using $\mathrm{Na}^{+}$as a cheap compatible solute. One such example is SAPK3 (qHT45_1.S), a serine/threonine-protein kinase that has been previously shown to be associated with increased salinity tolerance through its role in signal transduction in response to hyperosmotic stress (Huai et al., 2008; Basu \& Roychoudhury, 2014; Guan et al., 2019). By using $\mathrm{Na}^{+}$as a cheap compatible solute, plants would be able to avoid ionic toxicity and alleviate osmotic stress, while also conserving energy that can be used for biomass production (Munns et al., 2019, 2020). When considering the QTL and candidate genes identified here, we propose that the aquaporin gene family provides a promising avenue of research aimed at the improvement of sorghum for growth on saline soils. Additionally, while there were several other genes identified in this study that have previously been shown to contribute to increased abiotic stress and salinity tolerance, there were a significant number of unannotated genes. These genes remain attractive for future studies, as they may be pivotal in the maintenance of plant health and biomass production in marginal environments. 


\section{Acknowledgements}

We would like to acknowledge the WVU Genomics Core Facility, Morgantown WV for support provided to help make this publication possible and CTSI Grant \#U54 GM104942 which in turn provides financial support to the Core Facility. The authors wish to thank Ryan Percifield for assistance during data collection, Dr. Stephen DiFazio and Dr. Sandra Simon for guidance in data analysis, and the West Virginia University Evansdale Greenhouse for supplying space. This work was partially funded by the Eberly College of Arts and Sciences research award to Ashley N. Henderson. 


\section{Literature Cited}

Ahmad I, Maathuis FJM. 2014. Cellular and tissue distribution of potassium: Physiological relevance, mechanisms and regulation. Journal of Plant Physiology 171: 708-714.

Alexandersson E, Fraysse L, Sjövall-Larsen S, Gustavsson S, Fellert M, Karlsson M, Johanson U, Kjellbom P. 2005. Whole gene family expression and drought stress regulation of aquaporins. Plant Molecular Biology 59: 469-484.

Almodares A, Hadi MR, Ahmadpour H. 2008a. Sorghum stem yield and soluble carbohydrates under different salinity levels. African Journal of Biotechnology 7: 4051-4055.

Almodares A, Hadi MR, Dosti B. 2007. Effects of salt stress on germination percentage and seedling growth in sweet sorghum cultivars. Journal of Biological Sciences 7: 1492-1495.

Almodares A, Hadi MR, Dosti B. 2008b. The effects of salt stress on growth parameters and carbohydrates contents in sweet sorghum. Research Journal of Environmental Sciences 2: 298304.

Almodares A, Sharif ME. 2007. Effects of irrigation water qualities on biomass and sugar contents of sugar beet and sweet sorghum cultivars.

Basu S, Roychoudhury A. 2014. Expression profiling of abiotic stress-inducible genes in response to multiple stresses in rice ( Oryza sativa L.) varieties with contrasting level of stress tolerance. BioMed Research International 2014: 1-12.

Bhandal IS, Malik CP. 1988. Potassium estimation, uptake, and its role in the physiology and metabolism of flowering plants. In: Bourne GH, Jeon KW, Friedlander M, eds. International Review of Cytology. Academic Press, 205-254.

Blaha G, Stelzl U, Spahn CMT, Agrawal RK, Frank J, Nierhaus KH. 2000. [19] Preparation of functional ribosomal complexes and effect of buffer conditions on tRNA positions observed by cryoelectron microscopy. In: Methods in Enzymology. Elsevier, 292-309.

Boursier P, Läuchli A. 1990. Growth responses and mineral nutrient relations of salt-stressed sorghum. Crop Science 30: 1226-1233.

Bradbury PJ, Zhang Z, Kroon DE, Casstevens TM, Ramdoss Y, Buckler ES. 2007. TASSEL: software for association mapping of complex traits in diverse samples. Bioinformatics 23: $2633-2635$.

Brim CA. 1966. A modified pedigree method of selection in soybeans 1. Crop Science 6: 220220.

Broman KW, Sen Saunak. 2009. A guide to QTL mapping with R/qtl. New York; Springer.

Broman KW, Wu H, Sen S, Churchill GA. 2003. R/qtl: \{QTL\} mapping in experimental crosses. Bioinformatics 19: 889-890. 
Carillo P, Annunziata MG, Pontecorvo G, Fuggi A, Woodrow P. 2011. Salinity stress and salt tolerance. In: Abiotic Stress in Plants - Mechanisms and Adaptations.

Chen Z, Newman I, Zhou M, Mendham N, Zhang G, Shabala S. 2005. Screening plants for salt tolerance by measuring $\mathrm{K}+$ flux: a case study for barley. Plant, Cell \& Environment $\mathbf{2 8}$ : $1230-1246$.

Chen Z, Pottosin II, Cuin TA, Fuglsang AT, Tester M, Jha D, Zepeda-Jazo I, Zhou M, Palmgren MG, Newman IA, et al.2007. Root plasma membrane transporters controlling $\mathrm{K}+/ \mathrm{Na}+$ homeostasis in salt-stressed barley. Plant Physiology 145: 1714-1725.

Cheng S-H, Willmann MR, Chen H-C, Sheen J. 2002. Calcium signaling through protein kinases. The arabidopsis calcium-dependent protein kinase gene family. Plant Physiology 129: 469-485.

Churchill GA, Doerge RW. 1994. Empirical threshold values for quantitative trait mapping. Genetics 138: 963-971.

Cuin TA, Betts SA, Chalmandrier R, Shabala S. 2008. A root's ability to retain $\mathrm{K}^{+}$correlates with salt tolerance in wheat. Journal of Experimental Botany 59: 2697-2706.

Delormel TY, Boudsocq M. 2019. Properties and functions of calcium-dependent protein kinases and their relatives in Arabidopsis thaliana. New Phytologist 224: 585-604.

Doggett H. 1970. Sorghum. Sorghum.

Doggett H. 1988. Sorghum. Harlow, Essex, England: Longman Scientific \& Technical;

Fan Y, Shabala S, Ma Y, Xu R, Zhou M. 2015. Using QTL mapping to investigate the relationships between abiotic stress tolerance (drought and salinity) and agronomic and physiological traits. BMC Genomics 16: 43.

FAO. 2017. FAO soils portal.

Food and Agriculture Organization (FAO). 2008. Land and plant nutrition management service.

Food and Agriculture Organization (FAO). 2009. Land and plant nutrition management service.

Fox J, Weisberg S. 2019. An $\{R\}$ Companion to Applied Regression. Thousand Oaks, CA: Sage.

Fracasso A, Trindade L, Amaducci S. 2016. Drought tolerance strategies highlighted by two Sorghum bicolor races in a dry-down experiment. Journal of Plant Physiology 190: 1-14.

Genc Y, Oldach K, Taylor J, Lyons GH. 2016. Uncoupling of sodium and chloride to assist breeding for salinity tolerance in crops. New Phytologist 210: 145-156. 
Gonda I, Ashrafi H, Lyon DA, Strickler SR, Hulse-Kemp AM, Ma Q, Sun H, Stoffel K, Powell AF, Futrell S, et al.2019. Sequencing-based bin map construction of a tomato mapping population, facilitating high-resolution quantitative trait loci detection. The Plant Genome 12: 180010.

Govindarajulu R, Henderson AN, Xiao Y, Chaluvadi SR, Mauro-Herrera M, Siddoway ML, Whipple CJ, Bennetzen JL, Doust AN, Hawkins JS. 2020. Integration of high density genetic mapping with transcriptome analysis reveals candidate genes for tillering in sorghum. in prep.

Guan S, Xu Q, Ma D, Zhang W, Xu Z, Zhao M, Guo Z. 2019. Transcriptomics profiling in response to cold stress in cultivated rice and weedy rice. Gene 685: 96-105.

Guo YY, Tian SS, Liu SS, Wang WQ, Sui N. 2018. Energy dissipation and antioxidant enzyme system protect photosystem II of sweet sorghum under drought stress. Photosynthetica 56: 861872.

Hasan SA, Rabei SH, Nada RM, Abogadallah GM. 2017. Water use efficiency in the droughtstressed sorghum and maize in relation to expression of aquaporin genes. Biologia Plantarum 61: $127-137$.

Hasegawa PM. 2013. Sodium $\left(\mathrm{Na}^{+}\right)$homeostasis and salt tolerance of plants. Environmental and Experimental Botany 92: 19-31.

Henderson AN, Crim PM, Cumming JR, Hawkins JS. 2019. Phenotypic and physiological responses to salt exposure in Sorghum reveal diversity among domesticated landraces. bioRxiv: 848028.

Huai J, Wang M, He J, Zheng J, Dong Z, Lv H, Zhao J, Wang G. 2008. Cloning and characterization of the SnRK2 gene family from Zea mays. Plant Cell Reports 27: 1861-1868.

Jones WRG, Brady CJ, Speirs J. 1979. Ionic and osmotic relations in plant cells. In: Recent advances in cereal biochemistry. London: Academic Press, 63-103.

Julkowska MM, Saade S, Agarwal G, Gao G, Pailles Y, Morton MJL, Awlia M, Tester M. 2019. MVApp - Multivariate analysis application for streamlined data analysis and curation. Plant Physiology 180: 1261-1276.

Kadam S, Abril A, Dhanapal AP, Koester RP, Vermerris W, Jose S, Fritschi FB. 2017. Characterization and regulation of aquaporin genes of sorghum [Sorghum bicolor (L.) Moench] in response to waterlogging stress. Frontiers in Plant Science $\mathbf{8}$.

Kearsey MJ. 1998. The principles of QTL analysis (a minimal mathematics approach). 49: 1619-1623.

Knight H, Trewavas AJ, Knight MR. 1997. Calcium signalling in Arabidopsis thaliana responding to drought and salinity. The Plant Journal 12: 1067-1078. 
Liu P, Yin L, Wang S, Zhang M, Deng X, Zhang S, Tanaka K. 2015. Enhanced root hydraulic conductance by aquaporin regulation accounts for silicon alleviated salt-induced osmotic stress in Sorghum bicolor L. Environmental and Experimental Botany 111: 42-51.

Lynch M, Walsh B. 1999. Genetics and analysis of quantitative traits. The Quarterly Review of Biology 74: 225-225.

Maathuis FJ. 2009. Physiological functions of mineral macronutrients. Current Opinion in Plant Biology 12: 250-258.

Maurel C, Verdoucq L, Luu D-T, Santoni V. 2008. Plant aquaporins: Membrane channels with multiple integrated functions. Annual Review of Plant Biology 59: 595-624.

McCormick RF, Truong SK, Sreedasyam A, Jenkins J, Shu S, Sims D, Kennedy M, Amirebrahimi M, Weers BD, McKinley B, et al.2018. The Sorghum bicolor reference genome: improved assembly, gene annotations, a transcriptome atlas, and signatures of genome organization. The Plant Journal 93: 338-354.

Morton MJL, Awlia M, Al-Tamimi N, Saade S, Pailles Y, Negrão S, Tester M. 2019. Salt stress under the scalpel - dissecting the genetics of salt tolerance. The Plant Journal 97: 148163.

Mullet J, Morishige D, McCormick R, Truong S, Hilley J, McKinley B, Anderson R, Olson SN, Rooney W. 2014. Energy Sorghum--a genetic model for the design of C4 grass bioenergy crops. Journal of Experimental Botany 65: 3479-3489.

Munns R, Day DA, Fricke W, Watt M, Arsova B, Barkla BJ, Bose J, Byrt CS, Chen Z-H, Foster KJ, et al.2020. Energy costs of salt tolerance in crop plants. New Phytologist: 10721090.

Munns R, Passioura JB, Colmer TD, Byrt CS. 2019. Osmotic adjustment and energy limitations to plant growth in saline soil. New Phytologist.

Munns R, Tester M. 2008. Mechanisms of salinity tolerance. Annual Review of Plant Biology 59: $651-681$.

Negrão S, Schmöckel SM, Tester M. 2017. Evaluating physiological responses of plants to salinity stress. Annals of Botany 119: 1-11.

Oksanen J, Blanchet FG, Friendly M, Kindt R, Legendre P, McGlinn D, Minchin PR, O'Hara RB, Simpson GL, Soylmos P, et al.2019. vegan: Community Ecology Package.

Parihar P, Singh S, Singh R, Singh VP, Prasad SM. 2015. Effect of salinity stress on plants and its tolerance strategies: a review. Environmental Science and Pollution Research 22: 40564075 .

Paterson AH. 2008. Genomics of sorghum. International Journal of Plant Genomics 2008: e362451. 
Peterson BG, Carl P. 2019. PerformanceAnalytics: Econometric Tools for Performance and Risk Analysis.

R Core Team. 2013. $R$ : A language and enviornment for satistical computing. Vienna, Austria: R Foundation for Statistical Computing.

Reddy PS, Rao TSRB, Sharma KK, Vadez V. 2015. Genome-wide identification and characterization of the aquaporin gene family in Sorghum bicolor (L.). Plant Gene 1: 18-28.

Rengasamy P. 2006. World salinization with emphasis on Australia. Journal of Experimental Botany 57: 1017-1023.

Sakurai J, Ishikawa F, Yamaguchi T, Uemura M, Maeshima M. 2005. Identification of 33 rice aquaporin genes and analysis of their eexpression and function. Plant and Cell Physiology 46: $1568-1577$.

Shabala S. 2013. Learning from halophytes: physiological basis and strategies to improve abiotic stress tolerance in crops. Annals of Botany: mct205.

Shabala S. 2017. Signaling by potassium: another second messenger to add to the list? Journal of Experimental Botany 68: 4003-4007.

Snape JW, Riggs TJ. 1975. Genetical consequences of single seed descent in the breeding of self-pollinating crops. Heredity 35: 211-219.

Urao T, Katagiri T, Mizoguchi T, Yamaguchi-Shinozaki K, Hayashida N, Shinozaki K. 1994a. Two genes that encode $\mathrm{Ca}^{2+}$-dependent protein kinases are induced by drought and highsalt stresses in Arabidopsis thaliana. Molecular and General Genetics MGG 244: 331-340.

Urao T, Katagiri T, Mizoguchi T, Yamaguchi-Shinozaki K, Hayashida N, Shinozaki K. 1994b. An Arabidopsis thaliana cDNA encoding $\mathrm{Ca}^{2+}$-dependent protein kinase. Plant Physiology 105: 1461-1462.

Wu H, Shabala L, Zhou M, Su N, Wu Q, Ul-Haq T, Zhu J, Mancuso S, Azzarello E, Shabala S. 2019. Root vacuolar $\mathrm{Na}^{+}$sequestration but not exclusion from uptake correlates with barley salt tolerance. The Plant Journal: 1-13.

Wu H, Zhang X, Giraldo JP, Shabala S. 2018. It is not all about sodium: revealing tissue specificity and signaling roles of potassium in plant responses to salt stress. Plant and Soil 431: $1-17$.

Yang Z, Li J-L, Liu L-N, Xie Q, Sui N. 2020. Photosynthetic regulation under salt stress and salt-tolerance mechanism of sweet sorghum. Frontiers in Plant Science $\mathbf{1 0 .}$ 


\section{Tables}

Table 1. Rank scoring parameters of plant vigor. Plant vigor was assessed on a scale of 0 to 5 with 0 indicating no signs of stress and 5 indicating plant death.

\begin{aligned} & \hline Score Observation \\ & \hline 0 No leaf signs \\ & 1 Some leaf and leaf tip curling \\ & Severe leaf and leaf tip curling, few leaves \\ & 2 elongated \\ & 3 Most leaves dead but still producing new leaves \\ & 4 Plant still alive but no new growth \\ & 5 Plant dead \\ & \hline\end{aligned}


Table 2. QTLs identified in the RIL population using transformed least square means in control conditions, salt conditions, and with stress tolerance index values. The QTLs reported were identified when mapping using Multiple QTL Mapping (MQM) in control conditions $(0 \mathrm{mM} \mathrm{NaCl})$, salt conditions $(75 \mathrm{mM} \mathrm{NaCl})$, and with stress tolerance index (STI) values. QTLs are named using the following system: q[Trait][DAT]_[Chr].[Treatment]

\begin{tabular}{|c|c|c|c|c|c|c|c|c|c|c|c|c|c|}
\hline Trait & Trt & QTL Name & DAT & Chr & $\begin{array}{c}\text { Position } \\
(\mathbf{c M})\end{array}$ & $\begin{array}{c}\text { Bin (Max } \\
\text { LOD) }\end{array}$ & $\begin{array}{c}\text { Lod } \\
\text { score }\end{array}$ & p-value & PVE & Additive & $\begin{array}{c}\text { Start } \\
\text { Mb }\end{array}$ & $\begin{array}{c}\text { Peak } \\
\text { Mb }\end{array}$ & $\begin{array}{l}\text { End } \\
\text { Mb }\end{array}$ \\
\hline DAGB & Control & qDAGB45_2.C & 45 & 2 & 52.64 & 56.26 & 3.33 & $1.02 \mathrm{E}-04$ & 9.14 & -0.06 & 13.85 & 56.26 & 58.70 \\
\hline DAGB & STI & qDAGB45_2.STI & 45 & 2 & 52.64 & 56.26 & 4.42 & 7.53E-06 & 12.03 & -0.17 & 13.85 & 56.26 & 56.74 \\
\hline HT & Control & qHT45_9.C & 45 & 9 & 64.00 & 55.07 & 4.75 & $2.35 \mathrm{E}-05$ & 11.45 & -5.19 & 54.37 & 55.07 & 56.91 \\
\hline HT & Salt & qHT45_1.S & 45 & 1 & 125.00 & 77.03 & 4.93 & $1.58 \mathrm{E}-05$ & 12.07 & -4.36 & 18.46 & 77.03 & 80.57 \\
\hline HT & Salt & qHT45_7.S & 45 & 7 & 63.29 & 60.17 & 4.13 & $9.52 \mathrm{E}-05$ & 9.99 & -3.86 & 59.01 & 60.17 & 61.46 \\
\hline HT & STI & qHT45_9.STI & 45 & 9 & 64.00 & 55.07 & 3.61 & $3.00 \mathrm{E}-04$ & 8.87 & -0.04 & 54.37 & 55.07 & 56.68 \\
\hline LAGB & STI & qLAGBי̄5_4.STI & 45 & 4 & 73.00 & 66.68 & 6.26 & $1.30 \mathrm{E}-01$ & 15.35 & 0.00 & 62.29 & 66.68 & 66.68 \\
\hline LAGB & STI & qLAGB45_5.STI & 45 & 5 & 56.00 & 64.81 & 4.37 & $6.16 \mathrm{E}-02$ & 10.40 & 0.00 & 6.15 & 64.81 & 66.57 \\
\hline $\mathrm{RB}$ & STI & qRB45_4.STI & 45 & 4 & 67.00 & 62.29 & 3.29 & $1.12 \mathrm{E}-04$ & 9.09 & 0.08 & 60.42 & 62.29 & 66.68 \\
\hline $\mathrm{RS}$ & STI & qRS45_7.STI & 45 & 7 & 22.53 & 3.02 & 3.25 & $1.23 \mathrm{E}-04$ & 9.00 & -0.16 & 2.55 & 3.02 & 4.01 \\
\hline TAGB & STI & qTAGB45_4.STI & 45 & 4 & 73.00 & 62.29 & 4.55 & $5.60 \mathrm{E}-06$ & 12.34 & 0.12 & 62.17 & 62.29 & 66.68 \\
\hline $\mathrm{TB}$ & Salt & qTB45_4.S & 45 & 4 & 73.00 & 62.29 & 4.90 & $1.67 \mathrm{E}-05$ & 12.12 & 0.69 & 62.17 & 62.29 & 66.68 \\
\hline TB & STI & qTB45_4.STI & 45 & 4 & 71.00 & 62.29 & 4.82 & $2.97 \mathrm{E}-06$ & 13.02 & 0.10 & 62.17 & 62.29 & 66.68 \\
\hline
\end{tabular}

DAGB-dead aboveground biomass, LAGB-live aboveground biomass, RB-root biomass, RS-rank score, HT-height, TB-total biomass, TAGB-total aboveground biomass; Trt-treatment, STI-stress tolerance index, C-control, S-salt; P-Sorghum propinquum, B-Sorghum bicolor; DAT-days after treatment; Chr-chromosome, PVE-percent variance explained 


\section{Figures}
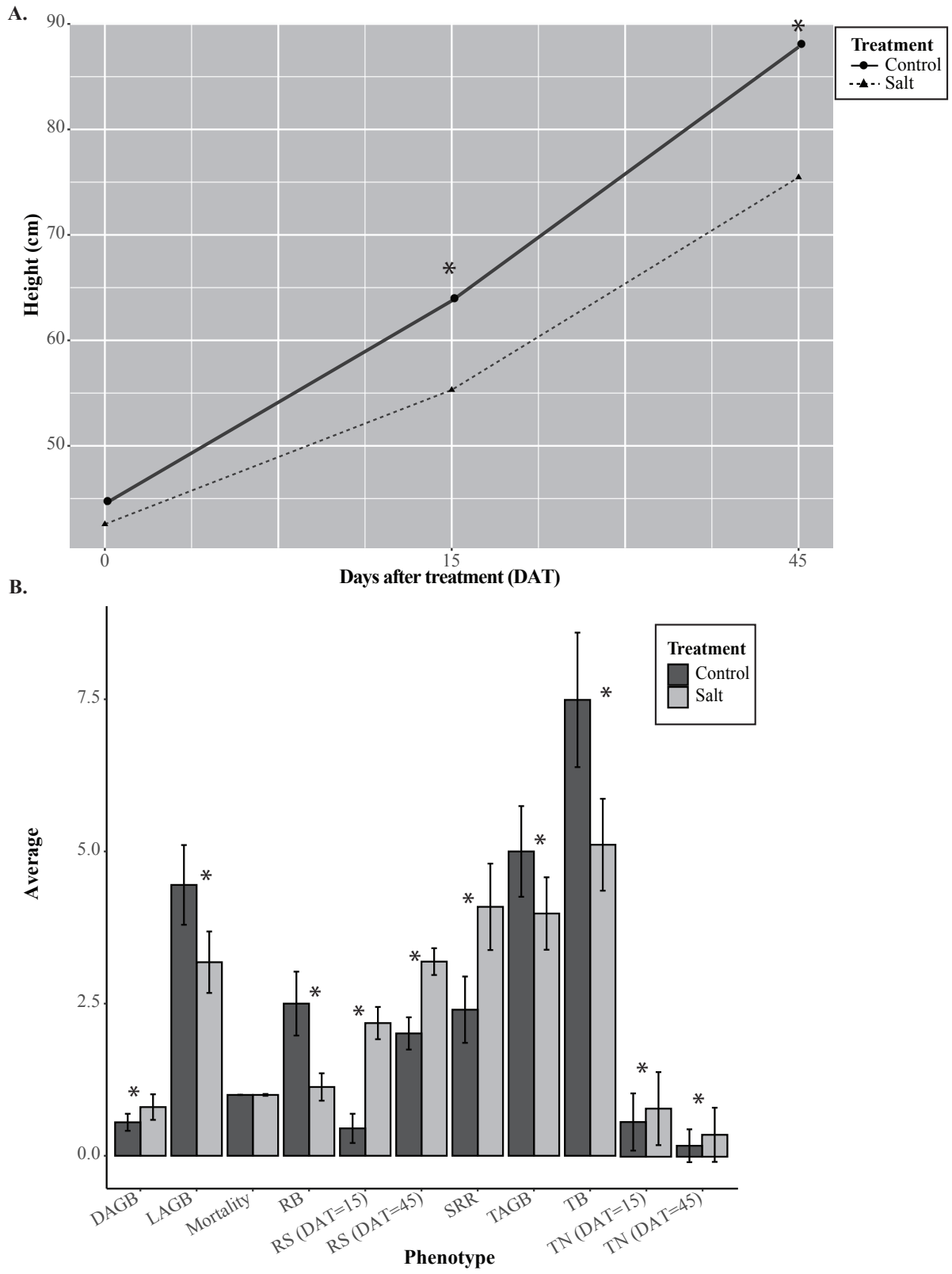

Figure 1. Phenotypic averages in control $(0 \mathrm{mM} \mathrm{NaCl})$ and treatment $(75 \mathrm{mM} \mathrm{NaCl})$ conditions. Phenotype averages for the control population and the salt population for height $(\mathrm{cm})(\mathrm{HT})$, dead aboveground biomass (DAGB) (g), live aboveground biomass (LAGB) (g), mortality, root biomass (RB) (g), rank score (RS) (0-5), shoot to root ratio (SRR), total aboveground biomass (TAGB) (g), total biomass (TB) (g), and tiller number (TN). In response to salt exposure, dead aboveground biomass, rank score, and shoot to root ratio increased, whereas height, live aboveground biomass, root biomass, total aboveground biomass, and total biomass decreased. 


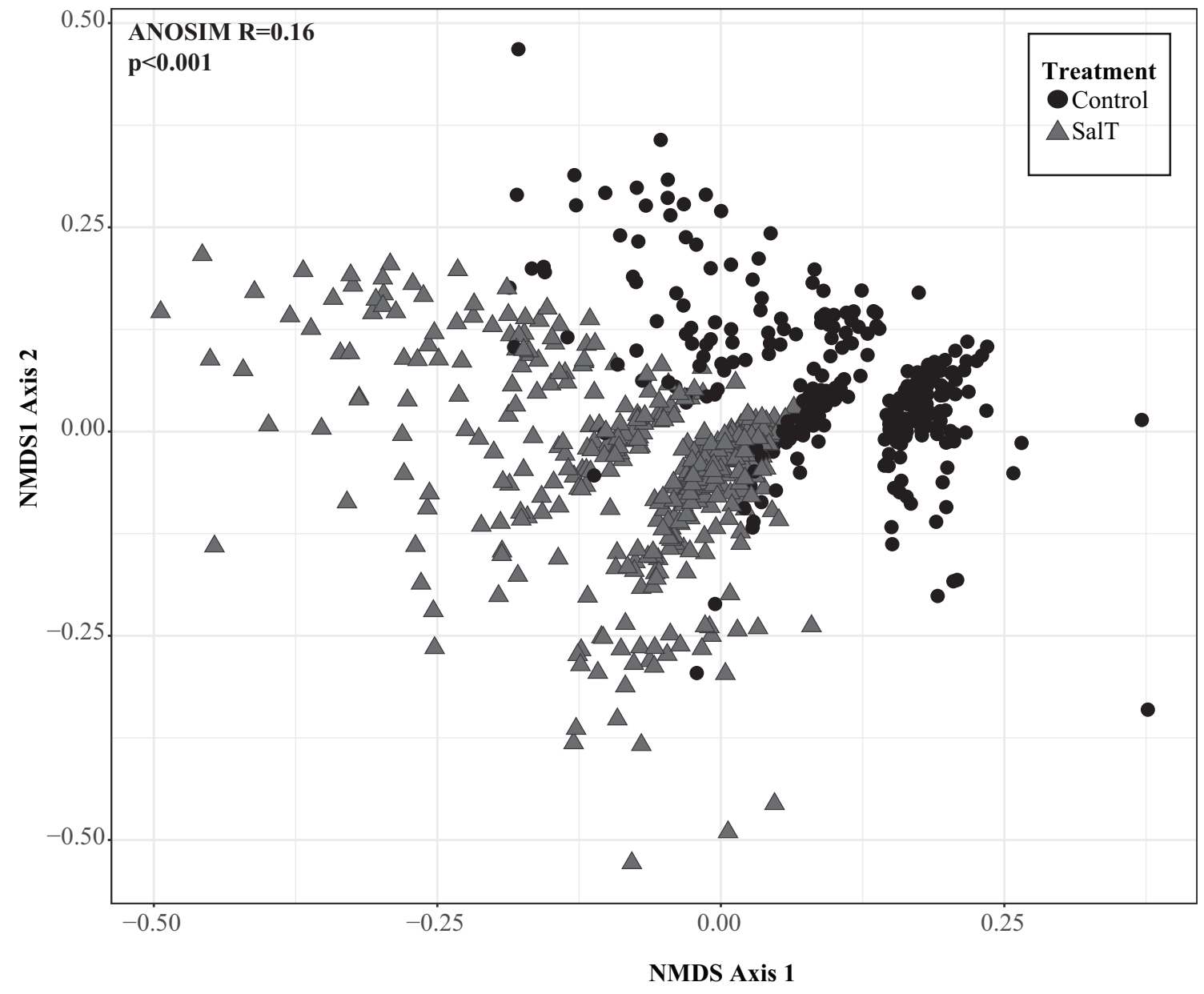

Figure 2. Non-metric multidimensional scaling (NMDS) analysis paired with an analysis of similarity (ANOSIM) reveals treatment clustering. A NMDS paired with an ANOSIM reveals individuals were more similar within a treatment than between treatments (ANOSIM R $=0.16$, $\mathrm{p}<0.001)$. 
A.

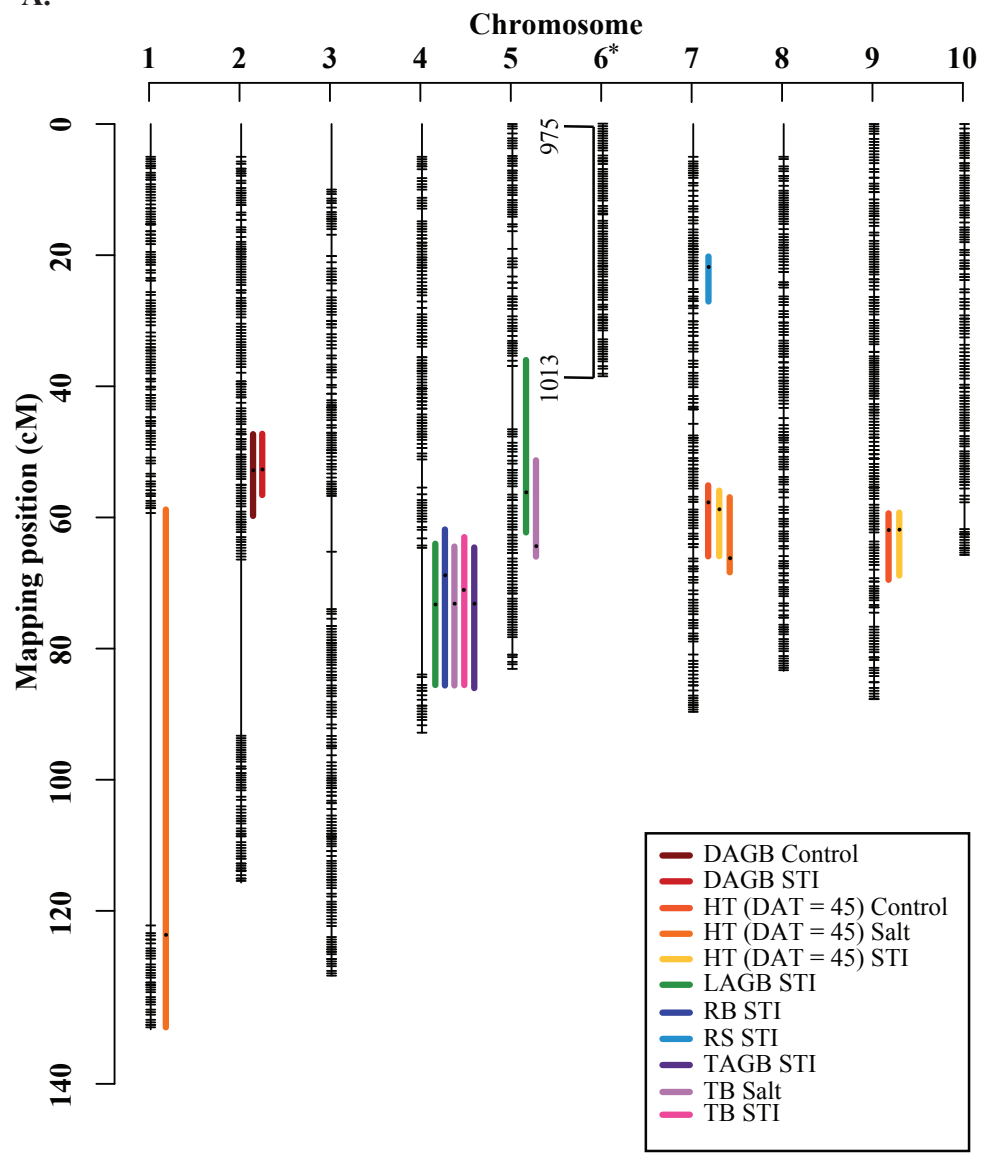

B.

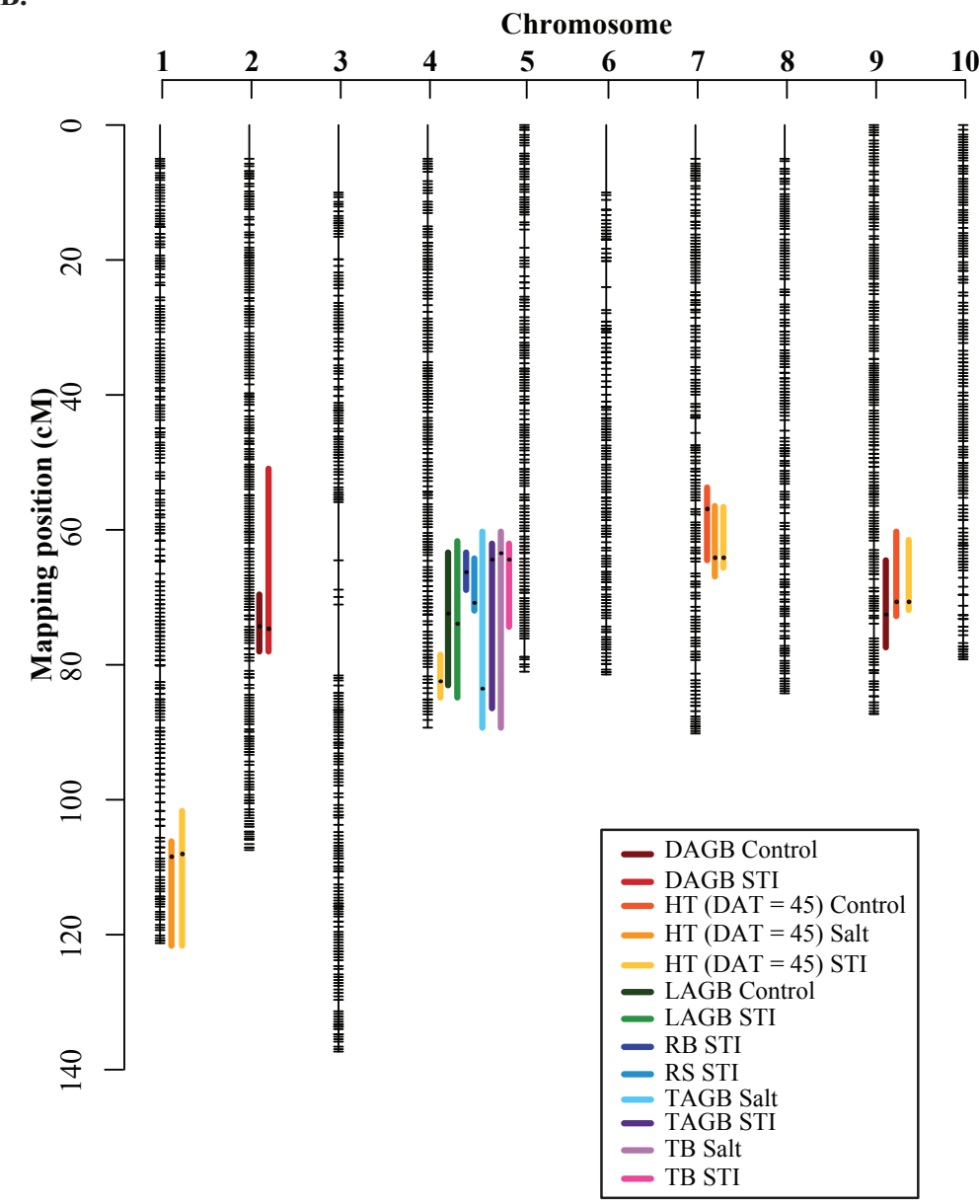

Figure 3. Sorghum genetic map with QTL locations for 14 traits from $177_{\text {ғз: }}$ RILs. (A) High-density genetic map with Mendelian segregating markers. QTL identified only when including distorted markers at $\mathrm{p}<10-5$ after Bonferroni correction. Empty regions are regions that were removed because bins were called heterozygous or markers were distorted or duplicates. (B) High-density genetic map that includes markers that deviated significantly from the Mendelian ratio (1:1). Empty spaces are regions that were removed because bins were either heterozygous or duplicate markers. The genetic map position is shown on the y-axis. Horizontal lines represent bins used as markers. Colored vertical lines show the physical position of each QTL for each trait in control conditions, salt conditions, or when STI values were mapped. *Note: the genetic distance on chromosome 6 is inflated due to segregation distortion. 


\section{Supplementary Tables}

Supplementary Table S1. Transformations of phenotypes. Phenotypes were transformed to meet normality. Transformed data was used in an analysis of variance and QTL mapping.

\begin{tabular}{|c|c|c|c|}
\hline Trait & Transformation & DAT & Treatment \\
\hline Height (HT) & & 0 & Control \\
\hline Height (HT) & & 15 & Control \\
\hline Rank Score (RS) & & 15 & Control \\
\hline Stem Diameter (SD) & & 29 & Control \\
\hline Height (HT) & & 45 & Control \\
\hline Rank Score (RS) & & 45 & Control \\
\hline Tiller Number (TN) & & 45 & Control \\
\hline Root Bimass (RB) & sqrt & 45 & Control \\
\hline Dead aboveground biomass (DAGB) & sqrt & 45 & Control \\
\hline Live aboveground biomass (LAGB) & & 45 & Control \\
\hline Total aboveground biomass (TAGB) & & 45 & Control \\
\hline Total biomass (TB) & & 45 & Control \\
\hline $\begin{array}{l}\text { Percent alive aboveground biomass } \\
\text { (PAAGB) }\end{array}$ & & 45 & Control \\
\hline Shoot to root ratio (SRR) & $\log$ & 45 & Control \\
\hline Height (HT) & & 0 & Salt \\
\hline Height (HT) & & 15 & Salt \\
\hline Rank Score (RS) & & 15 & Salt \\
\hline Stem Diameter (SD) & & 29 & Salt \\
\hline Height (HT) & & 45 & Salt \\
\hline Rank Score (RS) & & 45 & Salt \\
\hline Tiller Number (TN) & & 45 & Salt \\
\hline Root Bimass (RB) & & 45 & Salt \\
\hline Dead aboveground biomass (DAGB) & & 45 & Salt \\
\hline Live aboveground biomass (LAGB) & & 45 & Salt \\
\hline Total aboveground biomass (TAGB) & & 45 & Salt \\
\hline Total biomass (TB) & & 45 & Salt \\
\hline $\begin{array}{l}\text { Percent alive aboveground biomass } \\
\text { (PAAGB) }\end{array}$ & & 45 & Salt \\
\hline Shoot to root ratio (SRR) & $\log$ & 45 & Salt \\
\hline Height (HT) & sqrt & 0 & STI \\
\hline Height (HT) & sqrt & 45 & STI \\
\hline Rank Score (RS) & & 45 & STI \\
\hline Root Bimass (RB) & sqrt & 45 & STI \\
\hline Dead aboveground biomass (DAGB) & sqrt & 45 & STI \\
\hline
\end{tabular}




\begin{tabular}{llll} 
Live aboveground biomass (LAGB) & sqrt & 45 & STI \\
Total aboveground biomass (TAGB) & sqrt & 45 & STI \\
Total biomass (TB) & sqrt & 45 & STI \\
$\begin{array}{l}\text { Percent alive aboveground biomass } \\
\text { (PAAGB) }\end{array}$ & & 45 & STI \\
Shoot to root ratio (SRR) & & 45 & STI \\
\hline
\end{tabular}


Supplementary Table S2. Summary of markers retained following bin calling, removal of distorted regions, and removal of duplicate markers.

\begin{tabular}{|c|c|c|c|c|c|c|c|c|c|c|c|}
\hline & \multicolumn{11}{|c|}{ Markers Present on each Chromosome } \\
\hline & 1 & 2 & 3 & 4 & 5 & 6 & 7 & 8 & 9 & 10 & Total \\
\hline $\begin{array}{l}\text { Markers retained after bin } \\
\text { calling }\end{array}$ & 610 & 485 & 457 & 430 & 331 & 365 & 364 & 285 & 374 & 354 & 4055 \\
\hline $\begin{array}{l}\text { Markers retained after removing } \\
\text { distorted markers }\end{array}$ & 332 & 396 & 454 & 301 & 254 & 169 & 364 & 285 & 374 & 277 & 3206 \\
\hline $\begin{array}{l}\text { Markers retained after removing } \\
\text { duplicate markers }\end{array}$ & 163 & 214 & 230 & 145 & 151 & 94 & 174 & 170 & 209 & 142 & 1692 \\
\hline
\end{tabular}


Supplementary Table S3. Genetic map summary. (A) The genetic map used in this study to map salinity tolerance consisted of 10 total chromosomes spanning $888.7 \mathrm{cM}$ with a total of 1692 bin markers. On average markers were $0.5 \mathrm{cM}$ apart with a maximum spacing of $62.29 \mathrm{cM}$ of any marker being on chromosome 1. (B) Bin markers that deviated from the expected mendelian ratio (1:1) were removed from the analysis. A total of 866 bin markers were distorted across the 10 Sorghum chromosomes with 172 displaying preferential bias towards S. propinquum and 694 displaying preferential bias towards S. bicolor.

A.

\section{Genetic Map Information}

\section{Marker Distibution}

\begin{tabular}{rrrrrr} 
Chromosome & \multicolumn{2}{c}{$\begin{array}{l}\text { Length } \\
\text { (cM) }\end{array}$} & \multicolumn{2}{l}{$\begin{array}{l}\text { Acg. Spacing } \\
(\mathbf{c M})\end{array}$} & \multicolumn{2}{c}{$\begin{array}{l}\text { Max Spacing } \\
(\mathbf{c M})\end{array}$} \\
\cline { 3 - 6 } & 1 & 132.9 & 0.8 & 62.9 \\
2 & 214 & 110.4 & 0.5 & 26.9 \\
3 & 230 & 119.9 & 0.5 & 8.7 \\
4 & 145 & 87.8 & 0.6 & 19.3 \\
5 & 151 & 83.1 & 0.6 & 9.7 \\
6 & 94 & 38.4 & 0.4 & 1.2 \\
7 & 174 & 84.6 & 0.5 & 2.2 \\
& 170 & 78.3 & 0.5 & 1.6 \\
Total & 209 & 87.7 & 0.4 & 2.1 \\
9 & 142 & 65.7 & 0.5 & 4.1 \\
& 10 & 1692 & 888.7 & 0.5 & 62.9 \\
\hline
\end{tabular}


B.

\begin{tabular}{|c|c|c|c|c|c|c|}
\hline \multicolumn{7}{|c|}{ Distorted Marker Information } \\
\hline \multirow{3}{*}{ Chromosome } & \multirow{3}{*}{$\begin{array}{c}\text { Number of distorted } \\
\text { markers }\end{array}$} & \multicolumn{5}{|c|}{ Marker Type } \\
\hline & & \multirow[t]{2}{*}{ S. propinquum } & \multirow[t]{2}{*}{ S. bicolor } & \multirow{2}{*}{$\begin{array}{c}\text { Average marker } \\
\text { ratio } \\
\text { (SP:SB) }\end{array}$} & \multicolumn{2}{|c|}{ Region (Mb) } \\
\hline & & & & & Start & End \\
\hline 1 & 280 & & 280 & $20: 116$ & 18.60 & 75.83 \\
\hline 2 & 91 & 91 & & $112: 40$ & 61.09 & 70.23 \\
\hline 3 & 3 & & 3 & $39: 110$ & 43.51 & 44.58 \\
\hline 4 & 133 & & 133 & $35: 105$ & 55.96 & 66.64 \\
\hline 5 & 81 & 81 & & $107: 34$ & 6.37 & 59.45 \\
\hline 6 & 198 & & 198 & $16: 115$ & 0.09 & 50.15 \\
\hline 7 & & & & & & \\
\hline 8 & & & & & & \\
\hline 9 & 1 & & 1 & $48: 102$ & 1.01 & 1.01 \\
\hline 10 & 79 & & 79 & $29: 113$ & 54.47 & 61.09 \\
\hline Total & 866 & 172 & 694 & & & \\
\hline
\end{tabular}


Supplementary Table S4. Summary statistics of phenotypic values for control and salt treated populations.

\begin{tabular}{|c|c|c|c|c|c|c|c|c|c|}
\hline $\begin{array}{c}\text { Days after } \\
\text { treatment (DAT) }\end{array}$ & Trait & Treatment & Min & Max & Mean & S.D. & S.E. & Kurtosis & Skew \\
\hline \multirow{2}{*}{ 0 } & \multirow{2}{*}{ HT } & Control & 18.75 & 71.38 & 44.50 & 9.66 & 0.73 & 0.17 & -0.27 \\
\hline & & Salt & 21.67 & 63.12 & 42.57 & 8.50 & 0.64 & -0.49 & -0.10 \\
\hline \multirow{4}{*}{15} & \multirow{2}{*}{ HT } & Control & 34.17 & 99.76 & 63.75 & 13.19 & 0.99 & -0.10 & -0.13 \\
\hline & & Salt & 29.95 & 83.38 & 55.30 & 10.01 & 0.75 & -0.25 & 0.00 \\
\hline & \multirow{2}{*}{$\mathrm{RS}$} & Control & -0.49 & 2.10 & 0.45 & 0.48 & 0.04 & 0.05 & 0.71 \\
\hline & & Salt & 0.88 & 3.72 & 2.18 & 0.53 & 0.04 & -0.44 & 0.03 \\
\hline \multirow{22}{*}{45} & \multirow{2}{*}{ HT } & Control & 52.92 & 122.37 & 87.81 & 14.36 & 1.08 & -0.43 & 0.04 \\
\hline & & Salt & 46.32 & 112.47 & 75.46 & 11.50 & 0.86 & 0.12 & 0.12 \\
\hline & \multirow{2}{*}{$\mathrm{RS}$} & Control & 0.72 & 3.20 & 2.01 & 0.53 & 0.04 & -0.06 & -0.19 \\
\hline & & Salt & 1.68 & 4.55 & 3.19 & 0.44 & 0.03 & 0.83 & -0.46 \\
\hline & \multirow{2}{*}{$\mathrm{TN}$} & Control & -0.16 & 2.98 & 0.18 & 0.54 & 0.04 & 9.39 & 3.07 \\
\hline & & Salt & -0.35 & 5.14 & 0.36 & 0.89 & 0.07 & 10.11 & 2.99 \\
\hline & \multirow[b]{2}{*}{ M } & Control & 1.00 & 1.00 & 1.00 & 0.00 & 0.00 & & \\
\hline & & Salt & 0.67 & 1.04 & 1.00 & 0.03 & 0.00 & 144.19 & 11.53 \\
\hline & \multirow{2}{*}{$\mathrm{RB}$} & Control & 0.48 & 6.38 & 2.50 & 1.05 & 0.08 & 0.16 & 0.05 \\
\hline & & Salt & 0.09 & 2.48 & 1.13 & 0.45 & 0.03 & 0.21 & -0.32 \\
\hline & \multirow{2}{*}{ DAGB } & Control & 0.06 & 1.61 & 0.55 & 0.28 & 0.02 & 0.12 & 0.08 \\
\hline & & Salt & -0.30 & 2.80 & 0.80 & 0.42 & 0.03 & 0.71 & 0.58 \\
\hline & \multirow{2}{*}{ LAGB } & Control & 1.20 & 6.95 & 4.45 & 1.31 & 0.10 & -0.58 & -0.19 \\
\hline & & Salt & 0.32 & 6.22 & 3.18 & 1.01 & 0.08 & 0.00 & 0.01 \\
\hline & \multirow{2}{*}{ TAGB } & Control & 1.34 & 8.56 & 5.00 & 1.49 & 0.11 & -0.48 & -0.16 \\
\hline & & Salt & 0.57 & 7.11 & 3.98 & 1.19 & 0.09 & -0.31 & -0.23 \\
\hline & \multirow{2}{*}{ TB } & Control & 1.98 & 12.18 & 7.49 & 2.21 & 0.17 & -0.51 & -0.22 \\
\hline & & Salt & 0.66 & 9.42 & 5.11 & 1.51 & 0.11 & -0.12 & -0.24 \\
\hline & \multirow{2}{*}{ SRR } & Control & 0.10 & 9.38 & 2.40 & 1.09 & 0.08 & 11.86 & -1.64 \\
\hline & & Salt & 1.80 & 10.92 & 4.09 & 1.42 & 0.11 & 0.80 & 0.23 \\
\hline & \multirow{2}{*}{ PAAGB } & Control & 0.75 & 0.96 & 0.89 & 0.04 & 0.00 & 0.15 & -0.68 \\
\hline & & Salt & 0.41 & 1.10 & 0.78 & 0.10 & 0.01 & 2.02 & -0.64 \\
\hline
\end{tabular}

HT-height, RS-rank score, TN-tiller number, M-mortality, RB-root biomass (g), DAGB-dead aboveground biomass (g), LAGB-live aboveground biomass (g), TAGB-total aboveground biomass (g), TB-total biomass (g), SRR-shoot to root ratio, PAAGB-percent alive aboveground biomass 
Supplementary Table S5. Analysis of variance summary.

\begin{tabular}{|c|c|c|c|c|c|c|c|c|}
\hline \multirow[b]{2}{*}{ Phenotype } & \multirow[b]{2}{*}{$\begin{array}{l}\text { Days After } \\
\text { Treatment }\end{array}$} & \multirow[b]{2}{*}{ Control } & \multirow[b]{2}{*}{ S.D. } & \multirow[b]{2}{*}{ Salt } & \multicolumn{3}{|c|}{ RDPB } & \multirow[b]{2}{*}{ Significant } \\
\hline & & & & & S.D. & (Control-Salt)/Control & P-value & \\
\hline HT & 15 & 63.75 & 13.19 & 55.30 & 10.01 & 0.13 & $\begin{array}{c}4.69 \mathrm{E}-11 \\
1.19 \mathrm{E}-\end{array}$ & $* * *$ \\
\hline $\mathrm{RS}$ & 15 & 0.45 & 0.48 & 2.18 & 0.53 & -3.81 & 105 & $* * *$ \\
\hline $\mathrm{TN}$ & 15 & 0.57 & 0.94 & 0.79 & 1.20 & -0.39 & $1.62 \mathrm{E}-02$ & $*$ \\
\hline DAGB & 45 & 0.55 & 0.28 & 0.80 & 0.42 & -0.45 & $4.29 \mathrm{E}-13$ & $* * *$ \\
\hline HT & 45 & 87.81 & 14.36 & 75.46 & 11.50 & 0.14 & $2.30 \mathrm{E}-17$ & $* * *$ \\
\hline LAGB & 45 & 4.45 & 1.31 & 3.18 & 1.01 & 0.28 & $2.03 \mathrm{E}-21$ & $* * *$ \\
\hline Mortality & 45 & 1.00 & 0.00 & 1.00 & 0.03 & 0.00 & $2.12 \mathrm{E}-01$ & \\
\hline PAAGB & 45 & 0.89 & 0.04 & 0.78 & 0.10 & 0.13 & $1.82 \mathrm{E}-36$ & $* * *$ \\
\hline $\mathrm{RB}$ & 45 & 2.50 & 1.05 & 1.13 & 0.45 & 0.55 & $5.74 \mathrm{E}-47$ & $* * *$ \\
\hline $\mathrm{RS}$ & 45 & 2.01 & 0.53 & 3.19 & 0.44 & -0.58 & $1.26 \mathrm{E}-71$ & $* * *$ \\
\hline SRR & 45 & 2.40 & 1.09 & 4.09 & 1.42 & -0.71 & $1.50 \mathrm{E}-34$ & $* * *$ \\
\hline TAGB & 45 & 5.00 & 1.49 & 3.98 & 1.19 & 0.20 & $8.63 \mathrm{E}-12$ & $* * *$ \\
\hline TB & 45 & 7.49 & 2.21 & 5.11 & 1.51 & 0.32 & $2.06 \mathrm{E}-27$ & $* * *$ \\
\hline $\mathrm{TN}$ & 45 & 0.18 & 0.54 & 0.36 & 0.89 & -1.05 & $1.73 \mathrm{E}-02$ & $*$ \\
\hline
\end{tabular}

Significant Codes: $(*) 0.05(* *) 0.01(* * *) 0.001$

HT-height, RS-rank score, TN-tiller number, M-mortality, RB-root biomass (g), DAGB-dead aboveground biomass (g), LAGB-live aboveground biomass (g), TAGB-total aboveground biomass (g), TB-total biomass (g), SRR-shoot to root ratio, PAAGB-percent alive aboveground biomass; RDPB-relative decrease in plant biomass 
Supplementary Table S6. Genes within a 1.0 logarithm of the odds (LOD) confidence interval for each QTL when markers that deviated significantly from the expected

Mendelian ratio (1:1) were removed. (omitted from the document) 
Supplementary Table S7. Genes within a 1.0 logarithm of the odds (LOD) confidence interval for each QTL when markers that deviated significantly from the expected

Mendelian ratio were included. (omitted from the document) 


\section{Supplementary Table S8. Candidate genes identified in QTL windows when markers that deviated significantly from the expected Mendelian ratio (1:1) were removed.}

\begin{tabular}{|c|c|c|c|c|}
\hline QTL & Sorghum Gene ID & Sorghum Annotation & Arabidopsis Annotation & Rice Annotation \\
\hline qDAGB45_2.STI & Sobic.002G113900 & $\begin{array}{l}\text { similar to Putative } \\
\text { CLB1 protein (Calcium- } \\
\text { dependent lipid binding) } \\
\text { protein }\end{array}$ & $\begin{array}{l}\text { Calcium-dependent lipid- } \\
\text { binding (CaLB domain) family } \\
\text { protein }\end{array}$ & $\begin{array}{l}\text { lipid binding protein, putative, } \\
\text { expressed }\end{array}$ \\
\hline qDAGB45_2.STI & Sobic.002G114800 & $\begin{array}{l}\text { similar to Calcium- } \\
\text { dependent protein } \\
\text { kinase }\end{array}$ & $\begin{array}{l}\text { calcium-dependent protein } \\
\text { kinase } 16\end{array}$ & $\begin{array}{l}\text { CAMK_CAMK_like. } 32 \text { - CAMK } \\
\text { includes calcium/calmodulin } \\
\text { depedent protein kinases, } \\
\text { expressed }\end{array}$ \\
\hline qDAGB45_2.STI & Sobic.002G118300 & $\begin{array}{l}\text { similar to Hydrophobic } \\
\text { LEA-like protein }\end{array}$ & AWPM-19-like family protein & $\begin{array}{l}\text { AWPM-19-like membrane family } \\
\text { protein, putative, expressed }\end{array}$ \\
\hline qDAGB45_2.STI & Sobic.002G124700 & $\begin{array}{l}\text { similar to Aquaporin } \\
\text { PIP2-2 }\end{array}$ & $\begin{array}{l}\text { plasma membrane intrinsic } \\
\text { protein } 2\end{array}$ & $\begin{array}{l}\text { aquaporin protein, putative, } \\
\text { expressed }\end{array}$ \\
\hline qDAGB45_2.STI & Sobic.002G125000 & $\begin{array}{l}\text { similar to Aquaporin } \\
\text { PIP2-6 }\end{array}$ & $\begin{array}{l}\text { plasma membrane intrinsic } \\
\text { protein } 2\end{array}$ & $\begin{array}{l}\text { aquaporin protein, putative, } \\
\text { expressed }\end{array}$ \\
\hline qDAGB45_2.STI & Sobic.002G125200 & $\begin{array}{l}\text { similar to Aquaporin } \\
\text { PIP2-6 }\end{array}$ & $\begin{array}{l}\text { plasma membrane intrinsic } \\
\text { protein } 2\end{array}$ & $\begin{array}{l}\text { aquaporin protein, putative, } \\
\text { expressed }\end{array}$ \\
\hline qDAGB45_2.STI & Sobic.002G125300 & $\begin{array}{l}\text { similar to Aquaporin } \\
\text { PIP2-6 }\end{array}$ & $\begin{array}{l}\text { plasma membrane intrinsic } \\
\text { protein } 2\end{array}$ & $\begin{array}{l}\text { aquaporin protein, putative, } \\
\text { expressed }\end{array}$ \\
\hline qDAGB45_2.STI & Sobic.002G125700 & $\begin{array}{l}\text { similar to Aquaporin } \\
\text { PIP2-6 }\end{array}$ & $\begin{array}{l}\text { plasma membrane intrinsic } \\
\text { protein } 2\end{array}$ & $\begin{array}{l}\text { aquaporin protein, putative, } \\
\text { expressed }\end{array}$ \\
\hline qDAGB45_2.STI & Sobic.002G136300 & $\begin{array}{l}\text { similar to Calmodulin } \\
\text { binding heat shock } \\
\text { protein }\end{array}$ & $\begin{array}{l}\text { alpha/beta-Hydrolases } \\
\text { superfamily protein }\end{array}$ & $\begin{array}{l}\text { calmodulin-binding heat-shock } \\
\text { protein, putative, expressed }\end{array}$ \\
\hline qDAGB45_2.STI & Sobic.002G141900 & $\begin{array}{l}\text { similar to Similarity to } \\
\mathrm{Na}+/ \mathrm{H}+\text { antiporter }\end{array}$ & sodium:hydrogen antiporter 1 & $\begin{array}{l}\text { Citrate transporter protein, } \\
\text { putative, expressed }\end{array}$ \\
\hline qDAGB45_2.STI & Sobic.002G156000 & $\begin{array}{l}\text { similar to } \\
\text { Sodium/hydrogen } \\
\text { exchanger }\end{array}$ & $\mathrm{Na}+/ \mathrm{H}+$ antiporter 6 & $\begin{array}{l}\text { transporter, monovalent } \\
\text { cation:proton antiporter-2 family, } \\
\text { putative, expressed }\end{array}$ \\
\hline qDAGB45_2.STI & Sobic.002G174200 & $\begin{array}{l}\text { weakly similar to } \\
\text { Transcription factor } \\
\text { WRKY74 }\end{array}$ & $\begin{array}{l}\text { WRKY DNA-binding protein } \\
46\end{array}$ & WRKY74, expressed \\
\hline qDAGB45_2.STI & Sobic.002G174300 & $\begin{array}{l}\text { weakly similar to } \\
\text { Transcription factor } \\
\text { WRKY74 }\end{array}$ & $\begin{array}{l}\text { WRKY family transcription } \\
\text { factor }\end{array}$ & WRKY74, expressed \\
\hline qDAGB45_2.STI & Sobic.002G130800 & $\begin{array}{l}\text { similar to Putative } \\
\text { uncharacterized protein }\end{array}$ & $\mathrm{K}+$ uptake permease 11 & $\begin{array}{l}\text { potassium transporter, putative, } \\
\text { expressed }\end{array}$ \\
\hline qDAGB45_2.STI & Sobic.002G157800 & & $\begin{array}{l}\text { solute:sodium symporters;urea } \\
\text { transmembrane transporters }\end{array}$ & $\begin{array}{l}\text { urea active transporter, putative, } \\
\text { expressed }\end{array}$ \\
\hline qDAGB45_2.STI & Sobic.002G159100 & $\begin{array}{l}\text { similar to Putative } \\
\text { uncharacterized protein }\end{array}$ & $\begin{array}{l}\text { Chlorophyll A-B binding } \\
\text { family protein }\end{array}$ & $\begin{array}{l}\text { chlorophyll A-B binding protein, } \\
\text { putative, expressed }\end{array}$ \\
\hline qDAGB45_2.STI & Sobic.002G162400 & $\begin{array}{l}\text { similar to } \\
\text { Os09g0299400 protein }\end{array}$ & $\begin{array}{l}\mathrm{Ca} 2+\text { activated outward } \\
\text { rectifying } \mathrm{K}+\text { channel } 6\end{array}$ & $\begin{array}{l}\text { potassium channel protein, } \\
\text { putative, expressed }\end{array}$ \\
\hline qDAGB45_2.STI & Sobic.002G168550 & & cold shock domain protein 1 & $\begin{array}{l}\text { RNA recognition motif containing } \\
\text { protein, expressed }\end{array}$ \\
\hline qDAGB45_2.STI & Sobic.002G180300 & $\begin{array}{l}\text { similar to Voltage- } \\
\text { dependent anion } \\
\text { channel protein } 1 \mathrm{~b}\end{array}$ & $\begin{array}{l}\text { voltage dependent anion } \\
\text { channel } 1\end{array}$ & $\begin{array}{l}\text { isochorismate synthase } 1 \text {, } \\
\text { chloroplast precursor, putative, } \\
\text { expressed }\end{array}$ \\
\hline qDAGB45_2.STI & Sobic.002G178000 & & $\begin{array}{l}\text { Leucine-rich repeat } \\
\text { transmembrane protein kinase } \\
\text { protein }\end{array}$ & $\begin{array}{l}\text { senescence-induced receptor-like } \\
\text { serine/threonine-protein kinase } \\
\text { precursor, putative, expressed }\end{array}$ \\
\hline qDAGB45_2.STI & Sobic.002G178101 & & $\begin{array}{l}\text { Leucine-rich repeat } \\
\text { transmembrane protein kinase } \\
\text { protein }\end{array}$ & $\begin{array}{l}\text { senescence-induced receptor-like } \\
\text { serine/threonine-protein kinase } \\
\text { precursor, putative, expressed } \\
\text { CAMK_KIN1/SNF1/Nim1_like.16 }\end{array}$ \\
\hline qHT45_1.S & Sobic.001G379600 & $\begin{array}{l}\text { similar to CIPK-like } \\
\text { protein 1, putative, } \\
\text { expressed }\end{array}$ & SOS3-interacting protein 1 & $\begin{array}{l}\text { - CAMK includes } \\
\text { calcium/calmodulin depedent } \\
\text { protein kinases, expressed } \\
\text { CAMK_KIN1/SNF1/Nim1_like.15 }\end{array}$ \\
\hline qHT45_1.S & Sobic.001G523200 & $\begin{array}{l}\text { similar to CIPK-like } \\
\text { protein 1, putative, } \\
\text { expressed } \\
\text { similar to DNA damage }\end{array}$ & $\begin{array}{l}\text { CBL-interacting protein kinase } \\
9\end{array}$ & $\begin{array}{l}\text { - CAMK includes } \\
\text { calcium/calmodulin depedent } \\
\text { protein kinases, expressed }\end{array}$ \\
\hline qHT45_1.S & Sobic.001G212900 & $\begin{array}{l}\text { signaling and repair } \\
\text { protein }\end{array}$ & nijmegen breakage syndrome 1 & $\begin{array}{l}\text { FHA domain containing protein, } \\
\text { putative, expressed }\end{array}$ \\
\hline
\end{tabular}


qHT45_1.S

qHT45_1.S

qHT45_1.S

qHT45_1.S

Sobic.001G251700

qHT45_1.S

qHT45_1.S

qHT45_1.S

qHT45_1.S

qHT45_1.S

qHT45_1.S

Sobic.001G282700

qHT45_1.S

Sobic.001G294400

qHT45_1.S

Sobic.001G313100

qHT45_1.S

qHT45_1.S

Sobic.001G346500

qHT45_1.S

Sobic.001G346500

qHT45_1.S

Sobic.001G389000

qHT45_1.S

qHT45_1.S

Sobic.001G389900

Sobic.001G512300

qHT45_1.S

qHT45_1.S

qHT45_1.S

qHT45_1.S similar to Cell division

control protein 48

homolog D

similar to

Sodium/calcium

exchanger protein,

expressed

similar to Leaf

senescence protein-like

similar to

Serine/threonine-protein

phosphatase PP2A-4

catalytic subunit

similar to Proline-rich

protein precursor

similar to Proline-rich

protein precursor

similar to Proline-rich

protein precursor

similar to Proline-rich

protein, putative,

expressed

similar to Auxin

transporter-like protein

3

similar to Early-

responsive to

dehydration protein,

putative, expressed

similar to

Serine/threonine-protein

kinase SAPK3

similar to Calcium-

dependent protein

kinase isoform 1

similar to Heat shock

protein

similar to Vacuolar

cation/proton exchanger

$2(\mathrm{Ca}(2+) / \mathrm{H}(+)$

exchanger 2)

similar to Vacuolar

cation/proton exchanger

$2(\mathrm{Ca}(2+) / \mathrm{H}(+)$

exchanger 2)

similar to WRKY DNA

binding domain

containing protein,

expressed

similar to Aquaporin

SIP2-1

similar to Putative

voltage-dependent ion

channel

similar to Putative

potassium/proton

antiporter-like protein

similar to Aquaporin

TIP3-1

similar to Putative uncharacterized protein

similar to Harpininduced protein 1
ATPase, AAA-type, CDC48 protein

calcium exchanger 7

TRICHOME

BIREFRINGENCE-LIKE 19

protein phosphatase $2 \mathrm{~A}-3$

proline-rich protein 4

proline-rich protein 2

proline-rich protein 4

proline-rich protein 2

like AUXIN RESISTANT 2

early-responsive to

dehydration stress protein

(ERD4)

Protein kinase superfamily protein

Calcium-dependent protein kinase family protein

casein lytic proteinase B3

cation exchanger 2

cation exchanger 5

WRKY family transcription factor

small and basic intrinsic

protein $2 ; 1$

voltage dependent anion channel 4

$\mathrm{K}+$ efflux antiporter 5

tonoplast intrinsic protein $1 ; 3$

Late embryogenesis abundant

(LEA) hydroxyproline-rich

glycoprotein family

Late embryogenesis abundant

(LEA) hydroxyproline-rich

glycoprotein family cell division control protein 48

homolog E, putative, expressed

sodium/calcium exchanger protein, putative, expressed

expressed protein

OsPP2Ac-4 - Phosphatase 2A isoform 4 belonging to family 2 , expressed

POEI13 - Pollen Ole e I allergen

and extensin family protein

precursor, expressed

POEI11 - Pollen Ole e I allergen

and extensin family protein

precursor, expressed

POEI14 - Pollen Ole e I allergen

and extensin family protein

precursor, expressed

POEI3 - Pollen Ole e I allergen

and extensin family protein

precursor, expressed

transmembrane amino acid

transporter protein, putative, expressed

early-responsive to dehydration protein-related, putative, expressed CAMK CAMK like.41 - CAMK includes calcium/calmodulin depedent protein kinases,

expressed

CAMK CAMK like. 8 - CAMK

includes calcium/calmodulin depedent protein kinases,

expressed

chaperone protein clpB 1, putative, expressed

sodium/calcium exchanger protein putative, expressed

sodium/calcium exchanger protein putative, expressed

WRKY55, expressed aquaporin SIP2-1, putative, expressed

outer mitochondrial membrane porin, putative, expressed transporter, monovalent cation:proton antiporter-2 family, putative, expressed aquaporin protein, putative, expressed

harpin-induced protein 1 domain containing protein, expressed

harpin-induced protein 1 domain containing protein, expressed 


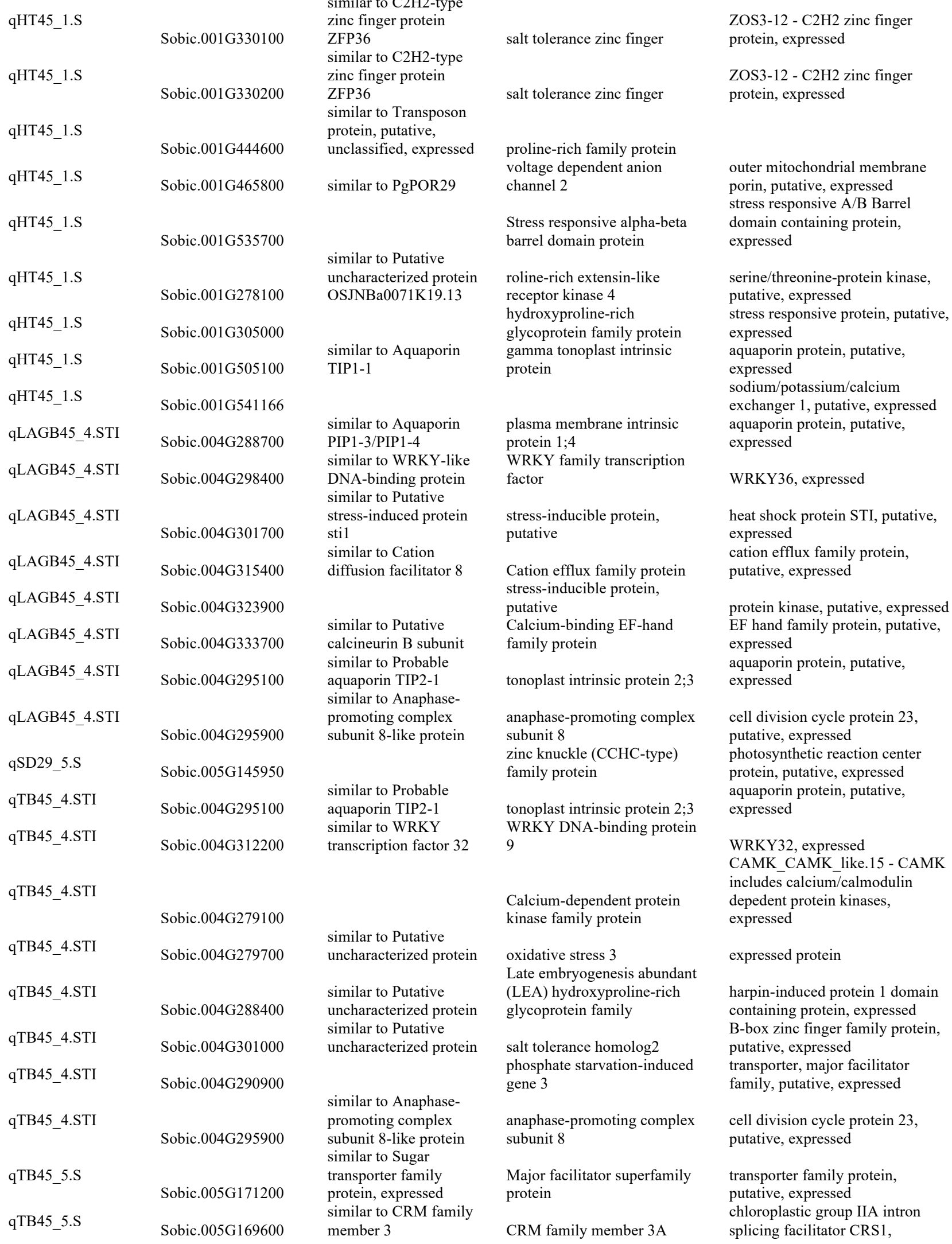

containing protein expressed similar to $\mathrm{C} 2 \mathrm{H} 2$-type zinc finger protein similar to C2H2-type c finger protein similar to Transposon protein, putative, voltage dependent anion Stress responsive alpha-bet glycoprotein family protein gamma tonoplast intrinsic

WRKY family transcription stress-inducible protein stress-inducible protein, putative

Calcium-binding EF-hand o Anaphasepromoting complex

similar to Probable aquaporin TIP2-1 similar to WRKY transcription factor 32

Calcium-dependent protein oxidative stress 3

ate embryogenesis abundant (LEA) hydroxyproline-rich

salt tolerance homolog2 phosphate starvation-induced 
qLAGB45_5.STI

Sobic.005G087000

qLAGB45_5.STI

qLAGB45_5.STI

qLAGB45_5.STI

qLAGB45_5.STI

qLAGB45_5.STI

qLAGB45_5.STI

qLAGB45_5.STI

qLAGB45_5.STI

qLAGB45_5.STI

qLAGB45_5.STI

qLAGB45_5.STI

qLAGB45_5.STI

qLAGB45_5.STI

qLAGB45_5.STI

qLAGB45_5.STI

qLAGB45_5.STI

qLAGB45_5.STI

qRS45_7.STI

qRS45_7.STI

qRS45_7.STI

qRS45_7.STI

qRS45_7.STI

qRB45_4.STI

qRB45_4.STI

qRB45_4.STI

qRB45_4.STI

qRB45_4.STI

qRB45_4.STI

Sobic.005G150900

Sobic.005G114000

Sobic.005G116400

Sobic.005G126600

Sobic.005G060100

Sobic.005G072900

Sobic.005G073000

Sobic.005G097400

Sobic.005G103050

Sobic.005G106432

Sobic.005G108601

Sobic.005G110415

Sobic.005G114500

Sobic.005G145950

Sobic.007G039500

Sobic.007G039600

Sobic.007G037900

Sobic.007G030900

Sobic.007G038500

Sobic.004G260500

Sobic.004G271800

Sobic.004G272700

Sobic.004G286700 similar to Chlorophyll $\mathrm{a} / \mathrm{b}$-binding apoprotein CP26 precursor weakly similar to AUX/IAA family protein, expressed similar to WRKY transcription factor 72 similar to Auxin response factor 23 similar to Putative growth-regulating factor 2

Sobic.004G284700

Sobic.004G295100

similar to F-box domain containing protein,

expressed

similar to

Os12g0174100 protein

similar to HSR203J, putative, expressed

similar to Aquaporin

NIP3-2

similar to Aquaporin

NIP3-2

similar to Organic

cation transporter-like protein

similar to Putative uncharacterized protein similar to Putative nodulin

similar to Peptide

transporter-like

weakly similar to

WRKY transcription

factor 66

similar to 4-coumarate--

CoA ligase 2 similar to Aluminum-

activated malate transporter-like similar to Putative anter-specific prolinerich protein APG similar to Probable aquaporin TIP2-1 light harvesting complex of photosystem II 5

AUX/IAA transcriptional regulator family protein WRKY DNA-binding protein 75

auxin response factor 2

growth-regulating factor 2 Outward rectifying potassium channel protein photosynthetic electron transfer A

auxin signaling F-box 3 O-fucosyltransferase family protein

carboxyesterase 17 zinc knuckle (CCHC-type) family protein zinc knuckle (CCHC-type) family protein phragmoplastin interacting protein 1

O-fucosyltransferase family protein zinc knuckle (CCHC-type) family protein NOD26-like intrinsic protein $5 ; 1$

NOD26-like intrinsic protein $5 ; 1$ binding protein (Copine) family

NOD26-like intrinsic protein $5 ; 1$

nitrate transporter 1.5

WRKY DNA-binding protein 14

4-coumarate:CoA ligase 3

Aluminium activated malate transporter family protein GDSL-like

Lipase/Acylhydrolase superfamily protein

tonoplast intrinsic protein $2 ; 3$ chloroplast precursor, putative, expressed

chlorophyll A-B binding protein, putative, expressed

OsIAA27 - Auxin-responsive

Aux/IAA gene family member, expressed

WRKY72, expressed auxin response factor, putative, expressed

growth regulating factor protein, putative, expressed

potassium channel protein, putative, expressed apocytochrome f precursor, putative, expressed

OsFBL55 - F-box domain and LRR containing protein, expressed growth regulator related protein, putative, expressed

stress responsive protein, putative, expressed

stress responsive protein, putative, expressed

cell death associated protein, putative, expressed

photosynthetic reaction center protein, putative, expressed photosynthetic reaction center protein, putative, expressed photosynthetic reaction center protein, putative, expressed photosynthetic reaction center protein, putative, expressed growth regulator related protein, putative, expressed photosynthetic reaction center protein, putative, expressed aquaporin protein, putative, expressed aquaporin protein, putative, expressed oxidoreductase family, NADbinding Rossmann fold containing

Oxidoreductase family protein $\mathrm{Ca}(2)$-dependent phospholipidprotein, expressed

copine-6, putative, expressed aquaporin protein, putative, expressed

peptide transporter PTR2, putative, expressed
WRKY66, expressed AMP-binding domain containing protein, expressed

aluminum-activated malate transporter, putative, expressed

GDSL-like lipase/acylhydrolase, putative, expressed aquaporin protein, putative, expressed 


\begin{tabular}{|c|c|c|c|c|}
\hline qRB45_4.STI & Sobic.004G298400 & $\begin{array}{l}\text { similar to WRKY-like } \\
\text { DNA-binding protein }\end{array}$ & $\begin{array}{l}\text { WRKY family transcription } \\
\text { factor }\end{array}$ & WRKY36, expressed \\
\hline qRB45_4.STI & Sobic.004G298900 & $\begin{array}{l}\text { similar to Chaperone } \\
\text { protein dnaJ-like }\end{array}$ & & OR, putative, expressed \\
\hline qRB45_4.STI & Sobic.004G299700 & $\begin{array}{l}\text { similar to Iron transport } \\
\text { protein } 2 \\
\text { similar to Putative }\end{array}$ & YELLOW STRIPE like 3 & \\
\hline qRB45_4.STI & Sobic.004G300600 & $\begin{array}{l}\text { serine/threonine- } \\
\text { specific protein kinase } \\
\text { similar to Putative }\end{array}$ & $\begin{array}{l}\text { Protein kinase superfamily } \\
\text { protein }\end{array}$ & $\begin{array}{l}\text { protein kinase domain containing } \\
\text { protein, expressed }\end{array}$ \\
\hline qRB45_4.STI & Sobic.004G301700 & $\begin{array}{l}\text { stress-induced protein } \\
\text { sti1 }\end{array}$ & $\begin{array}{l}\text { stress-inducible protein, } \\
\text { putative }\end{array}$ & $\begin{array}{l}\text { heat shock protein STI, putative, } \\
\text { expressed }\end{array}$ \\
\hline qRB45_4.STI & Sobic.004G301800 & $\begin{array}{l}\text { similar to Vacuolar } \\
\text { processing enzyme } 1\end{array}$ & $\begin{array}{l}\text { beta vacuolar processing } \\
\text { enzyme }\end{array}$ & $\begin{array}{l}\text { vacuolar-processing enzyme } \\
\text { precursor, putative, expressed } \\
\text { OsSAUR11 - Auxin-responsive }\end{array}$ \\
\hline qRB45_4.STI & Sobic.004G302200 & $\begin{array}{l}\text { similar to Auxin- } \\
\text { responsive protein-like } \\
\text { similar to WRKY }\end{array}$ & $\begin{array}{l}\text { SAUR-like auxin-responsive } \\
\text { protein family } \\
\text { WRKY DNA-binding protein }\end{array}$ & $\begin{array}{l}\text { SAUR gene family member, } \\
\text { expressed }\end{array}$ \\
\hline qRB45_4.ST & Sobic.004G312200 & $\begin{array}{l}\text { transcription factor } 32 \\
\text { similar to Cation }\end{array}$ & 9 & $\begin{array}{l}\text { WRKY32, expressed } \\
\text { cation efflux family protein, }\end{array}$ \\
\hline qRB45_4.STI & Sobic.004G315400 & diffusion facilitator 8 & $\begin{array}{l}\text { Cation efflux family protein } \\
\text { Double Clp-N motif- } \\
\text { containing P-loop nucleoside } \\
\text { triphosphate hydrolases }\end{array}$ & putative, expressed \\
\hline qRB45_4.STI & $\begin{array}{l}\text { Sobic.004G325000 } \\
\text { Sobic.004G288700 }\end{array}$ & $\begin{array}{l}\text { shock protein-like } \\
\text { similar to Aquaporin } \\
\text { PIP1-3/PIP1-4 }\end{array}$ & $\begin{array}{l}\text { superfamily protein } \\
\text { plasma membrane intrinsic } \\
\text { protein } 1 ; 4\end{array}$ & $\begin{array}{l}\text { expressed protein } \\
\text { aquaporin protein, putative, } \\
\text { expressed }\end{array}$ \\
\hline qRB45_4.STI & Sobic.004G275000 & $\begin{array}{l}\text { similar to DnaJ protein- } \\
\text { like }\end{array}$ & $\begin{array}{l}\text { Chaperone DnaJ-domain } \\
\text { superfamily protein }\end{array}$ & $\begin{array}{l}\text { heat shock protein DnaJ, putative, } \\
\text { expressed }\end{array}$ \\
\hline qRB45_4.STI & Sobic.004G279100 & & $\begin{array}{l}\text { Calcium-dependent protein } \\
\text { kinase family protein }\end{array}$ & $\begin{array}{l}\text { CAMK_CAMK_like. } 15 \text { - CAMK } \\
\text { includes calcium/calmodulin } \\
\text { depedent protein kinases, } \\
\text { expressed }\end{array}$ \\
\hline qRB45_4.STI & Sobic.004G286600 & $\begin{array}{l}\text { similar to Dehydrin } \\
\text { weakly similar to }\end{array}$ & $\begin{array}{l}\text { cold-regulated } 47 \\
\text { hydroxyproline-rich }\end{array}$ & dehydrin, putative, expressed \\
\hline qRB45_4.STI & Sobic.004G296100 & $\begin{array}{l}\text { Os } 02 \mathrm{~g} 0656100 \text { protein } \\
\text { similar to Amino acid } \\
\text { permease-like }\end{array}$ & $\begin{array}{l}\text { glycoprotein family protein } \\
\text { cationic amino acid transporter } \\
9\end{array}$ & $\begin{array}{l}\text { expressed protein } \\
\text { amino acid permease, putative, } \\
\text { expressed }\end{array}$ \\
\hline qRB45_4.STI & Sobic.004G296400 & $\begin{array}{l}\text { similar to Amino acid } \\
\text { permease-like }\end{array}$ & $\begin{array}{l}\text { cationic amino acid transporter } \\
9\end{array}$ & $\begin{array}{l}\text { amino acid permease, putative, } \\
\text { expressed }\end{array}$ \\
\hline qRB45_4.STI & Sobic.004G301500 & & $\begin{array}{l}\text { Vacuolar iron transporter } \\
\text { (VIT) family protein }\end{array}$ & $\begin{array}{l}\text { integral membrane protein, } \\
\text { putative, expressed }\end{array}$ \\
\hline qRB45_4.STI & Sobic.004G301600 & $\begin{array}{l}\text { similar to Nodulin-21- } \\
\text { like }\end{array}$ & $\begin{array}{l}\text { Vacuolar iron transporter } \\
\text { (VIT) family protein }\end{array}$ & $\begin{array}{l}\text { integral membrane protein, } \\
\text { putative, expressed }\end{array}$ \\
\hline qRB45_4.STI & Sobic.004G301650 & & $\begin{array}{l}\text { Vacuolar iron transporter } \\
\text { (VIT) family protein } \\
\text { Heavy metal }\end{array}$ & $\begin{array}{l}\text { integral membrane protein, } \\
\text { putative, expressed }\end{array}$ \\
\hline qRB45_4.STI & Sobic.004G317900 & $\begin{array}{l}\text { similar to } \\
\text { Os05g0337400 protein }\end{array}$ & $\begin{array}{l}\text { transport/detoxification } \\
\text { superfamily protein }\end{array}$ & expressed protein \\
\hline qRB45_4.STI & Sobic.004G318800 & $\begin{array}{l}\text { similar to Putative } \\
\text { uncharacterized protein }\end{array}$ & $\begin{array}{l}\text { Calcium-dependent } \\
\text { phosphotriesterase superfamily } \\
\text { protein }\end{array}$ & $\begin{array}{l}\text { SMP-30/Gluconolaconase/LRE- } \\
\text { like region containing protein, } \\
\text { expressed }\end{array}$ \\
\hline qRB45_4.STI & Sobic.004G329600 & $\begin{array}{l}\text { similar to Putative } \\
\text { uncharacterized protein }\end{array}$ & $\begin{array}{l}\text { Calcium-dependent } \\
\text { phosphotriesterase superfamily } \\
\text { protein }\end{array}$ & $\begin{array}{l}\text { SMP-30/Gluconolaconase/LRE- } \\
\text { like region containing protein, } \\
\text { expressed }\end{array}$ \\
\hline qRB45_4.STI & Sobic.004G330200 & $\begin{array}{l}\text { similar to Putative } \\
\text { uncharacterized protein } \\
\text { similar to Putative }\end{array}$ & $\begin{array}{l}\text { Calcium-dependent } \\
\text { phosphotriesterase superfamily } \\
\text { protein }\end{array}$ & $\begin{array}{l}\text { SMP-30/Gluconolaconase/LRE- } \\
\text { like region containing protein, } \\
\text { expressed }\end{array}$ \\
\hline qRB45_4.STI & Sobic.004G332700 & $\begin{array}{l}\text { monosaccharide } \\
\text { transporter } 6\end{array}$ & sugar transporter 1 & $\begin{array}{l}\text { transporter family protein, } \\
\text { putative, expressed }\end{array}$ \\
\hline qRB45_4.STI & Sobic.004G261400 & $\begin{array}{l}\text { similar to Putative } \\
\text { cysteine proteinase } \\
\text { similar to Putative }\end{array}$ & xylem cysteine peptidase 1 & $\begin{array}{l}\text { xylem cysteine proteinase } 2 \\
\text { precursor, putative, expressed }\end{array}$ \\
\hline qRB45_4.STI & Sobic.004G264100 & uncharacterized protein & cation/hydrogen exchanger 15 & $\begin{array}{l}\text { ATCHX15, putative, expressed } \\
\text { helix-loop-helix DNA-binding }\end{array}$ \\
\hline qRB45_4.STI & Sobic.004G264200 & $\begin{array}{l}\text { similar to } \\
\text { Os02g0710300 protein }\end{array}$ & ROOT HAIR DEFECTIVE6 & $\begin{array}{l}\text { domain containing protein, } \\
\text { expressed }\end{array}$ \\
\hline qRB45_4.STI & Sobic.004G269900 & & growth-regulating factor 2 & $\begin{array}{l}\text { growth-regulating factor, putative } \\
\text { expressed }\end{array}$ \\
\hline
\end{tabular}




$\begin{array}{cc}\text { qRB45_4.STI } & \text { Sobic.004G269900 } \\ \text { qRB45_4.STI } & \text { Sobic.004G279700 } \\ \text { qRB45_4.STI } & \text { Sobic.004G288400 } \\ \text { qRB45_4.STI } & \text { Sobic.004G301000 } \\ \text { qRB45_4.STI } & \\ \text { qRB45_4.STI } & \text { Sobic.004G308700 } \\ \text { qRB45_4.STI } & \text { Sobic.004G333700 } \\ \text { qRB45_4.STI } & \text { Sobic.004G298000 }\end{array}$

similar to Putative
uncharacterized protein
similar to Putative
uncharacterized protein
similar to Putative
uncharacterized protein
similar to Putative light-
harvesting chlorophyll-
a/b protein of
photosystem I
similar to Putative
calcineurin B subunit
similar to DnaJ-like
protein

growth-regulating factor 5

oxidative stress 3

Late embryogenesis abundant

(LEA) hydroxyproline-rich

glycoprotein family

salt tolerance homolog2

photosystem I light harvesting

complex gene 5

Calcium-binding EF-hand

family protein

DNAJ homologue 2

Major facilitator superfamily

protein growth-regulating factor, putative, expressed

expressed protein

harpin-induced protein 1 domain containing protein, expressed

B-box zinc finger family protein, putative, expressed

chlorophyll A-B binding protein, putative, expressed

EF hand family protein, putative, expressed

chaperone protein dnaJ, putative, expressed

transporter, major facilitator family, putative, expressed 
Supplementary Table S9. QTLs identified in the RIL population using transformed least square means in control conditions, salt conditions, and with stress tolerance index values when markers that deviated from the expected Mendelian ratio (1:1) were included. The QTLs reported were identified when mapping using Multiple QTL Mapping (MQM) in control conditions (0 mM $\mathrm{NaCl}$ ), salt conditions $(75 \mathrm{mM} \mathrm{NaCl})$, and with stress tolerance index (STI) values. QTLs are named using the following system: q[Trait][DAT]_[Chr].[Treatment]

\begin{tabular}{|c|c|c|c|c|c|c|c|c|c|c|c|c|c|}
\hline Trait & Trt & QTL Name & DAT & Chr & $\begin{array}{c}\text { Position } \\
(\mathrm{cM})\end{array}$ & $\begin{array}{c}\text { Bin (Max } \\
\text { LOD) }\end{array}$ & $\begin{array}{c}\text { Lod } \\
\text { score }\end{array}$ & p-value & PVE & Additive & $\begin{array}{c}\text { Start } \\
\text { Mb }\end{array}$ & $\begin{array}{c}\text { Peak } \\
\text { Mb }\end{array}$ & End Mb \\
\hline DAGB & $\mathrm{C}$ & qDAGB45_2.C & 45 & 2 & 72.7 & 65.42 & 4.91 & $1.63 \mathrm{E}-05$ & 12.15 & -0.08 & 64.40 & 65.42 & 67.54 \\
\hline DAGB & $\mathrm{C}$ & qDAGB45_9.C & 45 & 9 & 69.1 & 56.32 & 3.98 & $1.32 \mathrm{E}-04$ & 9.71 & -0.06 & 55.47 & 56.32 & 57.91 \\
\hline DAGB & STI & qDAGB45_2.STI & 45 & 2 & 73 & 62.28 & 4.21 & $1.24 \mathrm{E}-05$ & 11.63 & -0.20 & 13.85 & 62.28 & 67.54 \\
\hline LAGB & $\mathrm{C}$ & qLAGB45_4.C & 45 & 4 & 71.5 & 64.27 & 3.32 & $1.05 \mathrm{E}-04$ & 9.22 & 0.45 & 62.17 & 64.27 & 67.29 \\
\hline LAGB & STI & qLAGB45_4.STI & 45 & 4 & 73 & 63.41 & 4.22 & $1.22 \mathrm{E}-05$ & 11.65 & 0.10 & 62.06 & 63.41 & 67.49 \\
\hline HT & $\mathrm{C}$ & qHT45_7.C & 45 & 7 & 57.7 & 59.01 & 4.72 & $2.50 \mathrm{E}-05$ & 11.18 & -5.00 & 58.66 & 59.01 & 60.24 \\
\hline HT & $\mathrm{C}$ & qHT45_9.C & 45 & 9 & 63.4 & 55.07 & 5.32 & 6.57E-06 & 12.71 & -5.46 & 54.37 & 55.07 & 56.91 \\
\hline HT & S & qHT45_1.S & 45 & 1 & 108 & 75.72 & 5.17 & $9.14 \mathrm{E}-06$ & 12.57 & -4.44 & 76.22 & 75.72 & 80.57 \\
\hline HT & $\mathrm{S}$ & qHT45_7.S & 45 & 7 & 63.5 & 60.17 & 4.95 & $1.51 \mathrm{E}-05$ & 11.99 & -4.25 & 59.01 & 60.17 & 61.46 \\
\hline HT & STI & qHT45_1.STI & 45 & 1 & 107.8 & 77.00 & 5.45 & $3.37 \mathrm{E}-03$ & 10.63 & -0.04 & 75.67 & 77.00 & 80.57 \\
\hline HT & STI & qHT45_4.STI & 45 & 4 & 82.2 & 66.96 & 4.66 & $1.16 \mathrm{E}-02$ & 9.00 & 0.05 & 66.42 & 66.96 & 67.49 \\
\hline HT & STI & qHT45_7.STI & 45 & 7 & 63.5 & 60.17 & 7.16 & $1.93 \mathrm{E}-04$ & 14.34 & -0.05 & 59.01 & 60.17 & 60.24 \\
\hline HT & STI & qHT45_9.STI & 45 & 9 & 63.4 & 55.07 & 4.43 & $1.66 \mathrm{E}-02$ & 8.51 & -0.04 & 54.70 & 55.07 & 56.68 \\
\hline TAGB & S & qTAGB45_4.S & 45 & 4 & 83.4 & 67.29 & 3.40 & $8.65 \mathrm{E}-05$ & 9.49 & 0.40 & 61.70 & 67.29 & 68.41 \\
\hline TAGB & STI & qTAGB45_4.STI & 45 & 4 & 64 & 60.23 & 4.18 & $1.34 \mathrm{E}-05$ & 11.55 & 0.09 & 61.91 & 60.23 & 67.44 \\
\hline $\mathrm{TB}$ & S & qTB45_4.S & 45 & 4 & 63.7 & 62.29 & 3.73 & $3.90 \mathrm{E}-05$ & 10.37 & 0.51 & 61.70 & 62.29 & 68.41 \\
\hline TB & STI & qTB45_4.STI & 45 & 4 & 64.6 & 62.46 & 4.91 & $2.41 \mathrm{E}-06$ & 13.40 & 0.09 & 62.06 & 62.46 & 64.38 \\
\hline RS & STI & qR.S45_4.STI & 45 & 4 & 69.1 & 63.67 & 3.89 & $2.71 \mathrm{E}-05$ & 10.77 & -0.19 & 62.46 & 63.67 & 63.95 \\
\hline $\mathrm{RB}$ & STI & qRB45_4.STI & 45 & 4 & 64.6 & 62.46 & 4.13 & $1.53 \mathrm{E}-05$ & 11.40 & 0.08 & 62.17 & 62.46 & 62.54 \\
\hline
\end{tabular}

DAGB-dead aboveground biomass, LAGB-live aboveground biomass, RB-root biomass, RS-rank score, HT-height, TB-total biomass, TAGB-total aboveground biomass; Trt-treatment, STI-stress tolerance index, C-control, S-salt; P-Sorghum propinquum, B-Sorghum bicolor; DAT-days after treatment; Chr-chromosome, PVE-percent variance explained 


\section{Supplementary Figures}

Figure S1. Pearson correlations on raw phenotypes and transformed phenotypes for control and salt populations at 15 days and 45 days after treatment. (A) Control population 15 days after treatment (B) Salt population 15 days after treatment (C) Control population 45 days after treatment (D) Transformed control data 45 days after treatment (E) Salt population 45 days after treatment

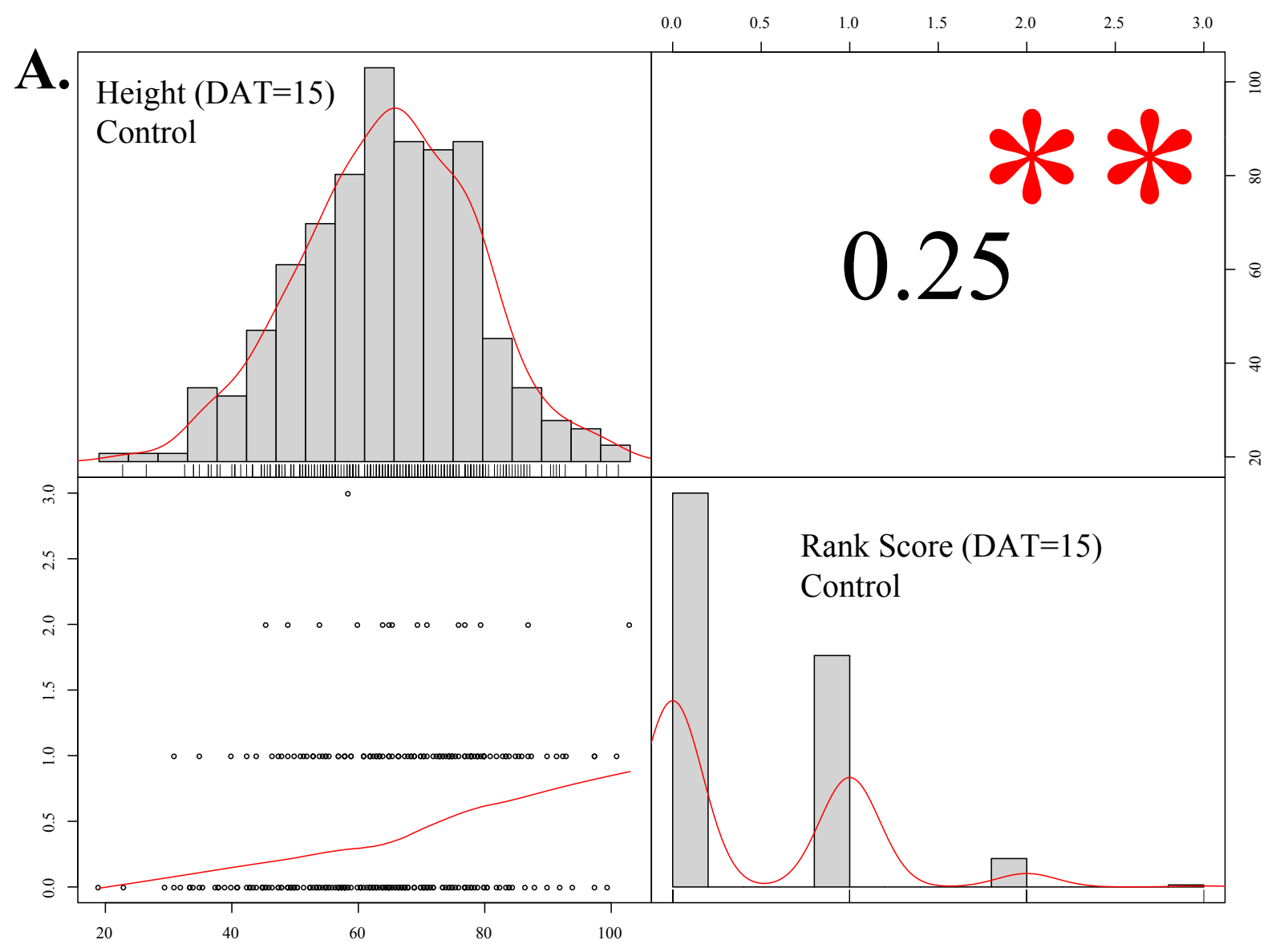




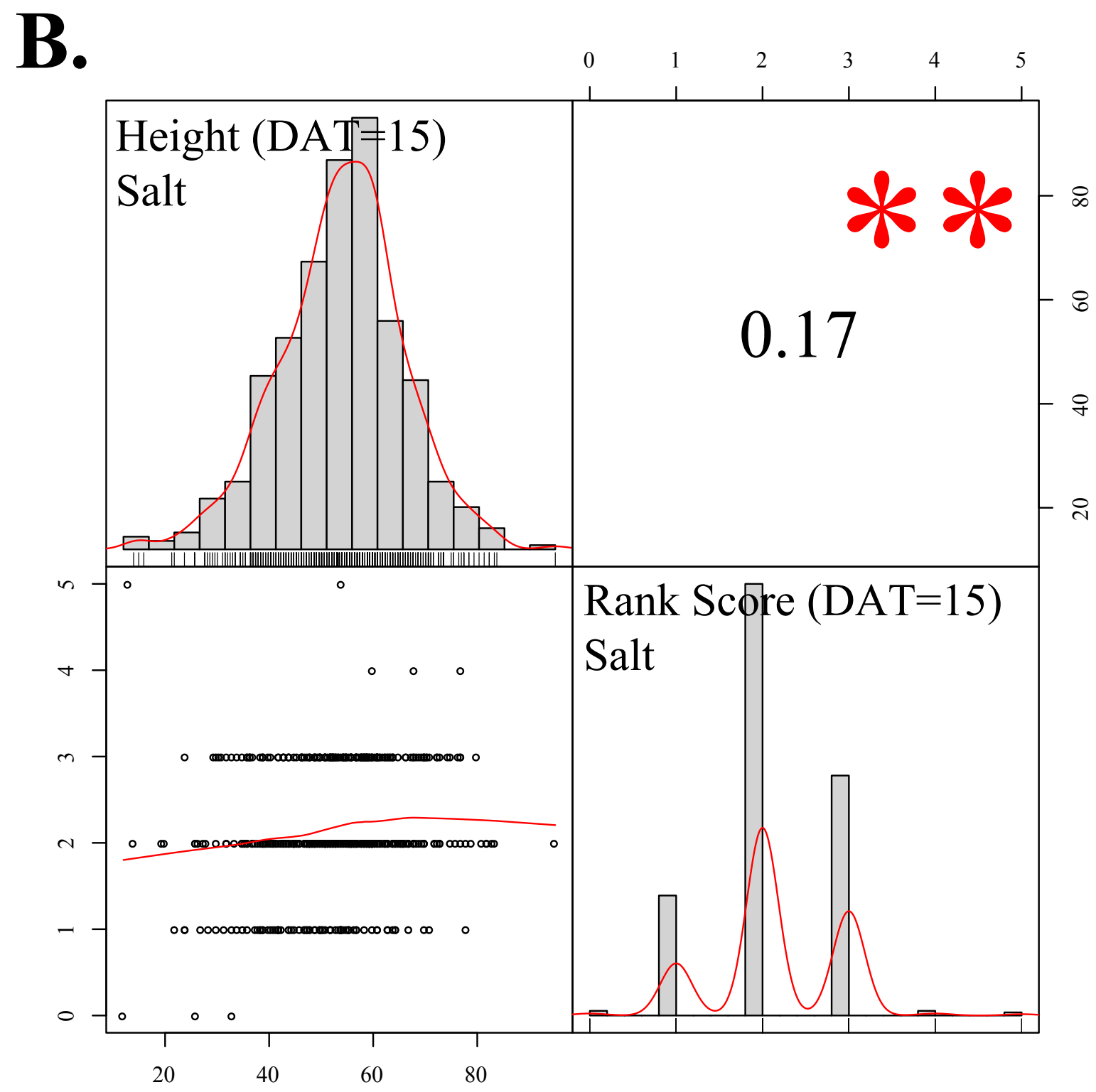




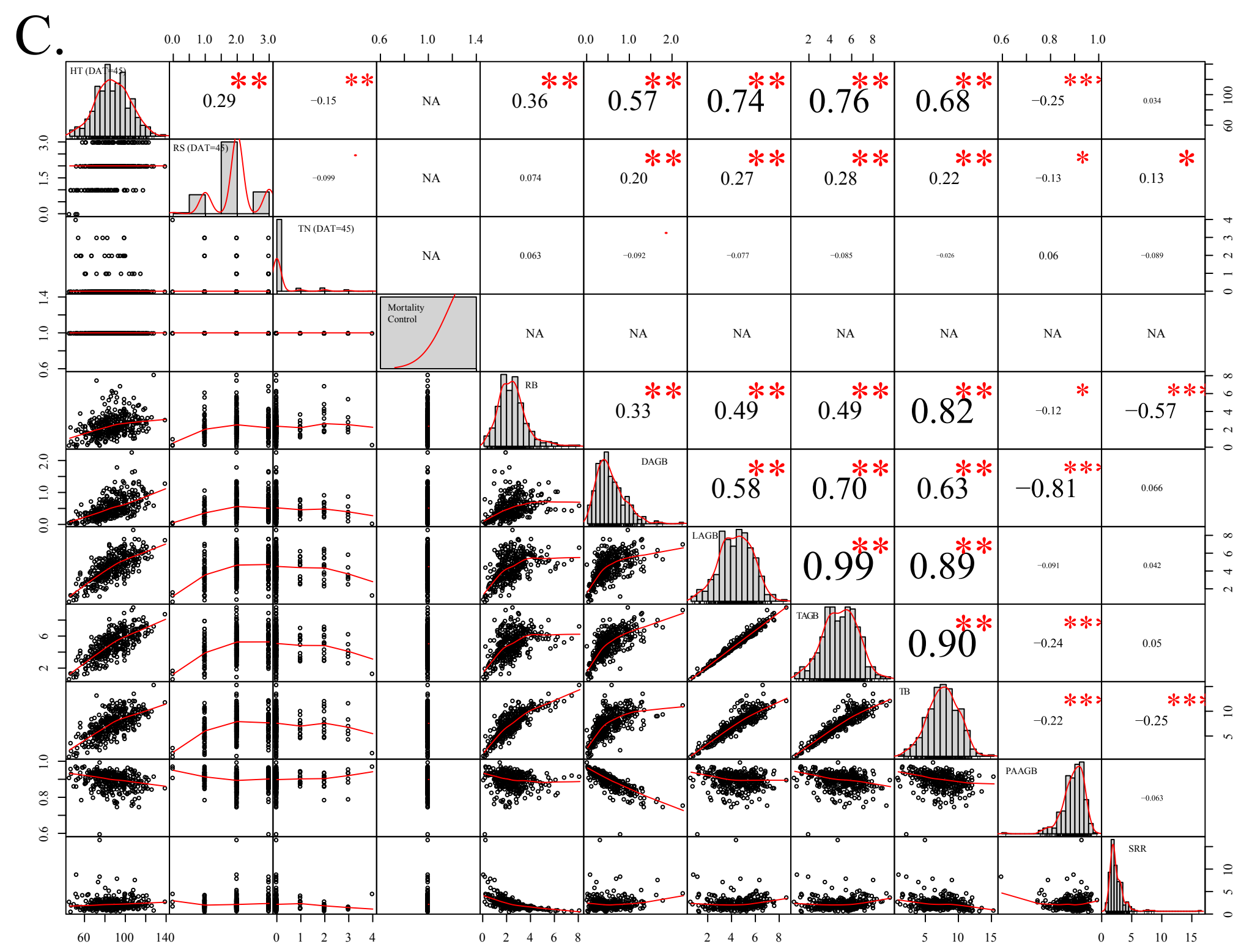


D. $\begin{array}{lrrrrrr}1.0 & 2.0 & 3.0 & 1.0 & 1.5 & 2.0 & 2.5\end{array}$ $\begin{array}{llllllllllllllll}1 & 2 & 3 & 4 & 5 & 6 & 7 & 2 & 4 & 6 & 8 & 12 & -2 & 0 & 1 & 2\end{array}$

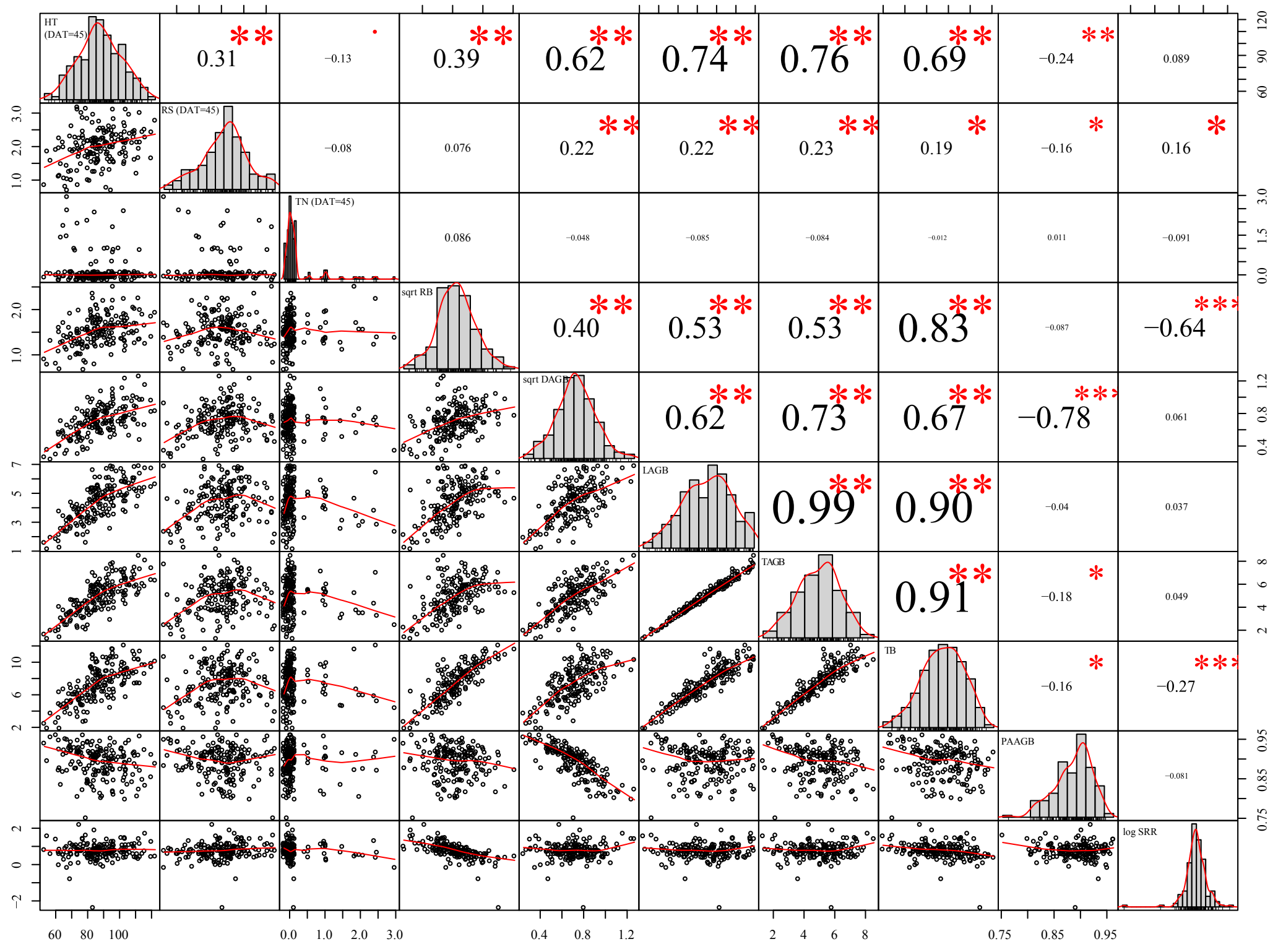




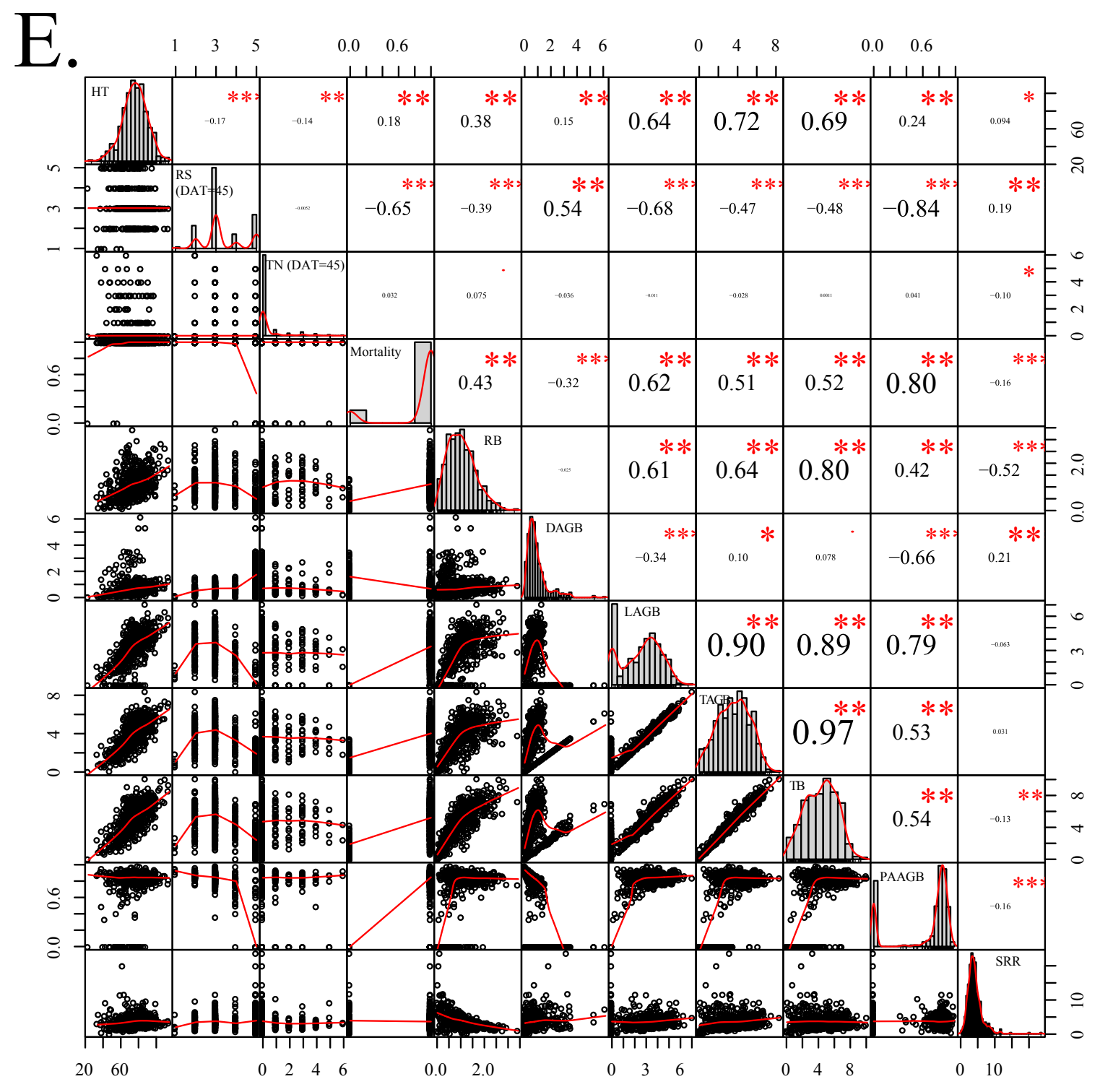


A.

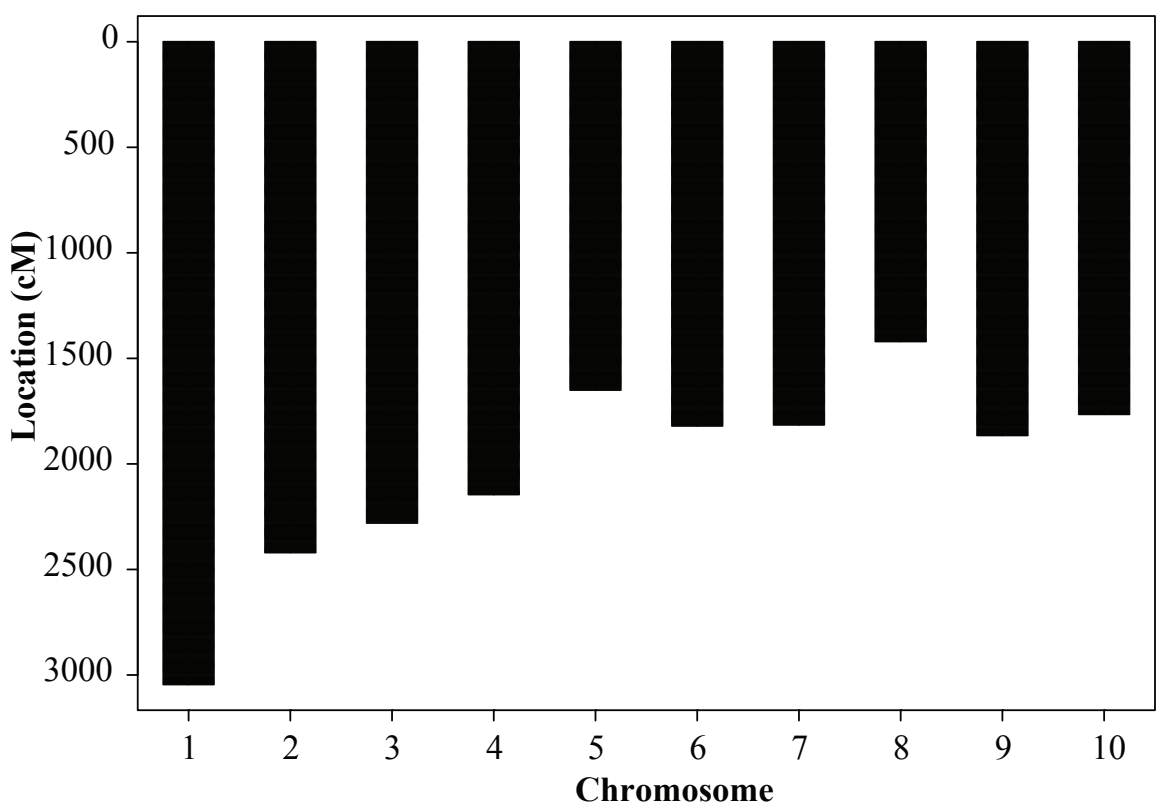

B.

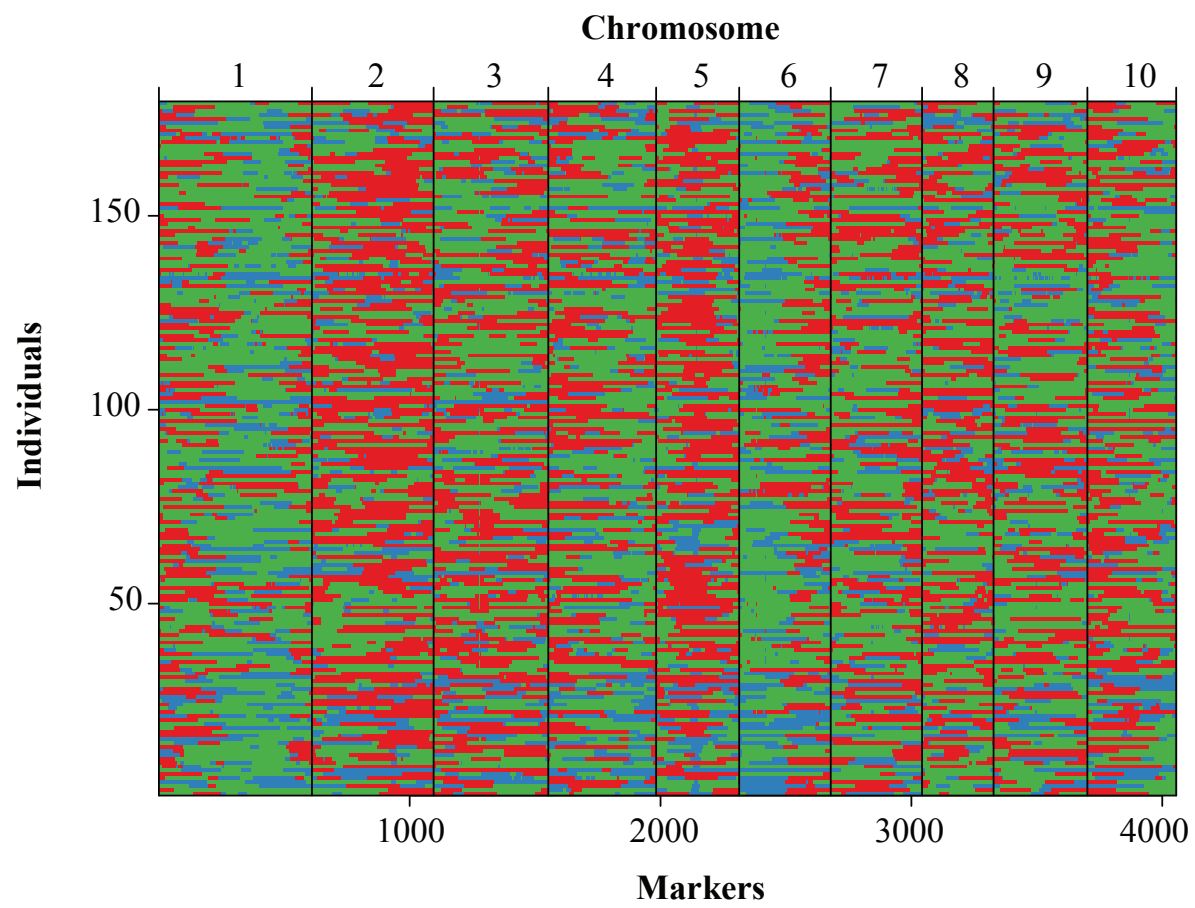

Figure S2. Sorghum genetic map after using a sliding window method to call bin markers as AA (S. propinquum), BB (S. bicolor), or AB. (A) Black horizontal lines represent bins on each of the 10 Sorghum chromosomes. (B) X-axis represents bin markers, Y-axis represents each of the 177 lines, colors represent the genotype data for each RIL at each marker. AA=Red, $\mathrm{BB}=$ Green, $\mathrm{AB}=\mathrm{Blue}$ 


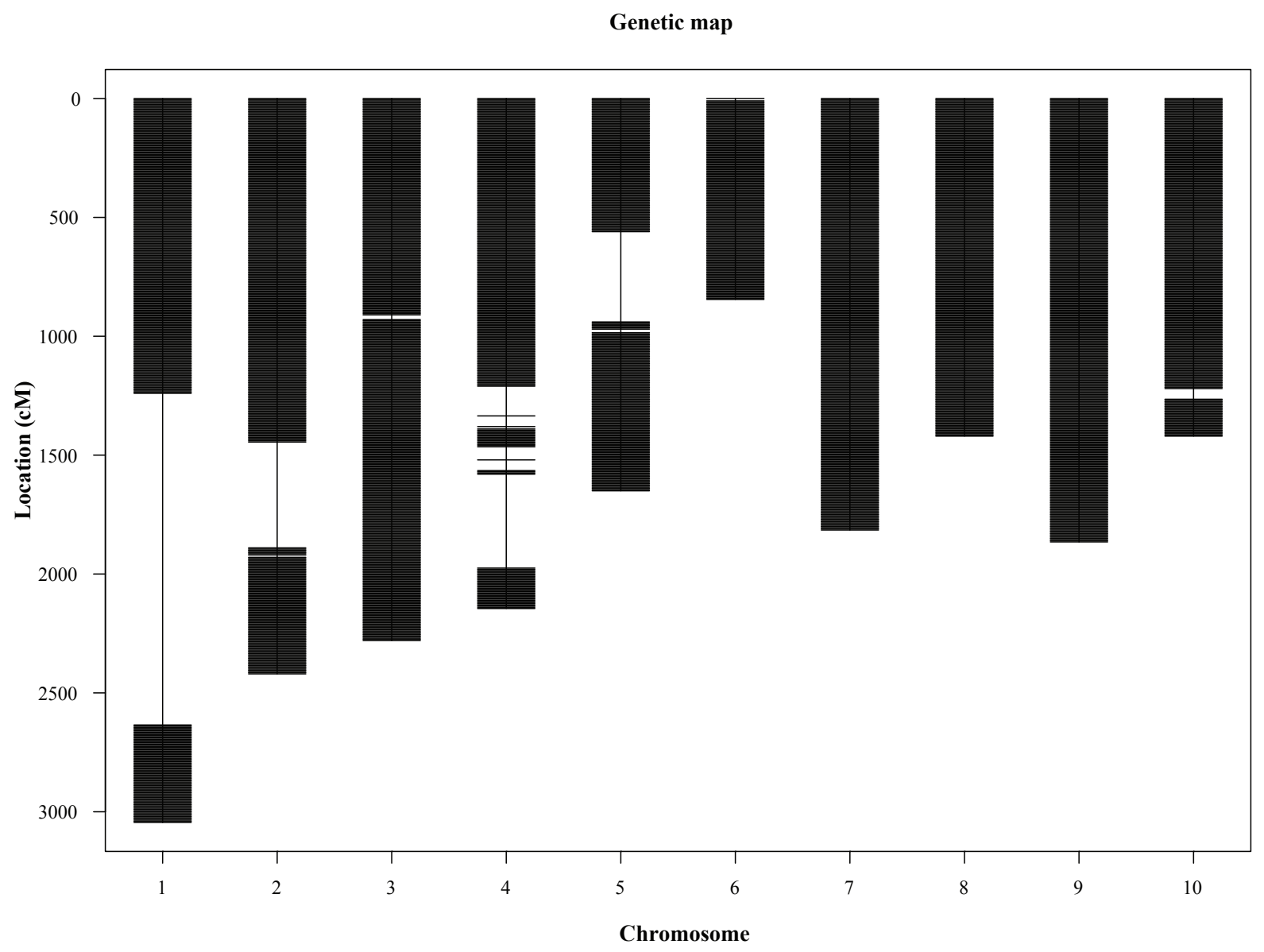

Supplementary Figure S3. Sorghum genetic map after removing markers that deviated significantly from the expected mendelian ratio (1:1). Black horizontal lines represent bins on each of the 10 Sorghum chromosomes. 


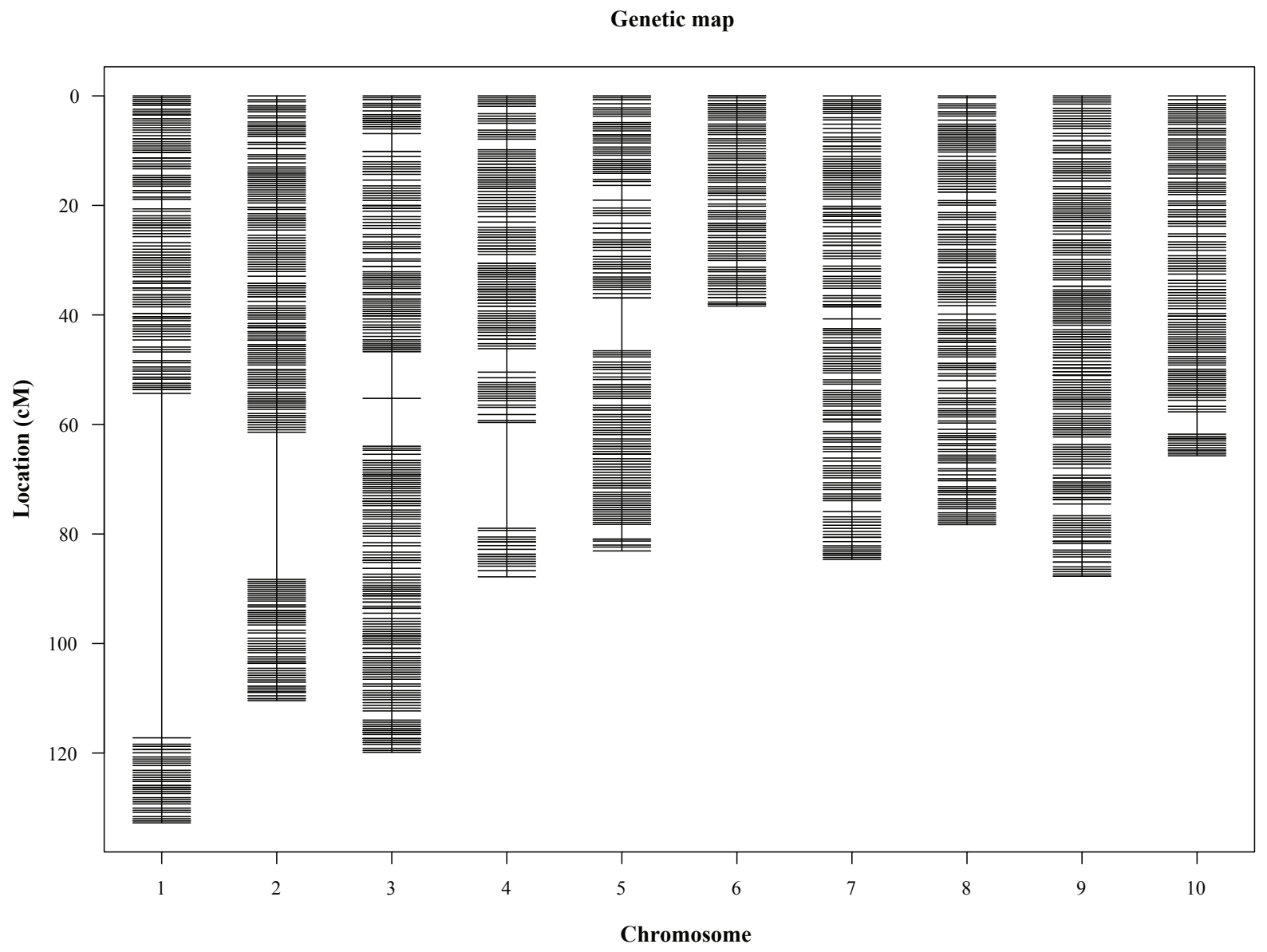

Supplementary Figure S4. Final Sorghum genetic map used to map phenotypic traits after removing duplicate bins. Black horizontal lines represent bins on each of the 10 Sorghum chromosomes 


\section{CHAPTER 6}

\section{GENERAL CONCLUSIONS}

Soil salinity is becoming increasingly prevalent in areas that are typically used for agriculture due to various natural and anthropogenic factors. As reviewed in Chapter 2, the overabundance of salts in the soil leads to both osmotic and ionic stress. In response to osmotic stress plants are unable to extract water and nutrients from the soil without altering their own osmotic potential, and plants experience deceased above- and belowground biomass accumulation due to reduction in cell elongation rates (Yeo et al., 1991; Passioura \& Munns, 2000; Fricke \& Peters, 2002; Munns \& Tester, 2008). Plants are able to overcome the ion-independent stress by producing and accumulating solutes that aid in osmotic adjustment. With water acquisition, however, plants acquire $\mathrm{Na}^{+}$and $\mathrm{Cl}^{-}$ions from the predominant $\mathrm{NaCl}$. During ionic stress, the overabundance of ions in the cytoplasm becomes toxic and disrupts ionic homeostasis. Disruption of ionic homeostasis results in the inactivation of enzymes, oxidative stress, and, ultimately leads to leaf senescence (Munns \& Tester, 2008; Iqbal et al., 2014; Parihar et al., 2015); however, if salts can be sequestered into vacuoles or extruded to the belowground biomass and soil, plants can continue to photosynthesize and produce enough carbon for continued growth and development.

Within my dissertation, I addressed the questions outlined in Chapter 1 relating to the morphological, physiological, and genetic variation of salinity tolerance in Sorghum bicolor. Specifically, in Chapter 3 I assessed the standing variation in morphological and physiological responses to salt exposure for a diverse panel of Sorghum genotypes. Significant variation was observed for live aboveground biomass, dead aboveground biomass, and root biomass. Accessions were first rank ordered for tolerance and then a subset of individuals were analyzed for proline content and ion profiles. Although much of the literature suggests proline accumulation is an indicator of tolerant genotypes due to its role in osmotic adjustment (Delauney \& Verma, 1993; Iqbal et al., 2014; Surender Reddy et al., 2015; Amini et al., 2015; de Freitas et al., 2019), we did not observe this correlation. Further, when ion profiles were analyzed, we observed an increase in $\mathrm{Na}^{+}$in response to treatment, but we did not observe lower accumulation of $\mathrm{Na}^{+}$in tolerant accessions compared to sensitive accessions. In fact, one of our most tolerant accessions (Sb-10) and one of our most sensitive accessions (Sb-1) showed similar ion profiles. When tolerance rankings were evaluated within the phylogenetic framework presented in Mace et al. ((Mace et al., 2013), I observed tolerant individuals clustering within the basal clade of the phylogenetic tree. Given the known drought tolerance of Sorghum bicolor, I hypothesized that the increased salinity tolerance observed (especially in the landrace durra) was a byproduct of the drought tolerance acquired during domestication.

In Chapter 4 I used two accessions that varied in response to salt exposure from Chapter 3. I dissected the spatial and temporal variation in gene expression of three genes known to play key roles in salt detoxification (Henderson et al., 2019). SOS1, NHX2, and HKT3 gene products aid in tolerance due to their role in extrusion, sequestration, and transport, respectively. Upon the addition of non-saline water, I observed expression changes suggesting osmotic adjustment in the tolerant accession. Further in the tolerant accession upon the addition of $150 \mathrm{mM} \mathrm{NaCl}, \mathrm{I}$ observed a delayed onset of gene expression suggesting $\mathrm{Na}^{+}$exclusion at the root level. 
Numerous gene expression changes in the sensitive accession across the time course indicate biological chaos and the inability to exclude ions. Additionally, recent research suggests that sensitive genotypes and species may experience a significant amount of $\mathrm{Na}^{+}$back-leak into the cytoplasm after sequestration, thus requiring increased gene expression of antiporters and transporters (Wu et al., 2019; Tyerman et al., 2019; Munns et al., 2020). The energy requirement associated with ion extrusion, sequestration, and transport comes with a significant cost. Therefore, the decreased biomass observed in the sensitive accession in Chapter 3 may be a result of energy limitations due to poor ionic control.

In Chapter 5, I used a recombinant inbred line (RIL) mapping population derived from wild, weedy, Sorghum propinquum (sensitive) and domesticated Sorghum bicolor (tolerant) to identify regions of the genome responsible for increased salinity tolerance. A high-density genetic map covering the 10 Sorghum chromosomes was constructed with bin markers from SNP data. Phenotypes associated with biomass production were mapped and a total of 146 candidate genes were identified from 18 QTL. Given that dead aboveground biomass and live aboveground biomass are key indicators of salinity tolerance, we focused on candidate genes in these QTL windows. We observed Sorghum propinquum loci positively affecting dead aboveground biomass, whereas we observed Sorghum bicolor loci positively affecting live aboveground biomass. Large amounts of dead aboveground biomass are often indicative of ionic toxicity whereas large amounts of live aboveground biomass are often indicative of osmotic tolerance. Further, candidate genes identified in these two QTL windows included genes associated with both osmotic and ionic stress alleviation. Altogether, I report that the increased tolerance observed in Sorghum bicolor is a result of superior osmotic adjustment, which is likely due to the drought tolerance acquired during domestication. With osmotic adjustment, roots can absorb water and nutrients to support new growth.

In summary, this dissertation work contributes to the field of salinity stress in C4 crops. While it is accepted that tolerance can be achieved by various mechanisms, much of the research over the past two decades specifically focuses on osmotic adjustment or ionic exclusion independently. From the findings of my dissertation, however, I suggest salinity tolerance in bicolor is a complex network of both. To elaborate, we concluded that: (1) tolerant accessions are located in the basal clade of Mace et al.'s (2013) phylogenetic tree, (2) tolerant accessions do not differ from sensitive accessions in proline production or $\mathrm{Na}^{+}$accumulation, (3) tolerant accessions experience an earlier osmotic response to aid in water acquisition, (4) tolerant accessions experience a delayed salt specific response, (5) genes that aid in osmotic adjustment aid in live aboveground biomass production, and (6) genes that aid in sensing, signaling and transport of $\mathrm{Na}^{+}$ions assist in ionic tolerance. In combination with recent literature, this work suggests that the ability to efficiently acquire water is the main mechanism associated with increased tolerance in Sorghum bicolor. Further, Sorghum bicolor may be effectively transporting and sequestering $\mathrm{Na}^{+}$, therefore, using sodium as a cheap osmolyte. This would adjust the osmotic pressure, reduce energy expenditures, and decrease ionic toxicity. 


\section{Literature Cited}

Amini S, Ghobadi C, Yamchi A. 2015. Proline accumulation and osmotic stress: an overview of P5CS gene in plants. Journal of Plant Molecular Breeding 3: 44-55.

Delauney AJ, Verma DPS. 1993. Proline biosynthesis and osmoregulation in plants. The Plant Journal 4: 215-223.

de Freitas PAF, de Carvalho HH, Costa JH, Miranda R de S, Saraiva KD da C, de Oliveira FDB, Coelho DG, Prisco JT, Gomes-Filho E. 2019. Salt acclimation in sorghum plants by exogenous proline: physiological and biochemical changes and regulation of proline metabolism. Plant Cell Reports 38: 403-416.

Fricke W, Peters WS. 2002. The biophysics of leaf growth in salt-stressed barley. A study at the cell level. Plant Physiology 129: 374-388.

Henderson AN, Crim PM, Cumming JR, Hawkins JS. 2019. Phenotypic and physiological responses to salt exposure in Sorghum reveal diversity among domesticated landraces. bioRxiv: 848028.

Iqbal N, Umar S, Khan NA, Khan MIR. 2014. A new perspective of phytohormones in salinity tolerance: Regulation of proline metabolism. Environmental and Experimental Botany 100: $34-42$.

Mace ES, Tai S, Gilding EK, Li Y, Prentis PJ, Bian L, Campbell BC, Hu W, Innes DJ, Han $\mathbf{X}$, et al.2013. Whole-genome sequencing reveals untapped genetic potential in Africa's indigenous cereal crop sorghum. Nature Communications 4: 2320.

Munns R, Day DA, Fricke W, Watt M, Arsova B, Barkla BJ, Bose J, Byrt CS, Chen Z-H, Foster KJ, et al.2020. Energy costs of salt tolerance in crop plants. New Phytologist: 10721090 .

Munns R, Tester M. 2008. Mechanisms of salinity tolerance. Annual Review of Plant Biology 59: $651-681$.

Parihar P, Singh S, Singh R, Singh VP, Prasad SM. 2015. Effect of salinity stress on plants and its tolerance strategies: a review. Environmental Science and Pollution Research 22: 40564075.

Passioura JB, Munns R. 2000. Rapid environmental changes that affect leaf water status induce transient surges or pauses in leaf expansion rate. Functional Plant Biology 27: 941-948.

Surender Reddy P, Jogeswar G, Rasineni GK, Maheswari M, Reddy AR, Varshney RK, Kavi Kishor PB. 2015. Proline over-accumulation alleviates salt stress and protects photosynthetic and antioxidant enzyme activities in transgenic sorghum [Sorghum bicolor (L.) Moench]. Plant Physiology and Biochemistry 94: 104-113.

Tyerman SD, Munns R, Fricke W, Arsova B, Barkla BJ, Bose J, Bramley H, Byrt C, Chen Z, Colmer TD, et al.2019. Energy costs of salinity tolerance in crop plants. New Phytologist 
221: $25-29$.

Wu H, Shabala L, Zhou M, Su N, Wu Q, Ul-Haq T, Zhu J, Mancuso S, Azzarello E, Shabala S. 2019. Root vacuolar $\mathrm{Na}^{+}$sequestration but not exclusion from uptake correlates with barley salt tolerance. The Plant Journal: 1-13.

Yeo AR, Lee $\lambda$-S, Izard P, Boursier PJ, Flowers TJ. 1991. Short- and long-term eeffects of salinity on leaf growth in rice (Oryza sativa L.). Journal of Experimental Botany 42: 881-889. 


\section{ACKNOWLEDGEMENTS}

First, and most of all, I would like to thank my Ph.D. advisor, Dr. Jennifer S. Hawkins. I met Jen as an undergraduate in 2012 and began volunteering in her lab in the Spring of 2013. At that time, I had planned on applying to dental school and was only looking to add some research experience to my resume. Little did I know, I would fall in love with research. When I first joined Jen's lab, I had no molecular biology background, I could not keep a plant alive at my own apartment, and I had no idea what research even consisted of. To be honest, I am not really sure what she saw in me and why she let me join her lab. Nevertheless, she did. She was very patient with me as I struggled through the learning curve. After only a few short months I realized how much I loved research. I volunteered all my free time in the lab as I was eager to learn as much as possible. Finally, months later Jen gave me a project of my own and I did not want to let her down. Jen never made me feel dumb for the things I did not know (and there was a lot I did not know). She was so patient and more time than I can count was ready to draw diagrams on the fly, talk through problems, and help me any way she could. After two years of volunteering, I decided to apply to Jen's lab for graduate school. Even though at this point I had been working in Jen's lab for two years, I was not sure what my "dissertation" work would be. The first semester I worked on a project Jen had funded, while thinking and figuring out what the next few years would have in store for me. Then, one day while taking a plant physiology class, I decided I wanted to investigate the whole plant response to abiotic stress. At this time, Jen was attending a conference in Europe, but I was excited and needed to talk to her about my ideas (immediately). The time change made it difficult, but I think after 1,000 text messages and emails I had harassed her enough and convinced her to let me do stress work. I realize now, given that this was not Jen's specialty, that this was a significant risk for her. At this time, she had not yet been tenured, and I had no funding of my own for this type of work, however, she took the risk and fully supported me. This did not go unnoticed. I made sure to work extra hard to figure out everything I could so I would not let her down. And to be honest, her limited knowledge in this area was an advantage for me because as I planned projects and explained my ideas, she constantly asked questions, which both tested my knowledge and made the process fun for both of us (I think...). In the last five years of graduate school, Jen has devoted endless hours for planned weekly meetings, impromptu daily meetings, numerous text message strings (more like text message tornados), and everything in between. Every time I planned projects that were 10x too big and physically impossible for one individual to complete, she dropped everything she was doing to help me collect my data. Every time I sat in her office in tears because I either felt stupid or my research wasn't working, she both supported me and gave me the kick I needed to jump back on the horse and figure it out. Every mistake I made, she never faulted me but instead helped me see it through and learn from it. Jen has supported me financially in each of my projects and for the numerous conferences I had the opportunity to attend. Jen has introduced me to some amazing scientists in the field and helped me grow. Jen has done more than me than I deserved, and it has never gone unnoticed or unappreciated. In addition to the academic support Jen has given me, she has helped me tremendously personally. My transition into graduate school was easy academically, but personally I faced some struggles. During this hard time of my life, Jen was the single most supportive person. On top of the time she dedicated to me academically, she dedicated a significant amount of time to me personally. And without her, I am not sure I would have persevered through graduate school. The time, energy, and commitment she gave me during this time helped me grow personally, and I am endlessly thankful. 
I am also especially thankful to my graduate committee members - Dr. Stephen DiFazio, Dr. Jonathan Cumming, Dr. Timothy Driscoll, and Dr. Vagner Benedito. Each of my committee members took a significant amount of time out of their own research and labs to individually meet with me and attend all of my requested meetings. They were generous in offering their time and their feedback, while also being extremely patient. I especially want to thank Dr. Jonathan Cumming. JC spent numerous hours with me during project design and during data analysis. During manuscript preparation and revision, JC was patient and supportive. He was always willing to take the extra time to make sure we were not missing anything. I am appreciative of this, as he contributed significantly to my growth and success. I would also like to give special thanks to Dr. Stephen DiFazio who also spent a significant amount of one-on-one time helping me design my research and analyze my data.

Many thanks to my lab mates and colleagues. I am especially thankful for Sandra Simon. Sandy and I both began graduate school after uncovering our passion for research during undergrad. During each of the Ph.D. benchmarks I was always a ball of stress and Sandy was always calm and collective. Sandy would talk me off a ledge and bring me back to reality. Sandy and I would spend endless hours meeting to discuss new literature, help each other with data analysis, and write new R scripts. Outside of LSB, Sandy and I spent a significant amount of time hiking. This friendship significantly contributed to both my personal and professional achievements. Thank you, Sandy. I also want to say thank you to Dr. Brandon Sinn and Dr. Rajanikanth Govindarajulu, who both shared their knowledge and significantly contributed to my research. Special thanks to Ryan Percifield, who spent a significant amount of time training me. Ryan was always very patient as I learned new techniques and took on new tasks. I am especially thankful that Ryan was so accommodating regarding my Genomics Core work hours. Ryan significantly contributed to my professional growth and was always fun to work with. Also, I want to acknowledge my office mates for keeping the office lively and full of baked goodies.

Many thanks to my dad who was always supportive, even though he never understood what I was doing. He never missed an opportunity to add in the words "Sorghum" or "Genome" to a sentence, just to let me know he paid attention. I want to give special thanks to my soon-to-be father- and mother-in-law, Jeff and Vicky Hostetler, who have taken the time to understand what it is I do (and have listened to my endless rants and struggles over the last three years).

Finally, I want to say thank you to my fiancé, Justin, for his unconditional love, support, and patience. Justin has taken the time to invest in my research and my academic growth. Justin has always been able to lighten up any stressful time with some jokes and ice cream (the keys to keeping a smile on my face). Justin has taken the time to learn about what I do and what it means. I am never surprised when he starts talking about DNA, RNA, or the soil microbes. He has taken the time and energy to invest in me and my career and I am not sure where I would be without his support.

Last, but not least, below you will find a figure I made and planned to use in Chapter 4, however it did not make the cut. Regardless, I felt the image warranted a place in my dissertation given the significant amount of time it took me to draw in Adobe Illustrator. This figure points out the important tissues sampled, in multiple research projects, within my dissertation. Don't be fooled, it may look like a Zea mays seedling, but it is in fact a Sorghum seedling. 


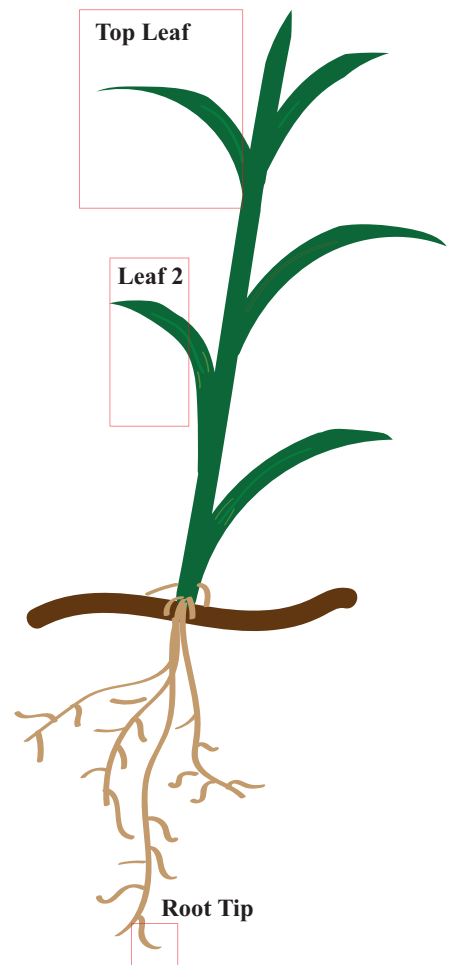

